\title{
Anteriore Musterbildung im Wirbeltierembryo - Die Induktion von Vorderhirn und Herz
}

\author{
Dissertation \\ zur Erlangung des Doktorgrades \\ der Mathematisch-Naturwissenschaftlichen Fakultäten \\ der Georg-August-Universität zu Göttingen
}

vorgelegt von

Lars Wittler

aus Gehrden

Göttingen 2002 
D7

Referent: $\quad$ Herr Prof. Dr. Michael Kessel

Abt. Molekulare Zellbiologie

AG. Entwicklungsbiologie

Max-Planck-Institut für biophysikalische Chemie

Göttingen

Korreferent: Herr Prof. Dr. Ulrich Ehlers

Institut für Zoologie und Anthropologie

Abt. für Morphologie, Systematik, Evolutionsbiologie

und Zoologisches Museum

Universität Göttingen

Tag der mündlichen Prüfung: 30.10.2002 
Meinen Eltern 


\section{Inhaltsverzeichnis}

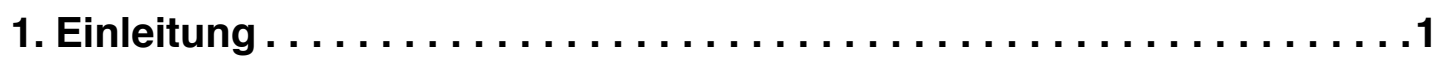

1. 1. Parakrine Faktoren in der Embryogenese . . . . . . . . . . . . . 2

1. 2. Wirbeltierembryonen als entwicklungsbiologische Modellorganismen . . . 3

1. 3. Die frühe Entwicklung des Huhnembryos . . . . . . . . . . . . . . 4

1. 4. Die Gastrulation im Mausembryo . . . . . . . . . . . . . . . . . . 7

1. 5. Embryonale Induktion - Das Konzept des Organisators . . . . . . . . . . 9

1. 6. Der Organisator im Amniotenembryo . . . . . . . . . . . . . . . . 11

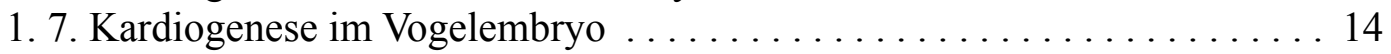

1. 8. Die Induktion des primären Herzfelds . . . . . . . . . . . . . . 15

1. 9. Das anteriore, sekundäre Herzfeld und die kardiale Neuralleiste . . . . . . 16

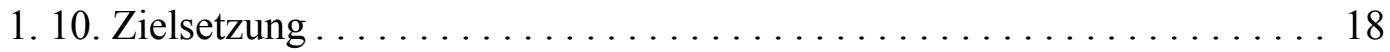

2. Material und Methoden $\ldots \ldots \ldots \ldots \ldots \ldots$

2. 1. Abkürzungen und Symbole . . . . . . . . . . . . . . . . . . . 19

2. 2. Chemikalien, Reagenzien und andere Materialien. . . . . . . . . . 21

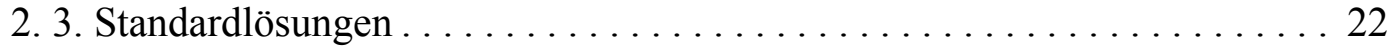

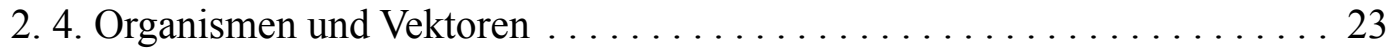

2. 4. 1. Plasmide. .......................... 23

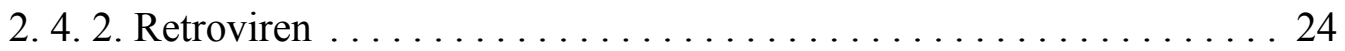

2. 4. 3. Bakterien ............................ 25

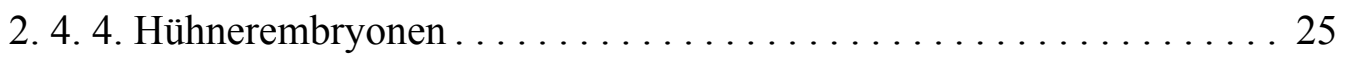

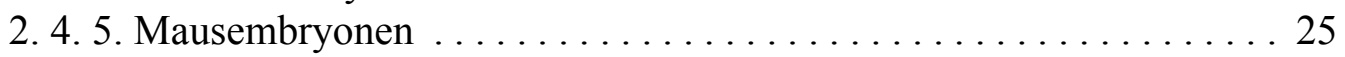

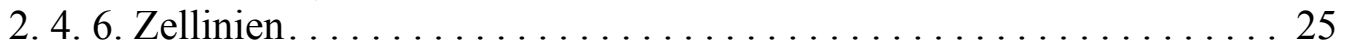

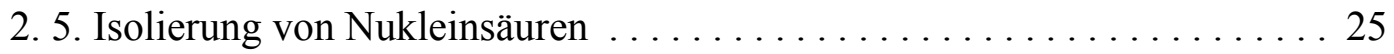

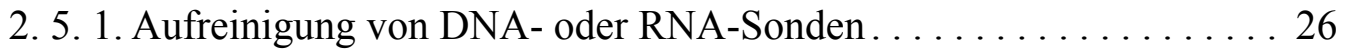

2. 5. 2. Isolierung von Gesamt-RNA aus Gewebe. . . . . . . . . . . 26

2. 5. 3. Elektrophorese und Isolation von DNA aus Agarosegelen . . . . . . . 27

2. 6. Modifizierung von Nukleinsäuren . . . . . . . . . . . . . . . . 27

2. 6. 1. Restriktionsverdau....................... . . 28

2. 6. 2. Dephosphorylierung der 5'-Enden von DNA-Fragmenten . . . . . . 28

2. 6. 3. Erzeugung von glatten Enden bei DNA-Fragmenten . . . . . . . . 28

2. 6. 4. Klonierung von doppelsträngigen, synthetischen

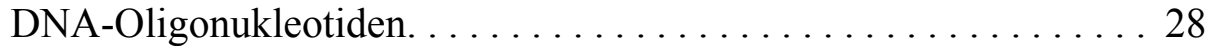

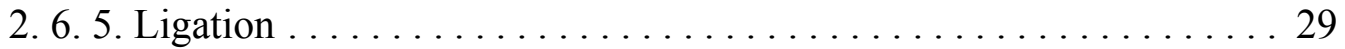

2. 6. 6. DNA-Konstrukte . . . . . . . . . . . . . . . . . . . . . 29

2. 6. 6. 1. Fusionskonstrukt von $c S z l$ mit einem Myc- bzw. His-Epitop. . 29

2. 6. 6. 2. Konstruktion des RCAS::cSzl-Retrovirus. . . . . . . . . 30

2. 6. 7. Konstruktion von cDNA-Banken aus 
embryonalem Hühnergewebe ...................... 31

2. 6. 8. Markieren von RNA-Sonden mit Digoxigenin oder Fluoreszein .... 33

2. 6. 9. Herstellung von radioaktiv markierten DNA-Molekülen ......... 34

2. 6. 10. Sequenzierungen ............................. 35

2. 7. Transformation von Bakterien ........................ 35

2. 7. 1. Herstellung von kompetenten Bakterien .................. 36

2. 7. 2. Transformation von elektrokompetenten Bakterien ........... 36

2. 7. 3. Transformation von chemokompetenten Bakterien............ 37

2. 8. Subtraktion von Klonen durch Kolonie-Hybridisierung . . . . . . . . . 37

2. 9. cDNA-Erststrang-Synthese für die

Reverse-Transkriptase-Polymerase-Kettenreaktion ............... 38

2. 10. Polymerase-Kettenreaktion (PCR) . . . . . . . . . . . . . . . . . . . 39

2. 11. Analyse der Klone aus den cDNA-Banken . . . . . . . . . . . . . . 40

2. 12. Zellkultur .............................. 41

2. 12. 1. Präparation primärer Huhnembryofibroblasten (CEFs) . . . . . . . 41

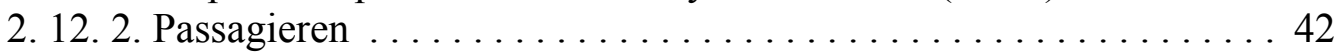

2. 12. 3. Einfrieren und Auftauen der Zellen................... 43

2. 12. 4. Transfektion von Zellen mit FuGene................. 43

2. 12. 5. Transfektion der embryonalen Hühnerfibroblasten mit retroviraler DNA .......................... 44

2. 12. 6. Immunhistologischer Nachweis der retroviralen Transfektion ... . . 44

2. 12. 7. Anreicherung der sekretierten rekombinanten Proteine und Retroviren im Zellkulturüberstand (Konditioniertes Medium). . 45

2. 13. Manipulationen am Hühnerembryo $\ldots \ldots \ldots \ldots \ldots \ldots \ldots \ldots \ldots$

2. 13. 1. Präparieren des Embryos aus dem Ei .................. 46

2. 13. 2. Entnahme von Gewebe ..................... 47

2. 13. 3. in vitro-Kultivierung von Hühnerembryonen (New Kultur/EC-Kultur) . . . . . . . . . . . . . . . . . . . 47

2. 13. 4. Transplantation von Mausgewebe in Hühnerembryonen ........ . 49

2. 13. 5. in ovo-Kultur ............................... 50

2. 13. 6. Zellmarkierung mit DiI ...................... 51

2. 13. 7. Applikation von Proteinfaktoren .................. 51

2. 13. 7. 1. Implantation von retroviral transfizierten

Hühnerfibroblasten . . . . . . . . . . . . . . . . . . . . 51

2. 13. 7. 2. Implantation von Heparin-Akrylamidkugeln ............ 51

2. 14. Whole mount (Ganzpräparat) in situ-Hybridisierung. . . . . . . . . . . 52

2. 15. Ausspritzen des embryonalen Gefäßsystems mit Kunststoff . . ....... 55

2. 16. Histologie . . . . . . . . . . . . . . . . . . . . . . . . . . . 56

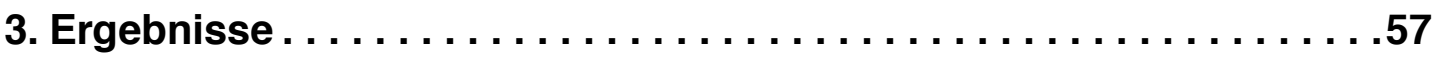

3. 1. Die Analyse der neuralinduzierenden Aktivität des Knotens des Mausembryos ............................... 57

3. 2. Ein Expressionsscreen identifiziert eine ventrale Synexpressionsgruppe . . 60

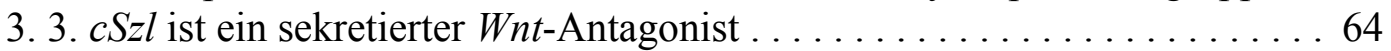

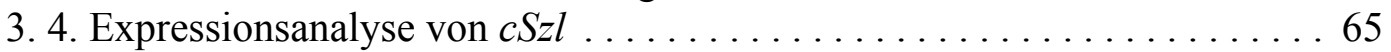

3. 5. cSzl-Expression und kardiale Neuralleiste .................. 69

3. 6. Die Expression von Crescent im Vergleich zu $c S z l \ldots \ldots \ldots \ldots \ldots \ldots 71$ 
3. 7. Experimente zur Funktion und Regulation von $c S z l$ und Crescent . . . . . 73

3. 7. 1. Der Einfluß von BMP2 auf die $c S z l$ - und Crescent-Expression . . . . 73

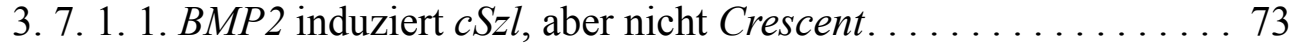

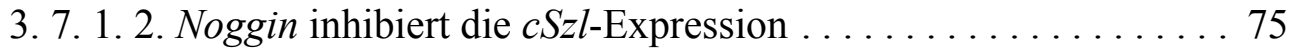

3. 7. 2. Der Einfluß von Fibroblasten Wachstumsfaktoren

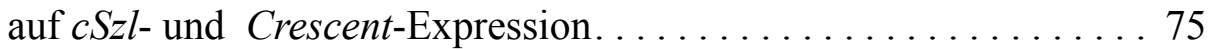

3. 7. 2. 1. FGF8 inhibiert $c S z l$, aber nicht Crescent . . . . . . . . . 75

3. 7. 2. 2. $F G F 8$ und $c S z l$ sind in voneinander getrennten Arealen

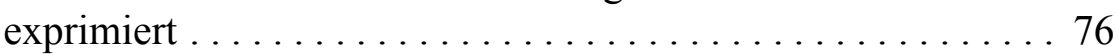

3. 7. 2. 3. $F G F 8$ inhibiert $c S z l$ direkt und spezifisch $\ldots \ldots \ldots \ldots \ldots 77$

3. 7. 3. Die Wirkung von $F G F 8$-Signalen auf die Expression kardialer Markergene . . . . . . . . . . . . . . . . . . . . . 77

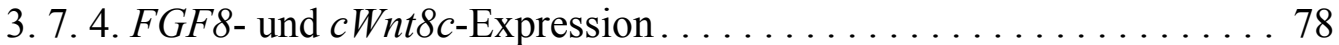

3. 7. 5. Ektopische $c S z l$ - und Crescent-Expression hat keinen Einfluß auf die Kardiogenese. . . . . . . . . . . . . . . . . . . . . . . 80

4. Diskussion . . . . . . . . . . . . . . . . . . . . . . . . 82

4. 1. Die Induktion der Vorderhirnanlage . . . . . . . . . . . . . . 82

4. 1. 1. Der Organisator des Mausembryos induziert rostrale

Neuralmarker. . . . . . . . . . . . . . . . . . . . . . 83

4. 1. 2. Anteriore Neuralinduktion in Amphibien, Vögeln und Säugern . . . . 85

4. 2. Wnt-Antagonismus und anteriore Musterbildung . . . . . . . . . 87

4. 2. 1. Die sekretierten Wnt-Antagonisten $c S z l$ und Crescent . . . . . . . 887

4. 2. 2. Sizzled und Crescent nur in Amphibien und Vögeln? . . . . . . . . . . 88

4. 2. 3. Sizzled und Crescent antagonisieren die Wnt8-Signalkaskade . . . . 89

4. 2. 4. Wnt-Antagonismus und anterior-posteriore Musterbildung . . . . . . 90

4. 2. 4. 1. Wnt-Antagonismus und Neuralinduktion . . . . . . . . . . 91

4. 2. 4. 2. Wnt-Antagonismus und die Induktion des anterioren lateralen Mesoderms . . . . . . . . . . . . . . . 93

4. 2. 5. Die Etablierung des Herzfeldes durch Signalmoleküle. . . . . . . . . . 94

4. 2. 6. Wnt-Antagonismus und das sekundäre Herzfeld. . . . . . . . . . 96

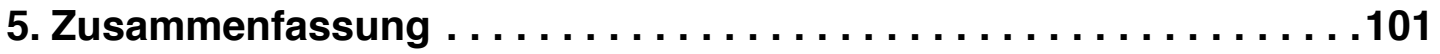

6. Literaturverzeichnis . . . . . . . . . . . . . . . . . . . . . . . . . . 102

7. Anhang . . . . . . . . . . . . . . . . . . . . . . . . .

7. 1 Tabellarische Zusammenstellung der durch whole mount in situ-Hybridisierung analysierten Klone aus dem Expressionsscreen. . . 113 
8. Publikationen . . . . . . . . . . . . . . . . . . . . . 118

9. Danksagung . . . . . . . . . . . . . . . . . . . . . . . . . 119

10. Lebenslauf . . . . . . . . . . . . . . . . . . . . . . . . . 121 


\section{Einleitung}

Die Zellen eines vielzelligen Lebewesens gehen aus einer einzigen Zelle, der befruchteten Eizelle (Zygote), hervor. Die Komplexität eines Organismus, wie beispielsweise eines Wirbeltieres, erfordert eine fein abgestimmte Regulation und Koordination während seiner Entwicklung, der Embryogenese. Die Mechanismen, die der Embryogenese zugrundeliegen, bis ins molekulare Detail aufzuklären, ist die Aufgabe entwicklungsbiologischer Forschung. Nach der Befruchtung teilt sich die Eizelle zunächst in einer Reihe sogenannter Furchungsteilungen. In dieser Phase sind die einzelnen Zellen, die Blastomeren, noch totipotent, jede Zelle hat die Fähigkeit, sich zu einem vollständigen Organismus zu entwickeln. Erst mit fortschreitender Entwicklung schlagen die Zellen ein bestimmtes Entwicklungsschicksal ein und spezialisieren sich. Am Ende der Furchungsteilungen steht das Morulastadium. Aus der Morula entsteht die Blastula, die im Wirbeltierembryo im Grundbauplan die Gestalt einer einschichtigen Hohlkugel hat. In der folgenden Phase der Entwicklung, der Gastrulation, beginnen Zellen in die Blastula einzuwandern und die primären Keimblätter Ektoderm, Mesoderm und Endoderm zu bilden. Aus den primären Keimblättern differenzieren sich im weiteren Verlauf der Embryogenese die verschiedenen Organsysteme und Strukturen des Organismus. So wird aus dem Ektoderm das Nervensystem, die Epidermis und die Neuralleiste. Aus dem Mesoderm entstehen Körpermuskulatur, Blutgefäßsystem und Herz, und aus dem Endoderm gehen das Verdauungssystem und die ihm assoziierten Organe, wie zum Beispiel Leber und Pankreas, hervor. Jedes der primären Keimblätter hat dabei Einfluß auf die Entwicklung der ihm benachbarten Keimblätter, vermittelt durch Signalmoleküle und Zell-Zell-Interaktionen. Während der frühen Embryogenese werden durch solche Signale Positionsinformationen gegeben, die im Embryo die korrekte Anlage der Organe ermöglichen. In der vorliegenden Arbeit wird untersucht, wie Zell-Zell-Interaktionen und Signalmoleküle die Entwicklung des anterioren Neuroektoderms, aus dem das Vorderhirn hervorgeht, und des anterioren Mesoderms, nämlich der Herzanlage, steuern. 


\section{1. Parakrine Faktoren in der Embryogenese}

Eine Vielzahl von musterbildenden Prozessen während der Embryogenese wird von parakrinen Faktoren gesteuert. Sie regulieren Zellproliferation, Apoptose, Zelldifferenzierung, die Determinierung des Zellschicksals und die Morphogenese. Die meisten dieser Faktoren können anhand ihrer Molekülstruktur vier großen Proteinfamilien zugeordnet werden. Die drei für diese Arbeit relevanten Proteinfamilien und ihre Signaltransduktionswege werden im folgenden kurz vorgestellt.

Die Gruppe der "Knochenwachstumsfaktoren" ( $B M P=$ Bone Morphogenetic Protein) gehört zur Superfamilie der transformierenden Wachstumsfaktoren (TGFß). Neben dem Aufbau des primären Körperplans des Embryos sind BMPs an der Entwicklung nahezu aller Organe und Gewebe beteiligt. (Hogan, 1996; Massague, 2000; Massague et al., 2000; Massague und Chen, 2000). BMPs binden Serin-Threonin-Kinase-Rezeptoren, die daraufhin Smad-Proteine aktivieren. Abhängig von der Kombination der aktivierten Smads wird Transkription in der Zelle aktiviert oder reprimiert.

Die Fibroblasten Wachstumsfaktoren $(F G F s)$ sind eine weitere große Proteinfamilie, die Schlüsselfunktionen innerhalb der Vertebratenembryogenese haben. In Säugetieren wurden bisher 23 verschiedene Gene als Mitglieder der $F G F$-Familie klassifiziert, viele besitzen Orthologe in anderen Vertebratentaxa. Allen FGFs ist eine 120 Aminosäuren große Domäne gemeinsam, die eine Rezeptor- und eine Heparin-Bindungsdomäne enthält (Basilico und Moscatelli, 1992; Ornitz und Itoh, 2001). FGF-Signale werden über den Rezeptor-Tyrosinkinase-Signaltransduktionsweg in die Zelle vermittelt.

Die vermutlich älteste Gruppe sekretierter Signalproteine in den Metazoa sind die Wnt-Faktoren (Nusse und Varmus, 1992; Wodarz und Nusse, 1998). In Vertebraten wurden bisher 19 Mitglieder gefunden und auch in allen anderen Tierstämmen wurden orthologe Wnt-Gene entdeckt. Wie BMPs und FGFs sind Wnt-Proteine sehr cysteinreich, sie enthalten eine invariante Abfolge von 23 Cysteinen (Wodarz und Nusse, 1998). Whts sind zwar sekretierte Faktoren, sie diffundieren aber durch ihre starke Glykolisierung nur schlecht im extrazellulären Raum. Durch Wnts werden unterschiedliche Signalkaskaden aktiviert. Der erste aufgeklärte Wnt-Signalweg wird als kanonischer Wnt-Signalweg bezeichnet (Wodarz und Nusse, 1998). Er wird über den Wnt-Rezeptor Frizzled vermittelt und führt zur nukleären Lokalisation des Pro- 
teins $\beta$-Catenin, das ursprünglich als Zellskelettkomponente identifiziert wurde (Willert und Nusse, 1998). Im Zellkern interagiert $\beta$-Catenin mit den DNA-bindenden Faktoren $T C F$ und $L E F$ und wirkt dort transkriptionskontrollierend (Willert und Nusse, 1998). Nicht alle Wnt-Faktoren aktivieren den kanonischen Signaltransduktionsweg. Die nicht-kanonischen Wnts stimulieren intrazelluläre Kalziumfreisetzung und aktivieren die Cam-Kinase II und die Proteinkinase C, vermittelt über GProteine (Kuhl et al., 2000). Außerdem wurde jüngst gezeigt, daß Wnt11 bei der Aktivierung des kardialen Differenzierungsprogramms im Krallenfrosch den JNK-Signaltransduktionsweg aktiviert (Pandur et al., 2002).

\section{2. Wirbeltierembryonen als entwicklungsbiologische Modellorganis- men}

Die Erforschung entwicklungsbiologischer Mechanismen benötigt geeignete Modellsysteme. Für die Embryogenese des Wirbeltieres sind diese hauptsächlich der Zebrabärbling Brachydanio rerio, der Krallenfrosch Xenopus laevis, die Maus Mus musculus und das Huhn Gallus gallus. Jeder dieser Modellorganismen bietet bestimmte experimentelle Vor- und Nachteile. Die Embryonen von Zebrabärbling und Krallenfrosch sind der experimentellen Manipulation relativ leicht zugänglich, und ihre Entwicklung läßt sich einfach beobachten. Ihre Embryologie ist jedoch aufgrund der großen evolutiven Distanz nur bedingt auf Säugetiere und damit auch auf den Menschen übertragbar. Die Maus steht von den genannten Modellsystemen dem Menschen evolutiv am nächsten, und gut etablierte molekulargenetische Untersuchungsmöglichkeiten erlauben eine detallierte Analyse ihrer Embryonalentwicklung. Doch die Phasen der frühen Embryogenese, die Gastrulation und frühe Neurulation, sind im Mausembryo wegen seiner geringen Größe und der intrakorporalen Entwicklung nur schwer zu untersuchen. Der Vogelembryo dagegen, im besonderen der Hühnerembryo, ist zum Zeitpunkt der Eiablage, vor Einsetzen der Gastrulation, bereits ca. $2 \mathrm{~mm}$ groß. Er läßt sich während der gesamten Embryogenese leicht beobachten und manipulieren, ein Vorteil, um die Rolle von Signalmolekülen auf die Etablierung des Vertebratenbaublans zu untersuchen. Die Embryonalentwicklung des Huhns wird von der Eiablage bis zum Schlüpfen anhand morphologischer Kriterien nach Hamburger und Hamilton in 46 Stadien eingeteilt (Stadium HH; Hamburger und 
Hamilton, 1951). Die frühesten Entwicklungsstadien von den intrauterinen ersten Furchungs- teilungen bis zur Initiierung der Gastrulation werden nach Eyal-Giladi und Kochav in EK-Stadien I-XIV eingeteilt (Eyal-Giladi und Kochav, 1976). Die Gastrulastadien der Maus wurden für diese Arbeit nach Downs und Davies bestimmt (Downs und Davies, 1993).

\section{3. Die frühe Entwicklung des Huhnembryos}

Das Vogelei wird im Uterus befruchtet und beginnt sich schon vor der Eiablage zu teilen. Die Furchungsteilungen sind zunächst superfiziell diskoidal, erst nach der vierten Teilung werden die zentralen Blastomeren komplett vom Dotter getrennt (Watt et al., 1993). Die marginalen Blastomeren bleiben in Verbindung mit dem Dotter. Nach den weiteren Furchungsteilungen bilden die zentralen Blastomeren eine dem Dotter aufliegende Keimscheibe, die bei der Eiablage aus etwa 60.000 Zellen besteht. Die Keimscheibe ist jetzt etwa $2 \mathrm{~mm}$ groß und läßt sich morphologisch in die periphere area opaca und die zentrale area pellucida unterteilen (Eyal-Giladi und Kochav, 1976). Dieses Stadium entspricht der Blastula anderer Wirbeltiere, mit dem Unterschied, daß die Zellen anstelle einer Hohlkugel in einer einschichtigen Zellage angeordnet sind. Die area opaca, hervorgegangen aus den marginalen Blastomeren, steht weiterhin in Verbindung mit dem Dotter, die area pellucida überspannt einen dotterfreien Raum, das Blastocoel. Diese Zellschicht ist der Epiblast, aus ihm wird sich der eigentliche Embryo entwickeln. Obwohl morphologisch noch nicht erkennbar, ist zu diesem Zeitpunkt bereits die zukünftige Position der anterior-posterioren Körperachse und der Startpunkt der Gastrulation festgelegt (Azar und Eyal-Giladi, 1979). Der Durchbruch der Radiärsymmetrie in der Keimscheibe erfolgt bereits während der Passage des Eis durch den Uterus. Hierbei wird das Ei konstant gedreht, was eine Verschiebung des dichteren Dotters gegenüber dem Keimvesikel zur Folge hat. Vegetale Determinanten geraten so in den zukünftig posterioren Bereich der Keimscheibe und positionieren in Kombination mit peripheren Signalen den Ausgangspunkt der Gastrulation (Boettger et al., 2001; Skromne und Stern, 2001). Dieser wird zuerst als Kollersche Sichel am posterioren Übergang von area opaca $\mathrm{zu}$ area pellucida, der posterioren Marginalzone, morphologisch sichtbar (Bachvarova et al., 1998). Die

Kollersche Sichel ist eine mehrschichtige, ins Blastocoel reichende Verdickung, von 
der aus sich Zellen unter den Epiblast zu schieben beginnen (Bachvarova et al., 1998; Eyal-Giladi et al., 1992). Sie bilden zusammen mit Zellen, die aus dem Epiblast delaminieren, eine einheitliche Zellschicht, den Hypoblast (Bachvarova et al., 1998). Signale aus dem Hypoblast nehmen bereits in diesem frühen Stadium Einfluß auf den darüberliegenden Epiblast und definieren in diesem die Areale, in denen sich im späteren Verlauf der Embryogenese das Nervensystem entwickeln wird (Foley et al., 2000; Knezevic und Mackem, 2001). Von der Kollerschen Sichel gehen umfangreiche Zellbeweg-ungen und Zellproliferationen aus, die den Beginn der Gastrulation anzeigen (Skromne und Stern, 2002). Einerseits wandern Zellen im Epiblast zur Mittellinie, andererseits proliferiert eine Zellpopulation im Median der Kollerschen Sichel gerichtet zum Zentrum des Epiblast (Boettger et al., 2001). Durch diese Zellproliferationen und Zellmigrationen wird der Primitivstreifen, eine sich nach anterior ausdehnende Struktur, gebildet. Der Primitvstreifen ist das Homolog zum Blastoporus der Amphibien und ist charakteristisch für alle Amnioten (Arendt und Nubler-Jung, 1999). Wie der Primitivstreifen dem Blastoporus der Amphibien entspricht, so ist seine anteriore Spitze, der Hensensche Knoten (Hensen, 1876), das funktionelle Homolog der dorsalen Blastoporuslippe (Stern, 2000). Nach ungefähr 16 Stunden Inkubation hat der Primitivstreifen seine größte anterior-posteriore Ausdehnung erreicht und zeigt nun eine charakteristische Morphologie: In seiner Mittellinie hat sich eine Furche, die Primitivgrube, gebildet. Hier ist die Basalmembran des Epiblast durchbrochen und Zellen können in den Raum zwischen Epiblast und Hypoblast einwandern (Schoenwolf und Watterson, 1989). Die ersten Zellen, die auf diese Weise durch die Spitze des Primitivtreifens migrieren, sind die Zellen des definitiven embryonalen Endoderms (Lopez-Sanchez et al., 2001; Schoenwolf und Sheard, 1990; Selleck und Stern, 1991). Sie schieben den Hypoblast nach außen in extraembryonale Bereiche, wo er sich nicht mehr am Aufbau des eigentlichen Embryos beteiligt. Den Zellen des definitiven Endoderms folgen die Zellen des axialen Mesoderms, zuerst das prächordale Mesoderm, das wegen seiner Struktur als prächordale Platte bezeichnet wird (Adelmann, 1922). Ihm folgen die Zellen des Chorda-Mesoderms. Von diesen durch die Spitze des Primitivstreifens migrierenden Zellen gehen musterbildende Signale auf das darüberliegende, bereits präneurale Ektoderm aus. Diese Signale stabilisieren den neuralen Charakter des zentralen Ektoderms und führen zu einer Veränderung der Morphologie der neuroektodermalen Zellen (Knoetgen et al., 1999). Im 
Kopffortsatzstadium (HH5) ist das neurale Ektoderm als Neuralplatte morphologisch klar vom epidermalen Ektoderm abgegrenzt (Schoenwolf, 1983; Schoenwolf und Powers, 1987). Zeitgleich mit den Zellen des axialen Mesoderms wandern auch Zellen posterior des Knotens in den Embryo ein. Bei ihnen entscheidet die anteriorposteriore Position im Primitivstreifen, welcher Mesodermtyp aus ihnen hervorgeht (Psychoyos und Stern, 1996; Schoenwolf et al., 1992). Je weiter kaudal sie einwandern, desto weiter lateral ist ihre zukünftige Position im Embryo. Die Zellen, die kurz vor dem definitven Primitivstreifenstadium (HH4) direkt hinter den prospektiven Kopfmesodermzellen durch den Primitivstreifen migrieren, sind die Zellen des zukünftigen Herzmesoderms (Garcia-Martinez und Schoenwolf, 1993; Psychoyos und Stern, 1996). Später, im Kopffortsatzstadium, folgen die Zellen des paraxialen Mesoderms. Weiter kaudal wandern die Zellen des intermediären Mesoderms und des lateralen Mesoderms ein (Psychoyos und Stern, 1996; Schoenwolf et al., 1992). Das am weitesten kaudale/laterale Mesoderm bildet das extraembryonale Gefäßsystem sowie die Blutzellen (Psychoyos und Stern, 1996; Schoenwolf et al., 1992).

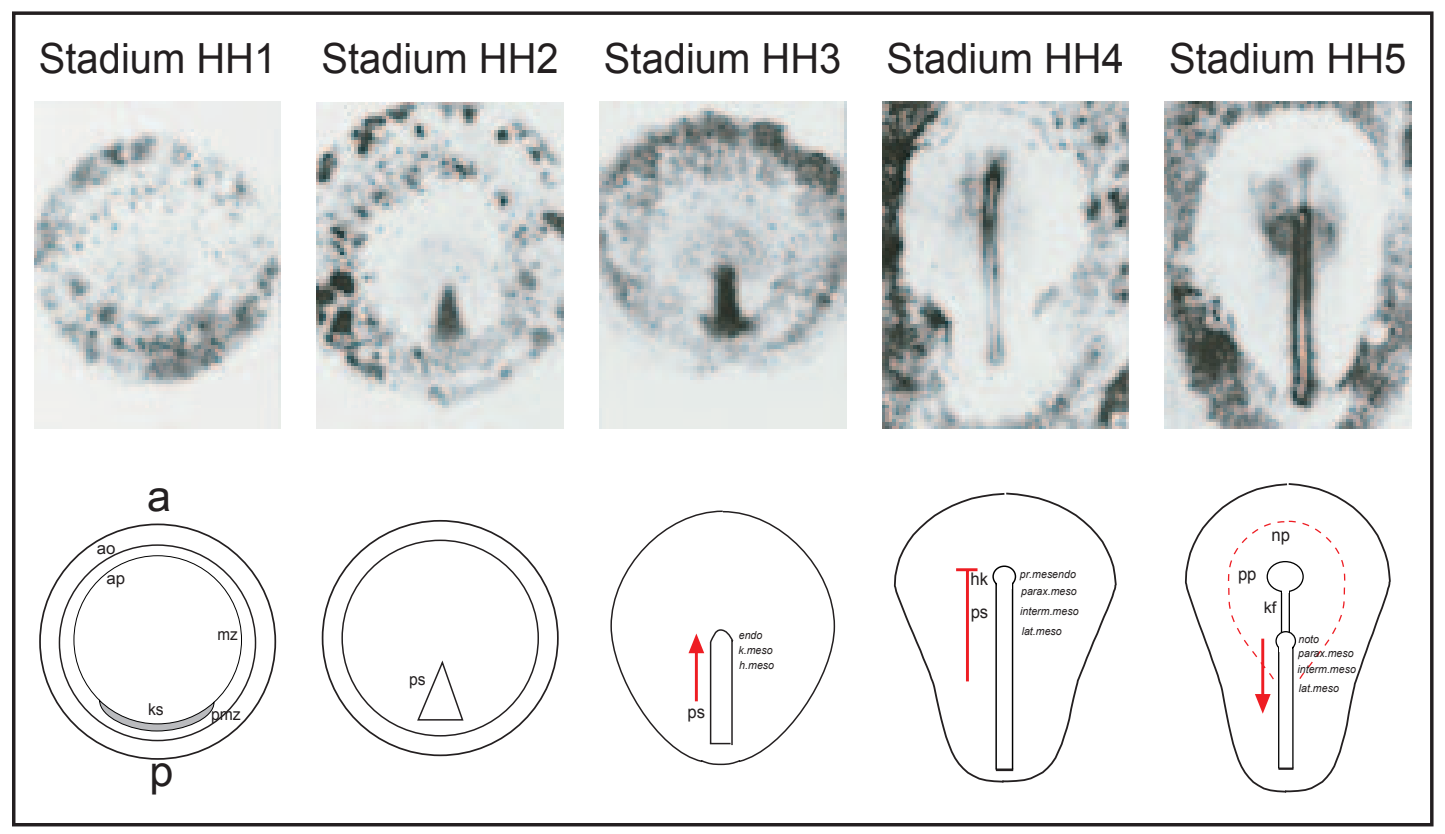

Abb. 1. 1.: Die ersten Stadien der Huhnentwicklung nach der Eiablage. Obere Reihe: Aufsicht auf Huhnembryonen während der Gastrulation in fünf Stadien nach Hamburger und Hamilton (1951; Stadien HH 1-5 aus Hamilton, 1965). Untere Reihe: Schemata der in der oberen Reihe gezeigten Stadien. Das Entwicklungsschicksal der einwandernden Zellen ist auf Höhe der Einwanderung in den Embryo in kursiver Schrift angegeben. Die Pfeile geben die Ausdehnungsrichtung des Primitivstreifens an, die gestrichelte Linie zeigt die Grenze der Neuralplatte. Abkürzungen: $\mathrm{a}=$ anterior, ao=area opaca, ap=area pellucida, endo=Endoderm, h.meso=Herzmesoderm, hk=Hensenscher Knoten, interm.meso=intermediäres Mesoderm, k.meso=Kopfmesoderm, ks=Kollersche 
Sichel, $\mathrm{kf}=$ Kopffortsatz, lat.meso=laterales Mesoderm, $\mathrm{mz}=$ Marginalzone noto=Notochord, $\mathrm{np}=$ Neuralplatte, $\quad \mathrm{p}=$ posterior, $\quad \mathrm{ps}=$ Primitivstreifen, $\mathrm{pmz}=$ posteriore Marginalzone, pr.mesendo=prächordales Mesendoderm, parax.meso=paraxiales Mesoderm, pp=prächordale Platte, parax. meso=paraxiales Mesoderm.

Mit der Bildung des Kopffortsatzes (ab HH5) beginnt der Primitivstreifen sich nach kaudal zurückzuziehen, bis in späteren Stadien (HH15-25) der Primitivstreifen und der Knoten in die Schwanzknospe übergehen und die Gastrulation vollständig abgeschlossen ist. Gleichzeitig beginnt anterior die Auffaltung des Neuralrohres und die Bildung der Kopffalte, so daß innerhalb des Embryos unterschiedliche Entwicklungsstufen vorliegen: Anterior ist die Gastrulation als erstes abgeschlossen und die Organogenese des Nervensystems, des Herzens und des Darms beginnt. Posterior findet weiterhin Gastrulation statt.

\section{4. Die Gastrulation im Mausembryo}

Nach den Furchungsteilungen besteht der Säugerembryo aus zwei Gruppen von Zellen, dem Trophoblasten und der inneren Zellmasse. Aus dem Trophoblasten werden sich extraembryonale Strukturen wie die Plazenta entwickeln, der eigentliche Embryo entsteht aus Zellen der inneren Zellmasse (Wolpert et al., 2000). Der Embryo ist in diesem Stadium noch nicht in den Uterus der Mutter implantiert und wird als Blastozyste bezeichnet.

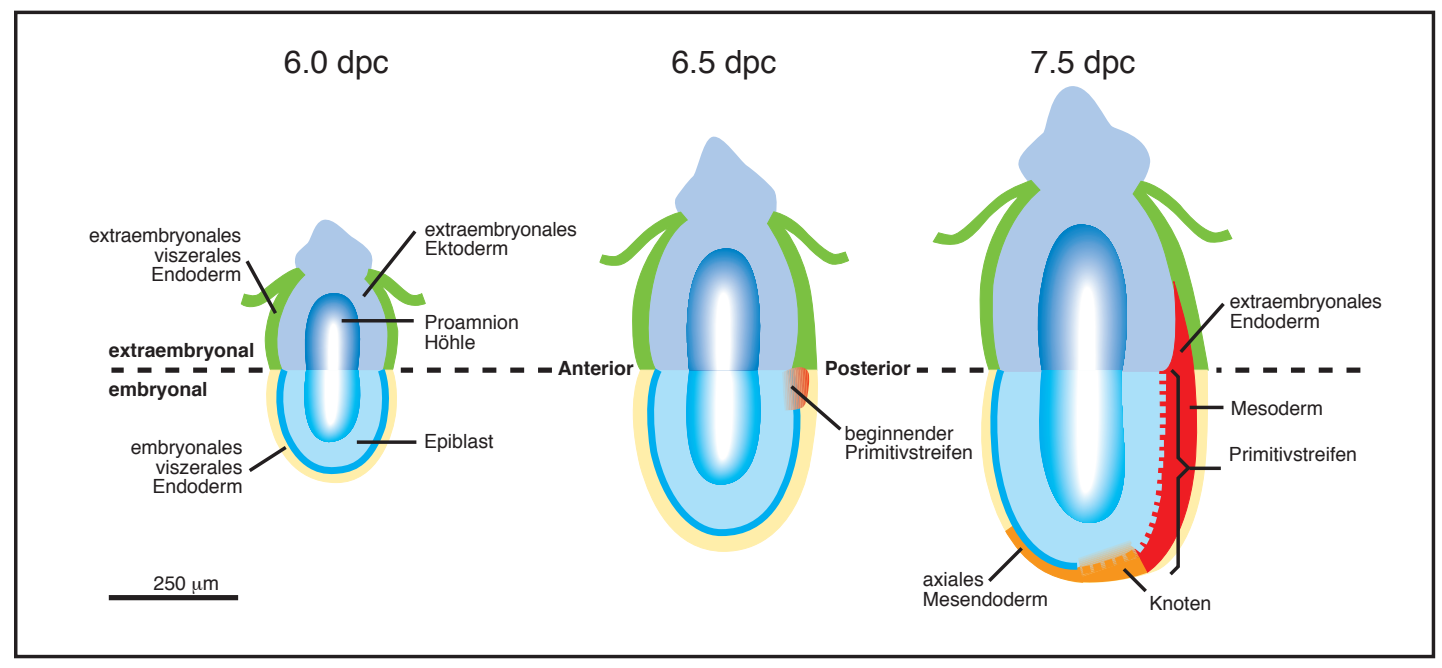

Abb. 1. 2.: Gastrulation im Mausembryo. Schematische Darstellung des embryonalen Zylinders im Vorgastrulastadium (6,0 dpc), zu Beginn der Gastrulation (6,5 dpc) und zur längsten Ausdehnung des Primitivstreifens (7,5 dpc). Erläuterungen siehe Text. Darstellung nach Beddington und Robertson, 1998. 
Die innere Zellmasse teilt sich in der weiteren Entwicklung des Embryos in zwei Regionen auf, das primitive Endoderm, das ein Teil des extraembryonalen Membransystems wird, und den Epiblast, aus dem der eigentliche Embryo hervorgehen wird. Sechs Tage nach der Befruchtung ist der Mausembryo in den Uterus implantiert und hat ein Entwicklungsstadium erreicht, das dem des Vogelembryos bei Eiablage entspricht. Im Gegensatz zum Vogelembryo und zu den meisten Säugerembryonen ist das Blastoderm des Mausembryos nicht scheibenförmig, sondern hat eine zylinderförmige Gestalt. Der Epiblast umschließt die Proamnionhöhle und ist außen vom extraembryonalen, viszeralen Endoderm umkleidet. Die zukünftig dorsale Seite des Embryos ist dabei der Proamnionhöhle zugewandt, sie weist also nach innen (Abb. 1. 2.; Beddington und Robertson, 1998). Etwa 6,5 Tage nach der Befruchtung (6,5 dpc) beginnt die Gastrulation mit der Bildung des Primitivstreifens. Er wird als eine Verdickung am zukünftig posterioren Ende des Embryos sichtbar und dehnt sich zur distalen Spitze des Embryos aus (Beddington und Robertson, 1998; Tam und Behringer, 1997). Durch den Primitivstreifen migrieren proliferierende Epiblastzellen und bilden das definitive Endoderm und das Mesoderm. Wie im Huhn verdrängt das definitive Endoderm das primitive Endoderm.

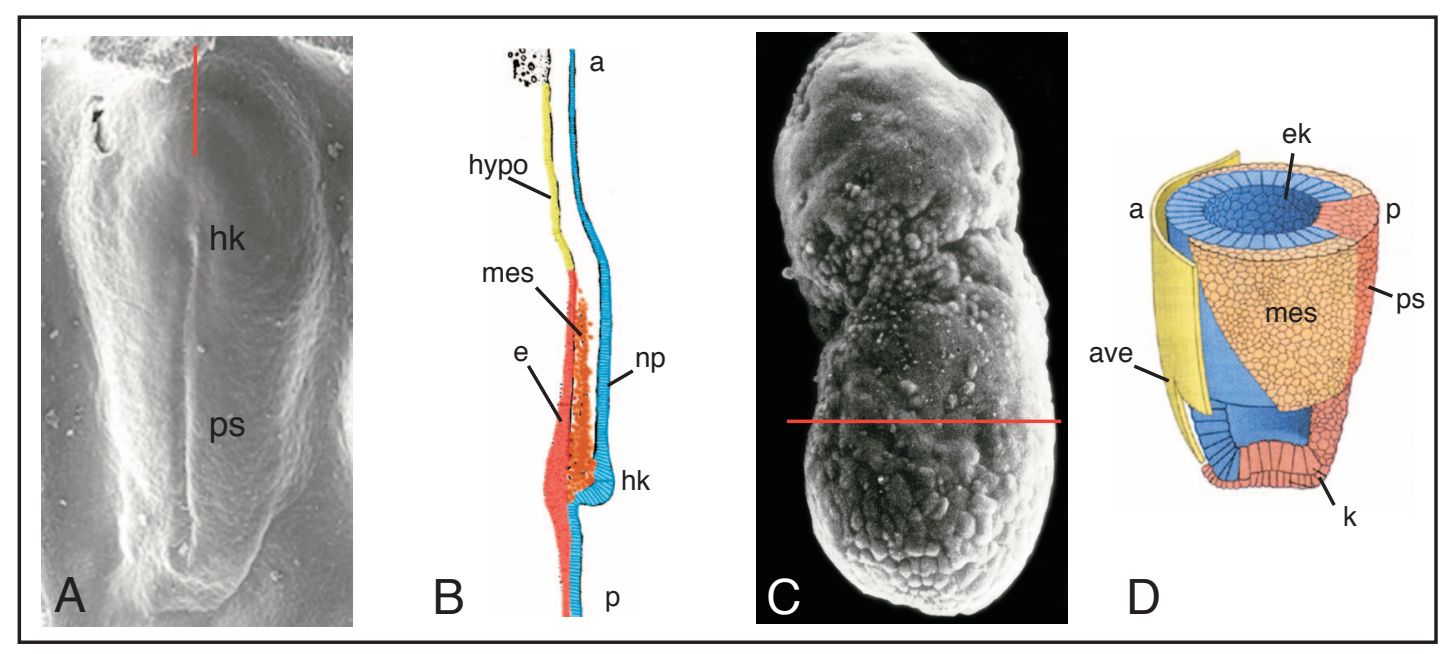

Abb. 1. 3.: Vergleich von Huhn- und Mausgastrula. (A) Rasterelektronenmikroskopische Aufnahme eines Huhnembryos im Stadium HH4. Die rote Linie zeigt die Schnittebene in (B) an; (B) Schematischer Querschnitt durch eine Huhngastrula. (C) Rasterelektronenmikroskopische Aufnahme eines Mausembryo im Gastrulastadium. Der rote Balken zeigt die Schnittebene in (D) an. (D) Schematischer Aufbau einer Mausgastrula. Abkürzungen: a=anterior, anp=anteriore Neuralplatte, ave=anteriores viszerales Endoderm, e=definitves Endoderm, ek=Ektoderm, epi=Epiblast, $\mathrm{hk}=$ Hensenscher Knoten, hypo=Hypoblast, mes=Mesoderm, k=Knoten, ps=Primitivstreifen. (A) von T. Böttger; (B) modifiziert aus Karlson, 1995; (C) von P. Tam; (D) aus Wolpert, 2000. 
Am anterioren Ende des Primitivstreifens formt sich eine dem Hensenschen Knoten des Vogelembryos korrespondierende Struktur, die im Säuger einfach als Knoten bezeichnet wird (Abb. 1. 3.). 8,5 Tage nach der Befruchtung hat die Neurulation bereits begonnen. Die anteriore Neuralplatte ist zu Neuralfalten aufgefaltet und im anterioren lateralen Mesoderm werden die Herzzellen spezifiziert. In den folgenden 24 Stunden macht der Embryo eine komplexe Drehung, die dazu führt, daß er von seinen extraembryonalen Membranen umgeben ist und in die Organogenesestadien eintreten kann (Wolpert et al., 2000).

\section{5. Embryonale Induktion - Das Konzept des Organisators}

Der Aufbau von zellulärer Vielfalt während der Embryogenese erfordert die spezifische Aktivierung bzw. Deaktivierung genetischer Information, also differentielle Genexpression. Zellintern wird dieses individuelle Profil an Genaktivität durch transkriptionskontrollierende Proteine erreicht. Extern erhalten die Zellen die Information über ihr Entwicklungsschicksal durch Signale benachbarter Zellen. Die Interaktion zwischen signalaussendenden (induzierenden) und signalempfangenden (reagierenden) Zellen, bei der sich die reagierenden Zellen in ihrem Entwicklungsschicksal verändern, wird als embryonale Induktion bezeichnet und ist einer der grundlegenden Mechanismen, die zur Organisation von Zellen zu Geweben und Organen führen (Gurdon, 1987). Das bekannteste Zentrum induktiver Aktivität ist die dorsale Urmundlippe der Amphibiengastrula, von seinen Entdeckern Hans Spemann und Hilde Mangold als "Organisationszentrum” beschrieben (Abb. 1. 4., A und B; Spemann und Mangold, 1924). Werden Zellen dieses Organisators in einen Wirtsembryo transplantiert, wird ein kompletter sekundärer Embryo induziert. Dieser besteht zum einen aus Zellen des Transplantats (Selbstdifferenzierung des Organisators; Spemann und Mangold, 1924), als auch aus Zellen, die unter dem Einfluß organisierender Signale des Transplantates ihr Entwicklungsschicksal ändern.

Durch Arbeiten am Krallenfrosch konnte in den letzten Jahren die molekulare Natur einer Vielzahl dieser Signale identifiziert und charakterisiert werden. Alle diese Faktoren haben bestimmte gemeinsame Eigenschaften: Sie sind spezifisch in der dorsalen Blastoporuslippe exprimiert und lösen, wenn sie in den frühen Froschembryo injiziert werden, die Bildung einer sekundären Körperachse aus (De Robertis et al., 2000). 


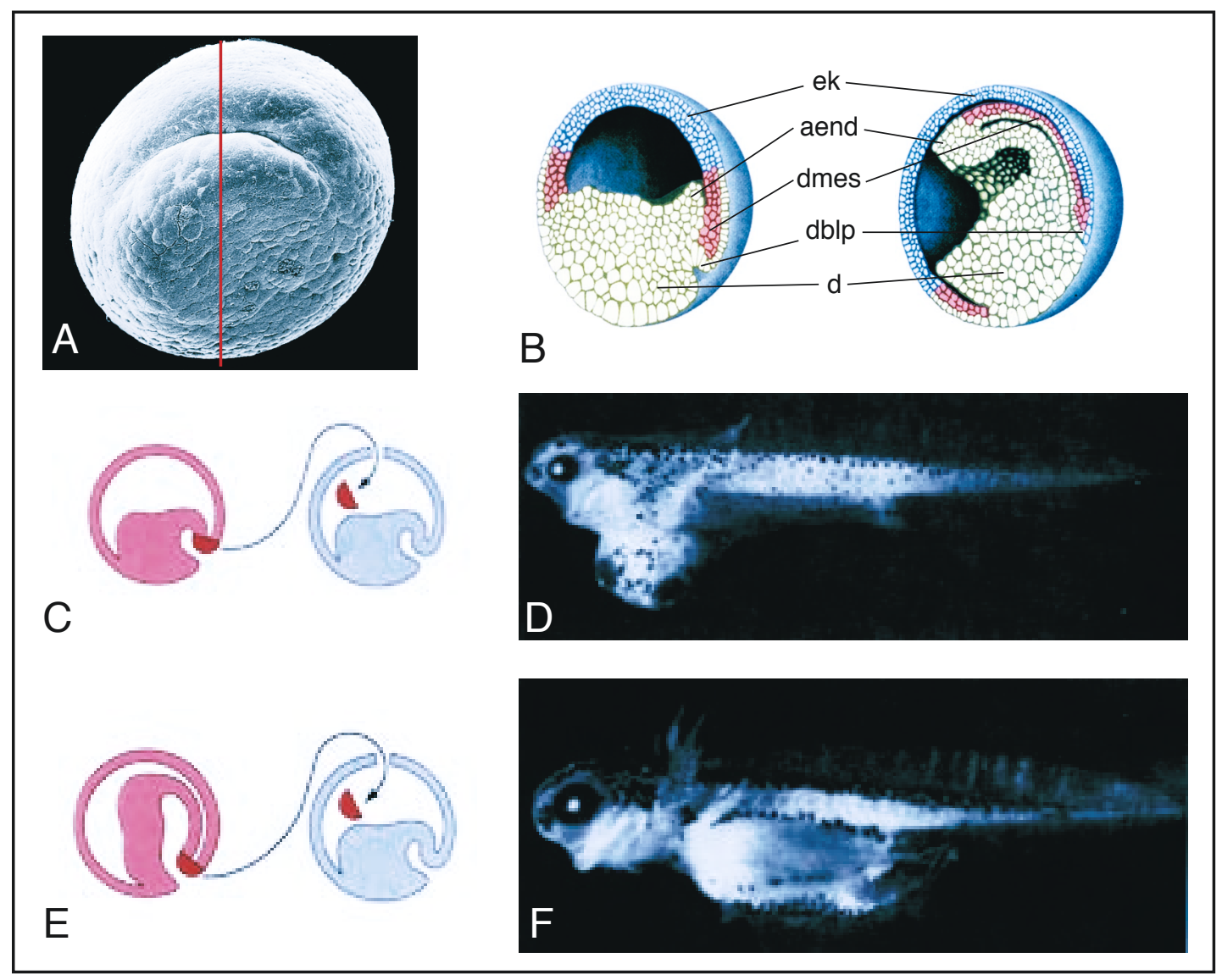

Abb. 1. 4.: Der Organisator im Amphibienembryo. (A) Rasterelektronenmikroskopische Aufnahme einer Xenopus-Gastrula, mit Blick auf auf den Blastoporus; (B) Schematischer Querschnitt durch eine Amphibiengastrula am Beginn der Gastrulation und zu einem fortgeschrittenen Zeitpunkt; Abkürzungen: aend=anteriores, definitives Endoderm, d=Dotterzellen, dblp=dorsale Blastoporuslippe, dmes=dorsales Mesoderm; (C-F) Kopf und Rumpforganisator im Amphibienembryo, $(\mathrm{C}+\mathrm{E})$ Transplantationsschemata der Organisatorregion einer jungen $(\mathrm{C})$ und einer älteren Gastrula; (D) Induktion von Kopfstrukturen im Molchembryo; (F) Induktion von Rumpf- und Schwanzstrukturen im Molchembryo. (A) entnommen aus Bard, 1995; (B) aus Wolpert, 2000; (C-F) aus Gilbert, 2000.

Die molekulargenetische Analyse dieser Signale hat dabei ein erstaunliches entwicklungsbiologisches Prinzip aufgedeckt: Die meisten vom Organisator sekretierten Faktoren inhibieren Signaltransduktionswege (De Robertis et al., 2000). Diese Inhibition erfolgt durch Bindung des sekretierten Inhibitors an einen Wachstumsfaktor im extrazellulären Raum, wodurch die Bindung des Faktors an seinen Rezeptor unterbunden wird. Wachstumsfaktoren der BMP-Familie, die im Embryo ventrales Mesoderm induzieren, werden durch die drei vom Organisator sekretierten Antagonisten Chordin, Noggin und Follistatin inhibiert (De Robertis, 1995; Piccolo et al., 1996). Eine andere Gruppe vom Organisator sekretierter Faktoren inhibiert Wnt-Wachstumsfaktoren. Wie die BMPs, induzieren Wnt-Moleküle in der Froschgastrula ventrales Meso- 
derm, zudem wirken sie posteriorisierend auf das Neuroektoderm (Kiecker und Niehrs, 2001). Ihre Antagonisten, Frizbee (Frzb), Dickkopf (Dkkl) und Crescent, dorsalisieren die Gastrula also nicht nur, sie etablieren auch anteriore Areale im Embryo (Glinka et al., 1998; Leyns et al., 1997; Pera und De Robertis, 2000; Shibata et al., 2000). Daß der Organisator nicht nur für die Induktion der Körperachse zuständig ist, sondern auch regionalisierend auf diese einwirkt, beobachteten schon Hans Spemann und Hilde Mangold: Die Transplantation der dorsalen Blastoporuslippe einer jungen Gastrula induziert im Wirtsembryo ektopische Kopfstrukturen, der Organisator einer älteren Gastrula dagegen nur den Rumpf und den Schwanz (Abb. 1. 4., C-F). Nieuwkoop schlug in seinem Modell zur Neuralinduktion und Regionalisierung des Neuroektoderms ein zweischrittiges Modell vor: Ein initiales Signal induziert einen anterioren Grundzustand, ein zweites, posteriorisierendes, richtet die anteriorposterior Regionalisierung ein (Nieuwkoop, 1952). Die Kenntnis um die Moleküle des Organisators und deren Eigenschaften führte zu einem Modell über die Achsenspezifizierung durch den Organisator im Amphibienembryo, in dem die Inhibierung der unterschiedlichen Signalmoleküle die entscheidende Rolle spielt: Um anteriores Neuroektoderm zu induzieren, müssen der Wnt- sowie der BMP-Signalweg inhibiert werden, was dem initialen Schritt des Nieuwkoopschen Modells entspräche (Niehrs, 1999). Die posteriore Regionalisierung der Neuralachse erfolgt durch Wnt-Moleküle, $F G F s$ und Retinsäure, die in einem nach posterior ansteigenden Gradienten exprimiert werden, bei gleichzeitiger Inhibierung des BMP-Signalweges (Niehrs, 1999; Chen et al., 2001; Kiecker und Niehrs, 2001).

\section{6. Der Organisator im Amniotenembryo}

Die der dorsalen Blastoporuslippe funktionell homologe Struktur im Vogel und Säugerembryo ist die anteriore Spitze des Primitivstreifens, der (Hensensche) Knoten (Abb. 1. 3.; Hensen, 1876; Waddington, 1932; Beddington, 1994). Wie im Amphibienembryo induziert der Hensensche Knoten eines Vogelembryos, wenn er in eine extraembryonale Region eines Wirtsembryos transplantiert wird, ein sekundäres Neuralsystem (Abb. 1. 5, A). Ebenso findet sich im Vogelembryo die zeitliche Trennung von Kopf- und Rumpforganisator. 


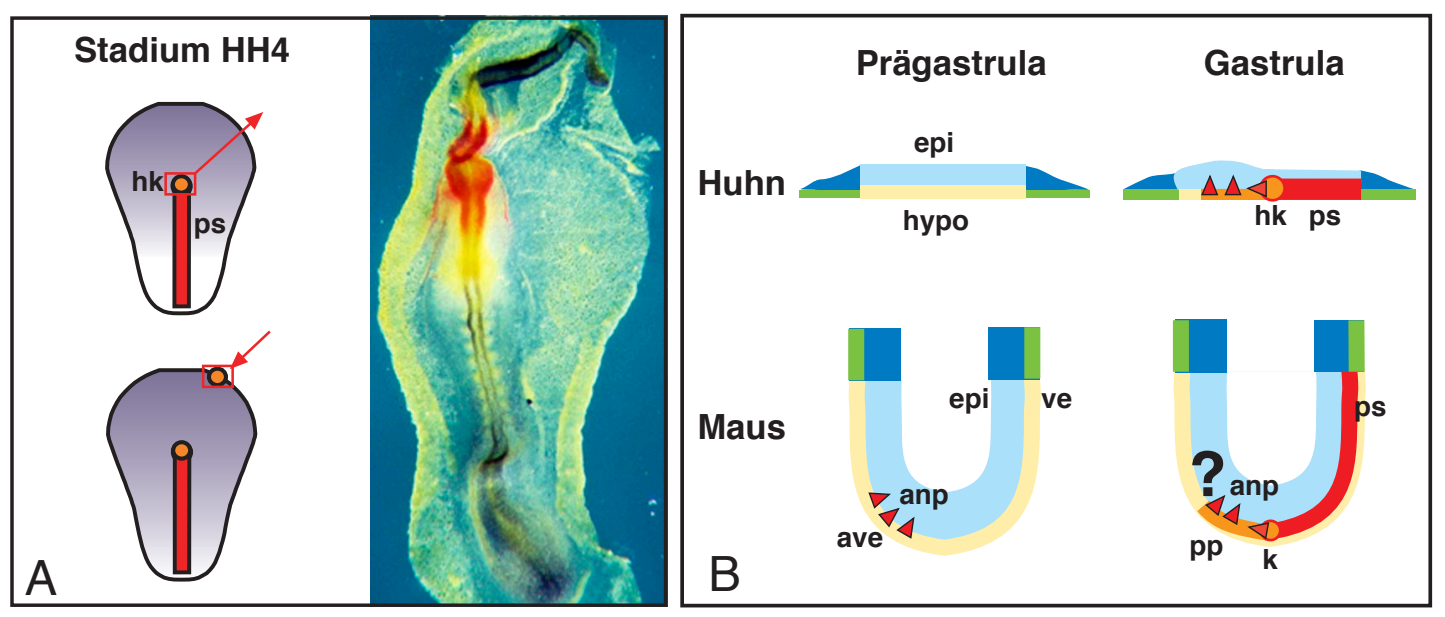

Abb. 1. 5.: Der Organisator im Huhn- und Mausembryo. (A) Der Hensensche Knoten organisiert Kopf- und Rumpfstrukturen; links Operationsschema, rechts: Huhnembryo, bei dem anteriore Strukturen durch OTX2-Expression (rot) und posteriore Strukturen durch HOXB1-Expression (schwarz) angezeigt werden. Der induzierte Embryo liegt mit den induzierten Kopfstrukturen am primären Embryo. (B) Die Induktion der anterioren Neuralplatte im Huhn- und Mausembryo. In der Maus wird die anteriore Neuralplatte durch Signale aus dem anterioren viszeralen Endoderm induziert, im Huhn durch Derivate des Organisators. Ob der Organisator der Mausgastrula ebenfalls anteriore Strukturen induzieren kann, wurde in dieser Arbeit untersucht. Abkürzungen: a=anterior, anp=anteriore Neuralplatte, ave=anteriores viszerales Endoderm, e=definitves Endoderm, ek=Ektoderm, epi=Epiblast, hk=Hensenscher Knoten, hypo=Hypoblast, mes=Mesoderm, k=Knoten, ps=Primitivstreifen. (A) aus Böttger et al., 2000.

Ein junger Knoten induziert eine Neuralachse, die Regionen anterioren und posterioren Charakters besitzt. Ein älterer Knoten, aus dem die Zellen des prächordalen Mesoderms bereits ausgewandert sind, induziert nur posteriores Neuralgewebe (Dias und Schoenwolf, 1990; Storey et al., 1992). Wird das prächordale Mesoderm verpflanzt, so wird eine anteriore Neuralplatte induziert, die Transplantation des Notochords führt zu der ektopischen Aktivierung von Neuralgewebe mit Mittel- und Hinterhirnidentität (Hara, 1961; Pera und Kessel, 1997; Knoetgen et al., 1999). Der Mausembryo ist gegenüber dem Huhnembryo im Stadium des definitiven Primitivstreifens (6,5 dpc) sehr klein, was die experimentelle Untersuchung der induktiven Kapazität des Mausknotens über lange Zeit erschwerte (Abb. 1. 2.). Erst 1994 gelang es, den Mausknoten an eine ektopische Position in einen Wirtsembryo zu transplantieren und die Induktion einer sekundären Körperachse zu beobachten (Beddington, 1994). Allerdings konnte bei diesen Transplantationsexperimenten nie die Induktion anteriorer Neuralstrukturen beobachtet werden, was zu der Hypothese führte, daß im Organisator der Maus anteriorisierende Signale fehlen und die Induktion anteriorer neuraler Strukturen durch andere, vom Knoten separierte Signalzentren, ausgeht. 
Unterstützt wurde diese Idee durch eine Reihe von Experimenten, die auf eine Funktion des anterioren primitiven Endoderms (anteriores viszerales Endoderm (AVE); siehe Abb. 1. 2.) bei der Etablierung der anterioren Neuralplatte hindeuteten. So sind viele Gene, die im Frosch im Spemannschen Organisator exprimiert sind, in der Maus schon vor der Ausbildung des Primitivstreifens in einer unabhängigen Domäne im AVE exprimiert. Dazu zählen die Signalmoleküle FGF8 und Nodal, der sekretierte Wnt-Antagonist Dkk1 sowie die Transkriptionsfaktoren Hesx1, Gsc, Lim1 und Otx2 (Ang et al., 1994; Dattani et al., 1998; Filosa et al., 1997; Glinka et al., 1998; Shawlot und Behringer, 1995; Tsang et al., 1999; Varlet et al., 1997). Wird das AVE entfernt, werden Marker der anterioren Neuralplatte nicht mehr exprimiert, und die Neuralplatte ist kleiner (Thomas und Beddington, 1996). Die genetische Inaktivierung der AVE-Marker Nodal, Otx2, Lim1, Hesx1 und Hex führt zu schweren Defekten in der Kopfentwicklung (Acampora et al., 1995; Ang und Rossant, 1994; Dattani et al., 1998; Matsuo et al., 1995; Shawlot und Behringer, 1995; Varlet et al., 1997; Weinstein et al., 1994). Auch bilden Mausmutanten, die aufgrund der Inaktivierung des Gens $H N F 3 \beta$ keinen Knoten haben, und in denen die BMP-Antagonisten Chordin und Noggin fehlen, Neuralgewebe (Ang und Rossant, 1994). Trotzdem bleibt unklar, ob die Etablierung der anterioren Neuralplatte im Säugerembryo wirklich von der induktiven Aktivität des Knotens abgekoppelt ist. Zwar induziert das extraembryonale Endoderm des Kaninchens, wenn es in einen Huhnembryo transplantiert wird, transient den anterioren Neuralplattenmarker GANF, das Ortholog von Hesxl aus dem Säuger (Knoetgen et al., 1999). Wird das AVE der Maus allerdings in einen Mauswirtsembryo transplantiert, werden keine anterioren Neuralstrukturen induziert (Beddington, 1994). Das gelingt nur, wenn das AVE in Kombination mit dem anterioren Epiblast und der Spitze des frühen Primitivstreifens transplantiert wird (Tam und Steiner, 1999). Obwohl klar ist, daß Signale aus dem anterioren viszeralen Endoderm an der Musterbildung der anterioren Neuralplatte im Säuger beteiligt sind, bleibt doch die Frage offen, ob der Kopf- und der Rumpforganisator im Säuger strukturell voneinander vollständig separiert ist, oder ob auch der Knoten in der Lage ist, Kopfstrukturen $\mathrm{zu}$ induzieren (Abb. 1. 5., B). 


\section{7. Kardiogenese im Vogelembryo}

Das erste funktionsfähige Organ im Embryo ist das Herz. Herzzellen fangen schon im 13-Somitenstadium (HH11) an, sich zu kontrahieren. Das Herz ist von diesem Zeitpunkt an für die Versorgung des Embryos mit Nährstoffen essentiell. Die molekularen Prozesse, die der Etablierung des Herzfeldes unterliegen, gleichen in ihren Prinzipien den musterbildenden Prozessen während der Neuralinduktion. Auch bei der kardialen Induktion sind sekretierte Signalmoleküle und ihre Inhibition für die Positionierung und Spezifizierung der Herzmesodermzellen zuständig.

Neben den Zellen des prächordalen Mesendoderms sind die Herzvorläuferzellen die ersten Zellen, die während der Gastrulation in den Embryo einwandern. Präkardiale Zellen sind vor Einsetzen der Gastrulation im Epiblast lateral des mittleren Primitivstreifens lokalisiert (Hatada und Stern, 1994; Rosenquist, 1966). Im Stadium HH3, dem intermediären Primitivstreifenstadium, liegen sie im mittleren Bereich des Primitivstreifens (Garcia-Martinez und Schoenwolf, 1993; Lopez-Sanchez et al., 2001). Da sie zu den ersten in den Embryo einwandernden Zellen gehören, bilden sie den anterioren Rand der sich ausbreitenden Mesodermschicht (Rosenquist, 1966). Im Kopffortsatzstadium (HH5) nehmen die kardialen Vorläuferzellen eine halbmondförmige Domäne in der anterior-lateralen Region des Embryo ein (Abb. 1. 6., A) und bilden das sogenannte primäre Herzfeld. Mit der Bildung der Kopffalte und des Darmportals beginnen die lateralen Bereiche des anterioren Embryos zusammenzuwachsen und den Vorderdarm zu bilden. Als Teil dieser Bewegung werden die kardialen Vorläuferzellen im Mesoderm der lateralen Platte ventral am Vorderdarm zusammengebracht und bilden den Herztubus (Abb. 1. 6., B). Die posteriore Öffnung des Herzschlauches, in die das Blut einfließt, ist der venöse Pol, anterior liegt die Ausflußöffnung, der arterielle Pol. Kurze Zeit nach der Fusion beginnen die Zellen des Herzmesoderms sich zu kontrahieren, das Herz beginnt zu schlagen. Der früheste molekulare Marker, der spezifisch für kardiale Zellen ist, ist das Homeoboxgen $N k x 2.5$ (Schultheiss et al., 1995). Nkx2.5-Transkripte sind über in situ-Hybridisierung in präkardialen Zellen ab dem Kopffortsatzstadium (HH5) im anterioren lateralen Mesoderm, dem Herzfeld, nachweisbar. Allerdings finden sich Nkx2.5-Transkripte auch im angrenzenden Endo- und Ektoderm. Vom Kopffaltenstadium (HH6) sind die Transkriptionsfaktoren GATA4, -5 und -6 in den kardialen Vorläuferzellen aktiv (Jiang 
et al., 1998). Vom Ein-Somitenstadium (HH7) an werden die ersten für Herzmuskelzellen charakteristischen Strukturproteine, wie muskelspezifische Aktine, Myosine und assoziierte Proteine, exprimiert.

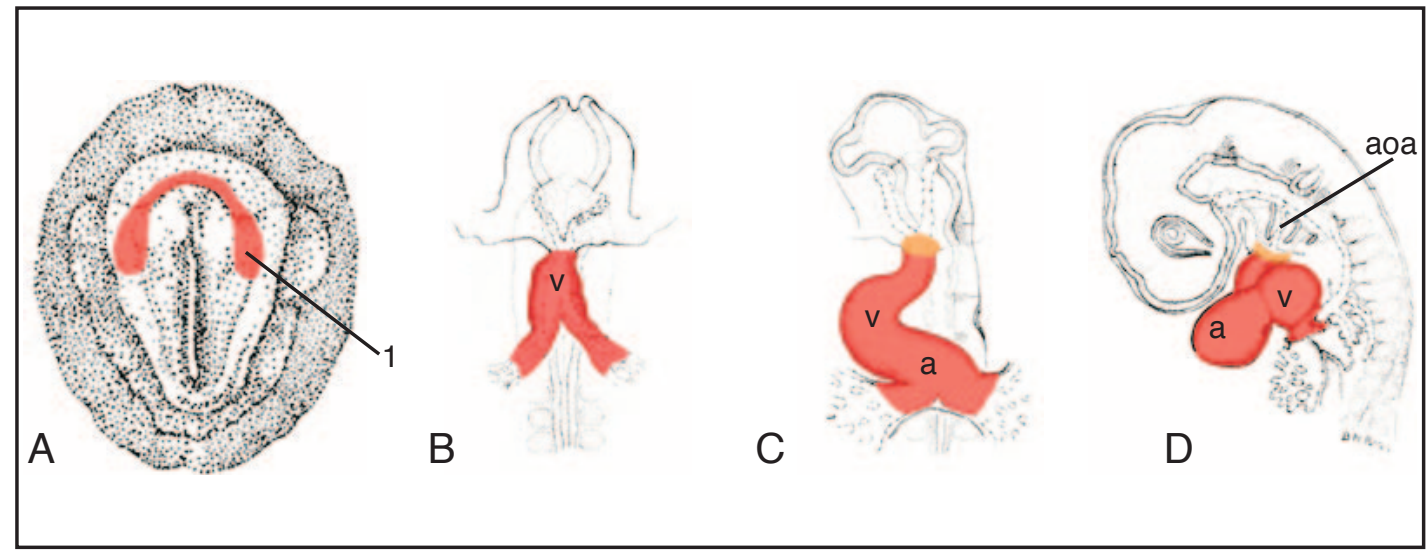

Abb. 1. 6.: Herzentwicklung im Huhnembryo. (A) Huhnembryo im Kopffortsatzstadium, rot unterlegt ist das Areal des primären Herzfeldes, wie es durch Nkx2.5-Expression angezeigt wird (1); (B) Embryo im Stadium HH9 (sechs Somiten), das Herzfeld fusioniert; (C) Stadium HH12 (16 Somiten), die Drehung des Herzschlauches beginnt; orange unterlegt ist der arterielle Pol des Herzens; (D) Stadium HH15, die sekundäre Verlängerung des Trunkus arteriosus findet statt, die Aortenbögen werden von kardialen Neuralleistenzellen besiedelt, orange unterlegt ist das Areal des sekundären Herzfeldes. Abkürzungen: a=Atrium, aoa=Aortenbogenarterien, v=Ventrikel; (A-D) modifiziert aus Karlson, 1995.

\section{8. Die Induktion des primären Herzfelds}

Im Vogelembryo scheinen, wie bei der Neuralinduktion, auch bei der Induktion der kardialen Vorläuferzellen Signale aus dem Hypoblast schon vor Ausbildung des Primitivstreifens eine Rolle zu spielen. Werden Explantate des Prägastrula-Epiblast mit Hypoblastexplantaten kokultiviert, wird neben anderen Mesodermtypen auch Herzmesoderm gebildet (Yatskievych et al., 1997). Explantate aus dem Primitivstreifen im intermediären Primitivstreifenstadium (HH3) differenzieren sich zu kontrahierenden Kardiomyozyten. Werden sie in posteriore Bereiche transplantiert, findet keine Differenzierung zu Kardiomyozyten statt (Montgomery et al., 1994). Die Zellen des intermediären Primitivstreifens sind also noch nicht determiniert (Inagaki et al., 1993). Die Spezifizierung der kardialen Vorläuferzellen in kardiale Muskelzellen zu differenzieren, erfolgt im Stadium HH4-HH5, wenn die Zellen den Primitivstreifen verlassen haben. Im Stadium HH5-HH6 sind die Herzzellen dann determiniert. Eine zentrale Quelle für Herzmesoderm induzierende Signale ist das anteriore Endoderm 
aus dem definitiven Primitivstreifenstadium (HH4) und dem Kopffortsatzstadium (HH5). Wird dieses Gewebe mit Zellen aus dem posterioren Primitivstreifen kokultiviert, induziert es in ihnen die Expression der kardialen Markergene Nkx2.5, GATA4 und typischer kardialer Strukturproteine (Schultheiss et al., 1995). Als molekulare Signale für die Induktion des Herzmesoderms konnten $B M P$-Faktoren identifiziert werden. $B M P 2$ ist im Endoderm, BMP4 im Ektoderm um das präkardiale Mesoderm exprimiert. Für beide Faktoren konnte gezeigt werden, daß sie kardiale Marker in nicht-kardiogenen Regionen des Embryos induzieren können (Andree et al., 1998; Schultheiss et al., 1997). Werden sie durch ihren Antagonisten Noggin blockiert, wird die Differenzierung der Kardiomyozyten verhindert (Schlange et al., 2000; Schultheiss et al., 1997). Der Einfluß der BMP-Signale auf die Kardiogenese wurde durch die gezielte Inaktivierung des BMP2-Gens in der Maus und durch die BMP2-Mutante im Zebrabärbling belegt. In beiden Organismen führt der Verlust des $B M P$-Signals zu schweren Defekten in der Herzentwicklung (Kishimoto et al., 1997; Zhang und Bradley, 1996). Neben den BMPs sind auch Mitglieder der FGF-Familie an der Induktion kardialer Marker beteiligt. Die Kombination von FGF4 und BMP2 löst in posterioren Arealen des HH4-Embryos Kardiogenese aus (Lough und Sugi, 2000). Für Wnt-Faktoren konnte ein inhibitorischer Einfluß auf die kardiale Induktion gezeigt werden (Marvin et al., 2001; Schneider und Mercola, 2001 ). Insbesondere $c W n t 8 c$ und Wnt3a aus dem Primitivstreifen, dem posterioren Mesoderm und dem Neuralrohr verhindern eine posteriore Aktivierung kardialer Markergene (Marvin et al., 2001; Tzahor und Lassar, 2001). Werden Wnt-Signale in posterioren Mesodermexplantaten durch den sekretierten Wnt-Antagonisten Crescent inhibiert, werden die kardialen Markergene Nkx2.5 und GATA4 aktiviert und das posteriore Mesoderm differenziert sich zu kontrahierenden Herzmuskelzellen (Marvin et al., 2001).

\section{9. Das anteriore, sekundäre Herzfeld und die kardiale Neuralleiste}

Nach der Fusion des präkardialen Mesoderms zum Herztubus im Sechs- bis SiebenSomitenstadium (HH8-HH9), wird durch eine Vielzahl morphogenetischer Prozesse aus dem geraden Herzschlauch das vierkammrige Amniotenherz gebildet. Zwischen dem 10- und 13-Somitenstadium (HH10-HH11) beginnt der Herzschlauch sich nach rechts zu drehen und untergliedert sich in fünf sukzessiv geformte Segmente (Mjaat- 
vedt et al., 2001; Abb. 1. 6., C). Das letzte dieser Segmente ist der Trunkus arteriosus oder Ausflußtrakt, der zwischen den Stadien HH11 bis HH22 ausgeformt wird (de la Cruz et al., 1977; Abb. 1. 6., C, D). Er ist der Verbindungskanal zwischen dem embryonalen rechten Ventrikel und den Aortenbögen. Während der weiteren Herzentwicklung, zwischen den Stadien HH14 und HH22, verlängert sich der Trunkus arteriosus und verlagert sich kaudal. Durch Zellmarkierungs-, Zellablations- und Eplantexperimente, wurde gezeigt, daß diese Verlängerung aus einem, vom primären Herzfeld unabhängigen, sogenannten sekundären oder anterioren Herzfeld erfolgt (Abb. 1. 6., D; Mjaatvedt et al., 2001; Waldo et al., 2001). Dieses sekundäre Herzfeld ist im splanchnischen Mesoderm am Ausflußtrakt an der Ansatzstelle der Aortenbögen lokalisiert. Von hier werden Mesodermzellen zur sekundären Verlängerung des Trunkus arteriosus rekrutiert, die dort zu Myokardzellen differenzieren. Wie im primären Herzfeld, sind im sekundären Herzfeld die kardialen Markergene $N k x 2.5$ und GATA4 sowie die Wachstumsfaktoren BMP2, -4 und -7 exprimiert, so daß die induktiven Ereignisse und die transkriptionelle Regulation bei der Rekrutierung der kardialen Myozyten des Trunkus arteriosus mit denen im primären Herzfeld vergleichbar sind (Mjaatvedt et al., 2001; Waldo et al., 2001). Zum Abschluß der Differenzierung des Trunkus arteriosus wandern Zellen der kardialen Neuralleiste aus den Kiemenbögen in den Ausflußtrakt ein und bilden das aortikopulmonare Septum, das den Ausflußtrakt in die Aorta ascendens und die Arteria pulmonalis aufteilt (Waldo et al., 1998). Die kardialen Neuralleistenzellen befinden sich während der Entwicklung des Ausflußtraktes in Nachbarschaft zu den Zellen des sekundären Herzfeldes. Daher ist anzunehmen, daß der koordinierte Ablauf der Morphogenese im Trunkus arteriosus durch Signale zwischen Neuralleistenzellen und dem sekundären Herzfeld vermittelt wird. Unterstützt wird diese Vermutung durch Arbeiten von Kirby und Mitarbeitern, die einen Zusammenhang zwischen $F G F$-Signalen, der kardialen Neuralleiste und der Herzentwicklung zeigen konnten (Farrell et al., 1999). 


\section{10. Zielsetzung}

Im Mittelpunkt der vorliegenden Arbeit standen die Einflüsse von induktiven Signalen auf Musterbildungsprozesse im frühen Vertebratenembryo. Mit Hilfe von Transplantationsexperimenten sollte im ersten Teil der Arbeit die induktive Kapazität des Säugerknotens bei der Anlage des Vorderhirns getestet werden. Davon ausgehend sollten durch einen Expressionsscreen Gene charakterisiert werden, die aufgrund ihrer zeitlich-räumlichen Aktivitätsmuster eine Funktion bei musterbildenden Vorgängen im anterioren Embryo haben können. Eines der neu identifizierten Gene, der sekretierte Wnt-Antagonist Sizzled ( $(\mathrm{Sz} l)$, wurde im zweiten Teil der Arbeit genauer analysiert. Ausgehend von seinem Expressionsmuster wurde für $c S z l$ eine Funktion in der primären Kardiogenese und im sekundären Herzfeld angenommen. Mit Hilfe von ektopischen Applikationen verschiedener Signalmoleküle, gezielter Überexpression und embryologischer Manipulation sollte gezeigt werden, wie $c S z l$ in das regulative Netzwerk bei der Einrichtung des Wirbeltierbauplans zu integrieren ist. 


\section{Material und Methoden}

\section{1. Abkürzungen und Symbole}

\begin{tabular}{|c|c|}
\hline$\%$ & Prozent \\
\hline A & Adenin \\
\hline aa & Aminosäure \\
\hline Abb. & Abbildung \\
\hline ADMP & anti-dorsalisierendes, morphogenetisches Protein \\
\hline ATP & Adenosintriphosphat \\
\hline ave & $\begin{array}{l}\text { anteriores viszerales Endoderm, das anteriore primitive } \\
\text { Endoderm der Säugetierembryonen }\end{array}$ \\
\hline BBR & Boehringer-Blockierungs-Reagenz \\
\hline BGH & Rinderwachstumshormon (engl. bovine growth hormon) \\
\hline BMP & Knochenwachstumsfaktor (engl. bone morphogenetic protein) \\
\hline $\mathrm{bp}$ & Basenpaare \\
\hline BSA & Rinderserumalbumin \\
\hline c & centi \\
\hline${ }^{\circ} \mathrm{C}$ & Grad Celsius \\
\hline $\mathrm{C}$ & Cytosin \\
\hline cDNA & komplementäre DNA \\
\hline CEF & embryonale Hühnerfibroblasten \\
\hline CHAPS & 3-[(3-Cholamidopropyl)-dimethylammonio]-1-propansulfonat \\
\hline $\mathrm{Ci}$ & Curie \\
\hline $\mathrm{cm}$ & Zentimeter \\
\hline CMV & Cytomegalovirus \\
\hline cpm & gezählte Zerfälle pro Minute (engl. counts per minute) \\
\hline cSzl & Huhn-Ortholog des Gens Sizzled \\
\hline $\mathrm{dCTP}$ & Desoxycytosintriphosphat \\
\hline dd & doppelt destilliert \\
\hline DIG & Digoxigenin \\
\hline DiI & $\begin{array}{l}\text { 1,1'-Dioctadecyl-3,3,3',3'-tetramethylindocarbocyaninpe- } \\
\text { chlorat }\end{array}$ \\
\hline DMEM & Zellkulturnährmedium (Dulbeccos modified eagle medium) \\
\hline DNA & Desoxyribonukleinsäure \\
\hline dNTP & Desoxynukleotidtriphosphat \\
\hline dpc & Tag nach Konzeption (engl. days post conception) \\
\hline DTT & 1,4 Dithiothreitol \\
\hline EDTA & Ethylendiamintetraazetat \\
\hline EK & $\begin{array}{l}\text { Einteilung der frühen Entwicklungsstadien des Hühnerembryos } \\
\text { nach Eyal-Giladi und Kochav, } 1976 .\end{array}$ \\
\hline EST & sequenzierter Abschnitt einer cDNA (engl. expressed sequence \\
\hline
\end{tabular}




\begin{tabular}{|c|c|}
\hline $\mathrm{fb}$ & Vorderhirn (engl. forebrain) \\
\hline FCS & fötales Kälberserum \\
\hline FGF & Fibroblastenwachstumsfaktor (engl. fibroblast growth factor) \\
\hline g & Gramm/Erdbeschleunigung \\
\hline G & Guanin \\
\hline $\mathrm{h}$ & Stunde(n) \\
\hline $\mathrm{hb}$ & Hinterhirn (engl. hindbrain) \\
\hline $\mathrm{HH}$ & $\begin{array}{l}\text { Stadien der Entwicklung des Hühnerembryos (Hamburger und } \\
\text { Hamilton, 1951) }\end{array}$ \\
\hline HMG & DNA-bindende Proteindomäne (engl. high mobility group) \\
\hline ISH & in situ-Hybridisierung \\
\hline $\mathrm{kb}$ & Kilobasen \\
\hline 1 & Liter \\
\hline LB & Bakterienmedium (Luria Broth) \\
\hline $\mathrm{m}$ & milli \\
\hline M & molar \\
\hline$\mu$ & mikro \\
\hline MAB & Maleinsäurepuffer \\
\hline MCS & $\begin{array}{l}\text { multiple Klonierungsstelle in Vektoren (engl. multiple cloning } \\
\text { site) }\end{array}$ \\
\hline $\min$ & Minute(n) \\
\hline mRNA & Boten-Ribonukleinsäure \\
\hline $\mathrm{n}$ & nano \\
\hline NBT-BCIP & Nitroblautetrazolium mit 5-Brom-4-chlor-3-indolylphosphat \\
\hline nc & Notochord \\
\hline $\mathrm{nf}$ & Neuralfalten \\
\hline np & Neuralplatte \\
\hline $\mathrm{nt}$ & Neuralrohr (engl. neural tube) \\
\hline NTMT & Natriumchlorid-Tris-Magnesium-Tween-Puffer \\
\hline OD 600 & optische Dichte bei $600 \mathrm{~nm}$ Wellenlänge \\
\hline $\mathrm{p}$ & pico \\
\hline PBS & phosphat-gepufferte Natriumchlorid-Lösung \\
\hline PBT & phosphat-gepufferte Natriumchlorid-Lösung mit Tween \\
\hline $\mathrm{PC}$ & Pannett-Compton-Salzlösung \\
\hline PCR & Polymerase-Ketten-Reaktion \\
\hline PFA & $4 \%$ Paraformaldehyd in PBS \\
\hline $\mathrm{pH}$ & $\begin{array}{l}\text { negativer dekadischer Logarithmus der Wasserstoffionenkonzen- } \\
\text { tration }\end{array}$ \\
\hline PNK & Polynukleotidkinase \\
\hline $\mathrm{pp}$ & prächordale Platte \\
\hline ps & Primitivstreifen \\
\hline RNA & Ribonukleinsäure \\
\hline rpm & Umdrehungen pro Minute (engl.: rotations per minute) \\
\hline RT & Raumtemperatur \\
\hline RT-PCR & Reverse-Transkriptase-Polymerase-Ketten-Reaktion \\
\hline $\mathrm{sc}$ & Rückenmark (engl. spinal cord) \\
\hline SDS & Natriumdodecylsulfat \\
\hline sec & Sekunden \\
\hline
\end{tabular}




$\begin{array}{ll}\text { Sfrp } & \begin{array}{l}\text { sekretierte frizzled-ähnliche Proteine (engl. secreted frizzled } \\ \text { related proteins) }\end{array} \\ \mathrm{T} & \text { Thymin } \\ \mathrm{T} 3 & \text { RNA-Polymerase } \\ \mathrm{T} 7 & \text { RNA-Polymerase } \\ \text { TBE } & \text { Tris-Borat-EDTA-Puffer für die Agarose-Gelelektroporese } \\ \text { Tris } & \text { Tris(hydroxymethyl)aminomethan } \\ \mathrm{U} & \text { Einheiten (engl:: units) } \\ \mathrm{UV} & \text { ultraviolett } \\ \mathrm{xg} & \text { Vielfaches der Erdbeschleunigung } \\ \mathrm{ZNS} & \text { zentrales Nervensystem } \\ \mu \mathrm{F} & \text { Elektrische Kapazität in } 10^{-6} \text { Faraday }\end{array}$

\section{2. Chemikalien, Reagenzien und andere Materialien}

Chemikalien wurden von den Firmen Amersham-Pharmacia (Freiburg), Difco Laboratories (Augsburg), Life Technologies (Karlsruhe), Merck (Darmstadt), Roth (Karlsruhe), Stratagene (Heidelberg), Sigma-Aldrich (Deisenhofen) bezogen, alle Chemikalien hatten den Reinheitsgrad p.a. (zur Analyse).

Enzyme und Reaktionspuffer wurden von den Firmen Roche (Mannheim), NEB (Schwalmbach), Gibco BRL (Karlsruhe), Promega (Mannheim), Stratagene (Heidelberg) und Qiagen (Hilden) bezogen. Radiochemikalien stammten von Amersham Buchler (Braunschweig).

Rekombinante Wachstumsfaktoren (rmFGF8, rmFGF4, rhBMP2, rmNoggin) stammten von R\&D Systems (Wiesbaden).

Es wurden die Kodak Röntgenfilme X-Omat AR und Biomax MR und der Diafilm Ekta-Chrome 64T verwendet. Insektennadeln und Wolframdraht stammten von PLANO (Marburg) (Insektennadeln: 0,1 mm Durchmesser, Länge $12 \mathrm{~mm}$, Wolframdraht: Durchmesser 0,125mm).

Plastikmaterial wurde von den Firmen Falcon, Eppendorf, Costar, Greiner, Sarstedt und Nunc, Glaswaren von der Firma Schott bezogen.

Mikroskopische Aufnahmen wurden an einem Olympus BX60 und an Zeiss Stereomikroskopen Stemi SV11 mit Photoeinrichtung erstellt. 


\section{3. Standardlösungen}

DEPC- $\mathrm{H}_{2} \mathrm{O}: \mathrm{ddH}_{2} \mathrm{O}$ wurde mit 0,1\% Diethylpyrokarbonat (DEPC) für $12 \mathrm{~h}$ bei $37^{\circ} \mathrm{C}$ unter leichtem Schütteln inkubiert und anschließend autoklaviert. Diese Behandlung inaktiviert RNasen.

LB-Medium: 10 g Bacto-Trypton, 5 g Bacto-Hefe-Extrakt, $10 \mathrm{~g} \mathrm{NaCl}$; auf 1 Liter mit $\mathrm{ddH}_{2} \mathrm{O}$ auffüllen und autoklavieren.

Phosphatpuffer (PBS) (20x): $800 \mathrm{~g} \mathrm{NaCl}, 20 \mathrm{~g} \mathrm{KCl}, 115 \mathrm{~g} \mathrm{Na}_{2} \mathrm{HPO}_{4} \cdot 2 \mathrm{H}_{2} \mathrm{O}, 24 \mathrm{~g}$ $\mathrm{KHPO}_{4}$ ad $5 \mathrm{l}$ mit ddH $\mathrm{H}_{2} \mathrm{O}$; $\mathrm{pH}$ auf 7,5 mit $\mathrm{NaOH}$ oder $\mathrm{HCl}$, autoklavieren.

PBT: $0,1 \%$ Tween-20 in PBS.

Pennet-Compten Puffer: Lösung A: $121 \mathrm{~g} \mathrm{NaCl}, 15,5 \mathrm{~g} \mathrm{KCl}, 12,7 \mathrm{~g} \mathrm{MgCl}_{2} \cdot 6 \mathrm{H}_{2} \mathrm{O}$, 10,4 $\mathrm{g} \mathrm{CaCl}_{2} \cdot 2 \mathrm{H}_{2} \mathrm{O}, \mathrm{dH}_{2} \mathrm{O}$ auf 1 1; Lösung B: 2,365 $\mathrm{g} \mathrm{Na}_{2} \mathrm{HPO}_{4} \cdot 2 \mathrm{H}_{2} \mathrm{O}, 0,188 \mathrm{~g}$ $\mathrm{NaH}_{2} \mathrm{PO}_{4} \cdot 2 \mathrm{H}_{2} \mathrm{O}, \mathrm{dH}_{2} \mathrm{O}$ auf 1 1; autoklavieren. Zum Gebrauch $60 \mathrm{ml}$ Lösung $+900 \mathrm{ml}$ $\mathrm{dH}_{2} \mathrm{O}+40 \mathrm{ml}$ Lösung B.

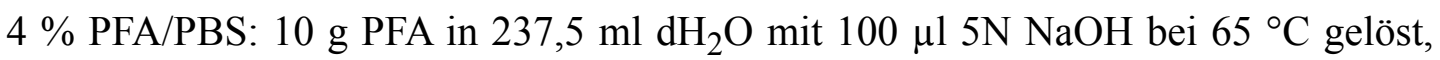
$12,5 \mathrm{ml} 20 \mathrm{x}$ PBS zugefügt, bei $-20^{\circ} \mathrm{C}$ gelagert.

6x Probenpuffer für Agarose-Gelelektrophorese: 0,125\% Bromphenolblau, $25 \%$ Ficoll, 100 mM EDTA.

Saline: $0,86 \% \mathrm{NaCl}$ in $\mathrm{dH}_{2} \mathrm{O}$; autoklavieren.

20x SSC: 3 M NaCl, 300 mM Natriumcitrat, pH mit Zitronensäure einstellen.

TBE (10x): 108 g Tris, 55 g Borsäure, 4 ml EDTA (0,5 M) mit dd $\mathrm{H}_{2} \mathrm{O}$ auf 1 Liter auffüllen. 
TE: 10 mM Tris-HCl pH 8, 0,1 mM EDTA.

Tyrodes Puffer (10x Stammlösung): $80 \mathrm{~g} \mathrm{NaCl}, 2 \mathrm{~g} \mathrm{KCl}, 2,71 \mathrm{~g} \mathrm{CaCl}_{2} \cdot 2 \mathrm{H}_{2} \mathrm{O}, 0,5 \mathrm{~g}$ $\mathrm{NaH}_{2} \mathrm{PO}_{4} \cdot 2 \mathrm{H}_{2} \mathrm{O}, 2 \mathrm{~g} \mathrm{MgCl} 2 \cdot 6 \mathrm{H}_{2} \mathrm{O}, 10 \mathrm{~g}$ Glukose in $11 \mathrm{dH}_{2} \mathrm{O}$ lösen; autoklavieren; am Tag des Gebrauchs 1:10 in $\mathrm{dH}_{2} \mathrm{O}$ verdünnen.

\section{4. Organismen und Vektoren}

\section{4. 1. Plasmide}

Standardklonierungen wurden in Bluescript II Ks+ (Stratagene) durchgeführt, PCRFragmente wurden in den pGEMT-easy (Invitrogene) kloniert. Für die Klonierung der RCAS-cSzl-Retroviren wurde der Slax12-Shuttlevektor verwendet (Morgan und Fekete, 1996).

Die cDNA-Banken wurden in einen von H. Knötgen konstruierten, eukaryontischen Expressionsvektor pCMV3 kloniert (Knoetgen, 2000). Dieser Vektor ermöglicht über SfiI-Schnittstellen eine gerichtete Klonierung von cDNA-Molekülen. Der Vektor verfügt über den Promotor des eukaryontischen Cytomegalo-Virus (CMV) und die Polyadenylierungssequenz des Rinderwachstumshormons (BGHpA). Dem CMVPromotor gegenüber liegt ein T7-Promotor. Der Vektor genügt also folgenden Kriterien: Die cDNAs können gerichtet in ihn hineinkloniert werden, womit einerseits eine Überexpression des Gens im Hühnerembryo oder in der Zellkultur möglich ist, andererseits kann über den Vektor unmittelbar Gegenstrang RNA für die in situ-Hybridisierung gewonnen werden. In den pCMV3 ligierte cDNA-Fragmente wurden mit Hilfe der folgenden Primer sequenziert, bzw. amplifiziert: Aufwärts der MCS (769789) bindet der CMV-Vorwärts-Primer (CGCAAATGGGCGGTAGGCGTG). Der pCDNA-Primer (TAGAAGGCACAGTCGAGG) bindet abwärts der MCS (10521069).

Die unten aufgeführten Plasmide enthalten huhnspezifische cDNA-Insertionssequenzen. Angegeben sind der Genname, der Name des verwendeten Vektors, das Enzym 
zum Linearisieren des Vektors, die RNA-Polymerase für die Synthese der Gegenstrang-RNA sowie die Bezugsquelle für das Plasmid.

\begin{tabular}{|l|l|l|l|}
\hline Genname & $\begin{array}{l}\text { Restriktions } \\
\text { enzym }\end{array}$ & $\begin{array}{l}\text { RNA- } \\
\text { Polymerase }\end{array}$ & Bezugsquelle \\
\hline Crescent & XbaI & T3 & diese Arbeit \\
\hline NKX2.5 & HindIII & T3 & Schultheiss et al., 1995 \\
\hline GATA4 & XbaI & Sp6 & Evans, 1998 \\
\hline cWnt8c & BamHI & T7 & Hume und Dott, 1993 \\
\hline GANF & HindIII & T7 & Knoetgen et al., 1999b \\
\hline OTX2 & EcoRI & T3 & Bally-Cuif et al., 1995 \\
\hline$H O X B 1$ & HindIII & T7 & Guthrie et al., 1992 \\
\hline$C H-T$ & BamHI & T7 & Kispert et al., 1995 \\
\hline$c S Z L$ & HindIII & $\mathrm{T} 7$ & diese Arbeit \\
\hline FGF8 & EcoRI & $\mathrm{T} 7$ & Crossley et al., 1996 \\
\hline
\end{tabular}

Tab. 2. 1.: Auflistung der für die Gegenstrangsynthese verwendeten Plasmide

\section{4. 2. Retroviren}

Als Ausgangsvirus für die Klonierung des rekombinanten Retrovirus RCAS-cSzl wurde das replikationskompetente Retrovirus RCAS-BP(A)-AP (Alkalische Phosphatase) verwendet, das auch als Kontrollvirus diente. Weitere verwendete Proviren waren RCAS-Crescent (zur Verfügung gestellt von A. Lassar) und RCAS-Wnt3a (zur Verfügung gestellt von C. Tabin).

Zur Aufreinigung der Plasmid-DNA wurden die Qiagen-Systeme MINI (bis $10 \mu \mathrm{g}$ ), MIDI (bis $500 \mu \mathrm{g}$ ) und MAXI (bis $1 \mathrm{mg}$ ) benutzt. Diese Art der Plasmid-Präparation entspricht einer modifizierten Form der alkalischen Lyse in Verbindung mit einer Anionenaustauschersäule. Für Transfektionen wurde im Anschluß an das Qiagenprotokoll noch zweimal mit je einem Volumen Phenol/Chloroform/Isoamylalkohol (25/ 24/1 v/v/v) extrahiert. Die DNA wurde darauf einmal mit Chloroform/Isoamylalkohol $(24: 1 \mathrm{v} / \mathrm{v})$ ausgeschüttelt und nach Zugabe von einem zehntel Volumen $3 \mathrm{M}$ Natri- 
umazetatlösung ( $\mathrm{pH}$ 5,2) mit 2,5 Volumen Ethanol ausgefällt. Das Pellet wurde in $70 \%$ Ethanol gewaschen, erneut zentrifugiert getrocknet und darauf in $\mathrm{dH}_{2} \mathrm{O}$ gelöst.

\section{4. 3. Bakterien}

Für Standardklonierungen von Plasmiden wurde der E.coli Stamm DH5-alpha verwendet, die Plasmid-cDNA-Banken wurden in den E. coli Stamm X110-blue (Stratagene) kloniert.

\section{4. 4. Hühnerembryonen}

Befruchtete Hühnereier der Rasse White Leghorn wurden von Lohmann Tierzucht (Cuxhaven) bezogen. Die Eier wurden bei $38^{\circ} \mathrm{C}$ und $60 \%$ Luftfeuchtigkeit bis zum gewünschten Stadium inkubiert.

\section{4. 5. Mausembryonen}

NMRI-Wildtyp-Mäuse stammten von Harlan Winkelmann, Borchen. Die Mäuse wurden im Alter von von 8 Wochen zur Gewinnung vieler Embryonen superovuliert. Die superovulierten Weibchen wurden mit NMRI-Männchen verpaart und am nächsten Morgen auf den Vaginalpropf untersucht, der eine erfolgreiche Verpaarung anzeigt. Der Mittag des Tages nach der Verpaarung ist Tag 0,5 nach Konzeption. Am Tag 6,5 nach Konzeption wurden die Mäuse getötet und die Embryonen herauspräpariert.

\section{4. 6. Zellinien}

Für die retrovirale Transfektion wurden primäre embryonale Hühnerfibroblastenzellen (CEFs) aus 11,5 Tage alten Hühnerembryonen verwendet, Transfektionen mit Überexpressionsvektoren wurden in COS7- oder HEK286-Zellen durchgeführt. 


\section{5. Isolierung von Nukleinsäuren}

Plasmid-DNA wurde nach dem Qiagen-Plasmid-Aufreinigungsprotokoll präpariert. Die selektive Kultivierung plasmidtragender Bakterien erfolgte stets in LB-Medium mit $50 \mu \mathrm{g} / \mathrm{ml}$ Ampicillin, da alle verwendeten Vektoren mit Ampicillinresistenz ausgestattet waren.

\section{5. 1. Aufreinigung von DNA- oder RNA-Sonden}

Radioaktiv markierte DNA-Moleküle, bzw. mit Digoxigenin oder Fluoreszein markierte RNA-Moleküle, wurden über Sephadex Gelfiltrationssäulen (ProbeQuant G50, Amersham-Pharmacia) von freien Nukleotiden gereinigt.

\section{5. 2. Isolierung von Gesamt-RNA aus Gewebe}

Die Gewinnung von Gesamt-RNA erfolgte mit Hilfe des RNeasy-Mini RNA-Isolation Kits (Qiagen). Gewebeteile wurden wie in 2. 11. 2. beschrieben aus den Embryonen isoliert und mit einer Mikropipette in ein in flüssigem Stickstoff tiefgekühltes Eppendorfgefäß überführt. Zum Aufschluß der Zellen und zur Inaktivierung aller Proteine, vor allem der RNA abbauenden Enzyme, wurden die Gewebestücke in einem denaturierenden Puffer (Puffer RLT; enthielt Guanidiniumisothiocyanat und 2-Merkaptoethanol) durch Auf- und Abpipettieren homogenisiert. Die RNA-Moleküle aus dem Homogenat wurden anschließend an eine Anionenaustauschersäule gebunden und nach mehrmaligen Waschen in $30 \mu 1$ RNAse-freiem Wasser eluiert. Reinheit und Konzentration der präparierten RNA wurde am Spektralphotometer überprüft.

\section{5. 3. Elektrophorese und Isolation von DNA aus Agarosegelen}

Für analytische und präparative Zwecke wurden DNA-Fragmente in einem Agarosegel elektrophoretisch aufgetrennt. Es wurden entsprechend der erwarteten Fragmentgrößen 0,75 - 2\%ige Agarosegele (Gibco BRL) in 1x TBE, mit etwa $10 \mu \mathrm{g} / \mathrm{ml}$ Ethidiumbromid verwendet. Als Laufpuffer diente 1x TBE. Vor dem Auftragen wurden die Proben mit einem Fünftel ihres Volumens an Auftragspuffer versetzt und nach 
dem Anlegen einer konstanten Spannung von 1 bis 7 V/cm aufgetrennt. Die DNAFragmente wurden durch Anregung mit UV-Licht (Wellenlänge $258 \mathrm{~nm}$ ) analysiert. Präparative Gele wurden, um eine Beschädigung der DNA zu verhindern, bei langwelligem UV-Licht bearbeitet. Für die Präparation von Nukleinsäuren aus dem Gel wurden die zu isolierenden Banden mit einem Skalpell aus dem Gel herausgeschnitten. Die Aufreinigung aus der Agarose erfolgte nach zwei unterschiedlichen Methoden, der Elektroelution und der Elution über den "Qiaquick-Gel-Extraction-Kit” (Qiagen). Für die Elektroelution wurden die Agarosestücke in einen Dialyseschlauch überführt. Je nach Größe des ausgeschnittenen Agarosestückes wurden 500-1000 $\mu 1$ 0,5x TBE in den Dialyseschlauch hinzupipettiert und beide Enden mit Gefrierbeutelklammern verschlossen. Anschließend wurde für 15 bis 20 min eine Spannung von 8 $\mathrm{V} / \mathrm{cm}$ angelegt. Darauf wurde die Polung für weitere $30 \mathrm{~s}$ vertauscht und anschließend der Puffer aus dem Dialyseschlauch in ein Eppendorfreaktionsgefäß überführt. Die Puffer-DNA-Lösung wurde darauf zweimal mit Phenol-Chloroform und einmal mit Chloroform-Isoamylalkohol extrahiert. Schließlich erfolgte eine Ethanolpräzipitation. Das Präzipitat wurde in $\mathrm{dH}_{2} \mathrm{O}$ aufgenommen. Alternativ wurden DNA-Fragmente mit dem Qiaquick-Gel-Extraction-Kit über eine Anionenaustauschersäule nach Angaben des Herstellers eluiert.

\section{6. Modifizierung von Nukleinsäuren}

Die verwendeten Techniken und Methoden basieren, soweit nicht anders beschrieben, auf Sambrook et al., 1989.

\section{6. 1. Restriktionsverdau}

Für analytische Restriktionsverdaue wurden 500 ng bis $1 \mu \mathrm{g}$ DNA mit 10 U Restriktionsenzym innerhalb von $2 \mathrm{~h}$ geschnitten und anschließend auf einem Agarosegel ausgewertet. Für präparative Verdaue wurden $10 \mu \mathrm{g}$ DNA mit $100 \mathrm{U}$ Restriktionsenzym für $4 \mathrm{~h}$ inkubiert. 


\section{6. 2. Dephosphorylierung der 5'-Enden von DNA-Fragmenten}

Mit Restriktionsenzymen geschnittene Vektoren wurden zur Verhinderung der Religation vor der Ligation von DNA-Fragmenten dephosphoryliert. Dazu wurden die geschnittenen Vektoren zunächst aufgereinigt (Nukleotid Removal Kit, Qiagen) und dann mit Hilfe des Enzyms Alkalische-Phosphatase innerhalb von 30 min bei $37^{\circ} \mathrm{C}$ dephosphoryliert (1 U Intestinale Phosphatase für 20 pmol Vektor, Roche).

\section{6. 3. Erzeugung von glatten Enden bei DNA-Fragmenten}

DNA-Fragmente mit 5'-überhängenden Enden (bis zu $5 \mu \mathrm{g}$ ) wurden mit Hilfe des Klenow-Enzyms (2,5 U) in Gegenwart von dNTPs $(50 \mu \mathrm{M})$ im T4-DNA-PolymerasePuffer (50 mM TrisHCl pH 7,5, $10 \mathrm{mM} \mathrm{MgCl}_{2}, 1 \mathrm{mM}$ DTT) für $30 \mathrm{~min}$ bei $37^{\circ} \mathrm{C} \mathrm{zu}$ glatten DNA-Enden aufgefüllt.

DNA-Fragmente mit 3'-überhängenden Enden (bis zu $5 \mu \mathrm{g}$ ) wurden mit Hilfe der T4DNA-Polymerase (1 U) in Gegenwart von dNTPs $(50 \mu \mathrm{M})$ im T4-DNA-PolymerasePuffer für 20 min bei Raumtemperatur zu glatten DNA-Enden abgebaut.

2. 6. 4. Klonierung von doppelsträngigen, synthetischen DNA-Oligonukleotiden

Bei verschiedenen Klonierungsschritten wurden komplementäre, einzelsträngige DNA-Oligonukleotide mit einer Größe von 18 bis 40 Nukleotiden (Eurogentec, Belgien) verwendet. Zwei komplementäre einzelsträngige Oligonukleotide wurden dabei auf eine Konzentration von $100 \mathrm{pmol} / \mu 1$ mit Wasser (Millipore) eingestellt und dann bei Raumtemperatur zu gleichen Verhältnissen gemischt. Mit Hilfe der Polynukleotidkinase (PNK, Roche, Mannheim) wurden die Oligonukleotide innerhalb von 30 $\min$ bei $37^{\circ} \mathrm{C}$ an den $5^{\prime}$-Enden phosphoryliert (Tab. 2. 2.). Die phosphorylierten Oligonukleotide wurden mit dem Nukleotid-Removal-Kit von Qiagen mit einer Ausbeute von etwa $50 \%$ aufgereinigt und in $30 \mu \mathrm{l}$ mit einer Endkonzentration von etwa 0,8 $\mathrm{pmol} / \mu 1$ eluiert. 


\begin{tabular}{|l|l|}
\hline doppelsträngiges Oligonukleotid $50 \mathrm{pmol} / \mu \mathrm{l}$ & $1 \mu \mathrm{l}$ \\
\hline $\begin{array}{l}\text { 10x PNK Puffer (500 mM TrisHCl pH 8,2,100 } \mathrm{mM} \mathrm{MgCl}_{2}, 50 \mathrm{mM} \\
\text { DTT, } 1 \mathrm{mM} \text { EDTA, } 1 \mathrm{mM} \text { Spermidin) }\end{array}$ & $6 \mu \mathrm{l}$ \\
\hline $1 \mathrm{mM}$ ATP & $1,5 \mu \mathrm{l}$ \\
\hline Wasser (Millipore) & $46,5 \mu 1$ \\
\hline $10 \mathrm{U} / \mu 1$ PNK & $5 \mu 1$ \\
\hline Gesamtvolumen & $60 \mu \mathrm{l}$ \\
\hline
\end{tabular}

Tab. 2. 2.: Ansatz zur Phosphorylierung von Oligonukleotiden

\section{6. 5. Ligation}

Die Ligation von DNA-Fragmenten erfolgte mit Hilfe der T4-DNA-Ligase (1 U, Promega oder Roche) in einem Volumen von $10 \mu \mathrm{l}$ im Ligationspuffer ( $30 \mathrm{mM}$ TrisHCl pH 7,8, $10 \mathrm{mM} \mathrm{MgCl}_{2}, 10 \mathrm{mM}$ DTT, 0,5 mM ATP). Dazu wurden $25 \mathrm{ng}$ bis $50 \mathrm{ng}$ des dephosphorylierten Vektors mit einem 3- bis 10-fachen Überschuß an phosphoryliertem DNA-Fragment zugegeben und über Nacht bei $16^{\circ} \mathrm{C}$ inkubiert. Falls synthetische Oligonukleotide in einen Vektor ligiert wurden, wurden diese in einem hundertfachen Überschuß gegenüber dem Vektor eingesetzt.

\section{6. 6. DNA-Konstrukte}

\section{6. 6. 1. Fusionskonstrukt von $c S z$ l mit einem Myc- bzw. His-Epitop}

Der pCMV3-cSzl-Vektor wurde mit einem Myc-, bzw. His-Epitop am 3'-Ende versehen. Hierzu wurden für die Epitope spezifische Oligonukleotide, wie unter 2. 6. 4. beschrieben, in die KpnI/HindIII Schnittstellen des pBsIIKs+ ligiert. Die durch das Oligonukleotid kodierten Aminosäuren sind unter der Nukleotidsequenz angegeben: 


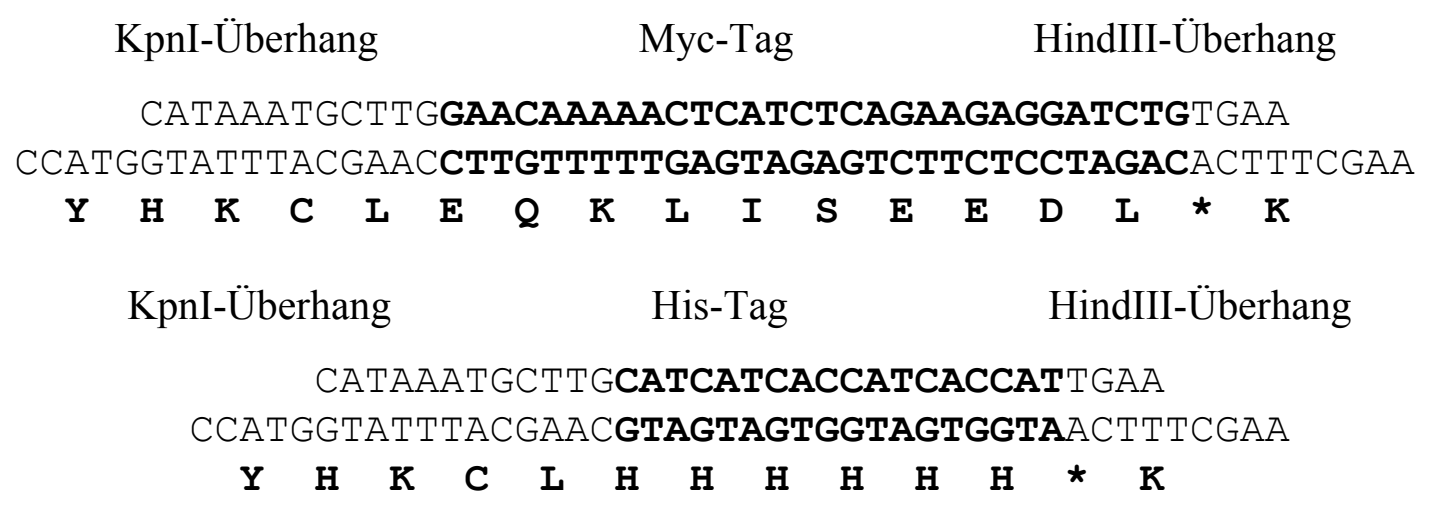

$c S z l$ wurde nun aus dem pCMV mit KpnI herausgeschnitten und in die KpnI Schnittstelle des modifizierten pBsIIKs+::His/Myc kloniert. Mit BamHI wurde das $c$ Szl::His/ Myc-Fusionskonstrukt in den pCMV3 zurückkloniert.

\title{
2. 6. 6. 2. Konstruktion des RCAS::cSzI-Retrovirus
}

Zur Konstruktion eines RCAS::cSzl-Retrovirus, mußte der $c S z l$-Klon zunächst in den Slax12-Shuttlevektor umkloniert werden. Vom pCMV3::cSzl-Vektor wurde mittels PCR die $c S z l$-Sequenz amplifiziert. Dabei wurde als 5'-Primer eine Sequenz gewählt, die eine NcoI-Schnittstelle enthielt, als 3'-Primer wurde der pCDNA-Primer (siehe Abschnitt 2. 4. 1.) benutzt.

RCAS::cSzl-up-Primer:

\author{
NcoI-Erkennungssequenz \\ TTTGGCAAGCTGGGACTCGGTCTCACATGCTGTTGACTGC
}

Um ein möglichst fehlerfreies Amplifikat zu erhalten, wurde anstelle der standardmäBig benutzten Taq-Polymerase die Pwo-Polymerase (aus Pyrococcus woesei) eingesetzt, die über eine $3^{\prime}-5^{\prime}$ Exonukleaseaktivität verfügt und daher die Amplifikation mit höherer Genauigkeit als die Taq-Polymerase durchführt. Die PCR-Reaktion wurde nach folgendem Protokoll durchgeführt: 


\begin{tabular}{|c|c|c|}
\hline Schritt & Temperatur & Dauer \\
\hline 1. Initiale Denaturierung & $94^{\circ} \mathrm{C}$ & $2 \min$ \\
\hline 2. Denaturierung & $94^{\circ} \mathrm{C}$ & $15 \mathrm{sec}$ \\
\hline 3. Annealing & $60^{\circ} \mathrm{C}$ & $30 \mathrm{sec}$ \\
\hline \multirow[t]{2}{*}{ 4. Synthese } & $72^{\circ} \mathrm{C}$ & $1 \mathrm{~min}$ \\
\hline & 10 Zyklen & \\
\hline 1. Denaturierung & $94^{\circ} \mathrm{C}$ & $15 \mathrm{sec}$ \\
\hline 2. Annealing & $60^{\circ} \mathrm{C}$ & $30 \mathrm{sec}$ \\
\hline \multirow[t]{2}{*}{ 3. Synthese } & $72^{\circ} \mathrm{C}$ & $1 \mathrm{~min}+20 \mathrm{sec} / \mathrm{Zyk}$ \\
\hline & 20 Zyklen & \\
\hline Finale Synthese & $72^{\circ} \mathrm{C}$ & $7 \mathrm{~min}$ \\
\hline
\end{tabular}

Tab. 2. 3.: PCR-Reaktionsprogramm für die Pwo-Polymerase

Das PCR-Produkt wurde mit Bsa-1, einem Schizomer von NcoI, und mit HindIII verdaut und in die Nco-1/HindIII Schnittstellen des Slax12-Vektors ligiert. Die MCSdes Slax12-Vektors ist von ClaI-Schnittstellen flankiert, über die das $c S z l$-Konstrukt in den RCAS-Provirus ligiert werden konnte.

\section{6. 7. Konstruktion von cDNA-Banken aus embryonalem Hühnergewebe}

Um bisher unbekannte Gene, die an der Musterbildung des Hühnerembryos beteiligt sind, identifizieren zu können, wurden aus embryonalem Hühnergewebe cDNAExpression-Banken angelegt. Bei der Herstellung dieser Banken mußte berücksichtigt werden, daß das Ausgangsmaterial nur in geringer Menge zur Verfügung stand. Außerdem sollte vor allem cDNA in voller Länge gewonnen und diese gerichtet kloniert werden. Darüber hinaus sollte eine einfache Subtraktion die Isolierung von entwicklungsbiologisch relevanten Genen begünstigen. Um diesen Anforderungen gerecht zu werden, wurde eine durch die Polymerase-Kettenreaktion amplifizierte und gerichtet klonierte cDNA-Bank mit Hilfe eines modifizierten SMART-cDNA LibraryConstruction Kits (Clontech) hergestellt. Dazu wurde $1 \mu \mathrm{g}$ Gesamt-RNA (siehe 2. 5. 3.) verwendet. Zur Erststrangsynthese der cDNA wurde die Reverse Transkriptase 
(MMLV Reverse Transkriptase, Superscript II, Gibco BRL) eingesetzt. Als Primer für diese Reaktion diente ein Oligo-dT-Primer, CDS III (5'-ATTCTAGAGGCCGAGGCGGCCGACATG-(T) ${ }_{30}-\mathrm{N}_{-1} \mathrm{~N}-3^{\prime}$ ), der spezifisch an die Poly-A-Enden der Boten-RNA (mRNA) hybridisiert und so die Kopie der in der Gesamt-RNA unterrepräsentierten mRNA ermöglicht. Die Fähigkeit der Reversen Transkriptase, nach dem vollständigen Kopieren der mRNA in cDNA an das DNA-Molekül im RNADNA-Hybrid Cytodinreste anzuhängen, erlaubte, den SMART III-Primer über dessen Guanidinreste komplementär zu binden. Anschließend kopierte die Reverse Transkriptase den SMART III-Primer an den cDNA-Erststrang (engl. Primer Extension). Die Erststrangsynthese lieferte so DNA-Kopien der mRNA, die am 3'Ende die Sequenz des CDS III-Primers, und sofern sie in ihrer ganzen Länge in cDNA kopiert wurden, am 5'-Ende die Sequenz des SMART III-Primers aufwiesen. Unvollständige Kopien der mRNA besaßen nur die CDS III-Sequenz am 3'-Ende und nicht die SMART III-Sequenz am 5'-Ende und wurden in der nachfolgenden PCR nicht amplifiziert. Da die Sequenz des SMART III-Primers des Herstellers ein ATG enthielt, wurde abweichend von dem kommerziellen Protokoll ein modifizierter SMART IIIPrimer (5'-AAGCAGTGGTATCAACGCAGAGTGGCCATTACGGCCGGG-3') verwendet (Eurogentec). In dessen Sequenz wurde das störende ATG durch ein ACG ausgetauscht, um nach der später erfolgenden Klonierung der cDNAs in einen eukaryontischen Expressionsvektor pCMV3 keine unerwünschte Initiation der Translation innerhalb des 5'-Primers zu ermöglichen. Um ausreichende Mengen an cDNA zu erhalten und komplette cDNA-Kopien anzureichern, wurde die cDNA nun in einer PCR amplifiziert. Als spezifische Primer wurden der 5'-PCR Primer (5'-AAGCAGTGGTATCAACGCAGAGT-3'), der komplementär zur SMART III-Sequenz war, und der CDS III-Primer verwendet. 18 bis 20 Zyklen waren bereits ausreichend, um die cDNA so stark zu amplifizieren, daß sie auf einem Agarosegel mit Ethidiumbromid sichtbar gemacht werden konnte (Abb. 3. 2.). In allen Fällen ergab sich stets das gleiche Bandenmuster und diente als Kontrolle für eine gelungene cDNA-Synthese. Anschließend wurde die cDNA in den eukaryontischen Expressionsvektor, pCMV3, kloniert. Dazu wurden die cDNA-Moleküle in einem Agarosegel elektrophoretisch aufgetrennt und alle mit einer Länge von mehr als 1000 Nukleotiden aus dem Gel ausgeschnitten und eluiert. Dann wurden sie mit dem Restriktionsenzym SfiI in dem 5'- und 3'-Primer, die jedes amplifizierte cDNA-Molekül flankieren, geschnitten. Das 
Restriktionsenzym SfiI hat eine Erkennungssequenz aus zwei Abschnitten, die aus vier Basen bestehen und die um 5 Nukleotide beliebiger Basensequenz von einander getrennt sein müssen (GGCCNNNNNGGCC). Durch einen Verdau mit Sfil konnten daher zwei verschiedene Enden entstehen, die zur gerichteten Klonierung der cDNAMoleküle in den Expressionsvektor geeignet waren. Außerdem verringerte die Verwendung von einem Restriktionsenzym statt zwei verschiedenen die Wahrscheinlichkeit, daß durch interne Schnittstellen in den $\mathrm{zu}$ klonierenden Genen diese ungewollt zerschnitten wurden. Die Ligation der geschnittenen cDNA-Fragmente in den Vektor pCMV3 mußte mit einer besonders hohen Ausbeute geschehen, um bei der späteren Subtraktion die Selektion von Klonen ohne ein Insert (religierte pCMV3Vektoren) nicht zu begünstigen. Um den mit dem Restriktionsenzym SfiI an beiden Schnittstellen geschnittenen pCMV3-Vektor sicher von nur einfach geschnittenem Vektor elektrophoretisch trennen zu können, wurde ein pCMV3-Vektor mit einem Insert von 1500 Nukleotiden mit SfiI geschnitten, dephosphoryliert und dann aus dem Gel aufgereinigt. Für die Ligation wurden anstelle der sonst üblichen 50 ng Vektor 400 bis $500 \mathrm{ng}$ des geschnittenen Vektors eingesetzt. Um eine hohe Transformationseffizienz bei der Elektroporation des Ligationsansatzes in die Bakterien zu erreichen, wurde der Ligationsansatz zuvor entsalzt. Die Transformation erfolgte in den ultrakompetenten E.coli-Stamm X110-blue (Stratagene), der laut Hersteller eine Transformationseffizienz von bis zu $1 * 10^{9}$ Klonen pro $\mu$ g eingesetzter Plasmid-DNA hat. Die transformierten Bakterien wurden zu je 35.000 Kolonien auf 24 mal $24 \mathrm{~cm}$ Agarplatten ausgestrichen (15 g Bacto Agar in 1 L LB-Medium, autoklaviert, nach dem Abkühlen auf $50^{\circ} \mathrm{C}$ mit $2 \mathrm{ml} 50 \mathrm{mg} / \mathrm{ml}$ Ampicillin versetzt).

\section{6. 8. Markieren von RNA-Sonden mit Digoxigenin oder Fluoreszein}

Zur in situ-Hybridisierung wurde mit Digoxigenin bzw. Fluoreszein markierte Gegenstrang-RNA verwendet. Die Gegenstrang-RNA wurde nach dem „Run-off“-Prinzip synthetisiert. Dazu wurde zunächst das die cDNA enthaltende Plasmid am 5'-Ende der cDNA mit einem Restriktionsenzym geschnitten. Dabei wurden nur Restriktionsenzyme verwendet, die ein 5'-überhängendes Ende erzeugten. Es wurden $10 \mu \mathrm{g}$ des Plasmids mit dem entsprechenden Restriktionsenzym (100 U) in einem Ansatz von $100 \mu 1$ linearisiert. Anschließend wurde der Ansatz über das PCR-Purification-Kit 
(Quiagen) aufgereinigt und in $30 \mu$ l eluiert. Vom Eluat wurde $1 \mu 1$ auf einem $1 \%$ igen Agarose/TBE Gel analysiert, bei entsprechender Qualität wurde $1 \mu \mathrm{l}$ des Eluats als Ausgangsmaterial der RNA-Synthesereaktion eingesetzt. Ebenso wie ein linearisiertes Plasmid, konnte auch ein PCR-Amplifikat als Ausgangsmaterial für eine RNASynthesereaktion eingesetzt werden, solange eine RNA-Polymerase-Sequenz auf dem Amplifikat enthalten war. Auch die PCR-Reaktion wurde über den PCR-PurificationKit aufgereinigt und in $30 \mu \mathrm{l} \mathrm{dH}_{2} \mathrm{O}$ eluiert.

Der Ansatz (Tab. 2. 3.) wurde bei $37^{\circ} \mathrm{C}$ für $2 \mathrm{~h}$ inkubiert. Dann wurde er auf $50 \mu 1 \mathrm{mit}$ Wasser (Millipore) aufgefüllt und mit Hilfe von Sephadex-Gelfiltrationssäulen von dem Überschuß an nicht eingebauten Nukleotiden gereinigt (siehe 2. 2.). Ein Zehntel des Ansatzes wurde auf ein Agarosegel aufgetragen, um die Qualität und Quantität der Synthese zu überprüfen. Die RNA-Sonde wurde bei $-20^{\circ} \mathrm{C}$ gelagert.

\begin{tabular}{|l|l|}
\hline linearisiertes Plasmid/PCR-Amplifikat $(1 \mu$ Eluat) & $1 \mu \mathrm{l}$ \\
\hline $\begin{array}{l}\text { 10x Transkriptions-Puffer } \\
\text { (Roche, } 400 \mathrm{mM} \text { TrisHCl pH 8,0, } 60 \mathrm{mM} \mathrm{MgCl}, 100 \mathrm{mM} \text { DTT, 20 mM Spermidin) }\end{array}$ & $2 \mu \mathrm{l}$ \\
\hline $\begin{array}{l}\text { 10x Digoxigenin oder Fluoreszein RNA labelling mix } \\
\text { (Roche, 10 mM ATP, CTP bzw. GTP, 6,5 mM UTP und 3,5 mM Digoxingenin bzw. Fluo- } \\
\text { reszein-12-UTP) }\end{array}$ & $2 \mu 1$ \\
\hline RNasin (100 U/ml; Promega) & $1 \mu 1$ \\
\hline RNA-Polymerase (SP6, T3 oder T7 abhängig vom Promoter des Plasmids) & $1 \mu \mathrm{l}$ \\
\hline Wasser (Millipore) & $13 \mu 1$ \\
\hline
\end{tabular}

Tab. 2. 3.: Ansatz zur Markierung von RNA-Sonden

\section{6. 9. Herstellung von radioaktiv markierten DNA-Molekülen}

Zur Herstellung von radioaktiv markierten DNA-Molekülen wurden zwischen 50 ng und $100 \mathrm{ng}$ der aufgereinigten DNA (siehe 2. 5.) bei $95^{\circ} \mathrm{C}$ für 10 min denaturiert und anschließend sofort auf Eis gekühlt. Hexamernukleotide mit jeder möglichen Sequenz $\left(\mathrm{N}_{6}\right)$ dienten als Primer für das Klenow-Fragment, das diese unter Einbau von radioaktiven dCTP innerhalb von $1 \mathrm{~h}$ bei $37^{\circ} \mathrm{C}$ verlängerte (Tab. 2. 4.; Multiprime DNA labelling System RPN1601, Amersham-Pharmacia). Die markierte DNA-Sonde wurden mit der G50-Säule von dem Überschuß an nicht eingebauten Nukleotiden 
gereinigt (siehe 2. 5. 1.). Der Einbau der radioaktiven Nukleotide wurde in dem L1701 Liquid Scintillation System (Beckman) gemessen. Es wurden spezifische Aktivitäten von $1 * 10^{8}$ bis $3 * 10^{8} \mathrm{cpm} / \mu \mathrm{g}$ DNA erreicht.

\begin{tabular}{|l|l|}
\hline zu markierende DNA & $50 \mathrm{ng}-100 \mathrm{ng}$ in $28 \mu \mathrm{l}$ \\
\hline$(\mathrm{N})_{6}$ Primer/BSA Mix & $5 \mu \mathrm{l}$ \\
\hline $\begin{array}{l}\text { Klenow-Puffer (50 mM TrisHCl, } \\
10 \mathrm{mM} \mathrm{MgCl}\end{array}, 1 \mathrm{mM}$ DTT) & $10 \mu \mathrm{l}$ \\
\hline${ }^{32}$ Phosphor- $\alpha$-dCTP $(50 \mu \mathrm{Ci})$ & $5 \mu \mathrm{l}$ \\
\hline Klenow-Enzym & $1 \mu \mathrm{l}$ \\
\hline Wasser (Millipore) & auf $100 \mu \mathrm{l}$ \\
\hline
\end{tabular}

Tab. 2. 4.: Ansatz zur radioaktiven Markierung von DNA-Fragmenten

\section{6. 10. Sequenzierungen}

Sequenzierungen erfolgten mittels des Taq Dye Deoxy Terminator Kits (Perkin Elmer-ABI) auf ABI 377 Sequenziergeräten. Sie wurden als Service von Angestellten der Abteilung Molekulare Zellbiologie durchgeführt. Die Sequenzanalyse wurde mit der Sequencer-Software (Gene Codes Corporation; Version 3.1.1.), Datenbankanalysen wurden mit den verschiedenen Datenbanken des "National Center for Biotechnology Information" (NCBI, www.ncbi.nih.org) und mit Celera durchgeführt.

\section{7. Transformation von Bakterien}

Transfomationen wurden in selbst hergestellten elektrokompetenten Bakterien (Stamm DH5 $\alpha$ ), in X110-blue (Stratagene) oder in chemokompetenten DH5 $\alpha$ (Gibco BRL) durchgeführt. 


\section{7. 1. Herstellung von kompetenten Bakterien}

Zellen des E. coli Stammes DH5 $\alpha$ wurden auf einer LB-Platte ausgestrichen und über Nacht inkubiert. Von dieser Platte wurden frische Einzelkolonien gepickt und in je 50 ml LB-Medium in einem $500 \mathrm{ml}$ Glaskolben überführt. Diese Vorkultur wurde bei mäßigem Schütteln (ca. $200 \mathrm{rpm}$ ) über Nacht inkubiert. Von der Vorkultur wurden zwei $500 \mathrm{ml}$ LB-Kulturen in 21 Glaskolben mit je $3 \mathrm{ml}$ angeimpft. Das Wachstum der Kulturen wurde mit Hilfe der optischen Dichte bei einer Wellenlänge von $600 \mathrm{~nm}$ gegen bakterienfreies Medium kontrolliert. Die Zellen benötigten zum Erreichen einer Dichte von 0,5 OD etwa $4 \mathrm{~h}$. Dann wurden die Kulturen für 10 bis 15 min auf Eis gekühlt. Die Zellsuspension wurde anschließend zu je $250 \mathrm{ml}$ in auf Eis vorgekühlte Zentrifugenbecher für den GS3-Rotor gegeben. Die Zentrifugenbecher wurden vorher gespült und dann unter UV sterilisiert (2 mal $90 \mathrm{sec}$, Biorad GS Gene Linker UV Chamber). Nach einer Zentrifugation von $5000 \mathrm{~g}$ für $20 \mathrm{~min}$ (5500 rpm für den GS3-Rotor) wurde der Überstand abgenommen und das Bakterienpellet in $5 \mathrm{ml}$ Eiswasser resuspendiert und je zwei Ansätze zusammengegeben. Nach Zugabe von je $250 \mathrm{ml}$ Eiswasser wurde erneut, wie oben, zentrifugiert und das Pellet in $250 \mathrm{ml}$ Eiswasser resuspendiert und wieder, wie oben, zentrifugiert. Das Pellet wurde nach der Entfernung des Überstandes in der zurückbleibenden Lösung resuspendiert. Dann wurden $40 \mathrm{ml}$ eiskaltes $10 \%$ Glycerin zugegeben und die Bakteriensuspension in zwei $50 \mathrm{ml}$ Falcon Röhrchen überführt und für $15 \mathrm{~min}$ bei $3500 \mathrm{rpm}$ und $4{ }^{\circ} \mathrm{C}$ in einer Heraeus Zentrifuge sedimentiert. Das Bakterienpellet wurde dann in einer seinem Pelletvolumen vergleichbaren Menge an eiskaltem $10 \%$ Glycerin resuspendiert und in vorgekühlte Eppendorfgefäße zu $50 \mu \mathrm{l}$ aliquotiert, in flüssigem Stickstoff eingefroren und bei $-80{ }^{\circ} \mathrm{C}$ gelagert.

\section{7. 2. Transformation von elektrokompetenten Bakterien}

Zur Transformation wurde ein BioRad-Gene-Pulser mit Pulse-Controller verwendet. $\mathrm{Zu} 50 \mu \mathrm{l}$ kompetenten Bakterien wurde $1 \mu \mathrm{l}$ Plasmidansatz gegeben. Anschließend wurden die Bakterien in eine Elektroporationsküvette (1 $\mathrm{mm}$ Elektrodenabstand) überführt. Die elektrokompetenten DH5 $\alpha$ wurden mit einer Spannung von 1,7 KV, einer Kapazität von $25 \mu \mathrm{F}$ und einem Widerstand von 200 Ohm elektroporiert, der 
Stamm X110-blue benötigte einen Widerstand von 600 Ohm. Sofort nach dem Spannungspuls wurden $950 \mu \mathrm{l}$ vorgewärmtes LB zu den Bakterien gegeben, die Bakteriensupension wurde in ein $15 \mathrm{ml}$ Falcon-Röhrchen überführt und für $60-90 \mathrm{~min}$ bei $37^{\circ} \mathrm{C}$ unter Schütteln inkubiert. Verschiedene Volumina des Transformationsansatzes wurden anschließend auf LB-Ampicillin-Agar-Platten (50 $\mu \mathrm{g} / \mathrm{ml}$ Ampicillin) ausplattiert.

\section{7. 3. Transformation von chemokompetenten Bakterien}

Die Bakterien wurden auf Eis aufgetaut. Die kompetenten Zellen wurden in vorgekühlte 15 ml Falcon-Polypropylen-Röhrchen (Nr. 2059) pipettiert. Nach Zugabe des Transformationssansatzes $(10 \mu \mathrm{l})$ und vorsichtigem Mischen wurden die Zellen für 30 min auf Eis inkubiert. Nach einem Hitzeschock $\left(42^{\circ} \mathrm{C}\right.$, für exakt $\left.45 \mathrm{sec}\right)$ wurden die Bakterien sofort für 2 min auf Eis gestellt. Dann wurden $900 \mu 1$ auf $42^{\circ} \mathrm{C}$ vorgewärmtes LB-Medium zupipettiert und die Bakterien 60 min bei einer Drehzahl von 225 bis $250 \mathrm{rpm}$ bei $37^{\circ} \mathrm{C}$ auf einem Schüttler inkubiert. Die Bakterien wurden auf Ampicillinhaltigen LB-Agaroseplatten (50 $\mu \mathrm{g} / \mathrm{ml}$ Ampicillin) ausplattiert. Die Platten wurden über Nacht bei $37^{\circ} \mathrm{C}$ inkubiert, bis die Kolonien einen Durchmesser von 0,1-1 mm erreicht hatten.

\section{8. Subtraktion von Klonen durch Kolonie-Hybridisierung}

Um Gene, die sowohl in der cDNA-Probe aus der prächordalen Platte, als auch in der cDNA aus dem Hensenschen Knoten in hohem Ausmaß vorkamen, zu unterdrücken, wurden von der ausplattierten Plasmid-Bank der prächordalen Platte Filter gezogen und diese mit der radioaktiv markierten cDNA aus dem Hensenschen Knotens hybridisiert. Von den Filtern wurde eine Autoradiographie erstellt. Anschließend wurden nur die Klone analysiert, die nach einer Autoradiographie negativ waren. Diese Klone enthielten Gene, die entweder in beiden cDNA-Proben in nur geringer Menge oder aber nur in der cDNA-Probe aus der prächordalen Platte vorhanden waren. Die Kolonien wurden in einer Dichte von etwa 35.000 Kolonien pro $24 \mathrm{~cm}$ mal $24 \mathrm{~cm}$ Bakterienplatte ausplattiert. Die Klone wurden bis zu einem Koloniedurchmesser von etwa $0,5 \mathrm{~mm}$ bei $37^{\circ} \mathrm{C}$ inkubiert und anschließend für mindestens $1 \mathrm{~h}$ bei $4^{\circ} \mathrm{C}$ gelagert. Es wurden Qiabrane Membranen (Qiagen) auf die Platten aufgelegt und die Position 
der Membran auf der Platte wurde durch Durchstechen von Membran und Agarplatte mit einer in Tusche geschwärzten Kanüle markiert. Die Membranen wurden nach etwa einer Minute von der Bakterienplatte abgezogen und mit der Bakterienseite nach oben für 4 min auf Filterpapier inkubiert, das mit Denaturierungslösung $(0,5 \mathrm{M} \mathrm{NaOH}, 1,5$ $\mathrm{M} \mathrm{NaCl}$ ) getränkt war. Anschließend erfolgte je eine vierminütige Inkubation auf in Neutralisierungslöung getränktem Filterpapier (0,5 M TrisHCl pH 7,4, 1,5 M NaCl) und auf in $2 \mathrm{x}$ SSC (0,3 M NaCl, $30 \mathrm{mM}$ Natriumzitrat, $\mathrm{pH}$ 7,0 mit Zitronensäure eingestellt) getränktem Filterpapier. Dann wurden die Membranen getrocknet und für 1,5 h bei $80^{\circ} \mathrm{C}$ gebacken.

Zur Hybridisierung von radioaktiv markierten DNA-Sonden auf die an die Membranen gebundene DNA wurden die Membranen zunächst für $1 \mathrm{~h}$ mit der Prähybridisierungslösung $\left(0,5 \mathrm{M} \mathrm{Na}_{2} \mathrm{HPO}_{4}\right.$ mit $\mathrm{H}_{3} \mathrm{PO}_{4}$ auf $\mathrm{pH} 7$ eingestellt, $7 \%$ SDS $)$ bei $65^{\circ} \mathrm{C}$ im Hybridisierungsofen inkubiert. Anschließend wurde die für 5 min bei $95^{\circ} \mathrm{C}$ denaturierte, radioaktiv markierte DNA Sonde in Prähybridisierungslösung zugegeben und über Nacht bei $65^{\circ} \mathrm{C}$ inkubiert. Nach der Hybridisierung wurden die Membranen bei $65^{\circ} \mathrm{C}$ für je 20 min zweimal mit 2x SSC/0,1 \% SDS, einmal mit 1x SSC/0,1\% SDS bei $65^{\circ} \mathrm{C}$ für $20 \mathrm{~min}$ und einmal mit $0,1 \times \mathrm{SSC} / 0,1 \% \mathrm{SDS}$ gewaschen, um überschüssige und unspezifisch bindende Sonden zu entfernen. Die Membranen wurden in Folie eingeschlagen und in einer Röntgenkassette auf einem XOMAT-Film (Kodak) gelegt. Der Film wurde je nach Stärke des Signals über Nacht bzw. bis zu drei Tagen exponiert.

\section{9. cDNA-Erststrang-Synthese für die Reverse-Transkriptase-Poly- merase-Kettenreaktion}

Die reverse Transkription wurde mit dem „First-Strand cDNA Sythesis Kit“ (Pharmacia) durchgeführt. Dazu wurden 3 bis $5 \mu$ g Gesamt-RNA in $20 \mu$ l Wasser (Millipore) aufgenommen und anschließend bei $65^{\circ} \mathrm{C}$ für 10 min denaturiert. $\mathrm{Zu} \mathrm{dem}$ Reaktionsansatz wurde weiterhin folgendes hinzupipettiert (Tab. 2. 5.): 


\begin{tabular}{|l|l|}
\hline Gesamt-RNA $(3$ bis $5 \mu \mathrm{g})$ & $20 \mu \mathrm{l}$ \\
\hline $\begin{array}{l}\text { Random Hexanukleotid Primer } \\
(\mathrm{pd}(\mathrm{N}) 6 \text { Primer } 0,2 \mu \mathrm{g} / \mathrm{ml})\end{array}$ & $1 \mu \mathrm{l}$ \\
\hline DTT $(100 \mathrm{mM})$ & $1 \mu \mathrm{l}$ \\
\hline Bulk first-strand cDNA Reaction Mix & $11 \mu \mathrm{l}$ \\
\hline
\end{tabular}

Tab. 2. 5.: Ansatz zur cDNA-Synthese

Der Reaktionsansatz wurde für $1 \mathrm{~h}$ bei $37^{\circ} \mathrm{C}$ inkubiert. Teile des Reaktionsansatzes wurden direkt in der Polymerase-Kettenreaktion eingesetzt oder bei $-20^{\circ} \mathrm{C}$ gelagert.

\section{10. Polymerase-Kettenreaktion (PCR)}

Die Polymerase-Kettenreaktion (Saiki et al., 1988) wurde sowohl analytisch zur Orientierungsüberprüfung von DNA-Fragmenten in Vektoren und zur Expressionsanalyse in Form der Reversen-Transkriptase-Polymerase-Kettenreaktion (RT-PCR) als auch präparativ zur Herstellung von DNA-Konstrukten und zur Amplifikation der cDNA für die Plasmid-cDNA-Banken verwendet.

Die PCR zum Nachweis eines DNA-Fragments in einem Vektor bzw. die Überprüfung der Orientierung von klonierten DNA-Fragmenten in Vektoren wurde mit der TaqPolymerase (Thermus aquaticus) durchgeführt. Dazu wurden 1 bis 10 pg der Plasmid DNA, 0,5 $\mu \mathrm{M}$ je Primer, $200 \mu \mathrm{M}$ je Desoxynukleotid, $1 \mathrm{U}$ Taq-Polymerase und entsprechender Puffer (10 mM TrisHCl pH8,8, $50 \mathrm{mM} \mathrm{KCl,} \mathrm{1,5} \mathrm{mM} \mathrm{MgCl}_{2}$ ) verwendet. Es wurde das folgende Temperaturprofil entweder in einem Mastercycler (Eppendorf) oder in einem Trio-Thermoblock (Biometra) durchfahren (Tab. 2. 6.). 


\begin{tabular}{|l|l|l|}
\hline Schritt & Temperatur & Dauer \\
\hline 1. Initiale Denaturierung & $94^{\circ} \mathrm{C}$ & $3 \mathrm{~min}$ \\
\hline 2. Denaturierung & $94^{\circ} \mathrm{C}$ & $30 \mathrm{sec}$ \\
\hline 3. Annealing & $45^{\circ} \mathrm{C}$ bis $65^{\circ} \mathrm{C}$ & $30 \mathrm{sec}$ \\
\hline 4. Synthese & $72^{\circ} \mathrm{C}$ & $1 \mathrm{~min}$ pro kb \\
\hline 5. Endsynthese & $72^{\circ} \mathrm{C}$ & $5 \mathrm{~min}$ \\
\hline
\end{tabular}

Tab. 2. 6.: Protokoll einer Standard-PCR. Die Schritte 2. bis 4. wurden in der Regel 30 mal wiederholt.

Die PCR-Amplifikate wurden für die weitere Bearbeitung (Sequenzierungen, Restriktionsverdaue oder Ligationsreaktionen) über das PCR-Purification-Kit (Quiagen) aufgereinigt. Hierbei wird das Amplifikat über eine Anionenaustauschersäule entsalzen und von den Primern getrennt.

\section{11. Analyse der Klone aus den cDNA-Banken}

Die Klone der cDNA aus der prächordalen Platte sollten möglichst schnell, effektiv und in großer Anzahl analysiert werden. Eine erste Eingrenzung der zu analysierenden Klone wurde durch die Koloniehybridisierung (siehe Abschnitt 2. 5.) erreicht. Hierdurch wurden präferenziell Klone gewählt, die nicht zu den ubiquitär exprimierten, sogenannten "Housekeeping”-Genen zählten. Mit den ausgewählten Klonen wurden 96-Mikroreaktionsgefäßplatten, die in einen PCR-Thermoblock paßten und in deren Reaktionsgefäße jeweils 0,5 ml LB-Medium vorgelegt waren, beimpft. Die Platten wurden für 6 Stunden bei $37^{\circ} \mathrm{C}$ inkubiert. Je $1 \mu 1$ aus den Reaktionsgefäßen wurden daraufhin als Ausgangsmaterial für eine PCR-Reaktion eingesetzt. Der Rest wurde mit $1 / 2$ Volumen $65 \%$ Glycerol versetzt und bei $-80^{\circ} \mathrm{C}$ gelagert. Die PCR wurde unter Standardbedingungen in der 96-Reaktionsgefäßplatte in einem $50 \mu 1$ Ansatz durchgeführt. Als Primer wurden der pCMV3-Vorwärts-Primer und der pCDNA-Primer verwendet (siehe Abschnitt 2. 4. 1.), so daß jedes Amplifikat über einen Promotor der T7-RNA-Polymerase enthielt. Je $5 \mu 1$ der PCR wurden auf einem $1 \%$ igen Agarosegel in 0,5x TBE aufgetragen und unter UV-Licht analysiert. Dadurch 
wurde erkennbar, ob die ausgewählten Klone eine cDNA-Sequenz enthielten, und welche Größe die Insertionssequenz hatte. Anhand dieser Qualitätsüberprüfung wurden die Klone für den nächsten Analyseschritt ausgewählt. Klone, die keine Insertion enthielten, und Klone, deren inserierte cDNA kleiner als $1 \mathrm{~kb}$ war, wurden von der weiteren Analyse ausgeschlossen. Die übrigen Amplifikationsreaktionen wurden über den "High-Throughput-PCR-Purification-Kit" (Quiagen; siehe Abschnitt 2. 10. 1.), eine, auf die gleichzeitige Aufreinigung von bis zu 96-PCR-Reaktion optimierte, modifizierte Version des "PCR-Purification-Kits", aufgereinigt. Von dem $30 \mu 1$ Eluat wurden $10 \mu 1$ für eine Sequenzierreaktion (siehe Abschnitt 2. 6. 10.) benutzt. Der Rest wurde bei $-20^{\circ} \mathrm{C}$ gelagert. Abhängig von den Sequenzinformationen konnten die Amplifakate im folgenden als Ausgangsmaterial für die Synthese einer DIG-markierten RNA-Sonde benutzt werden (siehe Abschnitt 2. 6. 8.) und die Expression des Klons durch in situ-Hybridisierung analysiert werden (siehe Abschnitt 2. 14.)

\section{12. Zellkultur}

Alle Zellkulturarbeiten wurden in einer Sterilwerkbank durchgeführt. PBS und $\mathrm{dH}_{2} \mathrm{O}$ wurden vor Gebrauch autoklaviert, Medien wurden gegebenenfalls sterilfiltriert (Falcon 7105 Bottle Top Filter, 0,22 $\mu \mathrm{m}$ Porengröße). Alle Gegenstände, die in der Sterilwerkbank benutzt wurden, wurden vor Gebrauch mit $70 \%$ Ethanol abgesprüht bzw. autoklaviert. Für Pipettierarbeiten wurden gestopfte Einmalpipetten und gestopfte Pipettenspitzen verwendet. Alle Flaschen wurden vor dem Öffnen und vor dem Wiederverschließen abgeflammt, genauso wie Glaspasteurpipetten, die zum Absaugen der Medien benutzt wurden.

\section{12. 1. Präparation primärer Huhnembryofibroblasten (CEFs)}

Hühnerembryonen wurden nach 11,5 Tagen Bebrütung unter sterilen Bedingungen präpariert. Das Ei wurde vor dem Öffnen mit 70 \% Ethanol gereinigt. Der Embryo wurde mit einer groben Pinzette in eine Petrischale überführt. Dort wurden Kopf und Extremitäten abgeschnitten, der Körper gründlich mit PBS abgespült und in eine neue Petrischale transferiert. Das Gewebe wurde nun in kleine Sücke zerteilt und in einen 
$50 \mathrm{ml}$ Erlenmeyerkolben mit Glaskugeln und Magnetrührer pipettiert. Nach Zugabe von 5ml vorgewärmten Trypsin-EDTA (Gibco BRL, 0,5 g/1 Trypsin, 0,2 g/l EDTA) wurden die Gewebestücke 10 min bei $37^{\circ} \mathrm{C}$ und niedriger Geschwindigkeit homogenisiert. Das Trypsinat wurde in ein $50 \mathrm{ml}$ Zellkultur-Röhrchen gegeben und so lange stehen gelassen, bis größere Bestandteile sedimentiert waren. Der Überstand wurde über ein $100 \mu \mathrm{m}$ Nylonsieb (Cell Strainer, Falcon) zusammen mit $10 \mathrm{ml}$ Medium einschließlich 10 \% FCS in ein neues Zellkulturröhrchen geschüttet. Der Rest des Gewebeextraktes wurde mit weiteren 2,5 ml der Trypsinlösung versetzt und für weitere $5 \mathrm{~min}$ bei $37^{\circ} \mathrm{C}$ im Erlenmeyerkolben gerührt. Die Trypsinate wurden zusammengegeben und bei $1000 \mathrm{Upm} 5$ min lang zentrifugiert. In der Zwischenzeit wurden vier Zellkulturpetrischalen (Durchmesser 14,5 cm) mit jeweils $20 \mathrm{ml}$ Zellkulturmedium vorbereitet. Das Zellpellet wurde in $8 \mathrm{ml}$ Medium resuspendiert und gleichmäßig auf die Platten verteilt. Durch Schwenken der Platten breiteten sich die Zellen gleichmäBig aus. Die Platten wurden bei $37^{\circ} \mathrm{C}$ und $5 \% \mathrm{CO}_{2}$ im Zellkulturschrank (Heraeus BBD 6220) inkubiert. Am nächsten Tag, und danach jeden zweiten Tag, wurde das Medium ausgetauscht.

\section{CEF-Medium:}

DMEM (Dulbeccos Modified Eagle Medium mit 4500 mg/l Glucose, Gibco BRL)

$10 \%$ inaktiviertes fetales Kälberserum (Gibco BRL)

$2 \%$ Hühnerserum (Sigma)

2 mM L-Glutamin (Gibco BRL)

$100 \mathrm{U} / \mathrm{ml}$ Penicillin (Gibco BRL)

$100 \mu \mathrm{g} / \mathrm{ml}$ Streptomycin (Gibco BRL)

\section{12. 2. Passagieren}

Sobald die Zellkulturschalen konfluent mit Hühnerfibroblasten bewachsen waren, wurde das Medium abgesaugt und zweimal durch je $4 \mathrm{ml}$ PBS ersetzt. Anschließend wurde das PBS durch $1 \mathrm{ml}$ Trypsin-EDTA-Lösung ausgetauscht und für etwa $3 \mathrm{~min}$ bei $37^{\circ} \mathrm{C}$ bis zum vollständigen Ablösen der Zellen von der Kulturschale inkubiert. Die Proteolyse der Zellen wurde durch Zugabe von $4 \mathrm{ml}$ Medium abgestoppt und die 
abgelösten Zellen pelletiert (5 min, bei 1000 Upm). Das Zellpellet wurde in Medium resuspendiert und die Suspension so aufgeteilt, daß die Zellen im Vergleich zur Ausgangskultur drei- bis zehnfach verdünnt wurden.

\section{12. 3. Einfrieren und Auftauen der Zellen}

Zum Einfrieren von Zellen wurde eine konfluent bewachsene Zellkulturschale, wie für das Passagieren beschrieben, trypsinisiert und sedimentiert. Nach der Zentrifugation wurde das Zellpellet in 1,8 ml Zellkulturmedium resuspendiert. Die Zellsuspension wurde mit 0,2 ml Dimethylsulfoxid (DMSO, Sigma) versetzt und auf Kryoröhrchen (NUNC) verteilt. Die Röhrchen wurden zunächst $1 \mathrm{~h}$ bei $-20^{\circ} \mathrm{C}$ eingefroren, dann über Nacht auf $-80^{\circ} \mathrm{C}$ gelassen und schließlich in flüssigem Stickstoff gelagert. Zum Auftauen wurden die Zellen für höchstens 5 min ins $37^{\circ} \mathrm{C}$-Wasserbad gestellt und danach in Zellkulturmedium aufgenommen. Die Zellsuspension wurde, wie oben beschrieben, zentrifugiert und das Zellpellet in $10 \mathrm{ml}$ Medium resuspendiert. Der gesamte Ansatz wurde auf eine Zellkulturpetrischale gegeben und bei $37^{\circ} \mathrm{C}$, $5 \% \mathrm{CO}_{2}$ im Zellkulturschrank inkubiert. Sobald die Zellen Konfluenz erreicht hatten, wurden sie passagiert.

\section{12. 4. Transfektion von Zellen mit FuGene}

Die Zellen (embryonale Hühnerfibroblasten, HEK 293-Zellen oder COS 7-Zellen) wurden auf $3 \mathrm{~cm}$ Platten bis zu einer Dichte von etwa 50-80\% Konfluenz kultiviert. In ein Eppendorfgefäß wurden $88 \mu 1$ serumfreies DMEM-Medium (Gibco BRL) mit 12 $\mu 1$ des FuGene Reagenzes (Roche) versetzt. Nach 5 min wurde diese Mischung tropfenweise zu $4 \mu \mathrm{l}$ der zu transfizierenden DNA-Lösung (Konzentration $1 \mu \mathrm{g} / \mu \mathrm{l}$ ) hinzugegeben und durch vorsichtiges Schwenken gemischt. Nach weiteren 15 min wurde der Ansatz tropfenweise in das Medium der Zellkulturschale gegeben und diese weiter inkubiert. Mit dieser Methode wurden bis zu $20 \%$ der Zellen einer Zellkulturschale transfiziert. 
2. 12. 5. Transfektion der embryonalen Hühnerfibroblasten mit retroviraler DNA

Die Transfektion der Huhnembryofibroblasten mit den Proviren erfolgte mit Hilfe des „Calcium Phosphate Transfection Kits” von Invitrogen. Die Fibroblasten wurden so lange kultiviert, bis sie sich in einer schnellen Proliferationsphase befanden. Zur Transfektion sollten die Zellen ungefähr 50 \% Konfluenz erreicht haben. Die Transfektionen wurden auf einer $10 \mathrm{~cm}$ Zellkulturschale, die $10 \mathrm{ml}$ Medium enthielt, durchgeführt. 3-4 Stunden vor der Transfektion wurde das Medium auf der Schale gewechselt. Es wurden zwei Ansätze vorbereitet: Ansatz 1 enthielt $36 \mu$ einer $2 \mathrm{M}$ Kalziumchloridlösung und $20 \mu \mathrm{g}$ der zu transfizierenden DNA, mit sterilem Wasser auf $300 \mu$ l aufgefüllt. Der zweite Ansatz enthielt $300 \mu 1$ 2xHEPES gepufferte Salzlösung. Ansatz 1 wurde mit Hilfe einer Pipette tropfenweise zu Ansatz 2 hinzugegeben, während parallel mit einer $2 \mathrm{ml}$ Pipette und Pipettierhilfe konstant Luft durch die zweite Lösung geblasen wurde. Der gesamte Mischungsprozeß sollte ungefähr über 2 min durchgeführt werden. Während der Mischung bildete sich ein feines Präzipitat. Die Lösung wurde für 30 min bei Raumtemperatur stehengelassen, dann wurde die leicht trübe Lösung tropfenweise auf die Zellkulturschale mit den zu transfizierenden verteilt und die Zellen über Nacht bei $37^{\circ} \mathrm{C}$ und $5 \%$ Kohlendioxid inkubiert. Am nächsten Tag wurde das Medium gewechselt, wobei die Zellen zweimal mit PBS gewaschen wurden, um das Präzipitat, das sich an die Zellen angelagert hatte, wegzuspülen. Nach der Transfektion wurden die Zellen mindestens eine weitere Woche kultiviert. In den sich teilenden Zellen konnten sich die replikationskompetenten Retroviren verteilen und selbst bei einer geringen ersten Transfektionsrate alle Zellen infizieren.

\section{12. 6. Immunhistologischer Nachweis der retroviralen Transfektion}

Durch die Detektion des Retroviralen gag Proteins p19 durch den primären Antikörper AMV-3C2 aus der Maus (Potts et al., 1987; bezogen von der Developmental Studies Hybridoma Bank) konnte die Qualität der retroviralen Transfektion getestet werden. Die mit Retroviren transfizierten CEFs und als Kontrolle nichttransfizierte Zellen wurden auf 4-Kammer Objektträgern („chamber-slides”, 
NUNC), die zuvor für $1 \mathrm{~h}$ mit $0,1 \%$ iger Gelatinelösung inkubiert wurden, bei $37^{\circ} \mathrm{C}$ und $5 \% \mathrm{CO}_{2}$ kultiviert. Wenn die Zellen die gewünschte Dichte erreicht hatten, wurde das Medium durch 4 \% Paraformaldehyd in PBS ausgetauscht. Diese Fixierung wurde für 10 min bei Raumtemperatur durchgeführt. Hiernach wurden die Zellen drei mal für fünf Minuten mit PBS/0,05 \% Tween 20 gewaschen. In einem nächsten Schritt wurden die Zellen in 0,1\% Triton X-100 in PBS für 10 min bei Raumtemperatur permeabilisiert und darauf erneut drei mal für 5 min in PBS/0,05\% Tween 20 gewaschen. Vor der Inkubation mit dem ersten Antikörper wurden die Zellen in $5 \%$ NGS/0,05 \% Tween 1 h bei RT präinkubiert. Die Antikörperinkubation mit dem ersten Antikörper (AMV-3C2; Verdünnung 1/500 in PBS mit $5 \%$ NGS und 0,05 $\%$ Tween) wurde für $2 \mathrm{~h}$ bei RT oder bei $4^{\circ} \mathrm{C}$ über Nacht durchgeführt. Nach dreimaligem Waschen mit PBS/0,05 \% Tween wurde mit dem zweiten Antikörper (Ziege anti-Maus Alexa488 in $5 \%$ NGS/PBS/0,05 \% Tween 20) 30 min unter Lichtausschluß bei RT inkubiert. Nach erneutem dreimaligen Waschen in PBS/0,05 \% Tween, wurde optional eine Kernfärbung mit DAPI ( $1 \mu \mathrm{g} / \mathrm{ml}$ in PBS/0,05 \% Tween; Inkubation 1-2 min RT) durchgeführt. Nach weiterem Waschen wurden die Zellen entweder in Mowiol oder in "Anti-Fading Kit" (Molecular Probes) eingebettet und konnten im Fluoreszenzmikroskop kontrolliert werden. Infizierte Zellen leuchteten im Fluoreszenzlicht der Wellenlänge $488 \mathrm{~nm}$ rot auf.

\section{12. 7. Anreicherung der sekretierten rekombinanten Proteine und Retro- viren im Zellkulturüberstand (Konditioniertes Medium)}

Zellen nach der Transfektion bzw. retroviral infizierte Zellinien wurden zunächst bis zur Konfluenz mit dem beschriebenen Zellkulturmedium inkubiert. Mit Erreichen der Konfluenz wurde das Medium gegen ein Medium mit einer niedrigeren Serumkonzentration ausgetauscht (low-Serum Medium). Dieses Mediumkonnte bis zu drei Tagen auf den Zellen bleiben. Bevor es für ein Experiment eingesetzt wurde, wurde es durch einen 0,45 $\mu \mathrm{m}$ Cellulose-Acetat Spritzenfilter (Schleicher und Schuell) filtriert und bis zur Anwendung auf Eis gelassen. 
Low Serum Medium:

DMEM (Dulbeccos Modified Eagle Medium mit 4500 mg/l Glucose, Gibco BRL)

$2 \%$ inaktiviertes fetales Kälberserum (Gibco BRL)

0,2 \% Hühnerserum (Sigma)

2 mM L-Glutamin (Gibco BRL)

$100 \mathrm{U} / \mathrm{ml}$ Penicillin (Gibco BRL)

$100 \mu \mathrm{g} / \mathrm{ml}$ Streptomycin (Gibco BRL)

\section{13. Manipulationen am Hühnerembryo}

Befruchtete Hühnereier wurden bis zur Inkubation bei $15^{\circ} \mathrm{C}$ in einem Kühlschrank bis zu einer Woche aufbewahrt. Einen halben Tag vor Inkubation wurden sie auf Raumtemperatur aufgewärmt. Die Inkubation der Eier erfolgte bei $38^{\circ} \mathrm{C}$ unter Luftumwälzung und bei einer Luftfeuchtigkeit von etwa $60 \%$ in einem Kleinmotorbrüter bis zum Erreichen des gewünschten Entwicklungsstadiums. Die Eier lagen hierbei auf Rollen und konnten mit Hilfe einer automatischen Wendeeinrichtung mehrmals pro Tag gedreht werden, was vor allem für spätere Entwicklungsstadien notwendig war. Die Embryonen wurden ihren Entwicklungsstadien entsprechend nach Hamburger und Hamilton (Stadium HH; Hamburger und Hamilton, 1951) unterteilt. Für mikrochirurgische Manipulationen wurden verschiedene Instrumente hergestellt: Ein sehr feines Schneidewerkzeug wurde hergestellt, indem ein Stück feiner Wolframdraht an eine Pasteurpipette geschmolzen und in der Bunsenbrennerflamme geschärft wurde. Ebenfalls an Pasteurpipetten angeschmolzene Insektennadeln konnten durch Abknikken mit einer feinen Pinzette zu verschiedenen Werkzeugen funktioniert werden, mit denen sich beispielsweise Transplantate in den Embryo manipulieren ließen.

\section{13. 1. Präparieren des Embryos aus dem Ei}

Die Eier wurden nach der Inkubation mit einer kleinen Eierschalenschere am stumpfen Ende kreisrund aufgeschnitten. Die Vitellinmembran wurde mit einer feinen Präparationspinzette (Uhrmacherpinzette, Dumont No. 5) gefaßt und mit einer feinen, gebogenen Schere um die oben aufliegende Keimscheibe herumgeschnitten. Die Ausgeschnittene Vitellinmembran mitsamt dem anhaftenden Embryo wurde darauf mit 
einem Mikrolöffel in eine mit PBS, Tyrodes oder PC-Lösung gefüllte Petrischale überführt. Unter dem Stereomikroskop wurde der Embryo bei kleiner Vergrößerung mit zwei Uhrmacherpinzetten von der Vitellinmembran und dem anhaftenden Dotter befreit. Die Embryonen wurden daraufhin mit Wolframdrahtnadeln von dem größten Teil der area opaca befreit.

\section{13. 2. Entnahme von Gewebe}

Aus den präparierten Embryonen wurden Gewebestücke für die Isolation von RNA oder die Kultivierung in Kollagenkultur isoliert. Das Gewebe für die prächordale Platten cDNA-Bank stammte aus HH5 Embryonen, während für Mesodermexplantate HH4 Embryonen verwendet wurden. Die Embryonen wurden in Silikonschälchen mit Insektennadeln aufgespannt, wobei die Ventralseite nach oben wies. Präpariert wurden die Embryonen in Tyrodes. Die prächordalen Platten-Explantate wurden zur besseren Trennung der Gewebe in Tyrodes mit 0,2 \% (w/v) Dispase (Roche) präpariert. Für Explantate des Mesoderms der lateralen Platte wurde das Endoderm entfernt und das Mesoderm mit einer auf eine Pasteurpipette montierten Insektennadel, die leicht abgeknickt wurde, abgeschabt. Die explantierten Gewebe wurden mit einer Mikropipette aufgenommen und für Kollagenkulturen in DMEM überführt. Sollte RNA aus den Explantaten gewonnen werden, wurden die Explantate direkt in einem in flüssigem Stickstoff gekühlten Eppendorfgefäß tiefgefroren.

\section{13. 3. in vitro-Kultivierung von Hühnerembryonen (New-Kultur/EC-Kultur)}

Junge Hühnerembryonen können dotterfrei auf ihrer Vitellinmembran kultiviert werden. Diese Kulturtechnik wurde von New entwickelt (New, 1955) und von Stern leicht modifiziert (Stern, 1993) . Eine weitere Modifizierung stellte die von Chapman 2001 (Chapman et al., 2001) beschriebene EC-Kultur dar (EC-Culture = "early chick culture").

Bei der klassischen New-Kultur wurden die Embryonen, von einem Glasring unterstützt, über dünnflüssigem Albumin aufgespannt und mit ihrer Ventralseite nach oben orientiert. So konnten sie sich etwa bis zum 19-Somitenstadium entwickeln. Bei der 
EC-Kultur wurde die Vitellinmembran durch einen Filterring in Spannung gehalten, und der Embryo wurde auf ein Agarose-Albumin-Bett plaziert.

Wurden die Embryonen in der New Kultur kultiviert, wurden die bebrüteten Eier mit einer kleinen Schere am stumpfen Ende geöffnet, und das dickflüssige Eiweiß wurde verworfen. Das dünnflüssige Eiweiß wurde in einer Petrischale gesammelt. Das von der Vitellinmembran umhüllte Eigelb wurde in eine Schale mit Panett-Compton Saline (PC) gegeben. $\mathrm{Zu}$ diesem Zeitpunkt haftete noch Eiweiß am Dotter, das mit einer Pasteurpipette sorgfältig abgesaugt werden musste. Die Dotterkugel wurde daraufhin in eine etwa $3 \mathrm{~cm}$ hoch mit PC gefüllte Plastikwanne überführt und so orientiert, daß der Embryo oben lag. Im nächsten Arbeitsschritt wurde das Eigelb am Äquator mit einer gebogenen Schere aufgeschnitten und die Vitellinmembran vorsichtig vom Dotter abgezogen. Hierbei mußte darauf geachtet werden, daß der Embryo sich nicht von der Vitellinmembran löste. Die Vitellinmembran wurde mit dem Embryo nach oben auf eine im Puffer liegende Uhrglasschale gelegt. Ein Glasring mit einem Innendurchmesser von $22 \mathrm{~mm}$ wurde so auf die Vitellinmembran gelegt, daß der Embryo in der Mitte des Glasrings lag. Das Uhrglas wurde nun unter ein Stereomikroskop überführt, mit einer Mikropipette wurde überschüssiger Puffer abpipettiert und die Vitellinmembran über den Glasring drappiert. Der Glasring mit der Vitellinmembran wurde in eine 3,5 cm Schale gesetzt, die vorher mit 3-4 ml des vorher gesammelten dünnflüssigen Eiweißes gefüllt wurde. Anschließend wurde der Glasring mit zwei Spateln an der Zellkulturschale festgedrückt. Außerhalb des Glasringes befindliches Eiweiß wurde abgesaugt und der Embryo von Puffer, Eiweiß und Dotter gereinigt. Die Kulturschale wurde in eine feuchte Kammer gestellt und in einem Brutschrank bei $38^{\circ} \mathrm{C}$ bis zum gewünschten Entwicklungstadium inkubiert.

Für die EC-Kultur wurden mindestens einen Tag vor dem geplanten Experiment die Kulturschälchen vorbereitet. Hierzu wurden $120 \mathrm{ml}$ dünnflüssiges Eiweiß aus 24 uninkubierten Eiern gesammelt. Außerdem wurden $120 \mathrm{ml}$ einer NaCl-Lösung (Saline; 7,19 g NaCl/1 $1 \mathrm{~d} \mathrm{H}_{2} \mathrm{O}$ ), 0,72 g Bacto-Agar (Difco) sowie Penicillin/Streptomycin $(10000 \mathrm{U} / \mathrm{ml}$ Penicillin G und $10000 \mu \mathrm{g} / \mathrm{ml}$ Streptomycin in physiologischer Kochsalzlösung; GibcoBRL) benötigt. Der Agar wurde in einem $500 \mathrm{ml}$ Erlenmeyerkolben in der Saline auf einer Heizplatte unter Rühren gelöst. Das gesammelte dünnflüssige Eiweiß wurde in einem Wasserbad auf $49^{\circ} \mathrm{C}$ erhitzt. Auch der gelöste 
Agar wurde auf $49^{\circ} \mathrm{C}$ equilibriert. Wenn Agar und Eiweiß dieselbe Temperatur erreicht hatten, wurden sie unter Rühren gemischt und 5 U/ml Penicillin/Streptomycin hinzugefügt. Die 3,5 cm Kulturschalen wurden mit jeweils 2,5 ml des AlbuminAgars gfüllt. Die Kulturschälchen wurden daraufhin mehrere Stunden bis über Nacht bei Raumtemperatur getrocknet. In einem luftdicht verschlossenen Gefäß konnten sie dann 1-2 Wochen bei $4^{\circ} \mathrm{C}$ bis zum Gebrauch gelagert werden. Die Filterpapierringe wurden aus Whatmanpapier Nr. 2 geschnitten. Es wurden Quadrate mit 2 cm Kantenlänge angefertigt, in die dann ein kleeblattförmiges Loch gestanzt wurde. Die Filterpapiere wurden vor Gebrauch autoklaviert. Die bebrüteten Eier sollten vor dem Öffnen 15-30 min abgekühlt und mit 70 \% Ethanol abgespült sein. Das Ei wurde in einer $10 \mathrm{~cm}$ Glaspetrischale vorsichtig aufgeschlagen, so daß der Dotter unbeschadet in die Petrischale fließen konnte. Das Blastoderm sollte in den meisten Fällen dem Dotter aufliegen. Das dicke, an der Dotterkugel haftende Eiweiß wurde mit kleinen Papiertüchern abgestreift, da das Eiweiß verhindert, daß das Filterpapier an der Vitellinmembran anhaftet. War das Eiweiß entfernt, wurde das Filterpapier vorsichtig auf die Vitellinmembran gelegt, so daß der Embryo vom Papier eingerahmt war. Mit einer Schere wurde die Vitellinmembran am Rand des Papierfilters durchschnitten und dann der Papierfilter mitsamt Vitellinmembran und anhaftendem Embryo vorsichtig mit einer feinen Pinzette vom Dotter abgenommen. Hierbei mußte darauf geachtet werden, daß der Embryo sich nicht vom Filter löste. Nun wurde der Filter mit dem Embryo nach oben auf das Agarose-Albuminbett gelegt und wie die New-Kultur in einer feuchten Kammer inkubiert.

\section{13. 4. Transplantation von Mausgewebe in Hühnerembryonen}

Die Analyse des induktiven Potentials des Mausknotens erfolgte in in vitro kultivierten Hühnerembryonen. Die Mausembryonen wurden aus dem Uterus am Tag 6,5-7 nach Konzeption unter dem Stereomikroskop herauspräpariert und ihr Stadium bestimmt (Downs und Davies, 1993). Embryonen im späten Primitivstreifenstadium wurden in PBS präpariert. Hierzu wurden sie mit einer Haltepipette fixiert. Die distale Spitze des Eizylinders, die den Knoten enthält, wurde mit in der Flamme geschärften Wolframdrahtnadeln aus dem Embryo herausgeschnitten. Um das Transplantat auf dem Hühnerembryo nicht zu verlieren, wurde es, bevor es mit einer Mikropipette auf 
den in vitro kultivierten Embryo pipettiert wurde, mit einigen Partikeln Karminrot (Sigma) gefärbt. Die Transplantate wurden mit einer gebogenen Insektennadel am anterioren Rand der area pellucida zur area opaca zwischen das primitive Endoderm und das Ektoderm des Hühnerembryos implantiert. Die Hühnerembryonen wurden über Nacht ca. 12-20 h inkubiert. Nach der Inkubation wurden die Embryonen mit einer mikrochirurgischen Schere von der Vitellinmembran geschnitten und in eiskaltem $4 \%(w / v)$ PFA/PBS bei $4^{\circ} \mathrm{C}$ über Nacht fixiert.

\section{13. 5. in ovo-Kultur}

Manipulationen des Embryos in seiner Eischale ermöglichten, den Embryo sich über das in der Embryokultur erreichbare Entwicklungsstadium hinaus, theoretisch bis zum Schlüpfen, entwickeln zu lassen. Das Ei mußte unbewegt auf der Seite inkubiert werden. Um die Position des Embryos vorhersagen zu können, wurde der obere Apex des Eis mit einem Stift markiert. 15 min vor der Manipulation wurde das Ei aus dem Inkubator herausgeholt und mit Ethanol abgesprüht. Es wurde in einem Plastilinbett fixiert, und auf der Oberseite wurden zwei Streifen Klebeband (Scotch Magic Tape; 2 cm breit) sorgfältig verklebt. In das stumpfe Ende des Eis wurde ein Loch gebohrt, durch das mit einer 18 G1,5 Kanüle $2 \mathrm{ml}$ des dünnflüssigen Eiweißes abgezogen wurden. Hierdurch senkte sich der Dotter, und man konnte auf der Oberseite des Eis vorsichtig ein rundes Fenster mit ca. $2 \mathrm{~cm}$ Durchmesser schneiden. Das Blastoderm sollte im Zentrum des Fensters liegen. Der Dotter konnte nun wieder angehoben werden, indem durch das seitliche Loch mit Penicillin/Streptomycin versetzter Tyrodes Puffer nachgespritzt wurde. Um den Embryo sichtbar zu machen, wurde mit einer Glaskapillare, die mit einer Mundpipette vebunden war, schwarze Tinte (Higgins-non-Waterproof), verdünnt in Tyrodes, unter den Embryo gespritzt. Die Kapillare wurde außerhalb der area opaca durch die Vitellinmembran gestoßen, die Nadel tangential direkt unter den Embryo geführt und vorsichtig soviel Tinte in die Subgerminalhöhle eingespritzt, bis der Embryo gut sichtbar war. Der Embryo war nun von dorsal für Manipulationen oder Zellmarkierungen zugänglich. 


\section{13. 6. Zellmarkierung mit Dil}

Cell Tracker DiI (1,1-Dioctadecyl-3,3,3,3‘- tetramethyl indocarbocyanine perchlorate; Molecular Probes) ist ein lipophiler fluoreszierender Vitalfarbstoff, mit dem man auf einfache Weise Zellen markieren kann. Durch seine Intensität läßt er sich auch nach vielfachen Zellteilungen nicht ausdünnen. Aus dem lyophyllisierten Farbstoff wurde zunächst durch Zugabe von $10 \mu 1100 \%$ Ethanol auf $50 \mu \mathrm{g}$ CM-DiI eine Stocklösung hergestellt. Mit $90 \mu 1$ einer 10 \%igen Sukroselösung konnte dieser Stock für größere Injektionsvolumina verdünnt werden. Die DiI-Lösung wurde in eine Mikrokapillare eingefüllt und mit einem Mikroinjektor auf die zu markierenden Zellen aufgebracht.

\section{13. 7. Applikation von Proteinfaktoren}

\section{13. 7. 1. Implantation von retroviral transfizierten Hühnerfibroblasten}

Retroviral transfizierte embryonale Hühnerfibroblasten wurden bis zur Konfluenz kultiviert. Zwei Stunden vor der Implantation in Hühnerembryonen wurden sie mit einer abgebogenen Wolframdrahtnadel zu kompakten Streifen zusammengeschoben und im Zellkulturinkubator für mindestens eine weitere Stunde inkubiert. Unmittelbar vor der Operation wurden diese Streifen mit Hilfe einer in der Flamme geschärften Wolframdrahtnadel in kleine Blöcke für die Implantation zurechtgeschnitten. Diese wurden mit einer Mikropipette aufgenommen, kurz in PC-Puffer gewaschen, gegebenenfalls mit einigen Partikeln Karminrot angefärbt und dann vorsichtig auf den Embryo pipettiert. Die Zellen konnten dann in vorbereitete Taschen zwischen Endoderm und Ektoderm, wie für die Knotentransplantationen beschrieben, implantiert werden.

\section{13. 7. 2. Implantation von Heparin-Akrylamidkugeln}

Die rekombinanten Proteinfaktoren ( $\mathrm{rm} F G F 8 b, \operatorname{rm} F G F 4, \operatorname{rh} B M P 2$ und $\operatorname{rmNoggin}$ ) wurden von der Firma R\&D Systems bezogen. Sie wurden als Lyophyllisat geliefert und in verschiedenen Konzentrationen in PBS mit 0,1 \% BSA gelöst, aliquotiert und 
bei $-80^{\circ} \mathrm{C}$ gelagert. Die Proteine wurden an Heparin-Acrylamid-Kugeln (Sigma) gebunden. Dazu wurden die Kugeln dreimal in PBS gewaschen und in einem Uhrmachergläschen nach Größe sortiert. Kugeln, deren Größe einen Durchmesser von 100 $\mu \mathrm{m}$ nicht überschritt, wurden in eine Mikrotiterplatte überführt, die die jeweiligen Proteinlösungen enthielt. Die Kugeln wurden bis zu ihrer Verwendung mehrere Stunden bei $4{ }^{\circ} \mathrm{C}$ inkubiert. Als Kontrolle wurden die Kugeln nach dem Waschen in PBS in PBS $/ 0,1 \%$ BSA inkubiert. Um die Kugeln zu sortieren, in die Mikrotiterplatte zu überführen oder auf den Embryo $\mathrm{zu}$ transportieren, wurde aus einem an eine Pasteurpipette festgeschmolzenen Wolframdraht eine feine Schlinge gebogen, auf der die Kugeln plaziert werden konnten. Transplantiert wurden die Kugeln in Embryokulturen im Stadium HH3/4. Abhängig vom Operationstyp wurden die Kugeln in den anterioren Embryo an die Grenze von area opaca und area pellucida oder an den Primitivstreifen, direkt posterior vom Knoten verpflanzt. Hierzu wurde mit einer gebogenen Insektennadel eine Tasche ins Endoderm präpariert und die Kugeln mit Hilfe der Insektennadel zwischen Ektoderm und Endoderm an die gewünschte Position geschoben.

\section{14. Whole-Mount (Ganzpräparat)-in situ-Hybridisierung}

Die transkriptionelle Aktivität eines Genes wurde durch die in situ-Hybridisierung am ganzen Hühnerembryo nachgewiesen. Die Expression einzelner Gene wurde wie beschrieben analysiert (Wilkinson, 1992). Die gleichzeitige Detektion der Expression zwei verschiedener Gene in einem Embryo wurde wie beschrieben unternommen (Dietrich et al., 1997). Dabei wurden die Embryonen gleichzeitig mit einer digoxigenin- und mit einer fluoreszein-markierten RNA-Sonden hybridisiert, die dann in zwei getrennten Schritten mit Hilfe von Digoxigenin- bzw. Fluoreszein-spezifischen Antikörpern (Roche) detektiert wurden.

Die Hühnerembryonen wurden zunächst in PBS präpariert und in 4 \%iger Lösung (w/ v) aus Paraformaldehyd (PFA) in PBS über Nacht bei $4^{\circ} \mathrm{C}$ fixiert. Anschließend wurden die Embryonen entweder einzeln in Netze in 24-Titerplatten oder zu mehreren in Netze in 6-Titerplatten überführt und durch Umsetzen der Netze durch die unten tabellarisch aufgeführten Schritte geführt. Die Embryonen konnten wahlweise in $100 \%$ Methanol während der Methanol-Reihe (Tab. 2. 7.) bei $-20^{\circ} \mathrm{C}$ für einige Tage 
oder vor der Hybridisierung im Lagermix (s.u.) für einen längeren Zeitraum bei $-20^{\circ} \mathrm{C}$ gelagert werden. Die Inkubationdauer der Behandlung mit Proteinase K wurde mit dem Entwicklungsstadium der Embryonen variiert. Für Entwicklungsstadien jünger als HH7 wurde sie für 1 min durchgeführt und für spätere Stadien auf 3 min verlängert. Tabellarische Übersicht der Waschschritte und Inkubationen, während insgesamt 5 Tagen (Tab. 2. 7. bis Tab. 2. 11.):

\begin{tabular}{|l|l|}
\hline PBT & $2 \times 5 \mathrm{~min}$ \\
\hline $25 \%$ Methanol in PBT & $5 \mathrm{~min}$ \\
\hline $50 \%$ Methanol in PBT & $5 \mathrm{~min}$ \\
\hline $75 \%$ Methanol in PBT & $5 \mathrm{~min}$ \\
\hline $100 \%$ Methanol & $5 \mathrm{~min}$ \\
\hline $75 \%$ Methanol in PBT & $5 \mathrm{~min}$ \\
\hline $50 \%$ Methanol in PBT & $5 \mathrm{~min}$ \\
\hline $25 \%$ Methanol in PBT & $5 \mathrm{~min}$ \\
\hline PBT & $2 \times 5 \mathrm{~min}$ \\
\hline $6 \% \mathrm{H}_{2} \mathrm{O}_{2} /$ PBT & $30 \mathrm{~min}$ \\
\hline PBT & $3 \times 5 \mathrm{~min}$ \\
\hline $10 \mu \mathrm{g} / \mathrm{ml} \mathrm{ProtK/PBT}$ & $1-3 \mathrm{~min}$ \\
\hline $2 \mathrm{mg} / \mathrm{ml}$ Glyzin/PBT & $5 \mathrm{~min}$ \\
\hline PBT & $2 \times 5 \mathrm{~min}$ \\
\hline $0,2 \%$ Glutaraldehyde/4\% PFA/PBT & $20 \mathrm{~min}, 4^{\circ} \mathrm{C}$ \\
\hline PBT & $2 \times 5 \mathrm{~min}$ \\
\hline $\begin{array}{l}\text { Optional: } \\
50 \% \text { Formamid, } 5 \mathrm{xSC} \mathrm{pH} 4,5\end{array}$ & Lagern bei $-20^{\circ} \mathrm{C}$ \\
\hline Prähybridisierungslösung & $5 \mathrm{~min}$ \\
\hline Prähybridisierungslösung & $1 \mathrm{~h}, 70^{\circ} \mathrm{C}$ \\
\hline Hybridisierungslösung & über Nacht, $70^{\circ} \mathrm{C}$ \\
\hline
\end{tabular}

Tab. 2. 7.: Übersicht der Waschschritte und Inkubationszeiten am ersten Tag der in situ-Hybridisierung (PBT (0,1\% Tween-20 in PBS); Prähybridisierungslösung (50\% Formamid, 5x SSC pH 4,5, 1\% SDS, $50 \mu \mathrm{g} / \mathrm{ml}$ Hefe tRNA, $50 \mu \mathrm{g} / \mathrm{ml}$ Heparin); Hybridisierungslösung (Prähybridisierungslösung mit $1 \mu \mathrm{g} / \mathrm{ml}$ Gegenstrang-RNA (siehe 2.4.8) je Probe))

\begin{tabular}{|l|l|}
\hline $\begin{array}{l}\text { Lösung 1 (50 \% Formamid, } 5 \mathrm{xSC} \mathrm{pH} \\
4,5,1 \% \mathrm{SDS})\end{array}$ & $2 \times 30 \mathrm{~min}, 70^{\circ} \mathrm{C}$ \\
\hline $\begin{array}{l}\text { Lösung 3 (50 \% Formamid, } 2 \times \mathrm{SSC} \mathrm{pH} \\
4,5)\end{array}$ & $2 \times 30 \mathrm{~min}, 70^{\circ} \mathrm{C}$ \\
\hline
\end{tabular}




\begin{tabular}{|l|l|}
\hline $2 \% \mathrm{BBR} / \mathrm{MAB}$ & waschen \\
\hline $2 \% \mathrm{BBR} / \mathrm{MAB}$ & $1 \mathrm{~h}$ \\
\hline $20 \% \mathrm{FCS} / 2 \% \mathrm{BBR} / \mathrm{MAB}$ & $1 \mathrm{~h}$ \\
\hline $\begin{array}{l}\text { anti Fluoreszein Antikörper (1:2000) in } \\
20 \% \mathrm{FCS} / 2 \% \mathrm{BBR} / \mathrm{MAB}\end{array}$ & über Nacht, $4^{\circ} \mathrm{C}$ \\
\hline
\end{tabular}

Tab. 2. 8.: Übersicht der Waschschritte und Inkubationen am zweiten Tag der in situ-Hybridisierung (MAB (100 mM Maleinsäure, $150 \mathrm{mM} \mathrm{NaCl}, \mathrm{pH} 7,5$, mit NaOH eingestellt); BBR (Boehringer Blokkierungsreagens in MAB, Roche))

\begin{tabular}{|l|l|}
\hline MAB & $3 \times$ Waschen \\
\hline MAB & $5 \times 1 \mathrm{~h}$ \\
\hline $\begin{array}{l}\text { NTMT } \\
\text { pH } 8,0\end{array}$ & Waschen \\
\hline $\begin{array}{l}\text { NTMT } \\
\text { pH } 8,0\end{array}$ & $3 \times 30$ min \\
\hline Fast Red in NTMT pH 8,0 & 45 min bis $5 \mathrm{~h}$ \\
\hline PBT & $2 \times 10$ min \\
\hline $0,1 \mathrm{M} \mathrm{Glyzin/HCl} \mathrm{pH} 2,2$ & 10 min \\
\hline PBT & $5 \times 10$ min \\
\hline $4 \%$ PFA/PBS & über Nacht, $4^{\circ} \mathrm{C}$ \\
\hline
\end{tabular}

Tab. 2. 9.: Übersicht der Waschschritte und Inkubationen am dritten Tag der in situ-Hybridisierung. ( ${ }^{\star}$ Fast Red TR/Naphtol AS-MX Tabletten (Sigma) in je $1 \mathrm{ml}$ Wasser (Millipore) gelöst $(1 \mathrm{mg} / \mathrm{ml} \mathrm{4-}$ Chlor-2-methylbenzendiazonium, $0,4 \mathrm{mg} / \mathrm{ml} \quad 3$-Hydroxy-2-naphtholsäure-2,4-dimethylanilidphosphat, $0,15 \mathrm{mg} / \mathrm{ml}$ Levamisol, $100 \mathrm{mM}$ Tris $\mathrm{HCl}$ pH8,0), vor dem Gebrauch durch einen 0,22 $\mu \mathrm{m}$ Spritzenaufsatzfilter (Millipore) von unlöslichen Bestandteilen gereinigt; NTMT pH 8,0 (100 mM NaCl, $100 \mathrm{mM}$ Tris- $\mathrm{HCl} \mathrm{pH} \mathrm{8,} 50 \mathrm{mM} \mathrm{MgCl}$, 1\% Tween-20, 2 mM Levamisol))

\begin{tabular}{|l|l|}
\hline PBT & $2 \times 5$ min \\
\hline MAB & $3 \times$ Waschen \\
\hline MAB & $2 \times 30$ min \\
\hline $2 \%$ BBR/MAB & $1 \mathrm{~h}$ \\
\hline $20 \% \mathrm{FCS} / 2 \%$ BBR/MAB & $1 \mathrm{~h}$ \\
\hline $\begin{array}{l}\text { anti Digoxigenin Antikörper }(1: 2000) \\
\text { in } 20 \% \mathrm{FCS} / 2 \% \text { BBR/MAB }\end{array}$ & über Nacht, $4^{\circ} \mathrm{C}$ \\
\hline
\end{tabular}

Tab. 2. 10.: Übersicht der Waschschritte und Inkubationen am vierten Tag der in situ-Hybridisierung

\begin{tabular}{|l|l|}
\hline MAB & $3 \times$ Waschen \\
\hline MAB & $5 \times 1 \mathrm{~h}$ \\
\hline
\end{tabular}




\begin{tabular}{|l|l|}
\hline $\begin{array}{l}\text { NTMT } \\
\text { pH 9,5 }\end{array}$ & Waschen \\
\hline $\begin{array}{l}\text { NTMT } \\
\text { pH 9,5 }\end{array}$ & $3 \times 30$ min \\
\hline NBT/BCIP in NTMT pH 9,5* & $\begin{array}{l}2 \text { bis } 24 \mathrm{~h}, \text { im Dunkeln, mit mehrfa- } \\
\text { chem Lösungswechsel }\end{array}$ \\
\hline PBT & $2 \times 10$ min \\
\hline $50 \%$ Glyzerin/PBT & $1 \mathrm{~h}$ \\
\hline $80 \%$ Glyzerin/PBT & $1 \mathrm{~h}$, dann bei $4^{\circ} \mathrm{C}$ lagern \\
\hline
\end{tabular}

Tab. 2. 11.: Übersicht der Waschschritte und Inkubationen am fünften Tag der in situ-Hybridisierung. ( $200 \mu \mathrm{l} \mathrm{NBT/BCIP} \mathrm{Stammlösung} \mathrm{(} 18,75 \mathrm{mg} / \mathrm{ml} \mathrm{NBT,} \mathrm{9,4} \mathrm{mg/ml} \mathrm{BCIP} \mathrm{in} 67 \%$ DMSO (v/v), Roche) pro $10 \mathrm{ml}$ NTMT pH 9,5, Reaktion vor Licht schützen und Färbelösung alle $3 \mathrm{~h}$ wechseln; NTMT pH 9,5 (100 mM NaCl, 100 mM Tris- $\mathrm{HCl} \mathrm{pH} \mathrm{9,5,} 50$ mM MgCl 2,1 \% Tween-20, 2 mM Levamisol)).

Die Analyse der Embryonen erfolgte an einem Zeiss Stemi SV11-Binokular. Die Embryonen wurden mit einem Zeiss MC80 bei folgenden Einstellungen photographiert:

Belichtungszeit: $\quad$ automatisch, +1 für Dunkelfeld, 0 für Semi Hellfeld-Aufnahmen

ASA: $\quad 64$

Dunkelfeld: Glas, durchsichtig

Semi-Hellfeld: $\quad$ graue Plastik- oder gefrostete Glasscheibe

Film: $\quad$ Kodak T64

\section{15. Ausspritzen des embryonalen Gefäßsystems mit Kunststoff}

Um die Lagebeziehung von Genexpression und Gefäßmorphologie zu verdeutlichen, wurde das arterielle Gefäßssystem von Embryonen der Stadien HH13 bis HH25 mit einem speziellem Kunststoff (Batesons No.17 Plastic Replica Kit; Polysciences) ausgegossen. Der Kit bestand aus dem Monomer, einem Katalysator, einem Promoter und einem roten Farbstoff. Mit $10 \mathrm{ml}$ des Monomers wurden $250 \mu \mathrm{l}$ des Katalysators und 2 Tropfen des Promoters vermischt, zusätzlich wurden $1 \mathrm{ml}$ des Farbstoffs hinzugefügt. Der Kunstoff polymerisierte nach 30-45 min. Die Embryonen wurden in PBS präpariert und in einer Silikonschale mit Insektennadeln fixiert. Der Kunststoff wurde mit Hilfe einer Glaskapillare und einer Mundpipette vorsichtig in den Ventrikel des Herzschlauches pipettiert, so daß die Aortenbogenarterien langsam mit dem Kunst- 
stoff ausgefüllt wurden. Die Embryonen konnten nun in $4 \%$ PFA/PBS fixiert und durch Whole-Mount-in situ-Hybridisierung analysiert werden.

\section{16. Histologie}

Für die Anfertigung histologischer Schnitte wurden Embryonen und Gewebe in Paraplast eingebettet und an Mikrotomen (Leica) mit $8 \mu \mathrm{m}$ Schnittdicke geschnitten. Zum Einbetten wurden die Embryonen nach der whole mount in situ-Hybridisierung von $50 \%$ Glycerol/PBS über mehrere Schritte in $100 \% \mathrm{EtOH}$ überführt. Es folgte eine Infiltration mit Toluol. Im Toluol konnten die Präparate bis zu 2 Tage aufbewahrt werden. Vom Toluol wurden die Präparate in Paraplast bei $60^{\circ} \mathrm{C}$ überführt. Von dort wurden sie in Blöcke eingebettet und zum Schneiden am Mikrotom getrimmt. Nach dem Schneiden wurden die Schnitte in Xylolersatz entparaffiniert und mit Eukitt und Deckglas versiegelt. Die Schnitte wurden an einem Olympus BX60 unter Differential-Interferenzkontrast, Fluoreszenz oder im Hellfeld analysiert und mit einer Digitalkamera photographiert. Die Aufnamen wurden mit dem Analysis-Softwarepaket bearbeitet. 


\section{Ergebnisse}

\section{1. Die Analyse der neuralinduzierenden Aktivität des Knotens des Mausembryos}

Während von verschiedenen Autoren gezeigt werden konnte, daß der Hensensche Knoten des Huhnembryos die induktive Kapazität besitzt, Neuralachsen mit vollständiger anterior-posteriorer Identität zu induzieren, gelang für den Knoten des Mausembryos dieser Nachweis bisher nicht. Im Maus-zu-Maus-Transplantationsexperiment kann ein transplantierter Knoten aufgrund der geringen Größe des Wirtsembryos nur in Bereiche gesetzt werden, die posteriorisierenden Signalen ausgesetzt sind und daher nicht mehr oder nur noch schwer anteriorisierbar sind. Der Mausknoten sollte stattdessen in ein möglichst naives, für neuralinduzierende Signale kompetentes Umfeld gebracht werden. Daher wurde als Wirtsorganismus der Huhnembryo gewählt. Transplantiert wurde an die Grenze der area pellucida zur area opaca eines nach New kultivierten Huhnembryos im Primitivstreifenstadium (HH3 bis HH4). Das Ektoderm dieser Region ist spezifiziert für die Entwicklung zu Epidermis, bzw. extraembryonalem Ektoderm, besitzt aber zum Zeitpunkt der Transplantation die Kompetenz, in neurales Gewebe umprogrammiert zu werden (Spratt, 1952; Rosenquist, 1966; Schoenwolf und Sheard, 1990; Garcia-Martinez et al., 1993). Als zu analysierendes Gewebe wurde die distale Spitze des Eizylinders eines Mausembryos im späten Primitivstreifenstadium (ca. 6,5-7 Tage nach Befruchtung) gewählt. Dieser Bereich enthält den Knoten, aber auch die ersten, aus seiner Selbstdifferenzierung hervorgegangenen Derivate, wie prächordales definitives Endoderm und prächordales Mesoderm, sowie anteriore Bereiche des Primitivstreifens. Nach Transplantation des Mausgewebes wurde die Embryokultur ca. 15 Stunden weiterinkubiert, bis der primäre Embryo etwa das Stadium HH8-HH9 (vier bis sechs Somiten) erreicht hatte. Eine Selbstdifferenzierung des Transplantates wurde nicht beobachtet, da das Mausgewebe in der Embryokultur schon nach wenigen Stunden abstirbt. Die durch die 
Transplantation im Hühnerembryo hervorgerufenen Strukturen wurden mit Hilfe der in situ-Hybridisierung auf die Expression verschiedener Markergene untersucht. Die Expression der Homeoboxgene OTX2 (Marker für Vorderhirn und Mittelhirn) und GANF (exprimiert im anterioren Vorderhirn) galten als Indikator für anteriore Identität der induzierten Strukturen. Die Expression des Homeoboxgens $H O X B 1$ zeigte posteriore Identität an, da HOXB1 endogen im posterioren Hinterhirn und im Rükkenmark exprimiert wird (Guthrie et al., 1992). Durch den Nachweis des T-box Gens chT (Brachyury) wurde das induzierte Gewebe auf die Anwesenheit mesodermaler Zellen des Primitivstreifens und des Notochords überprüft.

Es wurden 57 Transplantationen durchgeführt, von denen $46 \%(n=26)$ eine induzierte ektopische Struktur zeigten. Diese ektopischen morphologischen Veränderungen hatten in vielen Fällen die Form von Neuralfalten und in einigen Fällen bildeten sich Neuralrohre. Bei 44 \% der analysierten Embryonen wurde OTX2 ektopisch aktiviert. Ektopische $G A N F$-Expression konnte bei 2 von 8 analysierten Embryonen nachgewiesen werden (25\%; Abb. 3. 1., D, E). 11 Embryonen wurden durch Doppel-in situHybridisierung parallel auf Induktion von OTX2 und $H O X B 1$ analysiert. Die induzierten Neuralplatten exprimierten in allen Fällen $O T X 2$ und $H O X B 1$, sie zeigten also eine klare anterior-posteriore Polarität, in allen Fällen wies der OTX2 positive, also anteriore Teil der Induktion in Richtung des primären Embryos (Abb. 3. 1., F-I). Um sicherzugehen, daß die Induktion der anterioren Neuralstrukturen direkt vom Transplantat erfolgte und die Neuralinduktion nicht durch einen vom Transplantat induzierten Hühnerorganisator hervorgerufen wurde, wurden die Embryonen durch Doppel-in situ-Hybridisierung auch auf die Anwesenheit von chT getestet. Insgesamt $42 \%$ der untersuchten Embryonen exprimierten chT ektopisch, wobei in nur einem Fall chT und OTX2 parallel in derselben induzierten Struktur nachweisbar waren (Abb. 3. 1., C). In zwei anderen Fällen wurde ausschließlich $\operatorname{chT}$ induziert und das über die gesamte ektopische Struktur (Abb. 3. 1., B). In diesen Fällen waren anstelle des Organisators Teile des hinter dem Knoten liegenden Primitivstreifens transplantiert worden, wodurch Strukturen mit ausschließlich posteriorer Identität induziert wurden. Da in $62 \%$ der auf OTX2 und chT parallel untersuchten Embryonen nur OTX2 alleine ektopisch aktiviert wurde, konnte eine indirekte Neuralinduktion durch das Transplantat ausgeschlossen werden. 
Insgesamt konnte durch die Transplantationsexperimente gezeigt werden, daß der Organisator der Maus unabhängig von Signalen aus dem anterioren viszeralen Endoderm eine ektopische Neuralplatte induzieren kann, die Vorderhirnidentität besitzt.

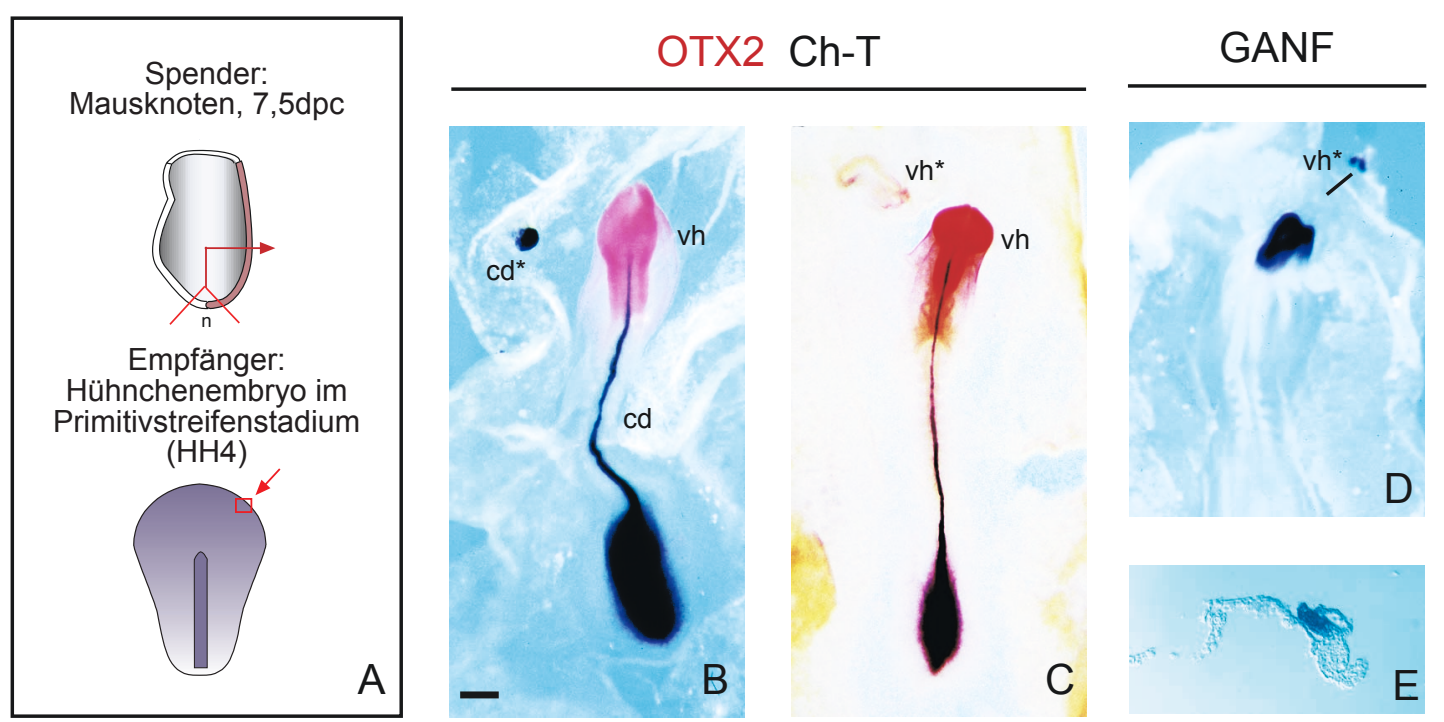

\section{OTX2 HOXB1}

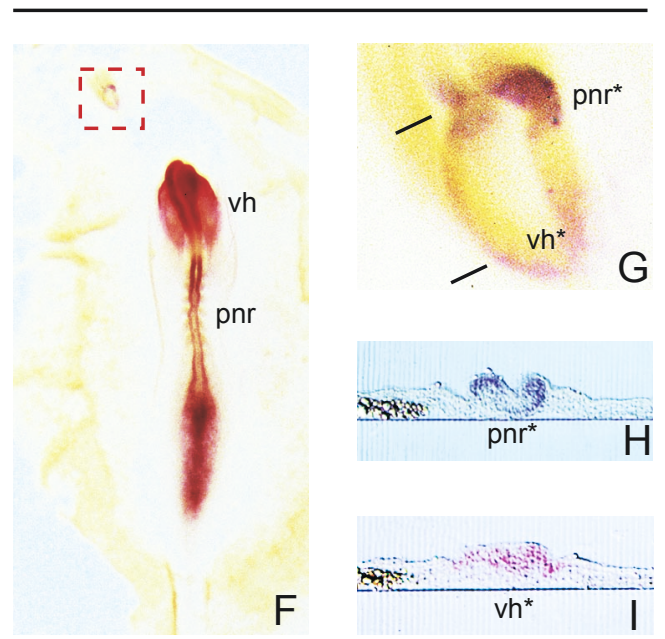

Abb. 3. 1.: Der Mausknoten induziert Neuralplatten mit anterior-posteriorer Identität. (A) Transplantationsschema; (B) Das Maustransplantat löst die Induktion von $c h T$ aus, der Embryo ist für $c h T$ (blauschwarz) und OTX2 (rot) angefärbt. (C) Induktion einer Neuralplatte mit anteriorer Identität durch ein Mausknoten-Transplantat, der Embryo ist mit OTX2 und $c h T$ gefärbt. (D) Induktion des anterioren Neuralplattenmarkers GANF durch den Mausknoten. (F-I) Der Mausknoten induziert eine Neuralplatte mit Vorderhirn und Rückenmarkidentität. Der Embryo ist gefärbt mit dem Vorderhirnmarker OTX2 und dem Marker des posterioren Neuralrohres HOXB1; eine Vergrößerung der induzierten Neuralplatte ist in $(\mathrm{G})$ abgebildet. $(\mathrm{H}+\mathrm{l})$ Querschnitte durch die induzierte Struktur.

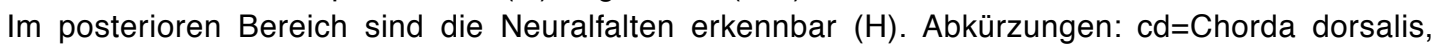
$\mathrm{cd}^{*}=$ induzierte Chorda dorsalis, $\mathrm{n}=$ Knoten, $\mathrm{pnr}=$ posteriores Neuralrohr, $\mathrm{pnr}^{*}=$ induziertes posteriores Neuralrohr, vh=Vorderhirn, vh*=induziertes Vorderhirn. Der Balken in (B) entspricht in (B, C, D, F) $600 \mu \mathrm{m}$, in (E, H) und (I) $75 \mu \mathrm{m})$. 


\begin{tabular}{l|c|c}
\hline ektopische Strukur & $26 / 57$ & $46 \%$ \\
\hline OTX2 & $8 / 18$ & $44 \%$ \\
\hline GANF & $2 / 8$ & $25 \%$ \\
\hline HOXB1 & $7 / 11$ & $63 \%$ \\
\hline chT & $3 / 7$ & $42 \%$ \\
\hline
\end{tabular}

Tabelle 3. 1.: Zusammenfassung der Transplantationsexperimente

\section{2. Ein Expressionsscreen identifiziert eine ventrale Synexpressions- gruppe}

Auch im Vogelembryo haben der Knoten und die ersten embryonalen Strukturen, die aus ihm differenzieren, nämlich das prächordale Endoderm und die prächordale Platte, einen anteriorisierenden Einfluß auf das neurale Ektoderm (siehe Abschnitt 1. 6.; Abb. 1. 5., A+B). Wird die prächordale Platte in einen Embryo im Primitivstreifenstadium transplantiert, so wird transient eine Neuralplatte induziert, die durch die Expression verschiedener Vorderhirnmarker charakterisiert ist (Knoetgen et al., 1999). Zwar wurden in den letzten Jahren viele Faktoren beschrieben, die in der prächordalen Platte exprimiert werden, es ist aber noch kein Molekül bekannt, das ausreichend ist, eine anteriore Neuralplatte zu induzieren.
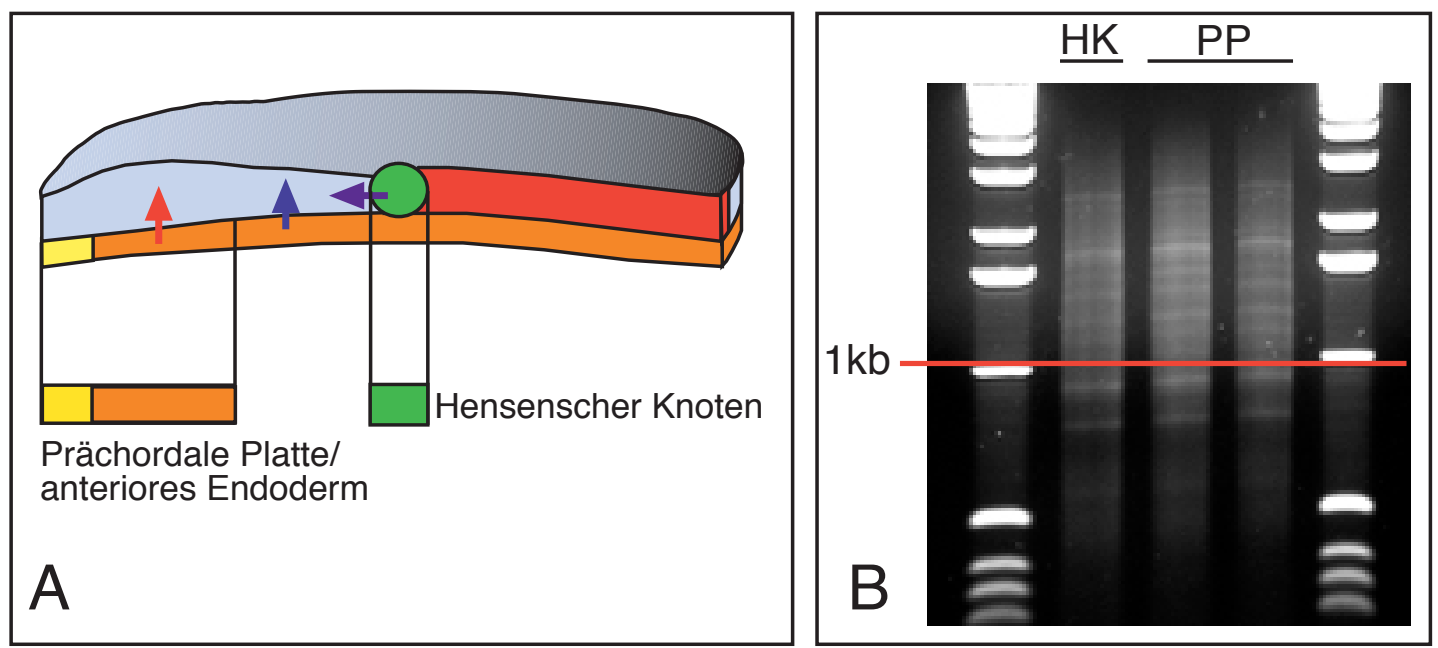

Abb. 3. 2.: (A) Schematischer Querschnitt durch einen Huhnembryo im Kopffortsatzstadium. Herausgehoben sind die Gewebebereiche, aus denen cDNA für die Banken gewonnen wurde. (B) Die cDNAs nach Auftrennung auf einem 1 \%igen Agarosegel, HK=cDNA aus dem Hensenschen Kno- 
ten, $\mathrm{PP}=\mathrm{cDNA}$ aus der prächordalen Platte. Die Amplifikate, die größer als $1 \mathrm{~kb}$ waren (Höhe der 1 $\mathrm{kb}$ Front $=$ rote Linie), wurden aus dem Gel eluiert und in den pCMV3 kloniert

Um neue Gene zu finden, die in der anterioren Musterbildung im Embryo eine Rolle spielen, wurde ein Expressionsscreen durchgeführt, der die prächordale Platte und das prächordale Endoderm als Ausgangsmaterial hatte. Zur Herstellung der cDNA-Banken wurden die prächordale Platte sowie der Hensensche Knoten aus Embryonen im Kopffortsatzstadium (HH5) isoliert (Abb. 3. 2., A). Aus jeweils 30 dieser Explantate wurde Gesamt-RNA gewonnen und $1 \mu \mathrm{g}$ zur cDNA Synthese verwendet. Von der Erststrang-cDNA wurde ein Fünftel durch PCR amplifiziert, um ausreichend Material für die Plasmid-cDNA-Bibliothek zu erhalten. Nach Auftrennung der Amplifikationsreaktionen auf einem Agarosegel wurden alle PCR-Amplifikate, die größer als $1 \mathrm{~kb}$ waren, aus dem Gel eluiert und in den Expressionsvektor pCMV3 ligiert (Abb. 3. 2., B). Dieser Ligationsansatz wurde in Bakterien transformiert und ausplattiert.

Die Auswertung der Transformationseffizienz ergab ca. 35.000 Klone je $\mu 1$ Ligationsansatz. Die cDNA-Banken enthielten die gesamte RNA-Population des untersuchten Gewebes, einschließlich der für den generellen Zellstoffwechsel zuständigen und damit entwicklungsbiologisch eher nicht relvanten Gene. Daher wurde ein einfacher Subtraktionsschritt durchgeführt, der die unabhängig von Entwicklungsstadium und Gewebetyp exprimierten Gene unterdrücken sollte (siehe Material und Methoden, Abschnitt 2. 8.). Die Subtraktion ermöglichte es, etwa $90 \%$ der Klone eines Ligationsansatzes von einer weiteren Analyse auszuschließen. Von den übrigen 10 \% wurden insgesamt 546 zufällig ausgewählte Klone sequenziert und über Datenbankvergleich auf bekannte Sequenzen und offene Leserahmen untersucht. Von diesen 546 sequenzierten Klonen hatten 274 (50 \%) einen offenen Leserahmen und von diesen 189 (70 \%) ein ATG, das als Startkodon in Frage kam. Diese Anreicherung von 5'Enden zeigte den Erfolg der SMART-PCR (siehe Material und Methoden, Abschnitt 2. 6. 7.). Insgesamt 304 (56\%) der sequenzierten Klone waren bereits im Huhn bekannt oder hatten homologe Sequenzen in anderen Organismen. Die übrigen $44 \%$ fanden sich nicht in der Datenbank, oder waren nur als sequenzierte eprimierte Genfragmente (EST, engl. expressed sequence tag) aufzufinden. Klone mit einer bekannten, bzw. homologen Sequenz ließen sich wie folgt in verschiedene funktionelle Klassen untergliedern (siehe auch Abb. 3. 3.): 16 \% waren nukleäre Faktoren, darunter Transkriptionsfaktoren, aber auch chromatinassoziierte Proteine. $12 \%$ konn- 
ten zu einer Gruppe stoffwechselrelevanter Enzyme zusammengefaßt werden, $8 \%$ der Klone kodierten für Proteine, die in Signaltransduktionskaskaden involviert sind. Für Transmembranproteine, einschließlich Rezeptorproteinen, kodierten $10 \%$ der analysierten Sequenzen, und zellzyklusspezifische Gene fanden sich in $6 \%$ der Sequenzen. Die übrigen 48 \% schließen Signalmoleküle, Zellskelettkomponenten und nicht weiter charakterisierbare Proteine ein (Abb. 3. 3.).

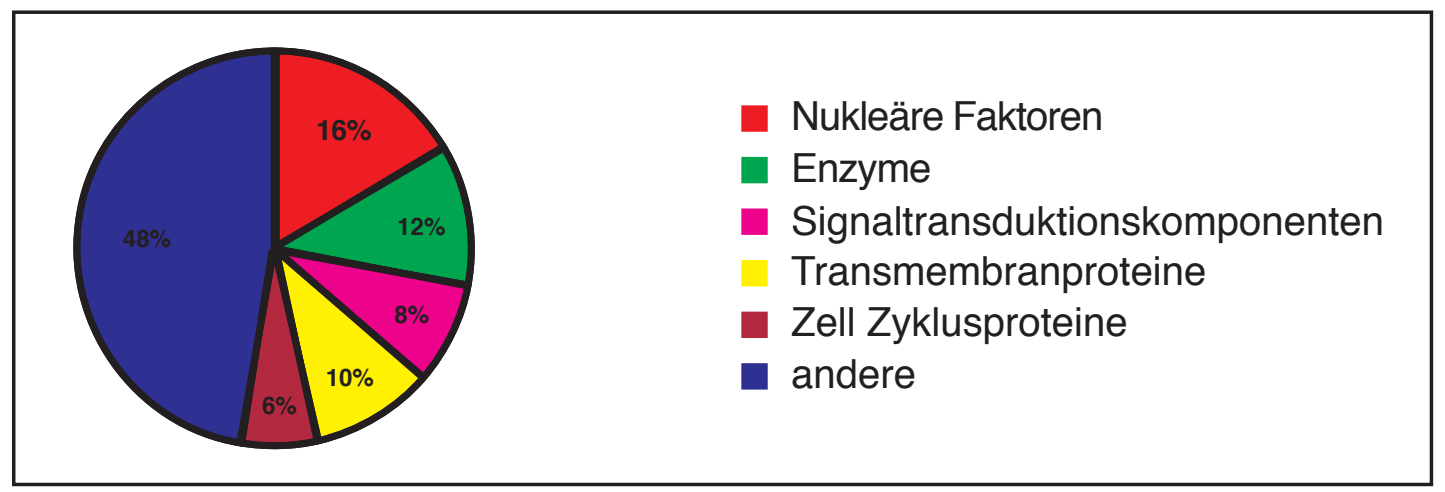

Abb. 3. 3.: Prozentuale Aufschlüsselung der analysierten Sequenzen in funktionelle Gruppen

Abhängig von der Datenbankanalyse wurden 72 Sequenzen durch in situ-Hybridisierung auf ein differentielles Expressionsmuster in verschiedenen Entwicklungsstadien (HH5, HH6/HH7 und HH8-HH10) analysiert. Von diesen 72 Genen zeigten 12 RNAProben kein Signal (16\%), 9 waren ubiquitär im gesamten Embryo exprimiert (12,5 \%). 51 Proben $(70 \%)$ hatten ein restriktives Expressionsmuster, wobei 29 dieser Gene $(57 \%)$ im Bereich der Neuralplatte exprimiert waren. In diese Gruppe fielen auch 6 Gene, die restriktiv in der anterioren Neuralplatte exprimiert waren, und 3 Gene, deren Transkripte verstärkt in den dorsalen Neuralfalten, der späteren Neuralleiste, nachweisbar waren. Eine signifikante Gruppe von 7 Genen (14\%) war im Kopffortsatzstadium (HH5) im anterioren und peripheren Mesoderm und Endoderm und in späteren Stadien im anterioren Intestinalportal, dem Herzmesoderm oder den Kiemenbögen aktiv. Da diese Bereiche im Vergleich zur Neuralplatte ventral liegen, wurden Gene mit diesem Expressionsmuster zu einer "ventralen" Synexpressionsgruppe zusammengefaßt (Abb. 3. 4., eine tabellarische Übersicht der durch ISH untersuchten Klone findet sich im Anhang, Abschnitt 7. 1.). Aus dieser Synexpressionsgruppe wurde der Klon PP283 (Abb. 3. 4.) im weiteren Verlauf der Arbeit im Detail untersucht. Die Sequenzanalyse des Klons zeigte, daß er die größte 
Sequenzähnlichkeit zu dem aus Xenopus laevis bereits bekannten, sekretierten WntAntagonisten Sizzled hat. Er wurde entsprechend "chicken Sizzled (cSzl)" genannt.
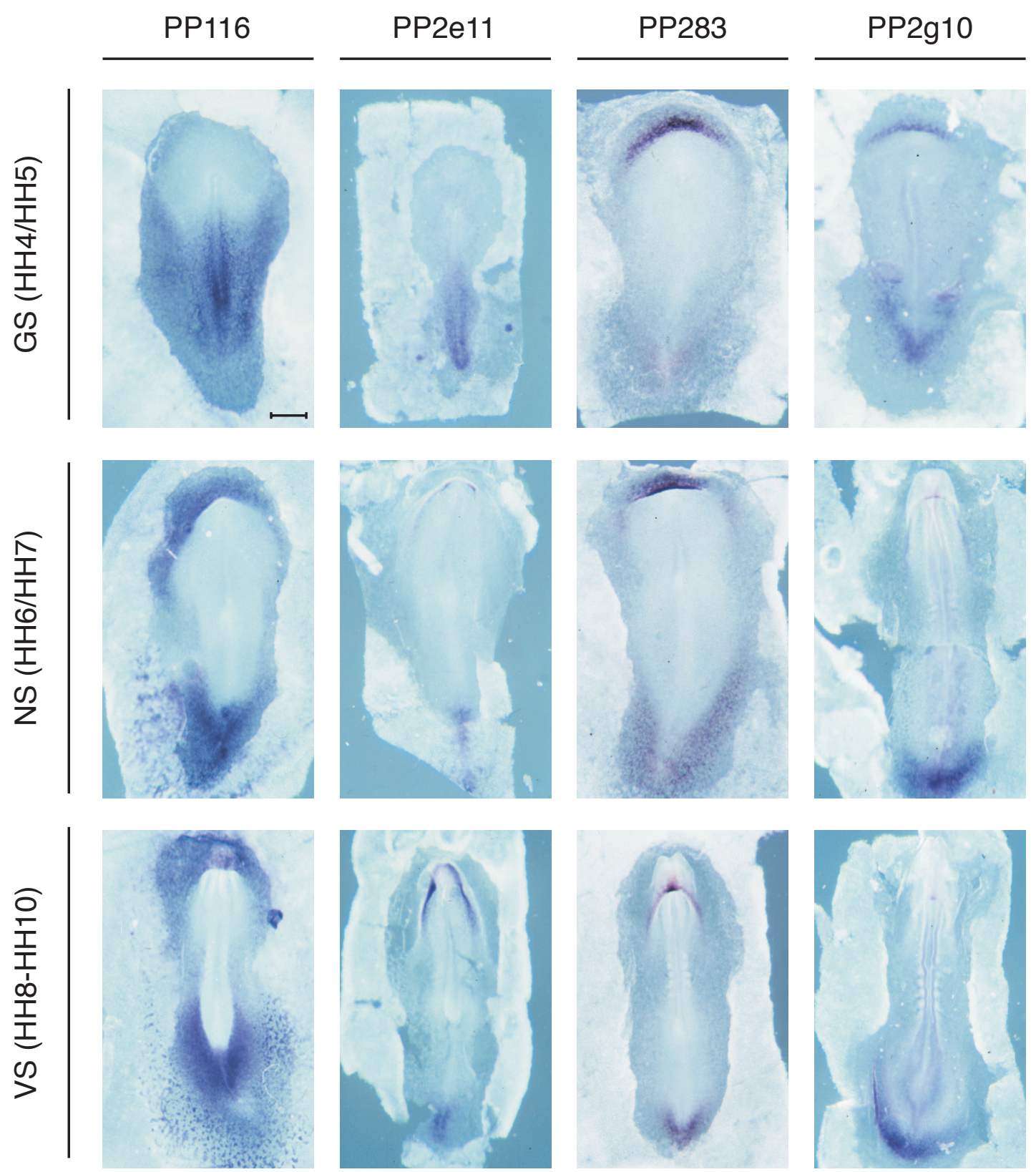

Abb. 3. 4.: Die "ventrale" Synexpressionsgruppe. Exemplarisch sind vier unterschiedliche Klone dieser Synexpressionsgruppe in drei verschiedenen Entwicklungsstadien abgebildet. Alle Embryonen sind von ventral photographiert. Alle Klone sind nur im Meso- oder Endoderm exprimiert und haben keine Expression im Ektoderm und im medialen Bereich des Embryos. Im Gastrulastadium (Gruppe GS, HH4/HH5) sind Transkripte im posterioren Primitivstreifen und im peripheren Endoderm nachweisbar. Mit der Ausbildung der Kopffalte (Gruppe NS, HH6/HH7) sind alle Klone dieser Expressionsgruppe im anterioren Intestinalportal (aip) und im Endoderm oder Mesoderm, das das aip flankiert, exprimiert. Im Vier- bis Zehn-Somitenstadium (Gruppe VS, HH8-HH10) sind die Klone im anterioren Intestinalportal und/oder im kardialen Mesoderm exprimiert. Der Klon PP283 wurde als das Huhnhomolog zum sekretierten Wnt-Antagonisten Sizzled identifiziert. Der Maßstab entspricht in allen Abbildungen $500 \mu \mathrm{m}$. 


\section{3. $c$ Szl ist ein sekretierter Wnt-Antagonist}

Der Klon PP283 enthielt den vollständigen offenen Leserahmen des $c S z l$-Transkripts. Er kodierte für ein Protein aus 284 Aminosäuren mit einem rechnerischen Molekulargewicht von 31130 g/mol (31 kda). Die abgeleitete Proteinsequenz ergab im Datenbankvergleich eine Aminosäureidentität von $65 \%$ mit dem sekretierten Xwnt8Antagonisten Sizzled aus Xenopus laevis.
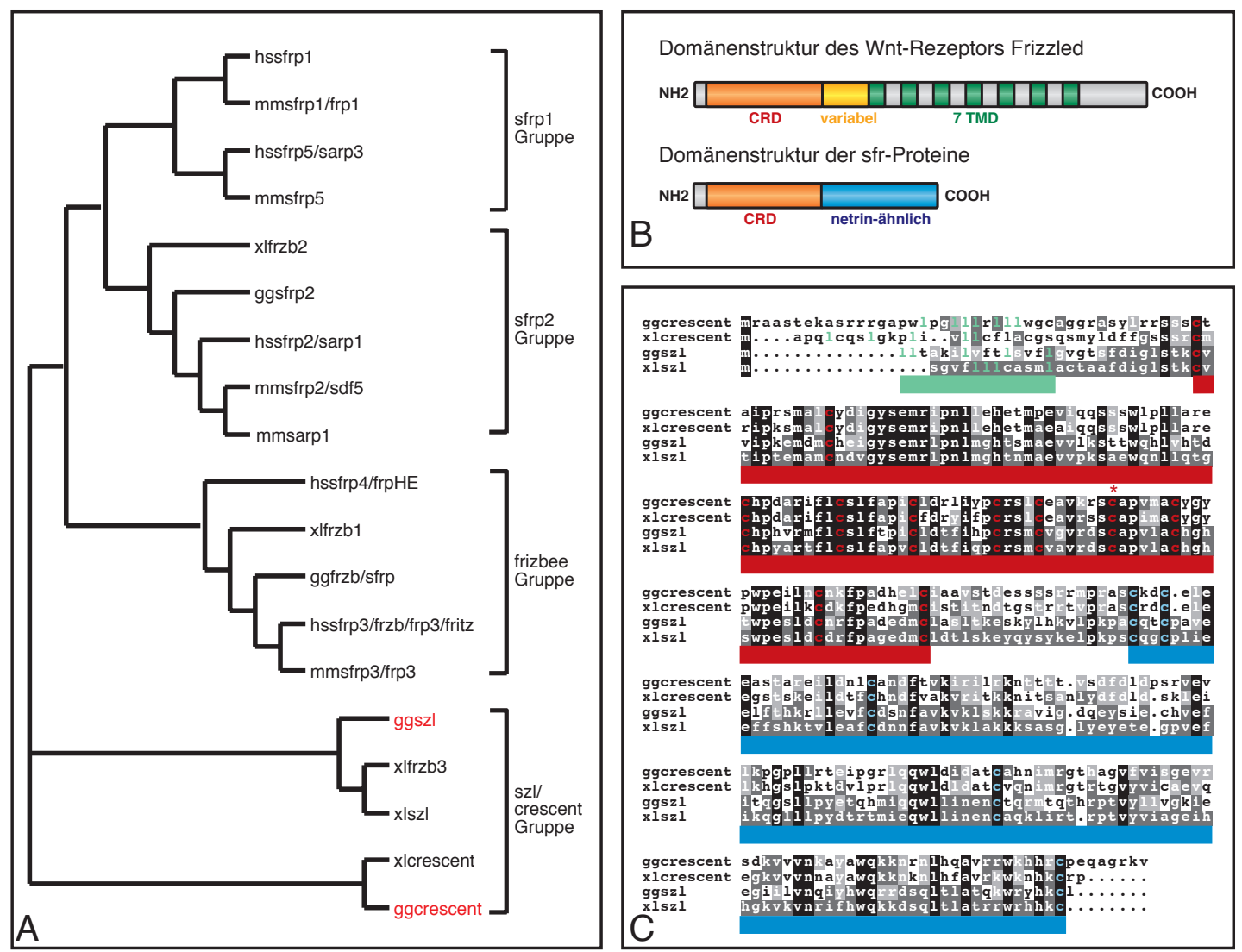

Abb. 3. 5.: (A) Verwandtschaftsdiagramm der bisher bekannten sekretierten Frizzled-ähnlichen Proteine. Sizzled und Crescent divergieren von den übrigen Mitgliedern der Proteinfamilie. Die in dieser Arbeit näher untersuchten Faktoren $c S z l$ (ggszl) und Huhn-Crescent (ggcrescent) sind rot dargestellt. (B) Domänenstruktur der sekretierten Frizzled-ähnlichen Proteine im Vergleich zum Wnt-Rezeptor Frizzled. Die Sfrps haben eine cysteinreiche Domäne (CRD) wie Frizzled, besitzen aber c-Terminal eine zusätzliche Domäne, die schwache Ähnlichkeit mit Netrin hat. Da sie sekretiert werden, fehlen den Sfrp die Transmembrandomänen des Rezeptors Frizzled (TMD). (C) Vergleich der Aminosäuresequenz von $c S z l$ (ggszl) mit den nächstverwandten Proteinen Sizzled aus dem Krallenfrosch (xIszI) und Crescent aus dem Huhn und Krallenfrosch (ggcrescent, xlcrescent). Die verschiedenen, konservierten Domänen sind farbig unterlegt: Rot unterlegt ist die cysteinreiche Domäne, blau die netrinähnliche Domäne. Die für die cysteinreiche Domäne charakteristischen Cysteine sind rot markiert. Der Stern zeigt das für Crescent und Sizzled charakteristische, von den übrigen sfr-Proteinen abweichende zusätzliche Cystein an. Grün unterlegt ist die leucinreiche Nterminale Signalpeptidsequenz.

Die nächstähnliche Sequenz in den Datenbanken war mit $40 \%$ Aminosäureidentität der ebenfalls sekretierte Wht-Antagonist Crescent aus Xenopus laevis und dem Huhn 
(38 \% Aminosäureidentität). Das nächstverwandte Gen aus der Maus und dem Menschen war das sekretierte, Frizzled-ähnliche Protein 5 (Sfrp, engl. secreted frizzled related protein) mit $32 \%$ Aminosäureidentität (Abb. 3. 5., A). N-terminal enthielt $c S z l$ eine für skretierte Proteine typische Signalsequenz, die durch eine Abfolge von Leucinen, Valinen und Isoleucinen charakterisiert ist (aa 13-20). Das Hauptcharakteristikum der Proteine aus der Frizzled-Familie ist eine cysteinreiche Domäne, die für die Bindung mit den Wnt-Proteinen verantwortlich ist (Rattner et al., 1997). Im cSzl-Protein erstreckte sich diese Domäne über 110 Aminosäuren von Position 29 bis Position 139. Generell enthält die zu Frizzled homologe cysteinreiche Domäne 10 Cysteine an konservierten Positionen. Als Besonderheit innerhalb der Sfrp-Familie enthielten Sizzled und Crescent ein zusätzliches Cystein zwischen den Cysteinen 8 und 9, so daß sich für diese Proteine folgender Konsensus in der cysteinreichen Domäne ergab: $\mathrm{C}^{1}$ X9-C $C^{2}-X 36-C^{3}-X 8-C^{4}-X 6-C^{5}-X 7-C^{6}-X 3-C^{7}-X 6-C^{8}-X 5-C^{*}-X 10-C^{9}-X 9-C^{10}$ (Chong et al., 2002). Im C-Terminus der Sfrp-Familie liegt eine weitere, weniger stark konservierte Domäne, die wegen ihrer schwachen Ähnlichkeit zu Netrin-Proteinen als Netrin-Modul bezeichnet wird (Abb. 3. 5., B, C).

\section{4. Expressionsanalyse von $c S z l$}

Eine erste Charakterisierung von $c S z l$ erfolgte über die Untersuchung seiner Expression während der Embryogenese. Das zeitlich-räumliche Expressionsmuster erlaubt häufig schon erste Annahmen über die Funktion eines entwicklungsbiologisch relevanten Gens. Die Expression von $c S z l$ wurde durch in situ-Hybridisierungen an ganzen Embryonen mit Digoxigenin markierten Riboproben vom Zeitpunkt der Eiablage bis zum Stadium HH25 analysiert. Schon vor der Initiation des Primitivstreifens waren $c S z l$-Transkripte im extraembryonalen Hypoblast nachzuweisen (Abb. 3. 6., A). Mit Bildung des Primitvstreifens wurden die cSzl exprimierenden Zellen durch den sich ausbreitenden Endoblasten nach anterior verschoben, wo sich die cSzlDomäne mit Auswachsen des Primitivstreifens als anteriore, halbmondförmige Domäne manifestierte (Abb. 3. 6., B). Die anteriore Expression war im Stadium des voll ausgebildeten Primitivstreifens auf das prächordale Endoderm fokussiert und persistierte dort auch während der Ausbildung der Kopffalte (HH6-HH7), (Abb. 3. 6., 
C, D). Zusätzlich fanden sich von diesen Stadien an $c S z l$-Transkripte auch im präkardialen Mesoderm (Abb. 3. 6., D). Zwischen dem Vier- und Zehn-Somitenstadium, wenn sich der Herzschlauch durch Zusammenwachsen des rechten und linken präkardialen Mesodermflügels bildet, war die $c S z l$-Expression im gesamten präkardialen Mesoderm nachweisbar (Abb. 3. 6., E, I).
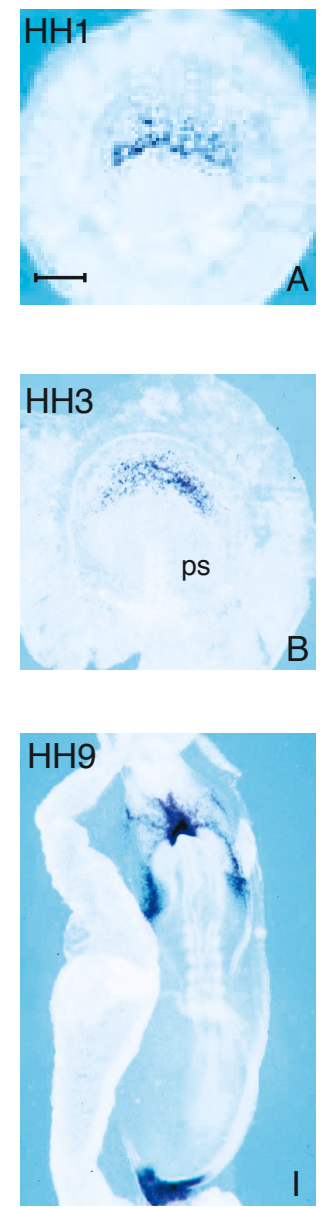
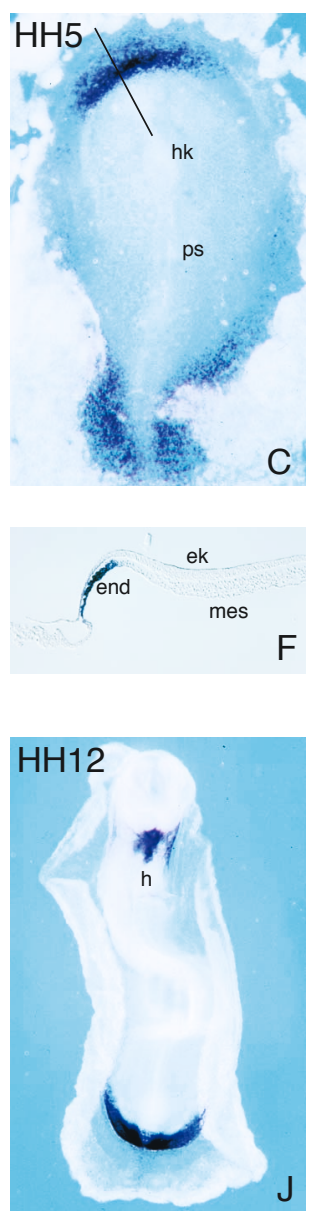
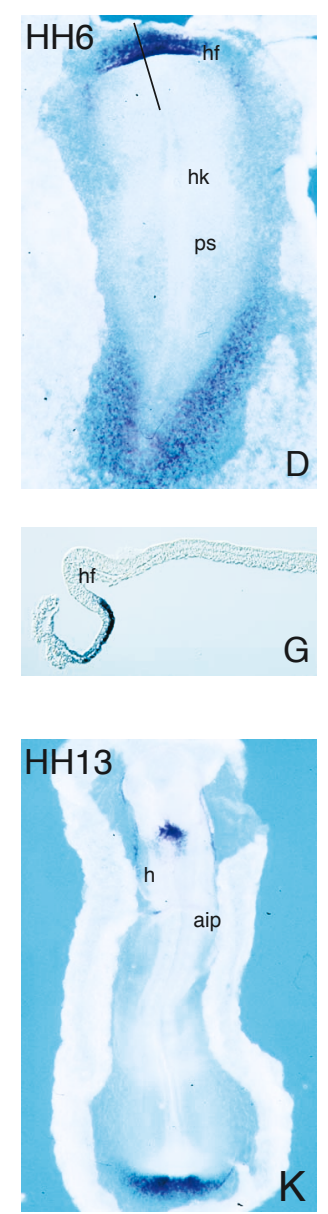
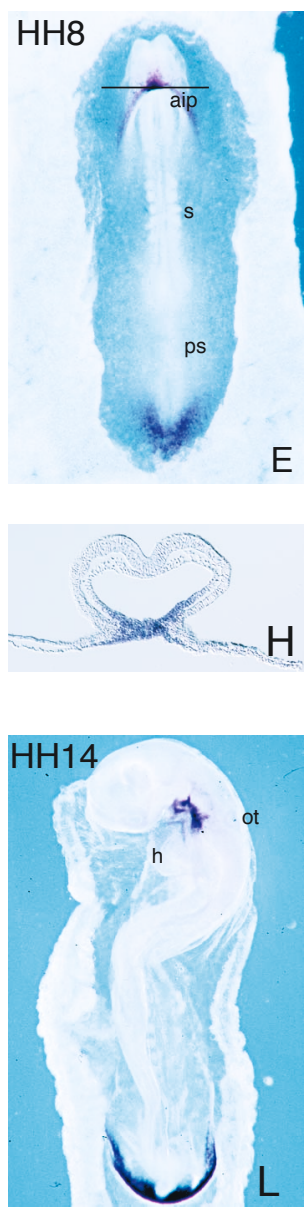

Abb. 3. 6.: Expression von $c S z l$ im Huhnembryo von der Eiablage bis zum Stadium HH14. (A) Zum Zeitpunkt der Eiablage wurde $c S z l$ im anterioren Hypoblast exprimiert. (B) Während der Entwicklung des Primitivstreifens blieb die $c S z l$-Expression im Hypoblast, wo sie vom definitiven Endoderm nach anterior geschoben wurde. (C) Im Kopffortsatzstadium ist $c S z l$ im anterioren Endoderm, vor der prächordalen Platte, nachweisbar; posterior ist Expression rechts und links vom Primitivstreifen zu sehen. (D) cSzl-Expression im Kopffaltenstadium (HH6); die Expression bleibt im anterioren Endoderm, außerdem sind cSzl-Transkripte im Mesoderm, das die Kopffalte flankiert, nachweibar. (E) Im Vier-Somitenstadium (HH8) ist $c S z l$ im anterioren Intestinalportal und im präkardialen Mesoderm exprimiert. Die posteriore Domäne fokussiert sich auf das kaudale Ende des Primitivstreifens. (F) Sagittalschnitt durch den Embryo in C. (G) Sagittalschnitt durch den Embryo in (D). (H) Transversalschnitt durch den Embryo in (E), auf Höhe des AIP. (I) Im Sechs-Somitensta-

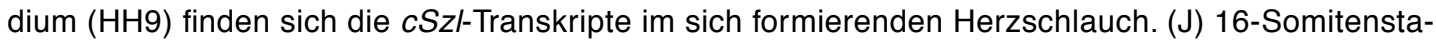
dium, die Expression beschränkt sich auf den anterioren Pol des Herzschlauches, im anterioren Intestinalportal wird $c S z /$ herunterreguliert; die posteriore Domäne nimmt ein scharf abgegrenztes, halbmondförmiges Areal ein. (K) 19-Somitenstadium, cSzl wird weiterhin stark im anterioren Pol des Herzschlauches und posterior vom Primitvstreifen exprimiert. (L) 22-Somitenstadium, der Embryo hat sich zur Seite gedreht, die Expression umschließt den Ausflußtrakt des Herzens. 
Abkürzungen: aip= anteriores Intestinalportal, end= Endoderm, ek= Ektoderm, h=Herz, hk=Hensenscher Knoten, kf=Kopffalte, mes=Mesoderm, ot=otisches Vesikel, ps=Primitivstreifen, $s=$ Somit. Der Messbalken entspricht in A und B $200 \mu \mathrm{m}$, in C-E un in I-L $500 \mu \mathrm{m}$.

In Schnitten durch einen, im Stadium HH8 auf $c S z l$-Transkripte untersuchten Embryo wurde die starke Expression im Bereich des anterioren Intestinalportals, die bis zum Stadium HH10 erhalten blieb, aber auch die schwächere Expression im präkardialem Mesoderm sichtbar (Abb. 3. 6., E, H). Mit der Fusion des Herzschlauches und seiner darauf folgenden Drehung, die in den Stadien HH12-HH14 stattfindet, blieben die cSzl-Transkripte auf den anterioren Pol beschränkt. Während dieser Stadien wurde $c S z l$ im anterioren Intestinalportal herunterreguliert. An Embryonen, deren Herzschlauch und angrenzende Aortenbögen im Stadium HH13 und HH16 mit einem Kunststoff ausgegossen wurden (Abb. 3. 8., A, B), wurde der Charakter dieser Expression besonders deutlich: $c S z l$ war in einem Ring exprimiert, der den anterioren Pol des Herzschlauches umgab. In Transversalschnitten eines HH14-Embryos durch diesen Bereich waren die $c S z l$-Transkripte zum einen am Pharynxboden, vor allem aber am Übergang vom somatischen Mesoderm zum Myokard des Aortensacks nachweisbar (Abb. 3. 7., B, C). Transversalschnitte durch diese Expressionsdomäne im Stadium HH18 zeigten cSzl-Transkripte im Mesoderm, das den Aortensack umgab. Weiterhin fand sich $c S z l$-Expression in der kaudalen Wand des Trunkus arteriosus, von wo sich die Expressionsdomäne in zwei Flanken in der dorsalen Wand des Perikardialraumes am vierten Kiemenbogen erstreckte. Die Expression um den Trunkus arteriosus persistierte bis zum Stadium HH24, wobei die Expressionsdomäne zwischen Stadium HH20 und HH25 zunehmend kleiner wurde und sich weiter nach kaudal verlagerte. Im Stadium HH23 umlagerte die Expressionsdomäne noch hufeisenförmig den Aortensack am Übergang zu den Aortenbögen. Die Domäne war rostral geschlossen und an den kaudalen Ausläufern, auf Höhe des sechsten Aortenbogens, verstärkt. In diesem späteren Stadium blieb die Expression auf die dorsale Perikardialwand beschränkt. Im Stadium HH24, kurz vor Einsetzen der Septierung des Trunkus arteriosus durch Zellen der kardialen Neuralleiste, wurde die $c S z l$-Expression deutlich herunterreguliert (Abb. 3. 8., C). Im Präparat eines HH24-Embryos, dessen Gefäße ebenfalls mit Kunststoff ausgegossen wurden, waren die letzten Spuren der Expression am Trunkus arteriosus zwischen dem vierten und dem sechsten Aortenbogen an ihrer Einmündung in den Trunkus arteriosus zu finden. cSzl-positive Zellen 
reihten sich in einer Linie entlang des Trunkus arteriosus auf. Dieses ist das Areal, in dem einwandernde Zellen der kardialen Neuralleiste den Trunkus arteriosus in Aorta ascendens und Pulmonararterie trennen (Abb. 3. 8., C).
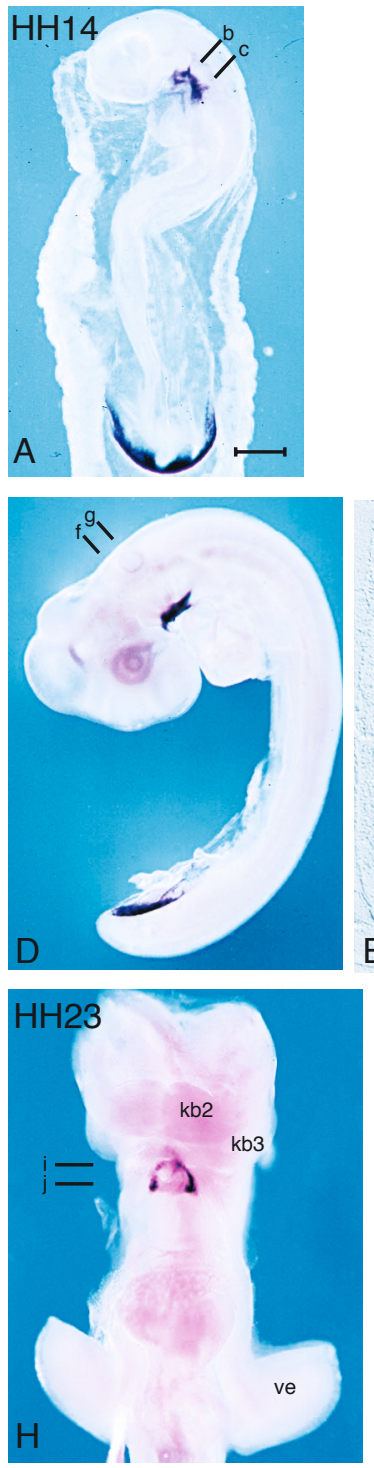
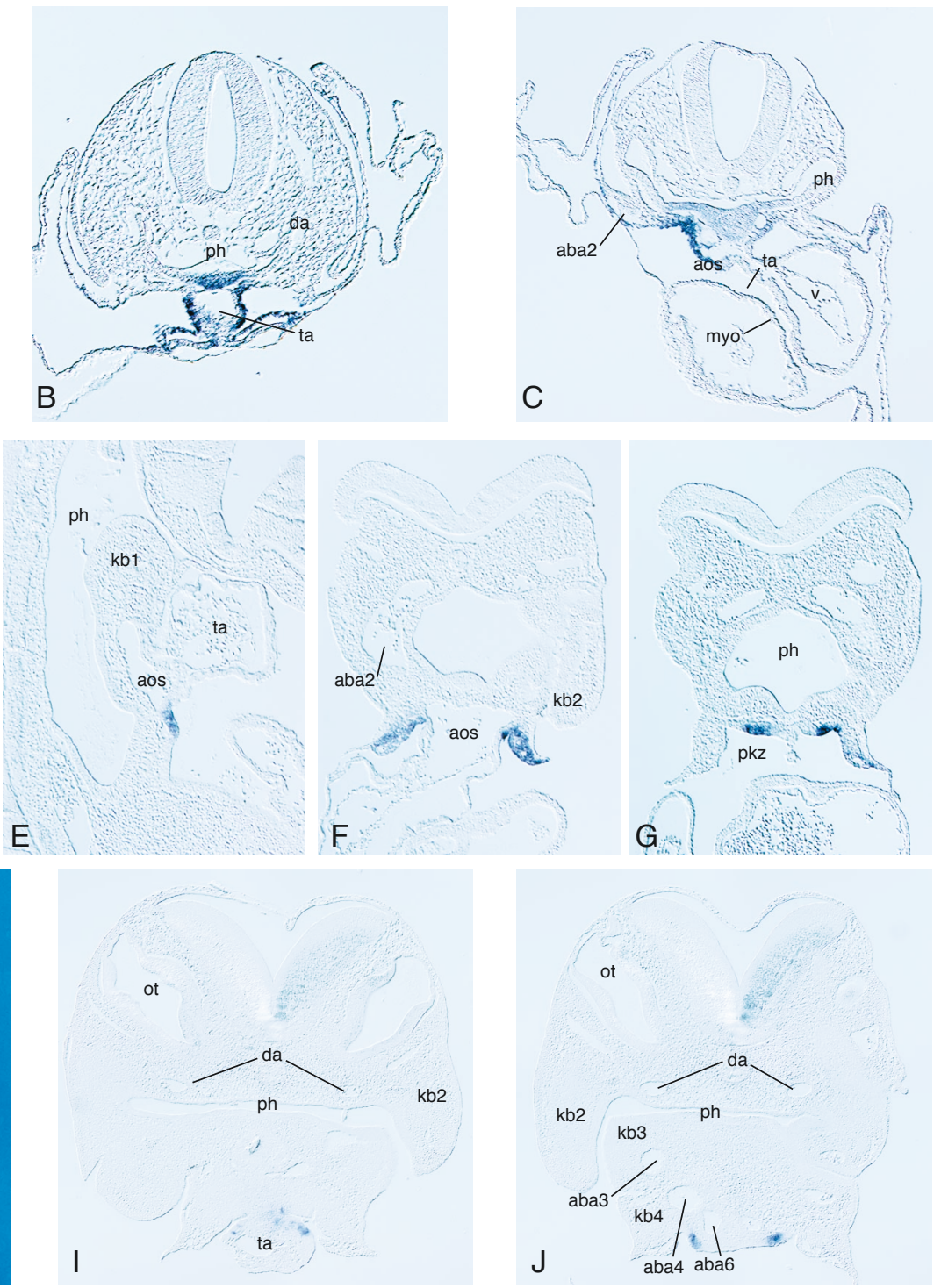

C
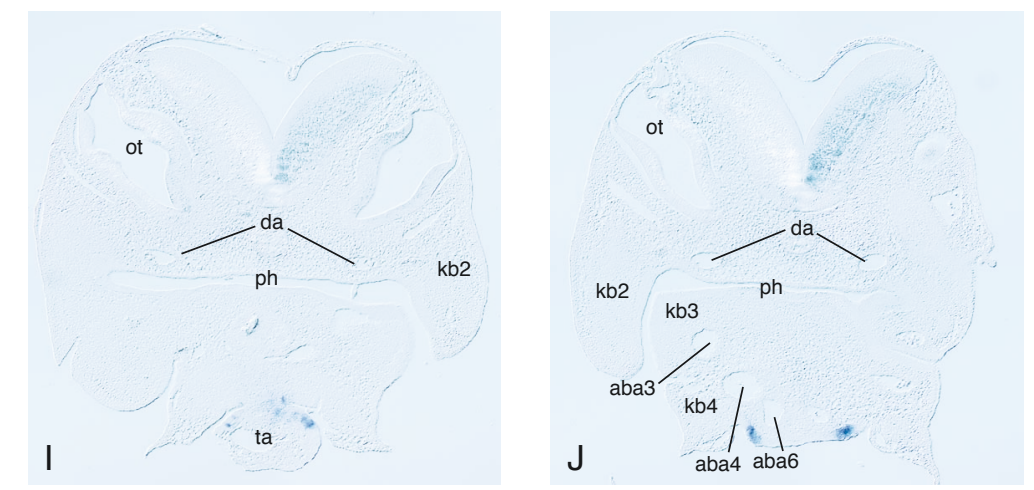

Abb. 3. 7.: cSzl-Expression in späteren Embryonalstadien. (A) HH14, Beschreibung siehe Abb. 3. 6., (L). (B) Transversalschnitt durch den kranialen Beginn der cSzl-Expression am arteriellen Pol des Herzens. cSzl-Transkripte sind am Pharynxboden und an den Wänden des Trunkus arteriosus nachzuweisen. (C) Transversalschnitt durch die cSzl-Expression am arteriellen Pol des Herzens, auf Höhe der zweiten Aortenbogenarterie. $c S z l$ ist im splanchnischen Mesoderm im Bereich des Aortensacks exprimiert. (D) CSzI-Expression im Stadium HH17, die Balken geben die Schnittebenen der Abbildungen (F) und $(G)$ an. (E) Sagittalschnitt auf Höhe des Trunkus Arteriosus. cSzl ist in der kaudalen Wand des Aortensacks. (F) Transversalschnitt durch die anteriore cSzl-Expressionsdomäne auf Höhe der zweiten Aortenbogenarterie. Im splanchnischen Mesoderm, das den Aortensack flankiert, ist $c S z l$ stark exprimiert. (G) Transversalschnitt auf Höhe des vierten Kiemenbogens. Die kaudalen Ausläufer der cSzl-Expression sind dargestellt. Die Transkripte sind in der Wand zum perikardialen Zölom, das der vierten Aortenbogenarterie unterliegt, nachweisbar. $(H)$ Aufsicht auf einen HH23 Embryo, dem zur besseren Darstellbarkeit der cSzl-Expressionsdomäne der Kopf zwischen erstem und zweiten Kiemenbogen und das Herz abpräpariert wurden. Die Expressionsdo- 
mäne umgibt den Ausflußtrakt hufeisenförmig und ist kaudal geöffnet. Gegenüber den jüngeren Stadien ist sie schwächer. (I) Transversalschnitt auf Höhe des zweiten Kiemenbogens. cSzl-Transkripte sind am dorsalen Trunkus arteriosus lokalisiert, insgesamt ist die Expression abgeschwächt. (J) Transversalschnitt auf Höhe des vierten Kiemenbogens. Die beiden kaudalen Ausläufer der Expressionsdomäne unterliegen der sechsten Aortenbogenarterie. Abkürzungen: aba=Aortenbogenarterie, aos=Aortensack, da=dorsale Aorta, $k b=$ Kiemenbogen, ot=otisches Vesikel ph=Pharynx, ta $=$ Trunkus arteriosus, ve $=$ Vorderextremität. Der Balken in (A) entspricht $500 \mu \mathrm{m}$ in (A) und (D) und $750 \mu \mathrm{m}$ in $(\mathrm{H})$.

Neben der anterioren Expression waren cSzl-Transkripte auch in einer zweiten, posterioren Expressionsdomäne nachzuweisen. Diese Expression war zuerst im Stadium HH3 posterior vom Primitivstreifen zu beobachten. Während der gesamten Gastrulation blieb die Expression im Mesoderm beidseitig des posterioren Primitivstreifens erhalten. Im weiteren Verlauf der Embryogenese verstärkte sich die Expression an der kaudalen Spitze des Embryos und bildete eine scharf abgegrenzte Expressionsdomäne. Bis in die Stadien HH22-HH23 war cSzl im Bereich der Schwanzspitze und am Saum distal der Hinterextremitätenanlagen exprimiert.

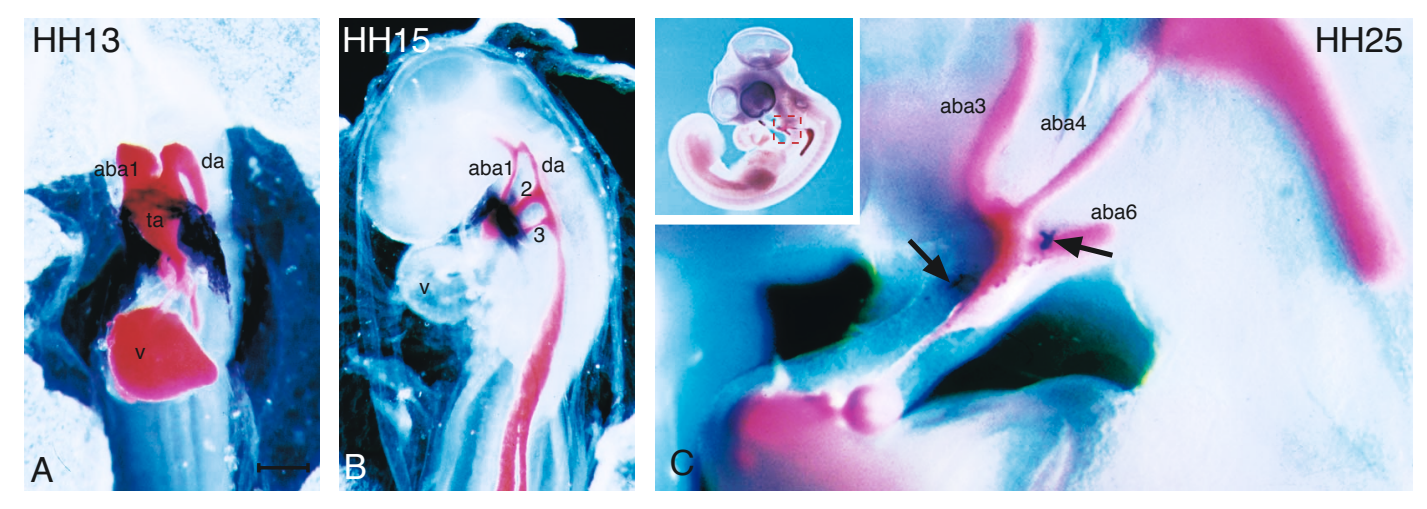

Abb. 3. 8.: cSzl-Expression und Formation der Aortenbogenarterien. In allen abgebildeten Embryonen wurde das Herz und die arteriellen Hauptgefäße mit Kunstoff ausgepritzt und darauf folgend eine Expressionsanalyse für $c S z l$ durchgeführt. (A) Embryo im 19-Somitenstadium (HH13). Die $c S z$-Expression umlagert den Trunkus arteriosus. (B) Stadium HH15, cSzl ist am Aortensack, im Bereich der Einmündung der Aortenbogenarterien, exprimiert. (C) Stadium HH25, cSzl wird herunterreguliert. Die letzten $c S z$-exprimierenden Zellen finden sich zwischen der Aortenbogenarterie 4 und 6, im Bereich der Septierung des Ausflußtraktes (siehe Pfeile). Abkürzungen: aba=Aortenbogenarterien, da=Dorsale Aorta, ta=Trunkus Arteriosus, v=Ventrikel. Der Messbalken in (A) entspricht $200 \mu \mathrm{m}$ in (A) und (B) und $100 \mu \mathrm{m}$ in (C).

\section{5. cSzl-Expression und kardiale Neuralleiste}

$c S z l$ war am Trunkus arteriosus in einem Bereich exprimiert, in den Zellen der kardialen Neuralleiste einwandern, bevor sie an den Differenzierungsvorgängen der späteren Kardiogenese beteiligt sind. Zunächst wurde untersucht, ob die Zellen der 
kardialen Neuralleiste, sobald sie den Trunkus arteriosus erreichen, einen Einfluß auf die $c S z l$-Aktivität haben.
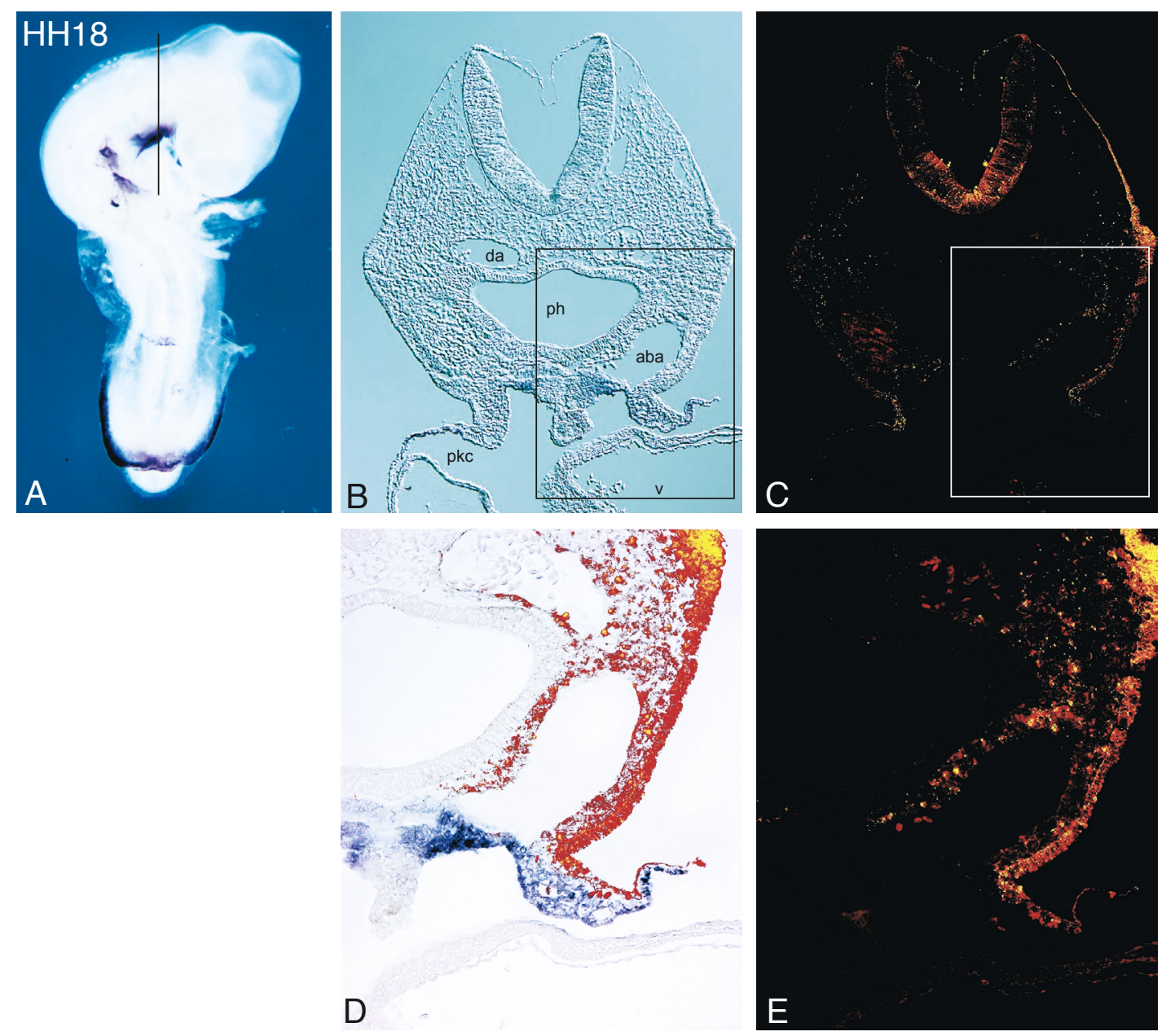

Abb. 3. 9.: cSzl-Expression und Neuralleistenzellen. (A) Embryo im Stadium HH18, dessen Neuralrohr im Stadium HH9 mit Dil fluoreszenzmarkiert wurde, und der darauf auf $c S z$-Expression analysiert wurde. (B) Transversalschnitt durch den in (A) abgebildeten Embryo. (C) Derselbe Schnitt wie in (B) unter Fluoreszenzlicht. Dil-markierte Zellen leuchten rot auf. Zu erkennen ist der Strom migrierender Neuralleistenzellen entlang der Aortenbögen. (D) Ausschnittsvergrößerung des Transversalschnittes aus (D), in dem über das histologische Bild das Fluoreszensbild (E) gelegt wurde. Die rot fluoreszierenden Neuralleistenzellen migrieren entlang der Aortenbögen an die cSzl-positiven Zellen heran. Abkürzungen: aba=Aortenbogenarterien, da=dorsale Aorta, ph=Pharynx, pkz=perikardiales Zölom.

Hierzu wurde der Kamm des dorsalen Neuralrohres zwischen der otischen Plakode und dem dritten Somitenpaar in Embryonen des Stadiums HH9 in ovo mit einer flammengeschärften Wolframnadel ablatiert und die Embryonen weiterinkubiert. Die Embryonen wurden im Stadium HH16/HH17 fixiert und auf $c S z l$-Transkripte durch Whole-Mount-in situ-Hybridisierung analysiert. In keinem der untersuchten Embryo- 
nen $(\mathrm{n}=6)$ konnte eine Veränderung der $c S z l$-Expression festgestellt werden. Zellen der kardialen Neuralleiste haben also keinen Einfluß auf die $c S z l$-Expression.

Um umgekehrt Indizien für einen möglichen Einfluß von $c S z l$ auf die Neuralleistenzellen zu erhalten, wurde das dorsale Neuralrohr in ovo kultivierter Embryonen im Stadium HH9 durch Mikroinjektion von DiI fluoreszenzmarkiert. Die Embryonen wurden im Stadium HH17/HH18 fixiert und für $c S z l$-Transkripte angefärbt. In histologischen Schnitten konnten dann die fluoreszierenden Neuralleistenzellen im Kontext der $c S z l$-Expression analysiert werden. In Abb. 3. 9. ist ein solcher Embryo dargestellt. Die Übereinanderlagerung des Fluoreszenzbildes mit der Hellfeldaufnahme, in der Histologie und Genexpression dargestellt sind, zeigte die Migration der Neuralleistenzellen entlang des Aortenbogens bis exakt in den Bereich der cSzlExpression. Das $c S z$-positive Mesoderm bildete eine Barriere für die Neuralleistenzellen und schien ihre Wanderung zu stoppen (Abb. 3. 9., D).

\section{6. Die Expression von Crescent im Vergleich zu cSzl}

$c S z l$ und Crescent divergieren in ihrer Aminosäurestruktur wesentlich von den übrigen Mitgliedern der Gruppe sekretierter Frizzled-ähnlicher Proteine und bilden daher im Verwandschaftsdiagramm dieser Proteine eine separate Gruppe (Abb. 3. 5., A). Ein Vergleich der $c S z l$ - und Crescent-Expression sollte Hinweise darüber geben, ob Crescent und $c S z l$ in einem ähnlichen Kontext in Musterbildungsprozessen involviert sind. Für diesen Vergleich wurden whole mount in situ-Hybridisierungen mit einer Crescent-RNA-Probe, den für cSzl gefärbten Embryonen gleichen Stadiums gegenübergestellt. Außerdem wurden Doppel-in situ-Hybridisierungen analysiert.

Wie $c S z l$ war auch Crescent schon vor Beginn der Gastrulation ventral exprimiert, aber schon hier waren Unterschiede in der Expression auffällig. Während $c S z l$ im primären Hypoblast exprimiert war, waren die Crescent-Transkripte im sekundären Hypoblast, posterior von der cSzl-Expressionsdomäne zu finden (Abb. 3. 10., A). Diese Zweiteilung der Expressionsdomänen blieb auch über die Gastrulation erhalten: Die $c S z l$-Transkripte fanden sich in der beschriebenen anterioren Domäne, Crescent war dagegen in einer Domäne im Endoderm und prächordalem Mesoderm exprimiert, die die gesamte Fläche des Embryos anterior vom Primitvstreifen einnahm (Abb. 3. 10., B+C). Auch im Kopffaltenstadium (HH6) war Crescent im Endoderm der Kopf- 
falte und im Endoderm, das dem axialen Mesoderm unterlag, exprimiert, während $c S z l$ auf das prächordale Endoderm des anterioren Intestinalportals beschränkt blieb (Abb. 3. 10., F+H). Eine in situ-Analyse, in der die Transkripte beider Gene angefärbt wurden, verdeutlichte die Beziehung beider Expressionsdomänen zueinander: $c S z l$ und Crescent waren in überlappenden, aber nicht identischen Expressionsdomänen exprimiert (Abb. 3. 10., F-K).

\section{Crescent-Expression}
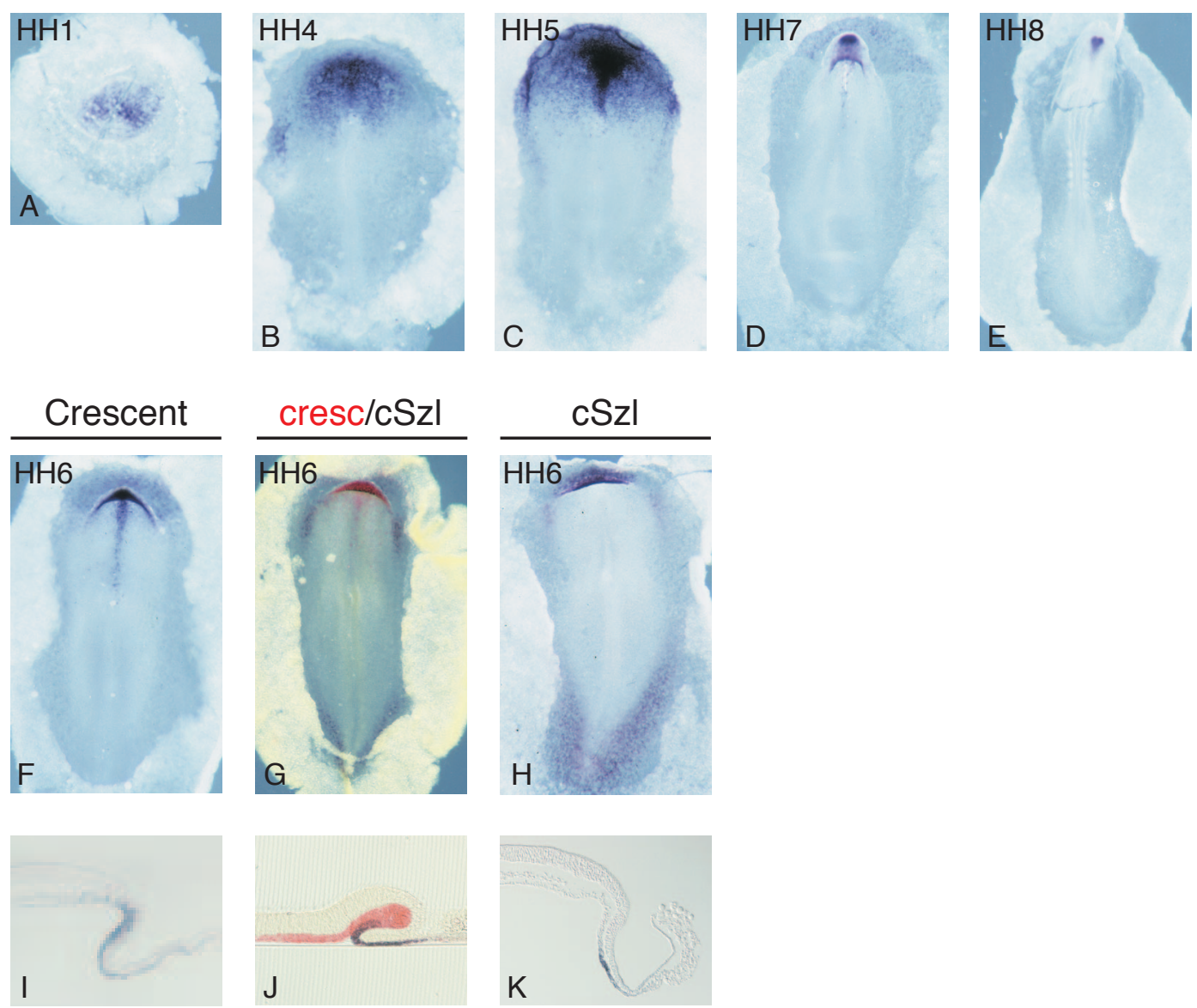

Abb. 3. 10.: Expression des sekretierten Wnt-Antagonisten Crescent. Alle abgebildeten Embryonen sind von ventral photographiert. (A) Crescent-Expression im Prägastrulastadium. Transkripte sind im Hypoblast, posterior von der cSzl-Expressionsdomäne, lokalisiert. (B) Stadium $\mathrm{HH} 4$; Crescent ist einer breiten endodermalen Domäne anterior vom Hensenschen Knoten exprimiert. (C) Kopffortsatzstadium (HH5): Die Crescent-Expression ist über das gesamte anteriore Endoderm nachweibar, wobei sie im Endoderm, das dem axialen Mesoderm unterliegt, verstärkt ist. (D) EinSomitenstadium (HH7): Crescent ist im Endoderm in der Kopffalte und schwächer im anterioren Darmportal exprimiert. Vereinzelte Crescent-positive Zellen sind auch im Endoderm unter dem Chordamesoderm zu erkennen. (E) Vier-Somitenstadium (HH8): Die Crescent-Expression beschränkt sich auf die prächordale Platte, einen Bereich, der frei ist von $c S z l$-Transkripten. $(\mathrm{F}-\mathrm{H})$ Vergleich von $c S z l-$ und Crescent-Expression im Kopffaltenstadium: (F) Crescent ist in der gesamten Kopffalte und im axialen Endoderm aktiv, cSzl dagegen nur im anterioren Endoderm $(H)$. (G) Doppel-in situ-Färbung von cSzl- und Crescent-Transkripten: Im anterioren Endoderm überlappen 
die cSzl- und Crescent-Expressionsdomänen. (I-K) Sagittalschnitte der in (F-H) abgebildeten Embryonen. Der Maßstab in (A) entspricht $300 \mu \mathrm{m}$ in (A) und $500 \mu \mathrm{m}$ in (B-H).

Im Vier-Somitenstadium (HH8) segregierten die Expressionsdomänen voneinander, cSzl blieb im anterioren Intestinalportal und im sich schließenden Herzschlauch, die Crescent-Expression beschränkte sich auf die prächordale Platte. Im Stadium HH10, wenn $c S z l$-Transkripte sich auf den anterioren Pol des primären Herzfeldes konzentrierten, schwächte sich die Crescent-Expression in der prächordalen Platte ab, bis im Stadium HH11 Crescent in der in situ-Analyse nicht mehr nachweisbar war.

\section{7. Experimente zur Funktion und Regulation von cSzl und Crescent}

Wnt-Signale sind zentral an einer Vielzahl embryologischer Prozesse beteiligt. So wird abhängig von Wnt-Signalen die Position und das Entwicklungsschicksal einer Zelle im Embryo definiert (Nordstrom et al., 2002). Genauso, wie das Wnt-Signal an Musterbildungsprozessen beteiligt ist, ist auch seine Modulation und Inhibition wichtig. Eine Vielzahl bisher klonierter Wnt-Antagonisten mit teilweise sehr klar definierten Expressionsdomänen verdeutlichen die Wichtigkeit dieses biologischen Prinzips. Eine Rolle der Inhibierung von Wnt-Signalen bei der Induktion kardialer Myozyten wurde in einer Studie von Martha Marvin und Andrew Lassar 2001 für Crescent gezeigt (Marvin et al., 2001). Da $c S z l$ während der Gastrulation, zum Zeitpunkt der kardialen Induktion, in einer mit Crescent überlappenden Expressionsdomäne zu finden und im weiteren Verlauf der Kardiogenese im Gegensatz zu Crescent im kardialen Mesoderm präsent war, wurde der Einfluß von $c S z l$ im Vergleich zu Crescent auf die Musterbildung im primären Herzfeld mit Hilfe von Transplantations- und Explantkulturexperimenten untersucht.

\section{7. 1. Der Einfluß von BMP2 auf die $c$ Szl- und Crescent-Expression}

\section{7. 1. 1. BMP2 induziert $c S z l$, aber nicht Crescent}

$B M P 2$ ist während der Gastrulation und frühen Neurulation im kardialen Halbmond mit $c S z l$ synexprimiert, eine weitere Expressionsdomäne hat es im Primitivstreifen. In einer Vielzahl von Studien konnte gezeigt werden, daß BMP2 die Transkriptionsfak- 
toren Nkx2.5 und GATA4 aktiviert, die bei der Differenzierung kardialer Myozyten eine zentrale Rolle spielen (Andree et al., 1998; Schlange et al., 2000; Schultheiss et al., 1997). Um zu untersuchen, inwiefern auch $c S z l$ und Crescent einer Kontrolle durch $B M P 2$ unterliegen, wurden Heparin-Acrylamid Kugeln, die mit $B M P 2$ in einer Konzentration von $0,2 \mu \mathrm{g} / \mu \mathrm{l}$ beladen waren, an anterior-laterale Positionen in HH4Embryonen, die nach New kultiviert wurden, transplantiert. Die Embryonen wurden im Stadium HH6-HH8 fixiert und auf $c S z l$-, bzw. Crescent-Expression analysiert. Alle mit BMP2-Kugeln operierten Embryonen, die auf $c S z l$ gefärbt wurden $(\mathrm{n}=8)$, zeigten eine ektopische Aktivierung oder Erweiterung der $c S z l$-Domäne (Abb. 3. 11., B+C). In Embryonen, die auf Crescent analysiert wurden, war dagegen keine Veränderung der Expression ( $\mathrm{n}=15)$ nachzuweisen (Abb. 3. 11., D+E). Kontrollembryonen, in die mit PBS/BSA beladene Kugeln implantiert wurden $(\mathrm{n}=10)$, zeigten keine Veränderung sowohl der $c S z l$, als auch der Crescent-Expression. BMP2 war also ausreichend für die Expression von $c S z l$.
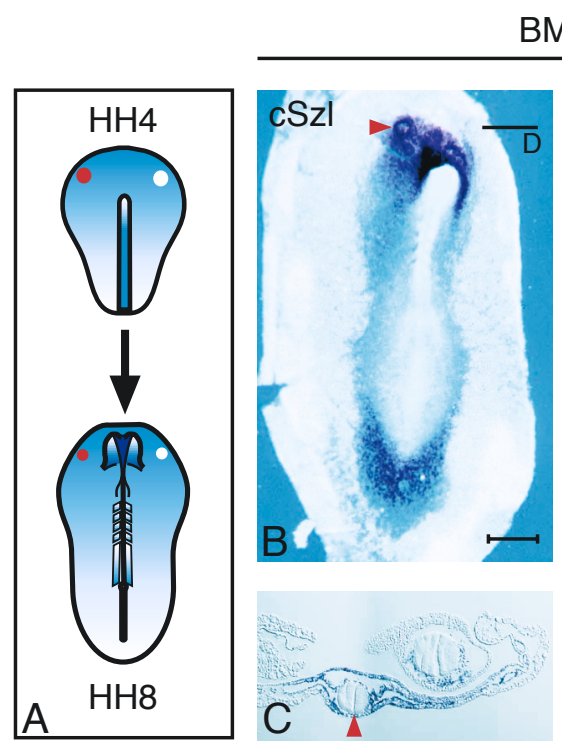

BMP2

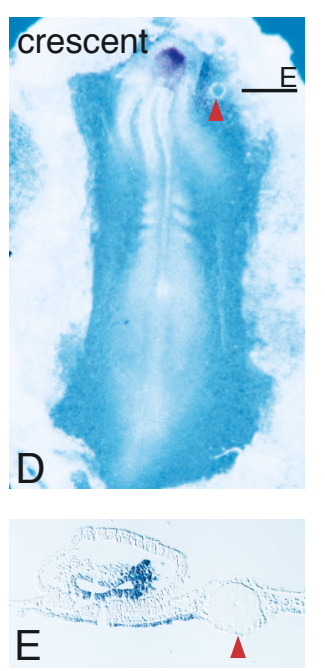

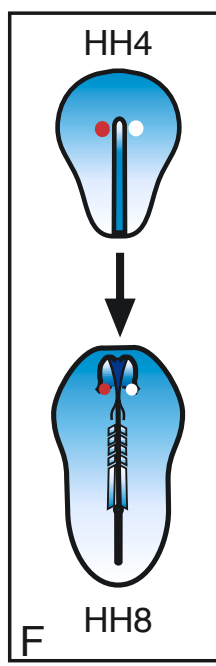

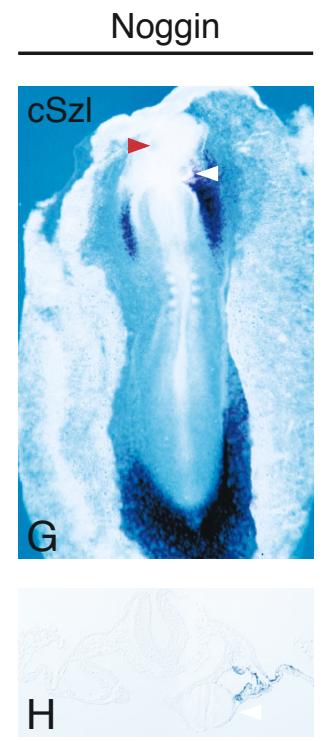

Abb. 3. 11.: Transplantationsexperimente zur Regulation von $c S z l$ durch $B M P 2$. (A) Operationsschema für die in (B) und (D) dargestellen Embryonen: Mit Protein beladene und Kontrollkugeln wurden im Stadium HH4 in den anterioren Embryo zwischen Endoderm und Ektoderm transplantiert. Im Stadium HH8 wurden die Embryonen fixiert und analysiert. (B) Embryo, der auf die in (A) dargestellte Weise operiert und auf die Aktivität von $C S z l$ getestet wurde. Im Bereich der BMP2Quelle wird $c S z$-Expression ektopisch aktiviert. (C) Transveralschnitt auf Höhe der BMP2-Quelle. $\mathrm{Zu}$ erkennen sind die $c S z l-p o s i t i v e n$ Zellen um die BMP2-Kugel herum. (D) Embryo, in den eine ektopische BMP2-Quelle transplantiert wurde, und der auf die Aktivität von Crescent analysiert wurde. Im Gegensatz zu cSzl wird Crescent nicht ektopisch aktiviert. (E) Transversalschnitt auf Höhe der BMP2-Kugel: Es ist keine ektopische Crescent-Aktivität im Bereich der BMP2-Quelle zu erkennen. (F) Operationsschema für den in (G) dargestellten Embryo: Die Kugeln wurden im Stadium $\mathrm{HH} 4$ so an den Primitivstreifen gesetzt, daß sie im Stadium HH8 im Bereich des anterioren 
Intestinalportals, in der endogenen $c S z$-Expressionsdomäne, lagen. (G) Embryo, in den eine mit Noggin-Protein beladene Heparin-Akrylamidkugel sowie eine Kontrollkugel in die endogene cSzlExpressionsdomäne transplantiert wurde. Im Bereich der Noggin-Quelle ist die Expression von $c S z I$ stark herunterreguliert. $(\mathrm{H})$ Transversalschnitt auf Höhe der Kontrollkugel. Um die Kontrollkugel herum ist $c S z l$ normal exprimiert. Die roten Pfeile zeigen die Position der Proteinquelle an, die weiBen Pfeile die Lage der Kontrollkugeln. Der Balken in (B) entspricht $500 \mu \mathrm{m}$ in (B), (D) und (G).

\section{7. 1. 2. Noggin inhibiert die cSzl-Expression}

Um zu testen, ob $B M P 2$ auch notwendig für die Aktivität von $c S z l$ ist, mußte die endogene $B M P$-Aktivität unterbunden werden. Hierfür wurden Heparin-AkrylamidKugeln, die mit dem BMP-Antagonisten Noggin (Konzentration 0,5 $\mu \mathrm{g} / \mu \mathrm{l}$ ) beladen waren, in HH4 Embryonen, die in der New-Kultur kultiviert waren, transplantiert. Die Kugeln wurden an den Primitivstreifen, posterior vom Hensenschen Knoten, transplantiert. Dort plaziert, kamen sie im Stadium HH8 mit großer Wahrscheinlichkeit in den Bereich des primären Herzfeldes und des anterioren Intestinalportales, den Arealen endogener BMP2- und $c S z l$-Expression. Auf die kontralaterale Seite wurden in BSA inkubierte Kontrollkugeln implantiert. Die Analyse der $c S z l$-Expression zeigte, daß in allen untersuchten Fällen $(\mathrm{n}=7)$ die $c S z l$-Expression um die Noggin-Quelle herum herunterreguliert wurde (Abb. 3. 11., G+H). BMP-Signale sind also notwendig, um $c S z l$ zu aktivieren, die Aktivität von Crescent wurde dagegen unabhängig von $B M P$-Signalen reguliert.

\section{7. 2. Der Einfluß von Fibroblasten-Wachstumsfaktoren auf $c$ Szl- und Crescent-Expression}

\section{7. 2. 1. FGF8 inhibiert $c S z l$, aber nicht Crescent}

FGF8 ist vom Kopffaltenstadium an im Pharynxendoderm, das dem kardialen Mesoderm unterliegt, sowie im Primitivstreifen aktiv. Um zu testen, ob $F G F 8$ regulativ auf die Expression von $c S z l$ Einfluß nimmt, wurden Heparin-Acrylamidkugeln mit $F G F 8$ in einer Konzentration von $0,5 \mu \mathrm{g} / \mu \mathrm{l}$ inkubiert und in HH4-Embryonen an den Primitvstreifen transplantiert, so daß die $F G F$-Quelle während der Kopffaltenbildung in die endogene $c S z l$-Expressionsdomäne gelangen konnte. Auf die kontralaterale Seite des Primitivstreifens wurden Kontrollkugeln, die in BSA inkubiert wurden, implan- 
tiert. Die Embryonen wurden bis zum Stadium HH8 inkubiert, fixiert und auf die Expression von $\mathrm{cSzl}$ bzw. Crescent getestet. Alle derart operierten Embryonen, die auf $c S z l$ getestet wurden $(\mathrm{n}=8)$, zeigten eine starke Reduktion der endogenen $c S z l$-Expression (Abb. 3. 12., B+C). Die Crescent-Expression wurde durch eine FGF8-Quelle nicht verändert (n=3; Abb. 3. 12., D).

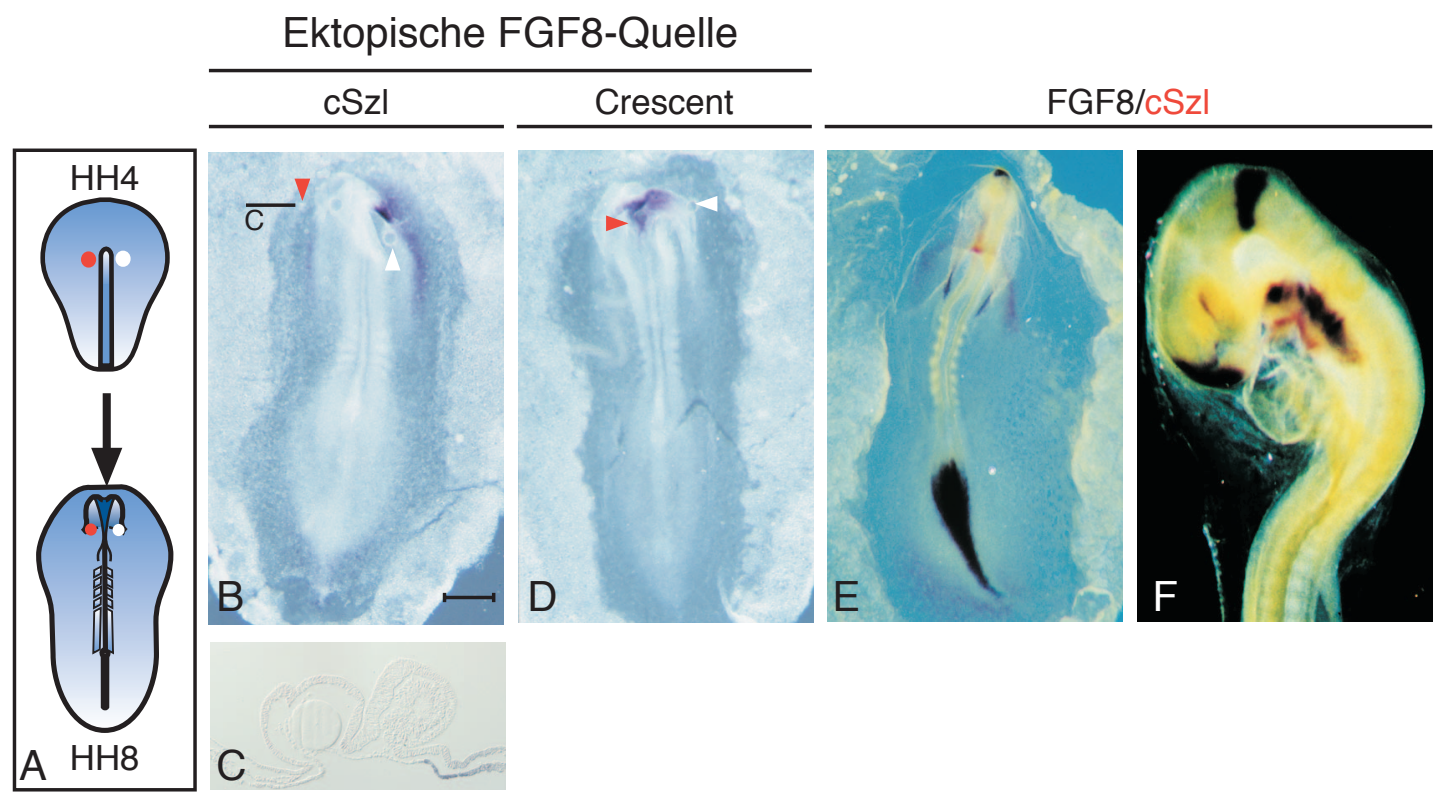

Abb. 3. 12:: FGF8 und cSzI/Crescent-Regulation. (A) Operationsschema: Mit FGF8-Protein getränkte Heparin-Akrylamidkugeln wurden im Stadium $\mathrm{HH} 4$ so an den Primitivstreifen gesetzt, daß sie im Vier-Somitenstadium ( $\mathrm{HH} 8$ ) in der endogenen $c S z l-$, bzw Crescent-Expressionsdomäne zu liegen kamen, kontralateral wurden in BSA getränkte Kontrollkugeln an den Primitivstreifen operiert. (B) Embryo, in dessen endogene $c S z l$-Expressionsdomäne eine FGF8-Quelle (roter Pfeil) und eine Kontrollkugel (weißer Pfeil) operiert wurde. Um die FGF8-Quelle herum ist $c S z l$ stark herunterreguliert, während an der Kontrollkugel die Expression unverändert ist. (C) Transversalschnitt durch die FGF8-Kugel. Mesoderm und Endoderm bilden sich um die Kugel herum korrekt aus, nur ist an der Kugel keine cSzl-Expression nachweisbar. (D) Embryo, in den eine ektopische FGF8-Quelle transplantiert wurde, und der auf Crescent-Expression analysiert wurde. Die Crescent-Expression wurde durch FGF8 nicht verändert. $(\mathrm{E}+\mathrm{F})$ Doppel-in situ-Hybridisierung für $c S z l$ (rot) und FGF8 (schwarz). (E) Embryo im Stadium HH12: FGF8 ist im Primitivstreifen und im pharyngealen Endoderm exprimiert. Hiervon deutlich abgesetzt ist die $c S z$-Expression, die einerseits den Primitivstreifen flankiert, andererseits im Endoderm des anterioren Intestinalportales und im kardialen Mesoderm nachweisbar ist. Noch deutlicher wird die klare Trennung der FGF8- und cSzl-Expressionsdomänen in (F): FGF8 ist in den Kiemenbögen, $c S z l$ im angrenzenden, sekundären Herzfeld exprimiert. Der Balken in (B) entspricht $500 \mu \mathrm{m}$ in (B), (D) und (E), $750 \mu \mathrm{m}$ in (F).

\section{7. 2. 2. FGF8 und $c S z l$ sind in voneinander getrennten Arealen exprimiert}

Um die biologische Signifikanz der Repression der $c S z l$-Expression durch $F G F 8$ zu belegen, wurde eine Doppel-Whole-Mount-in situ-Analyse der FGF8- und cSzlExpression durchgeführt. Die FGF8-Expressionsdomäne war von der $c S z l$-Expressi- 
onsdomäne in allen untersuchten Stadien stets eindeutig getrennt (Abb. 3. 12., E+F). Die räumliche Beziehung der beiden Expressionsdomänen zueinander unterstützen zusammen mit den Transplantationsexperimenten den inhibitorischen Einfluß des FGF8-Proteins auf die $c S z l$-Expression.

\section{7. 2. 3. FGF8 inhibiert $c S z l$ direkt und spezifisch}

In einem nächsten Transplantationsexperiment sollte geklärt werden, ob die Inhibition der $c S z l$-Expression direkt durch $F G F 8$ vermittelt wurde, oder ob der Effekt auf $c S z l$ aus einer Inhibierung des $c S z l$-Aktivators $B M P 2$ resultierte. Hierzu wurden Embryonen, in die eine $F G F 8$-Quelle in den Bereich der endogenen BMP2-Expression implantiert worden war, auf BMP2-Expression analysiert. Von den 11 auf diese Weise untersuchten Embryonen konnte bei keinem Exemplar eine Veränderung der BMP2Expressionsdomäne beobachtet werden (nicht abgebildet). Dieses Ergebnis belegte, daß FGF8 direkt inhibierend auf die Expression von $c S z l$ wirkte. Die Spezifität des FGF8-Signals wurde getestet, indem anstelle von $F G F 8$ der sehr ähnliche Faktor FGF4 in die $c S z l$-Expressionsdomäne transplantiert wurde. Die Embryonen wurden im vier bis sechs Somitenstadium (HH8/HH9) fixiert und auf $c S z l$-Expression analysiert. Im Gegensatz zu FGF8 konnte in den mit FGF4 operierten Embryonen in keinem Fall ( $\mathrm{n}=12)$ eine Reduktion der $c S z l$-Domäne beobachtet werden.

Insgesamt zeigten die Transplantationsexperimente, daß cSzl direkt und spezifisch von FGF8 inhibiert wurde. Auf die Expression von Crescent nahm FGF8 dagegen keinen Einfluß.

\section{7. 3. Die Wirkung von FGF8-Signalen auf die Expression kardialer Markergene}

Da $F G F 8$ inhibierend auf die $c S z l$-Expression wirkte, die BMP2-Expression aber nicht veränderte, konnte eine Inhibition der Expression von Nkx2.5 und GATA4 durch $F G F 8$ als indirektes Indiz für eine Beteiligung von $c S z l$ an ihrer Regulation bewertet werden. Wiederum wurden mit $F G F 8$ beladene Heparin-Akrylamidkugeln derart in HH4 Embryokulturen implantiert, daß die Kugeln im Stadium HH8/HH9 in den endogenen Expressionsdomänen von $N k x 2.5$ bzw. GATA4 positioniert waren. Auf die 
kontralaterale Seite desselben Embryos wurden in BSA inkubierte Kontrollkugeln implantiert. Der Einfluß von FGF8 auf die GATA4- und $N k x 2.5$-Expression wurde durch in situ-Hybridisierung analysiert. Tatsächlich wurde die GATA4-Expression durch FGF8 herunterreguliert (n=4; Abb. 3. 13., B). Die endogene Nkx2.5-Domäne wurde durch die ektopische FGF8-Quelle nicht verändert (n=12; Abb. 3. 13., C).

\section{Ektopische FGF8-Quelle}

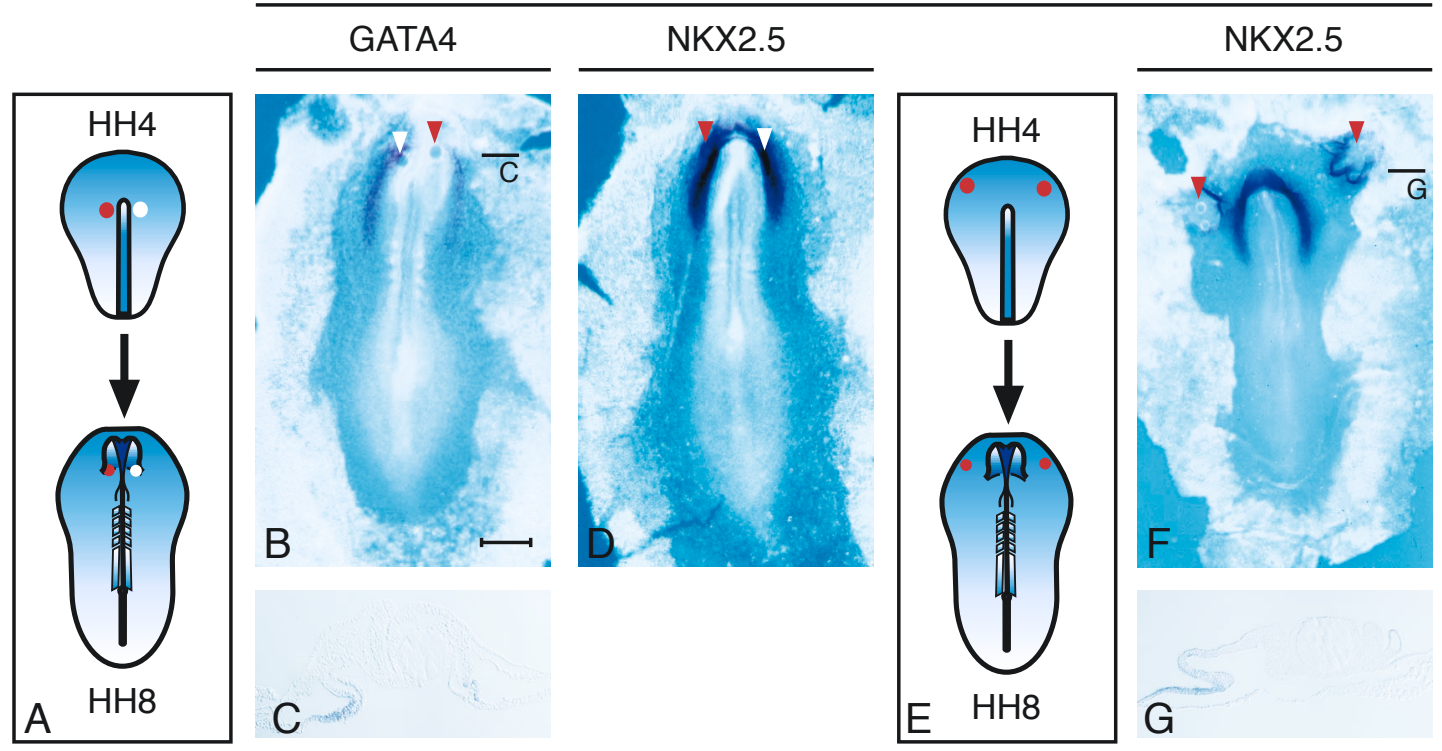

Abb 3. 13.: Die Wirkung von FGF8 auf die Expression kardialer Markergene. (A) Operationsschema für die in (B) und (D) dargestellten Embryonen: Eine mit FGF8-beladene Kugel, sowie auf der kontralateralen Seite eine Kontrollkugel, wurden in einen Stadium HH4-Embryo an den Primitivstreifen operiert, so daß sie im vier-Somitenstadium $(\mathrm{HH} 8)$ in der endogenen Expressionsdomäne der kardialen Markergene GATA4 und Nkx2.5 waren. (B) Embryo, der auf GATA4-Expression analysiert wurde. Im Bereich der FGF8-Quelle (roter Pfeil) ist GATA4 herunterreguliert. (C) Transversalschnitt auf Höhe der FGF8-Quelle. (D) Expression von Nkx2.5 nach Applikation einer ektopischen FGF8-Quelle in das Herzfeld. Die FGF8-Quelle hat keinen Einfluß auf die endogene Nkx2.5Expression. (E) Operationsschema für den in $\mathrm{F}$ abgebildeten Embryo: Mit FGF8 beladene Kugeln wurden an die anterior-laterale Grenze von area opaca und area pellucida transplantiert und im Stadium HH8 fixiert und analysiert. (F) Analyse der durch FGF8 ausgelösten morphologischen Veränderungen auf $N k x 2.5$-Expression. $N k x 2.5$ ist am Rand der induzierten Strukturen aktiviert; die roten Pfeile zeigen die Position der FGF8-Quellen. (G) Transversalschnitt durch die ektopische Nkx2.5Expression. Die Nkx2.5-positiven Zellen sind am Rand der durch FGF8 ausgelösten Induktion lokalisiert. Der Balken in (B) entspricht $500 \mu \mathrm{m}$ in (B), (D) und (F).

\section{7. 4. FGF8- und $c W n t 8 c$-Expression}

FGF8, FGF4 und $c W n t 8 c$ sind während der Gastrulation im Primitivstreifen und in der posterioren Neuralplatte coexprimiert. Es wurde daher, ebenfalls über Transplantationen durch Heparin-Akrylamid Kugeln, die mit FGF8 inkubiert waren, unter- 
sucht, ob ein FGF-Signal nicht nur durch die Inhibierung des anterioren anti-WntSignals $c S z l$, sondern auch direkt durch die Aktivierung von $W n t$-Signalen für die Etablierung des posterioren, nicht-kardialen Mesoderms zuständig ist. Zunächst wurde die FGF8-Quelle direkt so in die Embryokultur transplantiert, daß sie sich im Stadium HH8 im kardialen Mesoderm oder im AIP befand. Die Embryonen wurden auf die ektopische Aktivierung von $c W n t 8 c$ untersucht. In keinem der analysierten Embryonen ( $\mathrm{n}=9$ ) konnte eine Aktivierung von $c W n t 8 c$ um die FGF8-Quelle herum beobachtet werden (Abb. 3. 14., B).

\section{Ektopische FGF8-Quelle}

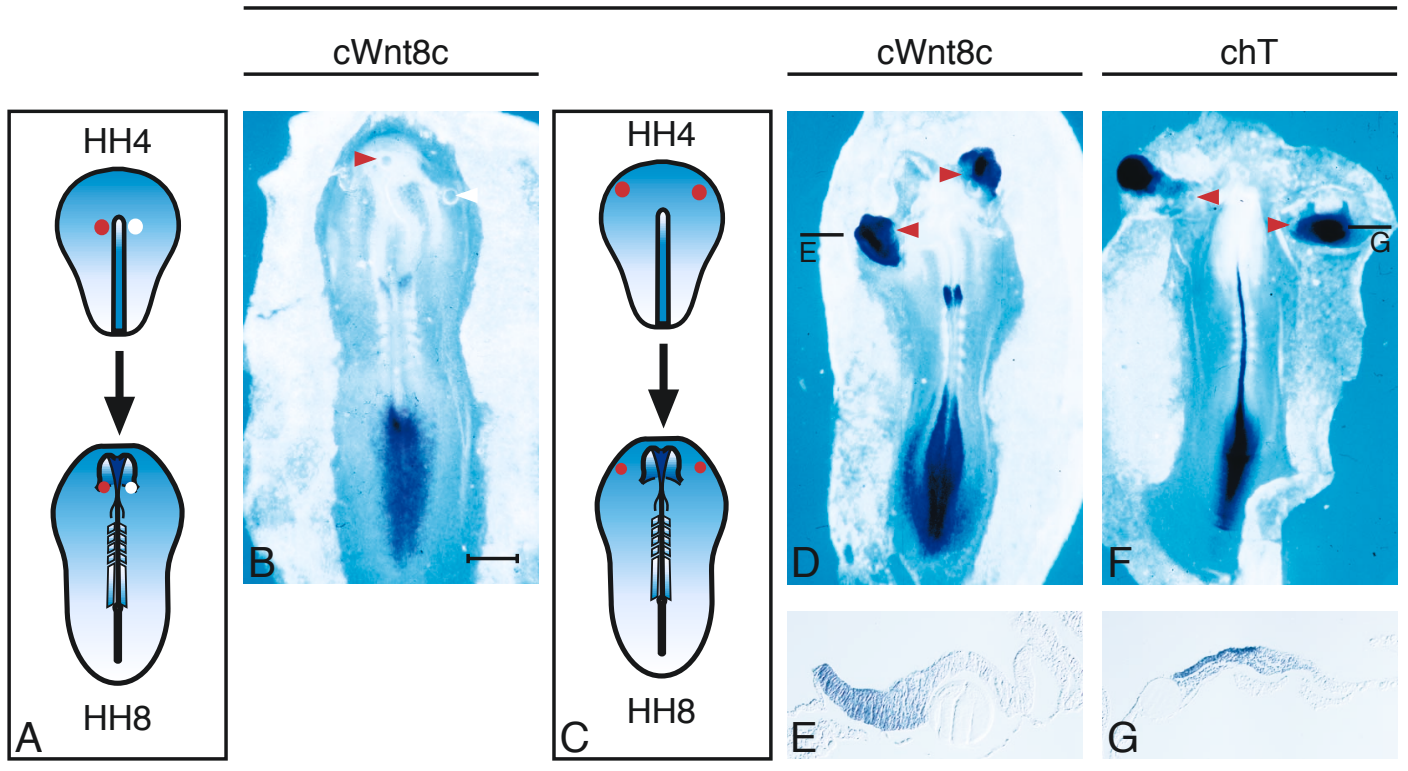

Abb. 3. 14.: Der Einfluß von FGF8 auf die Expression von $c W n t 8 c$ und $c h T$. (A) Operationsschema für den in B dargestellten Embryo. (B) Eine FGF8-Quelle im anterioren Intestinalportal induziert kein ektopisches cWnt8c. (C) Operationsschema für die in (D) und (E) abgebildeten Embryonen. Die FGF8-Quelle wurde anterior-lateral an den Übergang von area opaca zu area pellucida transplantiert, die Embryonen wurden im Stadium $\mathrm{HH} 8$ fixiert und analysiert. (D) Embryo mit starker ektopischer cWnt8c-Induktion um die FGF8-Quelle; die FGF8-Quellen sind durch die roten Pfeile markiert. (E) Transversalschnitt durch eine Induktion. Das FGF8-Protein löst sowohl eine Neuralisierung des Ektoderms, als auch die Induktion $c W n t 8 c$ positiver mesodermaler Zellen aus. (F) Embryo mit starken, durch FGF8 ausgelösten ektopischen Induktionen, der auf chTExpression analysiert wurde. Die Induktionen exprimieren $c h T$ stark. (G) Transversalschnitt durch die Induktion. Swohl ektodermale, als auch die mesodermalen Zellen im Bereich der Induktion exprimieren $c h T$. Der Balken in (B) entspricht $500 \mu \mathrm{m}$ in (B, D) und (F).

Wenn eine $F G F 8$-Quelle in einem HH4-Embryo an die anterior-laterale Grenze zwischen area opaca und area pellucida transplantiert wurde, wurden starke morphologische Veränderungen induziert. Diese Induktionen wurden bisher stets auf ihren neuralen Charakter untersucht. Tatsächlich beobachteten verschiedene Autoren die 
ektopische Aktivierung neuraler Marker (Sox2, Sox3) durch FGF8 (Storey et al., 1998; Streit et al., 2000). Neun Embryonen mit solchen, durch FGF8 ausgelösten Induktionen wurden auf die Aktivität von $c W n t 8 c$ getestet. Dabei zeigte sich, daß in allen neun Fällen in den induzierten Strukturen $c W n t 8 c$ stark exprimiert war (Abb. 3. 14., C, D).

Da $c W n t 8 c$ nicht nur im posterioren Primitivstreifen und im posterioren Mesoderm, sondern auch in der posterioren Neuralplatte exprimiert ist, sollte durch einen mesodermalen Marker gezeigt werden, ob die ektopische $c W n t 8 c$-Expression rein neural war, oder ob sie auch die Induktion posterioren Mesoderms durch $F G F 8$ anzeigte. Als mesodermaler Marker wurde chT (Brachyury) gewählt. Alle Induktionen $(\mathrm{n}=6)$ hatten starke chT-Aktivität (Abb. 3. 14., F, G). FGF8 ist also ein zentraler Faktor bei der Etablierung der posterioren, durch $W n t$-Signale charakterisierten Areale im Embryo.

Einige der Embryonen, in denen FGF8 im Stadium HH4 anterior lateral transplantiert wurde, wurden auf die Anwesenheit von $N k x 2.5$ getestet. Überraschenderweise konnte in einigen Fällen (3/7) eine ektopische Aktivierung von $N k x 2.5$ beobachtet werden. Die $N k x 2.5$-positiven Zellen waren dabei stets am äußeren Rand des induzierten Gewebes, in einer gewissen Entfernung zur FGF8-Quelle (Abb. 3. 13., F, G).

\section{7. 5. Ektopische $c S z l$ und Crescent-Expression hat keinen Einfluß auf die Kardiogenese}

Von anderen Autoren wurde bereits gezeigt, daß mediale Wnt-Signale die Expression kardialer Markergene herunterregulieren können (Marvin et al., 2001). Mit Hilfe von retroviral transfizierten embryonalen Hühnerfibroblasten, die $c S z l$ bzw. Crescent überexprimierten, sollte ein möglicher direkter Einfluß von Wnt-Antagonisten auf die Kardiogenese im gastrulierenden Huhnembryo überprüft werden. Hierzu wurden die cSzl- bzw. Crescent-exprimierenden Zellen an den Rand des Herzmesoderms zwischen Ektoderm und Endoderm in Stadium HH4-Embryokulturen transplantiert. Die Zellen sollten im Stadium HH8/HH9 in einem Areal, posterior-medial vom endogenen Herzfeld, positioniert sein. $c S z l$ und Crescent sollten an dieser Position mediale und posteriore Wnt-Signale derart inhibieren, daß eine Erweiterung des primären Herzfeldes zu erwarten gewesen wäre. Kontralateral wurden Fibroblasten transplantiert, die mit dem Alkalische-Phosphatase-Kontrollvirus transfiziert waren. Getestet 
wurde auf eine Erweiterung der endogenen Expressionen der kardialen Marker GATA4 und Nkx2.5 in Richtung des Zelltransplantats. In Kontrollexperimenten wurde durch in situ-Hybridisierung getestet, ob die retroviral transfizierten Zellen auch tatsächlich $c S z l$ bzw. Crescent überexprimierten. Zunächst wurden $c S z l$ - bzw. Crescentexprimierende Zellen allein transplantiert. Da für keines der untersuchten Markergene eine Veränderung der endogenen Expression beobachtet werden konnte (cSzl-Zellen operiert, Test auf Nkx2.5:n=29; cSzl operiert, Test auf GATA4: $\mathrm{n}=10$; Crescent-Zellen operiert, Test auf $N k x 2.5: \mathrm{n}=14)$. wurde in einer weiteren Experimentreihe geprüft, ob es durch die Kombination von $c S z l$ und Crescent-Signalen möglich war, das primäre Herzfeld ektopisch zu erweitern. Allerdings wurden auch in diesen Experimenten keine ektopische Veränderung des Herzfeldes durch die Zelltransplantate beobachtet (Test auf $N k x 2.5, \mathrm{n}=8$; Test auf GATA4 $\mathrm{n}=4$ ). Die von Marvin et al. im Explantsystem gezeigte Aktivierung von kardialen Markern durch den Wnt-Antagonisten Crescent konnte in der in vivo-Situation der Embryokultur nicht nachgestellt werden. 


\section{Diskussion}

Musterbildungsprozesse im Wirbeltierembryo werden über ein Netzwerk verschiedener, fein aufeinander abgestimmter Signalwege gesteuert. Innerhalb dieser Arbeit wurden Signale und Signalzentren, die bei der Etablierung anteriorer Strukturen im Wirbeltierembryo notwendig sind, genauer untersucht. Im ersten Teil der Diskussion werden die zellulären Interaktionen, die zu der Induktion der Vorderhirnanlage im Mausembryo führen, analysiert. Im zweiten Teil wird der innerhalb dieser Arbeit neu identifizierte, sekretierte Wnt-Antagonist $c S z l$ charakterisiert. Hierbei wird insbesondere die Rolle von Wnt-Antagonisten bei der Anlage des anterioren Mesoderms analysiert.

\section{1. Die Induktion der Vorderhirnanlage}

Das zentrale Nervensystem im Wirbeltierembryo entwickelt sich aus dem medialen Teil des Ektoderms. Die Zellen dieses Areals verändern während der Gastrulation ihre Zellmorphologie und setzen sich von den Zellen des epidermalen Ektoderms als Neuralplatte ab. Der rostrale Bereich der Neuralplatte wird sich im weiteren Verlauf der Embryogenese zum Vorderhirn entwickeln. Die Signale, die im Ektoderm eine anteriore Neuralidentität etablieren, stammen aus der dem Ektoderm unterliegenden Zellschicht. Im Amniotenembryo kommen als Signalquellen das extraembryonale, primitive Endoderm und nach Einsetzen der Gastrulation das definitve Endoderm sowie die Zellen des axialen Mesoderms in Frage. Im Maus- und Kaninchenembryo wurde die Rolle des extraembryonalen, anterioren viszeralen Endoderms (AVE) bei der Etablierung der anterioren Neuralplatte gut untersucht (siehe Abschnitt 1.3; Knoetgen et al., 1999a; Knoetgen et al., 1999b). Insbesondere die Transplantation des AVE des Kaninchenembryos in Hühnerembryokulturen konnte dieses induktive Potential belegen, denn nach Transplantation des Kaninchengewebes waren die anterioren Neuralplattenmarker GANF und OTX2 in einer transient induzierten 
Neuralplatte aktiviert (Knoetgen et al., 1999a). Unklar blieb, ob der Säugerembryo die Aktivität, anteriores Neuralgewebe zu induzieren, vollständig auf extraembryonale Gewebe verlagert hatte, oder ob das AVE zusätzlich zu ebenfalls anteriorisierenden Signalen aus dem Knoten agierte.

\section{1. 1. Der Organisator des Mausembryos induziert rostrale Neural- marker}

Die Transplantation des Knotens der Maus unter das naive Ektoderm einer Hühnerembryokultur zeigte, daß er eine komplette Neuralachse induzieren konnte. Die induzierten Neuralachsen hatten anteriore Identität (Vorderhirn) und posteriore Identitäten (Hinterhirn und Rückenmark). Der Säugerknoten sekretiert also, genauso wie der Hensensche Knoten des Huhnembryos, Signale, die zur Induktion der Vorderhirnanlage führen. Diese Signale sind innerhalb der Amniota soweit konserviert, daß sie untereinander austauschbar sind. Die Ergebnisse scheinen zunächst im Widerspruch zu Studien zu stehen, in denen der Mausknoten in Mausembryonen transplantiert wurde (Beddington, 1994; Tam und Steiner, 1999). In den dort beschriebenen Experimenten induzierte das transplantierte Gewebe zwar neurales Gewebe, anteriore Neuralmarker wurden jedoch in keinem Fall aktiviert. Allerdings konnte auch das AVE der Maus in dieser Art Transplantationsexperiment keine anterioren Marker induzieren. Erst die Kombination des Mausorganisators mit dem AVE und dem anterioren Epiblast einer frühen Mausgastrula aktivierte OTX2-Expression in 25\% der operierten Embryonen (Tam und Steiner, 1999). Das Fehlen anteriorer Strukturen in den induzierten Neuralachsen ist aber nicht auf das Fehlen von anteriorisierenden Signalen im Säugerknoten zurückzuführen. Vielmehr wurden die Transplantate unter ein Ektoderm implantiert, das die Kompetenz auf anteriorisierende Signale zu reagieren bereits verloren hat und sich in Richtung Hinterhirn und Rückenmark entwickelt. Dieses posteriore Ektoderm unterliegt außerdem schon Signalen aus den einwandernden Mesodermflügeln. Ein korrespondierender Implantationsort im Huhnembryo wäre auf Höhe des Primitivstreifens, in einem Bereich, der unter dem Einfluß posteriorisierender Signale, wie FGFs, Retinsäure und Wnt-Faktoren, liegt (Muhr et al., 1997; Nordstrom et al., 2002). Zwar wurde für das AVE beschrieben, daß seine anteriorisierende Aktivität aus der Inhibition posteriorisierender Signale resultiert 
(Kimura et al., 2000), nur scheint die Menge dieser rostralisierenden Substanzen nicht ausreichend zu sein. Werden nun Transplantate, die rostralisierende Faktoren sekretieren, kombiniert, können die kaudalisierenden Signale aus dem posterioren Mesoderm überwunden werden, was die Ergebnisse von Tam und Steiner erklären würde (Tam und Steiner, 1999). Die Mausknoten wurden in die Huhnembryokultur unter ein Ektoderm transplantiert, dessen normales Entwicklungsschicksal extraembryonal und in Teilen epidermal, nie aber neural war. Außerdem war zum Zeitpunkt der Operation kein Mesoderm unter diesem Ektoderm präsent.

Eine Selbstdifferenzierung des transplantierten Mausorganisators, wie man es bei der Transplantation des Huhnorganisators in Huhnembryonen beobachtet (Inagaki und Schoenwolf, 1993), blieb bei der Transplantation des Mausknotens in die Huhnembryokultur aus. Das Mausgewebe überlebte unter den Bedingungen der Huhnembryokultur lange genug, um neuralinduzierende Faktoren $\mathrm{zu}$ sekretieren, vor einer Differenzierung in axiales Mesoderm starb es allerdings ab (Zhu et al., 1999).

In $42 \%$ der untersuchten Induktionen wurde neben den neuralen Markern auch chT im Ektoderm am Transplantat aktiviert (Abb. 3. 1., C). Normalerweise ist chT im Primitivstreifen und im axialen Mesoderm des selbstdifferenzierenden Organisators exprimiert, eine ektodermale Expression von $\operatorname{ch} T$ wurde in Transplantationen des Hühnerorganisators nicht beobachtet (Knoetgen, 2000). Der Organisator sekretiert Faktoren, die eine Induktion von Organisatorqualitäten im umliegenden Gewebe verhindert. Eine solche "antidorsalisierende" Aktivität wurde beispielsweise für das $B M P$-ähnliche Protein ADMP beschrieben (Joubin und Stern, 1999; Yuan et al., 1995). Da sich das Transplantat aus der Maus nicht im Huhnembryo etablieren konnte, fehlte diese inhibitorische Aktivität und Gene wie chT konnten akiviert werden. In einigen Fällen wurde durch ein Maustransplantat eine starke Aktivierung von chT, ohne daß parallel neurale Marker induziert wurden, beobachtet (Abb. 3. 1., B). Hier wurden Teile des Primitivstreifens ohne den Organisator aus dem Mausembryo explantiert, wodurch ein sekundärer Primitivstreifen, der keine Fähigkeit zur Neuralinduktion, wohl aber zur Mesoderminduktion hat, induziert wird. Dieses entspricht Beobachtungen aus dem Huhn, wo durch die Transplantation eines Gewebestücks aus dem mittleren Primitivstreifen ausschließlich Mesodermmarker aktiviert wurden (Lemaire et al., 1997). 
Verglichen mit den Induktionen, die durch die Transplantation von AVE des Kaninchens im Huhnembryo ausgelöst wurden (Knoetgen et al. 2000), ist die Induktion durch den Maus-, wie auch durch den Kaninchenknoten, viel weitreichender. Eine anteriore Neuralplatte, die durch das AVE induziert wurde, ist stets transient (Knoetgen et al., 1999; Knoetgen et al., 2000). Eine weitere Differenzierung zu Neuralfalten oder einem Neuralrohr bleibt aus. Induktionen, die durch den Knoten ausgelöst werden, sind dagegen stabiler und bilden Neuralfalten (Abb. 3. 1., F-I), in manchen Fällen auch geschlossene Neuralrohre.

Eine räumliche Separierung der neuralinduzierenden Gewebe in einen Kopforganisator im extraembryonalen primitiven Endoderm und einen Rumpforganisator im Knoten findet im Säugerembryo also nicht statt. Der Knoten ist von entscheidender Bedeutung für die Induktion der Vorderhirnanlage. Die Ergebnisse aus den Transplantationsexperimenten werden auch durch molekulargenetische Inaktivierungsexperimente in der Maus gestützt. Werden nämlich die beiden ausschließlich im Knoten und in der prächordalen Platte exprimierten BMP-Antagonisten Chordin und Noggin gleichzeitig inaktiviert, initiieren die mutanten Embryonen zwar eine rostrale Neuralplatte, prägen aber keine anterioren Strukturen aus, da das zweite, stabilisierende Signal aus dem Knoten ausbleibt (Bachiller et al., 2000).

\section{1. 2. Anteriore Neuralinduktion in Amphibien, Vögeln und Säugern}

Im Amphibienembryo stammen die Signale, die zur Ausbildung des anterioren Nervensystems führen, von der dorsalen Blastoporuslippe und ihrem Derivat, der prächordalen Platte. Diese Zellen, die die Blastoporuslippe verlassen, migrieren als axiales Mesoderm unter das Ektoderm und sekretieren Proteine, die insbesondere Signale des $B M P$ - und des Wnt-Signaltransduktionsweges inhibieren und auf diese Weise das Ektoderm neuralisieren und eine anteriore Identität etablieren. Die Kaudalisierung der Neuralplatte erfolgt durch Signale, die vom Organisator und dem Notochord während der späteren Gastrulation sekretiert werden (Niehrs, 1999). Diese Abfolge der initialen Induktion einer anterioren Neuralplatte und deren spätere, graduelle Posteriorisierung wurde von Nieuwkoop als Aktivierungs-TransformationsModell zur Erklärung des Kopf- und Rumpforganisatorphänomens postuliert (Nieuwkoop, 1952); siehe auch Abschnitt 1. 4.). 
Dem Ektoderm der Amnioten unterliegt schon vor der Gastrulation eine potenzielle Signalquelle, das extraembryonale, primitive Endoderm. Für das AVE des Säugerembryos konnte eine anteriore neuralinduzierende Aktivität auf den Epiblast nachgewiesen werden. Und auch wenn der Hypoblast des Vogelembryos direkt keine anteriore Neuralplatte induzieren kann (Knoetgen et al., 1999), werden die Marker des medialen Epiblast wie Sox3 und OTX2 auch im Huhn schon vor Einsetzen der Gastrulation exprimiert und können durch den Hypoblast ektopisch aktiviert werden (Foley et al., 2000). Ebenso zeigen Explantexperimente, daß der Epiblast des Vogelembryos schon vor Einsetzen der Gastrulation Signalen ausgesetzt ist, die ihn in Richtung einer neuralen Differenzierung spezifizieren lassen (Wilson et al., 2000).

\begin{tabular}{|c|c|c|c|}
\hline \multirow{3}{*}{\multicolumn{2}{|c|}{$\begin{array}{l}\text { Amphibium } \\
\text { (Krallenfrosch) }\end{array}$}} & $\begin{array}{l}\text { frühe } \\
\text { Gastrula }\end{array}$ & $\begin{array}{l}\text { späte } \\
\text { Gastrula }\end{array}$ \\
\hline & & & \\
\hline & & $\begin{array}{l}\text { Aktivierungssignal: } \\
\text { Neuralisierung/ } \\
\text { Vorderhirnspezifizierung }\end{array}$ & $\begin{array}{c}\text { Transformationssignal: } \\
\text { Kaudalisierung }\end{array}$ \\
\hline \multirow[t]{2}{*}{$\begin{array}{l}\text { Vogel } \\
\text { (Huhn) }\end{array}$} & $\Delta \Delta \Delta$ & $\Delta \Delta \Delta<0$ & $a_{\Delta \Delta \Lambda \Lambda D^{p}}^{p}$ \\
\hline & $\begin{array}{l}\text { Aktivierungssignal: } \\
\text { Neuralinduktion }\end{array}$ & $\begin{array}{l}\text { Stabilisierungssignal: } \\
\text { erhält und stabilisiert } \\
\text { die Neuralplatte; Induziert } \\
\text { die Vorderhirnspezifität }\end{array}$ & $\begin{array}{c}\text { Transformationssignal: } \\
\text { Kaudalisierung }\end{array}$ \\
\hline \multirow[t]{2}{*}{$\begin{array}{l}\text { Säuger } \\
\text { (Maus) }\end{array}$} & & & \\
\hline & $\begin{array}{l}\text { Aktivierungssignal: } \\
\text { Neuralinduktion; } \\
\text { Vorderhirninduktion }\end{array}$ & $\begin{array}{l}\text { Stabilisierungssignal: } \\
\text { erhält und stabilisiert } \\
\text { die Vorderhirnidentität }\end{array}$ & $\begin{array}{c}\text { Transformationssignal: } \\
\text { Kaudalisierung }\end{array}$ \\
\hline
\end{tabular}

Abb. 4. 1.: Anteriore Neuralinduktion im Wirbeltierembryo. Schematische Darstellung des Prägastrulastadiums, einer frühen Gastrula und einer späten Gastrula im Frosch, im Vogel und in der Maus. Im Amphibium gibt es erst mit Einsetzen der Gastrulation aus dem Organisator Signale, die eine anteriore Neuralidentität induzieren (rote Pfeile). Der Organisator einer späten Gastrula posteriorisiert über kaudalisierende Faktoren die Neuralplatte (blaue Pfeile). Im Vogelembryo wird die Neuralidentität schon vor der Gastrulation durch den Hypoblast spezifiziert, Signale aus dem Hensenschen Knoten stabilisieren den neuralen Charakter und etablieren die anteriore Identität. 
Wie im Frosch kaudalisieren Signale aus dem späten Organisator die Neuralplatte. Im Säuger wird die anteriore Neuralidentität schon in der Prägastrula durch das anteriore viszerale Endoderm etabliert. Der Organisator der frühen Gastrula stabilisiert die anteriore Neuralplatte. In der späteren Gastrulation kaudalisiert der Organisator.

Mit Einsetzen der Gastrulation und der Etablierung des Knotens wird die Expression neural-induzierender und anteriorisierender Signale verstärkt und damit die anteriore Neuralidentität im Ektoderm stabilisiert. Wie in der Amphibiengastrula werden mit fortschreitendender Gastrulation, wenn das prächordale Mesoderm den Knoten verlassen hat, vom Knoten und dem posterioren Mesoderm FGFs, Retinsäure und WntFaktoren sekretiert, die kaudalisierend auf die Neuralplatte wirken (Muhr et al., 1997; Nordstrom et al., 2002). Die Ereignisse, die im Amniotenembryo zu einem anteriorposterior regionalisierten Nervensystem führen, können als eine Modifizierung des von Niewkoop postulierten Aktivierungs-Transformations-Modell zusammengefaßt werden: Ein initiales Signal, das “Aktivierungs”-Signal, aus dem Hypoblast bzw. dem anterioren viszeralen Endoderm spezifiziert die Zellen des Epiblast in Richtung einer anterioren Neuraldifferenzierung. Diese "präneuralen" Zellen sind noch nicht determiniert und können durch BMPs epidermalisiert werden. Erst durch Signale einer zweiten Signalquelle, dem Knoten bzw. dem prächordalen Mesoderm wird der anterior-neurale Status der Epiblastzellen stabilisiert und die Neuralplatte morphologisch etabliert. Von diesem Zeitpunkt an wird der Vorderhirnmarker GANF im Huhn exprimiert. Die während der fortschreitenden Gastrulation vom Knoten sekretierten Signale "transformieren", d.h. kaudalisieren die Neuralplatte (Abb. 4. 1.).

\section{2. Wnt-Antagonismus und anteriore Musterbildung}

\section{2. 1. Die sekretierten Wnt-Antagonisten $c S z l$ und Crescent}

Die aus der cDNA abgeleitete Primärstruktur des $c S z l$-Proteins hat $65 \%$ Aminosäureidentität mit dem bereits im Krallenfrosch beschriebenen, sekretierten Wnt-Antagonisten Sizzled $(x \mathrm{Sz} l)$. Exprimiert wird $x \mathrm{Sz} l$ schon vor Einsetzen der Gastrulation (Stadium 10) in der Animalkappe des Froschembryos. In der frühen Gastrula wird $x S z l$ in der ventralen Marginalzone und der ventralen Animalkappe exprimiert. Später in der Gastrulation sind die $x S z l$-Transkripte in der ventralen Blastoporuslippe, im 
ventralen Mesoderm und im Mesoderm des Herzfeldes exprimiert (Pera und De Robertis, 2000; Salic et al., 1997). Vergleicht man die Expression des $x \mathrm{Szl}$ mit $c S z l$, wird deutlich, daß beide Gene in ähnlichen Expressionsdomänen exprimiert sind. Wie $x S z l$ schon im Prägastrulaembryo exprimiert ist, sind $c S z l$-Transkripte im Hypoblast bereits vor Einsetzen der Primitivstreifenentwicklung nachweisbar (Abb. 3. 6.). Auch im Gastrulastadium korrespondieren die Expressionsdomänen in beiden Spezies. $c S z l$ ist in der Peripherie des Embryos, insbesondere am posterioren Primitivstreifen exprimiert. Diese Bereiche sind homolog zu den vegetalen und ventralen Arealen der Froschgastrula (Arendt und Nubler-Jung, 1999). In späteren Stadien decken sich cSzlund $x S z l$-Expression im Herzfeld und im ventralen Mesoderm. Die Expression von $x S z l$ während der Ausbildung der Aortenbögen und der späteren Kardiogenese wurde im Frosch bisher nicht untersucht.

Die Primärstruktur des Crescent-Proteins aus dem Huhn ist mit dem Crescent aus Xenopus laevis in der cysteinreichen Domäne zu 88 \% identisch, der Expressionsvergleich von Crescent im Frosch und im Huhnembryo zeigt, daß auch hier die Expressionsdomänen korrespondieren: Crescent wird im Frosch wie im Huhn im anterioren Endoderm und in der prächordalen Platte exprimiert. In späteren Stadien wird die anteriore Expression wie im Huhn herunterreguliert, allein im Pronephros wird Crescent weiterexprimiert. Für $c S z l$ und auch für Crescent kann also sowohl aufgrund der Sequenz-, als auch der Expressionsdaten angenommen werden, daß es sich um die orthologen Gene der aus dem Frosch beschriebenen Gene Sizzled und Crescent handelt (Pera und De Robertis, 2000; Pfeffer et al., 1997).

\section{2. 2. Sizzled und Crescent nur in Amphibien und Vögeln?}

Sowohl Datenbankanalysen als auch Southernblotanalysen verschiedener Wirbeltierspezies ergaben, daß sowohl Crescent als auch Sizzled nur in Amphibien (neben dem Xenopus laevis Sizzled wurde auch ein Sizzled-Gen im Axolotl gefunden (Bachvarova et al., 2001)) und in Vögeln vorzukommen scheinen (wobei keine weiteren Sauropsidenspezies untersucht wurden). Beide Proteine divergieren in ihrer Aminosäurestruktur von den übrigen Mitgliedern der Familie der skretierten, Frizzled verwandten Proteine relativ stark (Abb. 3. 5., A; Chong et al., 2002). Ihre sehr spezifischen und konservierten Expressionsmuster deuten auf eine wichtige Rolle während der 
Embryogenese hin. Sollten Säuger diese Gene in ihrer Evolution verloren haben, könnte dies einerseits bedeuten, daß im Säuger die Rolle des Wnt-Antagonismus während der Kardiogenese durch andere Mechanismen ersetzt wurde, andererseits ist auch denkbar, daß ähnliche Faktoren die Funktion von Sizzled und Crescent übernommen haben. In der Maus ist beispielsweise der sekretierte Wnt-Antagonist Frzb im kardialen Mesoderm exprimiert und könnte dort die Funktion von $c S z l$ übernommen haben (Hoang et al., 1998; Jaspard et al., 2000). Nicht auszuschließen ist allerdings, daß die Nukleotidsequenz der Säugergene derart von denen aus Amphibium und Vogel divergiert, daß die orthologen Gene selbst unter niedrig stringenten Hybridisierungsbedingungen nicht im Southernblot nachweisbar sind. Sizzled und Crescent sind nicht die einzigen Beispiele für ein entwicklungsbiolgisch relevantes Gen, das es offensichtlich nicht mehr in Säugetieren gibt. So ist der TGFß-Faktor ADMP (Dickmeis et al., 2001; Moos et al., 1995), der im Zebrabärbling, in Amphibien und in Vögeln existiert, weder in den Datenbanken der Humanen Genomprojekte, noch in den Datenbanken des Mausgenoms auffindbar.

\section{2. 3. Sizzled und Crescent antagonisieren die Wnt8-Signalkaskade}

Der amino-terminale Teil von Sizzled und Crescent zeigt Homologie zur extrazellulären cysteinreichen Domäne des Wnt-Rezeptors Frizzled. Damit gehören beide Faktoren zu einer größeren Proteinfamilie, für die gezeigt wurde, daß sie durch Bindung von Signalproteinen der Wnt-Gruppe die Aktivierung von Frizzled und damit die durch Wnt-Faktoren induzierte Signalkaskade inhibieren kann (Itoh und Sokol, 1999; Leyns et al., 1997; Uren et al., 2000; Xu et al., 1998). Für xSzl wurde diese Funktion gezeigt, indem $x S z l$ und Xwnt8 in Xenopus-Embryonen überexprimiert wurden. Die Überexpression von $x S z l$ führte zu einer Dorsalisierung des Froschembryos, die durch gleichzeitige Überexpression von Xwnt8 aufgehoben werden konnte. Umgekehrt konnte ein durch $X w n t 8$ ausgelöster, ventralisierender Effekt durch die Überexpression von $x S z l$ verhindert werden (Salic et al., 1997). Auch für das Crescent-Protein aus dem Huhn konnte gezeigt werden, daß es Wnt-Signale inhibiert. Wenn $c W n t 8 c$, das Xwnt8-Ortholog des Huhns, in Animalkappen aus Xenopusembryonen überexprimiert wurde, wurde die Expression von Siamois, einem Zielgen der durch Wnt8 aktivierten Signalkaskade, aktiviert. Crescent konnte in diesen Experimenten die 
Expression von Siamois verhindern. Wurde dagegen die Siamois-Expression durch $W n t 3 a$, einen $c W n t 8 c$ ähnlichen Wnt-Faktor, ausgelöst, war die Inhibition der Siamois-Expression weit geringer (Marvin et al., 2001). Ebenso wie die Daten von S. Dennis und Mitarbeitern (Dennis et al., 1999), zeigten diese Ergebnisse, daß die sekretierten $W n t$-Antagonisten sehr spezifisch $W n t$-Signale inhibieren können.

\section{2. 4. Wnt-Antagonismus und anterior-posteriore Musterbildung}

Die verschiedenen, bisher bekannten sekretierten Wnt-Antagonisten sind im frühen Prägastrula- und Gastrulaembryo in Strukturen exprimiert, die anteriore Identitäten im Embryo festlegen. Crescent, Frzb1, Sfrp2 und Dkk1 sind im Krallenfrosch in der frühen dorsalen Blastoporuslippe und in ihren frühen Derivaten, dem anterioren Endoderm und der prächordalen Platte, exprimiert (Glinka et al., 1998; Leyns et al., 1997; Pera und De Robertis, 2000). Im Huhn sind Crescent und Sizzled im Hypoblast, der dem prospektiven Vorderhirnareal unterliegt, Dkkl und Frzbl im Hensenschen Knoten sowie der prächordalen Platte präsent (Chapman et al., 2002). Die Wnt-Moleküle, die von den genannten sekretierten Proteinen inhibiert werden, sind dagegen in den peripheren, nicht-neuralen Arealen des Prägastrula-Embryos sowie in kaudalen Bereichen des Gastrulaembryos exprimiert. Im Huhnembryo sind dieses $c$ Wnt $8 c$ und Wnt $3 a$, deren Transkripte im Primitivstreifen und im posterioren Mesoderm nachweisbar sind (Marvin et al., 2001). Deutlich wird die Zweiteilung des Gastrulaembryos in eine anteriore, durch Wnt-Antagonisten charakterisierte Hälfte und eine posteriore Hälfte, die Wnt-Signalen unterliegt, in einem Embryo, in dem die Transkripte für Crescent und $c W n t 8 c$ gleichzeitig sichtbar gemacht wurden (Abb. 4. 2.). Auffallend ist, daß die Expressionsdomänen der Wnt-Signale und ihrer Inhibitoren so deutlich voneinander getrennt sind, daß eine Diffusion von Agonist und Antagonist für eine Interaktion nicht ausreichend ist. Eine Erklärungsmöglichkeit wäre, daß noch zusätzliche, nicht bekannte Wnt-Faktoren im posterioren Mesoderm exprimiert sind, deren Expressionsdomänen direkt an die Expressionsdomänen von Crescent und $c \mathrm{Sz} l$ grenzen. Andererseits sind Wnt-Proteine als Glykoproteine stark mit der Zelloberfläche assoziiert und könnten mit den migrierenden Zellen unter fortlaufender Signalaktivität mitgeführt werden. Erst wenn diese Zellen in das Anti-Wnt-Feld gelangen, wird 
die Wnt-Signalkaskade unterbrochen und die Zelle kann ihr Entwicklungsschicksal ändern, z.B. kompetent für andere Signale werden.

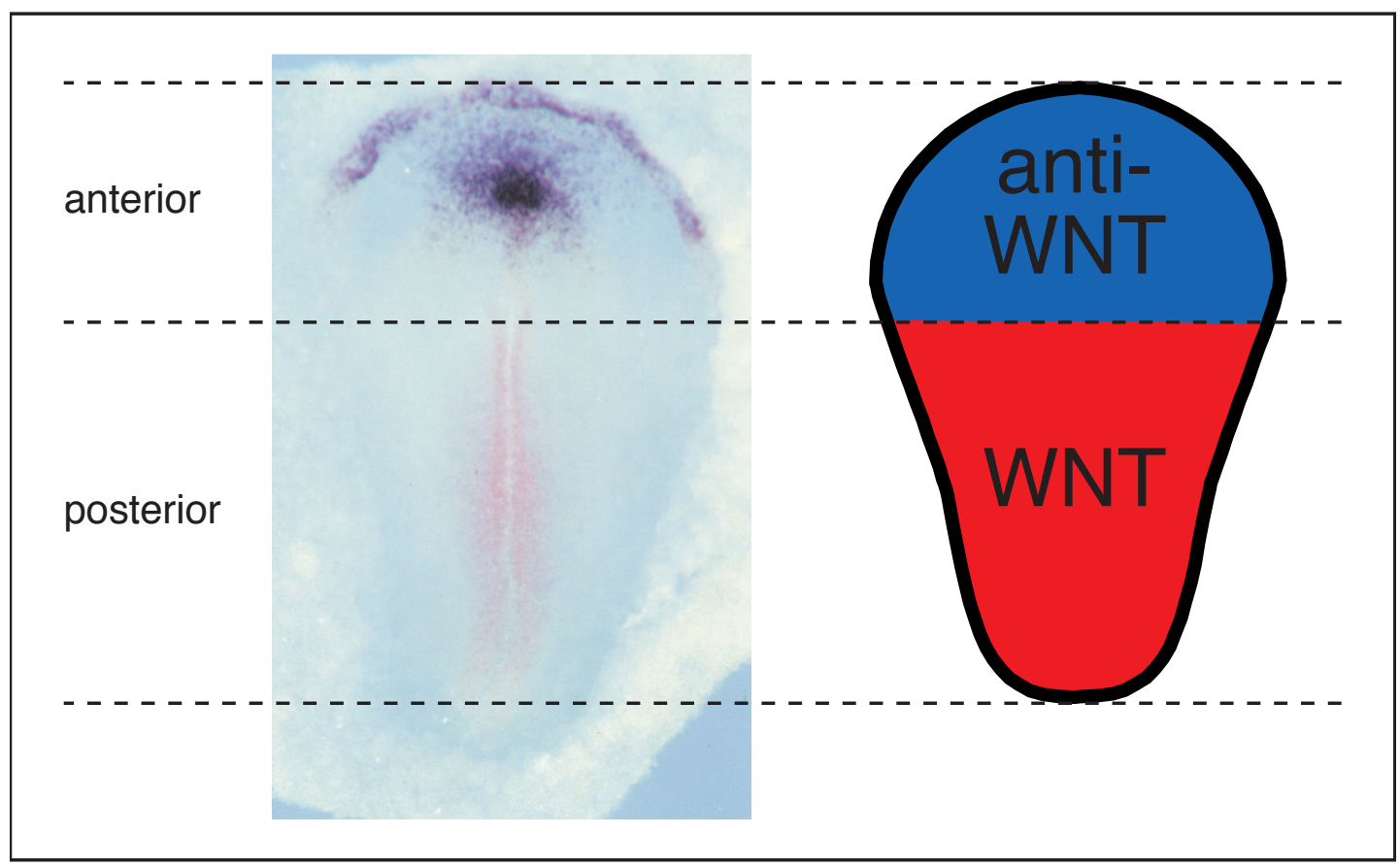

Abb 4. 2.: Wnt-Signale und Musterbildung im Wirbeltierembryo. Der Embryo wurde auf Crescent - (blau) und cWnt8c - (rot) Transkripte analysiert. Die anteriore Hälfte des Embryos ist frei von Wnt-Signalen. Hier werden die Wnt-Antagonisten Dkk1, cSzl, Frzb, Sfrp1/2 und Crescent exprimiert. Im Primitivstreifen und im posterioren Mesoderm sind die Gene für Wnt-Faktoren (cWnt8c, Wnt3a und Wnt11) aktiv.

In den folgenden zwei Abschnitten werden die möglichen und bekannten Einflüsse von Wnt-Antagonisten bei Musterbildungsprozessen im anterioren Neuroektoderm und im anterioren Mesoderm, unter besonderer Berücksichtigung von $\mathrm{cSz}$ l und Crescent, diskutiert.

\section{2. 4. 1. Wnt-Antagonismus und Neuralinduktion}

Die Klonierung des Wnt-Antagonisten D $k k 1$ im Krallenfrosch und dessen Eigenschaft als potenter Aktivator sekundärer Kopfstrukturen zeigte, daß die Inhibierung von Wnt-Signalen eine entscheidende Komponente bei der Etablierung des anterioren Nervensystems darstellt (Glinka et al., 1998). Ebenso induzierte die Überexpression von Crescent, Sizzled, Frzb und anderen Sfrps sekundäre Körperachsen mit anterioren Strukturen (Pera und De Robertis, 2000; Salic et al., 1997). Im Huhn sind für die Spezifizierung eines neuralen Entwicklungsschicksals in den medialen Epiblastzellen 
bereits vor Einsetzen der Gastrulation $F G F$-Signale notwendig. Durch $F G F$ wird im medialen Epiblast einerseits die Expression von BMP-Faktoren, die die Zellen ein epidermales Entwicklungsschicksal einschlagen lassen, herunterreguliert, andererseits aktiviert $F G F$ direkt neurale Qualitäten im Epiblast. $B M P$-Signale wiederum blockieren die FGF-Signale im lateralen Epiblast. So ist der Epiblast schon bei der Eiablage in mediale, prospektiv neurale Zellen und periphere, prospektiv epidermale Zellen unterteilt (Wilson et al., 2000). Gleichzeitig wird in den prospektiv epidermalen Zellen $c W n t 8 c$ exprimiert. Die Wnt-Signale blockieren die $F G F$-Aktivität und unterstützen die Entwicklung des Epiblast zu epidermalem Ektoderm (Wilson et al., 2001). Im zentralen Epiblast wird durch die Wht-Antagonisten $c S z l$ und Crescent die Aktivität der Wnt-Signale blockiert. Dieses System gegenseitiger Aktivierung und Inhibierung ist in sich stabil und ermöglicht die Etablierung zweier unterschiedlicher Zellidentitäten aus einer einheitlichen Zellpopulation.

Wie im Froschembryo ist im Huhnembryo die frühe Aktivierung des neuralen Ektoderms abhängig von der Inhibierung von BMP- und Wnt-Signalen, anders als im Frosch wird der ventralisierende/epidermalisierende Einfluß der BMPS jedoch initial nicht durch sekretierte $B M P$-Antagonisten, sondern durch $F G F$-Signale unterdrückt. Erst während der Gastrulation stabilisieren Chordin und Noggin aus dem Hensenschen Knoten das neurale Entwicklungsschicksal des medialen Ektoderms. Sekretierte Wnt-Antagonisten sind dagegen auch im Huhn schon initial Teil des neuralen Aktivierungssignals.

\section{Prägastrula}

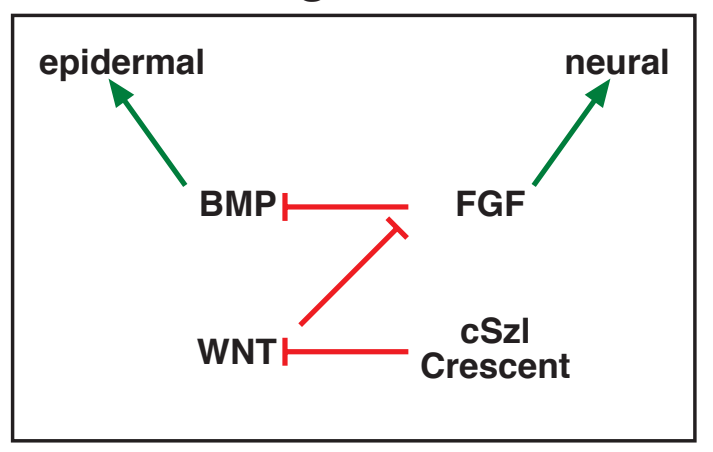

Gastrula

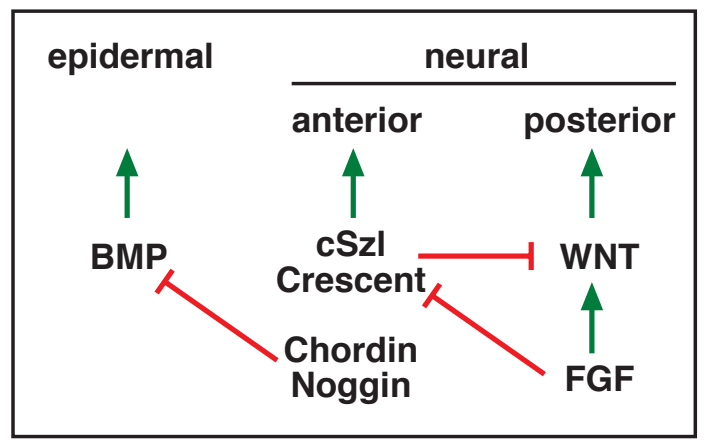

Abb. 4. 3.: Neuralinduktion und Wnt-Antagonismus. Die Schemata zeigen die regulativen Zusammenhänge zwischen den Signalmolekülen, die an den frühen Musterbildungsprozessen beteiligt sind, in einem Prägastrula- und einem Gastrulastadium im Huhn. Im zentralen Epiblast wird über FGF-Signale und die Inhibition von Wnt-Signalen das neurale Differenzierungsprogramm induziert. BMP- und Wnt-Faktoren im lateralen Epiblast aktivieren epidermale Identität. Während der Gastrulation wird der neurale Status durch die Inhibition epidermalisierender BMP-Signale und 
fortdauerndes FGF aufrechterhalten. Die Neuralachse wird durch Wnt und FGF posteriorisiert, die Wnt-Antagonisten erhalten die anteriore Identität.

4. 2. 4. 2. Wnt-Antagonismus und die Induktion des anterioren lateralen Mesoderms

Kardiales Mesoderm wird im Vogelembryo durch Signale aus dem anterioren Endoderm induziert. Zur kardialen Induktion wurde die Kombination zweier Signale postuliert: Das Signal aus dem anterioren Endoderm induziert in den Mesodermzellen die Kompetenz, zu kardialen Zellen zu differenzieren, ein zweites Signal spezifiziert die Herzmuskelzellen (Schultheiss et al., 1997; Schultheiss et al., 1995). Das spezifizierende Signal wird durch $B M P s$ vermittelt. $B M P 2$ und $B M P 4$ sind im Vogelembryo für die Differenzierung der anterior-lateralen Mesodermzellen zu Herzmuskelzellen notwendig, aber nicht hinreichend (Andree et al., 1998; Schlange et al., 2000; Schultheiss et al., 1997). Das zusätzliche, induzierende Signal aus dem anterioren Endoderm besteht in der Inhibition des kanonischen Wnt-Signalweges (Marvin et al., 2001; Tzahor und Lassar, 2001). Im posterioren Mesoderm und im Primitivstreifen werden $W n t 3 a$ und $c W n t 8 c$ exprimiert, der anteriore Embryo ist wie beschrieben (4. 2. 4.; Abb. 4. 2.) frei von $W n t$-Transkripten. Werden $W n t$-Faktoren im anterioren Embryo ektopisch überexprimiert, wird die Kardiogenese im präkardialen Mesoderm blokkiert (Marvin et al., 2001; Tzahor und Lassar, 2001). Sowohl Crescent als auch cSzl sind zum Zeitpunkt der Induktion des kardialen Mesoderms im anterioren Endoderm exprimiert, kommen also als Kandidaten für anteriore, Wnt-blockierende und damit kardiales Mesoderm induzierende Signale in Frage. Tatsächlich konnte gezeigt werden, daß in Explantaten des posterioren Mesoderms, die mit Crescent-Protein inkubiert wurden, kardiale Differenzierung erfolgt (Marvin et al., 2001). Explantate aus dem posterioren Primitivstreifen, in denen durch anteriores Endoderm kardiale Differenzierung ausgelöst werden konnte, ließen sich durch ektopische Crescent-Expression allerdings nicht in kardiales Gewebe umprogrammieren (Marvin et al., 2001). Im Unterschied zum posterioren Primitivstreifen ist im posterioren Mesoderm des Gastrulaembryos (HH4/HH5) cSzl exprimiert (Abb. 3. 6., C, D). Daher ist möglicherweise die Kombination von $c S z l$ und Crescent nötig, um in den Mesodermzellen effizient die Kompetenz für kardiale Spezifizierung zu erhalten. Ein Indiz für eine solche 
synergetische Aktivitität sind die überlappenden Expressionsdomänen von $c S z l$ und Crescent zum Zeitpunkt der kardialen Induktion (Abb. 3. 10., G, J). Es gelang nicht, kardiale Marker durch die Überexpression von Crescent oder $c S z l$, oder durch die Kombination beider Proteine im Embryo ektopisch zu aktivieren. Zum einen könnten das Ektoderm und das Endoderm, in dem das posteriore Mesoderm eingebettet ist, zusätzliche Faktoren exprimieren, die unabhängig von Wnt-Signalen die Induktion kardialer Myozyten inhibieren. Andererseits könnte die Konzentration der reprimierenden Wnt-Signale an den Transplantationsorten so hoch gewesen sein, daß die ektopischen $c S z l$ - und Crescent-Quellen nicht ausreichten, um Wnt-Signale aus dem Neuralrohr und vom Primitivstreifen vollständig zu blockieren.

Eine weitere Funktion von Crescent bei der Aktivierung des kardiogenen Differenzierungsprogramms, die unabhängig von seiner Rolle als Wnt-Antagonist ist, wurde in einer aktuellen Studie im Krallenfrosch gezeigt. Crescent wie auch Dkkl können in Animalkappen direkt den $J N K$-Signaltransduktionsweg aktivieren. Über den $J N K$ Signalweg wird dann das kardiale Transkriptionsprofil eingerichtet (Pandur et al., 2002). Die Differenzierung kardialer Zellen aus dem anterioren Mesoderm benötigt also mindestens die Kombination dreier Signalwege: Die Inhibierung des kanonischen Wnt-Signalweges, die Aktivierung des durch $B M P$ aktivierten $S M A D$-Signalweges sowie die Aktivierung des $J N K$-Signalweges. Inwiefern $c S z l$ neben der Aufgabe, Wnt-Proteine zu inhibieren, auch eine aktive Signalfunktion hat, bleibt zu untersuchen.

\section{2. 5. Die Etablierung des Herzfeldes durch Signalmoleküle}

Die in dieser Arbeit durchgeführten Untersuchungen zur Regulation von $c S z l$ und Crescent im kardiogenen Mesoderm erlauben ein Modell des regulativen Netzwerks, das zur Induktion kardialer Muskelzellen führt, aufzustellen.

Im gesamten peripheren/ventralen Endoderm und im Primitivstreifen wird BMP2 exprimiert, das notwendig und ausreichend ist, $c S z l$-Expression zu aktivieren. Da die Crescent-Expression unabhängig von $B M P$-Signalen reguliert wird, existiert nur im anterioren Embryo ein Überschneidungsbereich von $c S z l$-, Crescent- und BMP-Signalen. Dieses Areal ist frei von Wnt-Faktoren, so daß Mesodermzellen, die in diesen Bereich gelangen, die Kompetenz erhalten, in kardiale Myozyten zu differenzieren. 
Im Primitivstreifen wird mit FGF8 ein Aktivator von Wnt-Signalen und Repressor von $\mathrm{cSzl}$ exprimiert. Mesoderm, das hier entsteht, unterliegt also Wnt-Signalen und hat, solange diese Signale nicht inaktiviert werden, keine kardiogene Kompetenz. Mit Bildung der Kopffalte wird $F G F 8$ auch im anterioren Endoderm exprimiert. Hier reagieren die Zellen auf FGF8-Signale nicht mit der Induktion posterioren Mesoderms und aktivieren daher kein Wnt. Während $c S z l$ und GATA4 durch das anteriore FGF8 effektiv inhibiert werden (Abb. 3. 12., B; Abb. 3. 13., B), aktiviert FGF8 Nkx2.5 ektopisch (Abb. 3. 13., F). Tatsächlich sind die Expressionsdomänen von $c S z l$, GATA4 und $N k x 2.5$ nicht vollständig überlappend. Im Kopffalten- und Ein-Somitenstadium sind cSzl und GATA4 im lateralen Mesoderm und Endoderm des kardialen Halbmondes exprimiert, $N k x 2.5$-Transkripte sind weiter medial nachzuweisen (Schultheiss et al., 1995; Abb. 3. 6., E). Im kardialen Mesoderm werden also durch die Kombination von $B M P$ - und $F G F$-Signalen unterschiedliche Qualitäten geschaffen. Diese Untergliederung des Mesoderms könnte eine wichtige Funktion in der geregelten Morphogenese des Herzens haben. So führte die Inaktivierung von GATA4 im Huhn durch Gegenstrang-RNA zu schweren Defekten in der Herzentwicklung (Jiang et al., 1998). In der Musterbildung des Mesoderms während der Gastrulation hat $F G F 8$ also zwei unterschiedliche Aufgaben. Im Primitivstreifen induziert es posteriores Mesoderm, als Signal aus dem anterioren Endoderm verleiht es dem kardialen Mesoderm unterschiedliche Identitäten (Abb. 4. 3., B).

anterior-posterior

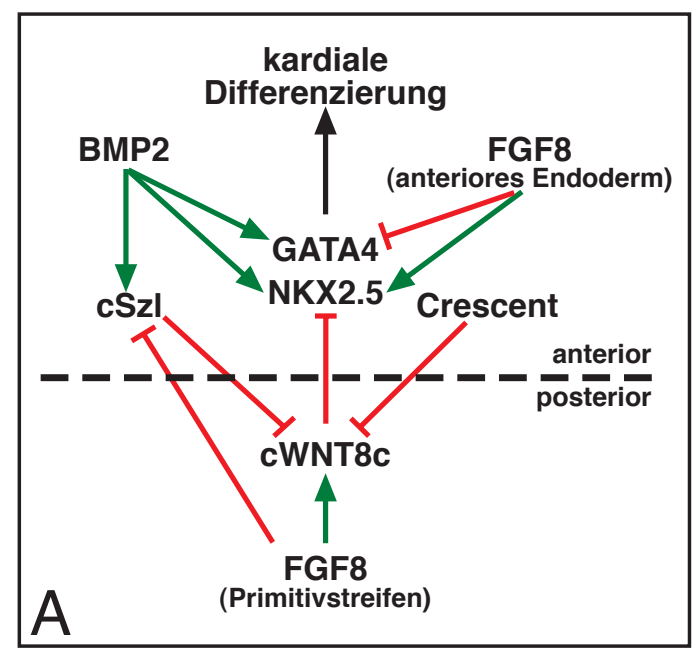

\section{dorsal-ventral}

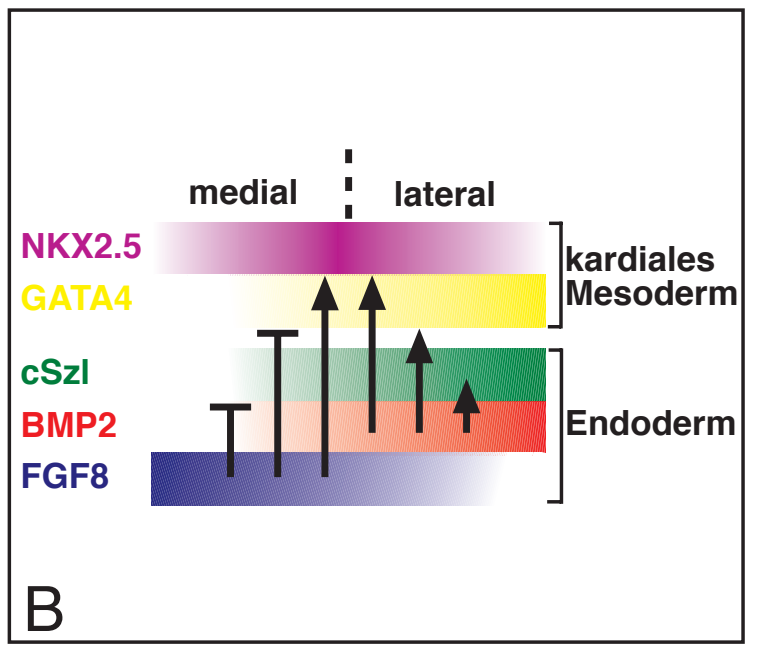

Abb. 4. 3.: Die Induktion des kardialen Mesoderms. (A) Das regulative Netzwerk, das zur Etablierung anteriorer und posteriorer Identitäten im Gastrulaembryo führt. Im Primitivstreifen wird 
über FGF8 und $c W n t 8 c$ das posteriore Mesoderm induziert. Im anterioren Embryo inhibieren die Wnt-Antagonisten Crescent und $c S z l$ die Posteriorisierung des anterioren Endoderms. Umgekehrt verhindert die inhibitorische Aktivität von FGF8 auf $c S z l$ die Anteriorisierung des posterioren Mesoderms. BMP2 und die spätere Aktivität von FGF8 im anterioren Mesoderm etablieren die Expressionsdomänen von Nkx2.5 und GATA4, die für die Differenzierung des anterioren lateralen Mesoderms in Kardiomyozyten zuständig sind. (B) Signale aus dem anterioren Endoderm aktivieren im anterioren lateralen Mesoderm kardiale Marker. BMP2 aktiviert $c S z l$ und die Transkriptionsfaktoren GATA4 und Nkx2.5, FGF8 aktiviert Nkx2.5, inhibiert dagegen GATA4. Diese unterschiedlichen Aktivitäten führen zu überlappenden, aber nicht identischen Expressionsdomänen der beiden kardialen Markergene, die für eine reguläre Morphogenese des Herztubus notwendig ist.

\section{2. 6. Wnt-Antagonismus und das sekundäre Herzfeld}

Im Gegensatz zu Crescent, dessen Expression kurz nach Ausbildung der Kopffalte im anterioren Endoderm herunterreguliert wird, bleibt $c S z l$ auch während der Morphogenese des Herzens im kardialen Mesoderm exprimiert. $c S z l$-Transkripte sind bis zum Stadium HH25 im splanchnischen Mesoderm am distalen Ende vom Ausflußtrakt des Herzschlauches nachweisbar.
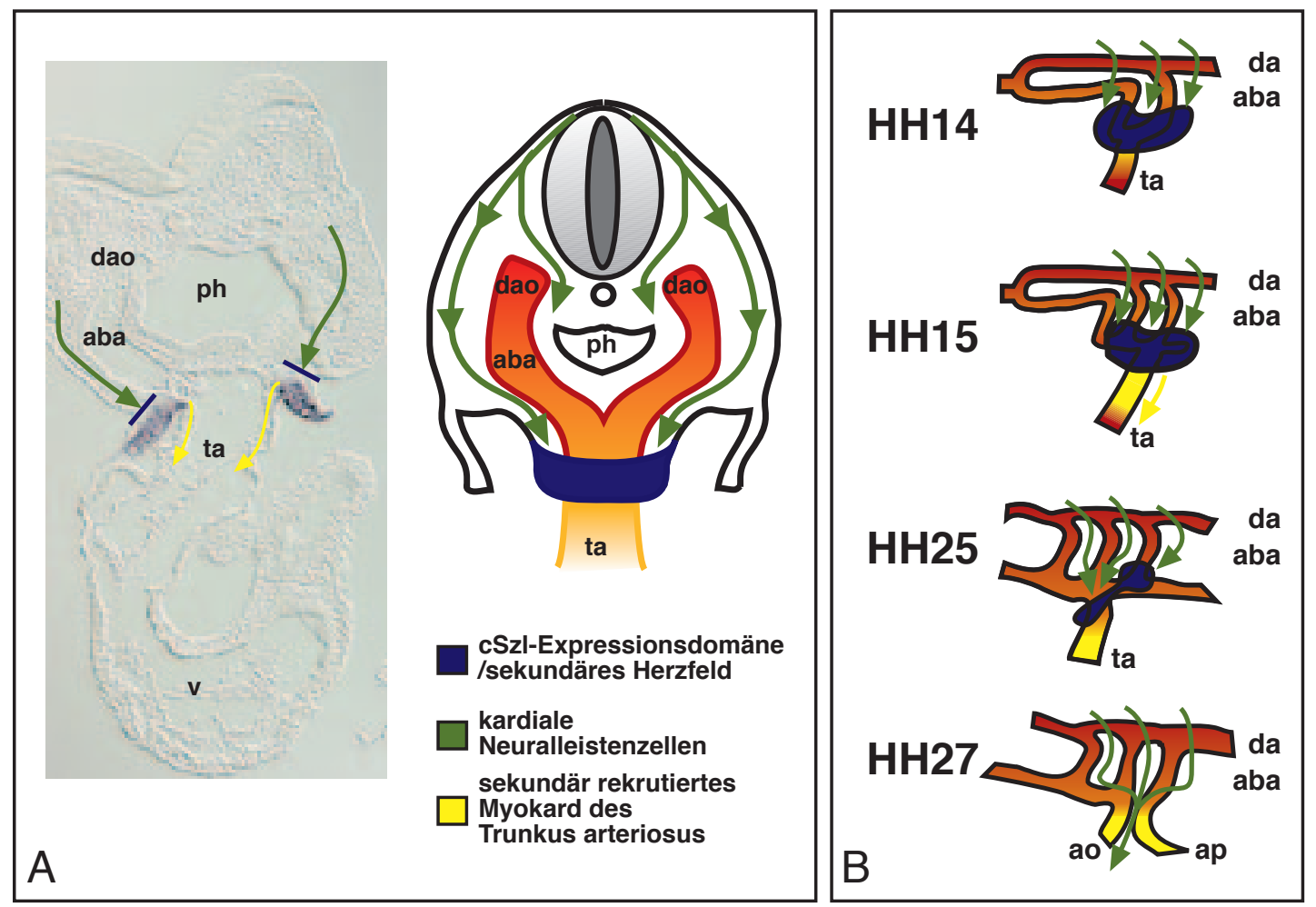

Abb. 4. 4.: Das sekundäre Herzfeld, die kardialen Neuralleistenzellen und die Morphogenese des Trunkus arteriosus. (A) Transversalschnitt durch einen $\mathrm{HH} 17-E m b r y o$, in dem durch in situHybridisierung cSzl-Transkripte angefärbt wurden, auf Höhe des zweiten Kiemenbogens durch den Trunkus arteriosus. Eingezeichnet ist als grüner Pfeil die Wanderungsrichtung der kardialen Neuralleistenzellen, die gelben Pfeile stellen das sekundäre Wachstum des Trunkus arteriosus dar. Die 
kardialen Muskelzellen, die zur Verlängerung des Ausflußtraktes führen, werden aus der cSzlExpressionsdomäne rekrutiert. (B) Die morphogenetische Umformung des Ausflußtraktes. Innerhalb der Stadien $\mathrm{HH} 14$ bis $\mathrm{HH} 27$ unterliegen die Aortenbogenarterien einem komplexen Umgestaltungsprozeß. Während dieser Zeit ist $c S z l$ in einem Ring um die Einmündung der Aortenbogenarterien in den Trunkus arteriosus exprimiert. Bis zum Stadium HH25, während der Ausflußtraktverlängerung, werden die Zellen der kardialen Neuralleiste durch das cSzl-positive Mesoderm aufgehalten. Vom Stadium HH25 an, wenn $c S z l$ herunterreguliert wird, starten die Zellen der kardialen Neuralleiste die Septierung des Ausflußtraktes. Abkürzungen: aba= Aortenbogenarterie; $\mathrm{ap}=$ Arteria pulmonaris; $\mathrm{da}=$ dorsale Aorta; $\mathrm{ph}=$ Pharynx; ta= Trunkus arteriosus.

Mit $c S z l$ wurde der erste Wnt-Antagonist beschrieben, der im anterioren Pol des Herzens von der primären Kardiogenese (HH4) bis zur finalen Differenzierung des arteriellen Systems (HH25) exprimiert ist. Am distalen Ende des Ausflußtraktes ist $c S z l$ mit $B M P 2, G A T A 4$ und Nkx2.5 koexprimiert, und von dort werden Kardiomyozyten zur sekundären Verlängerung des Ausflußtraktes während der Stadien HH14 bis HH22 differenziert (Mjaatvedt et al., 2001; Waldo et al., 2001). Aufgrund dieser Eigenschaften wurde das splanchnische Mesoderm als anteriores oder sekundäres Herzfeld definiert (Mjaatvedt et al., 2001; Waldo et al., 2001). Das regulative Netzwerk, das im sekundären Herzfeld zur Aktivierung der kardialen Markergene führt, ist dabei dem des primären Herzfelds sehr ähnlich. Auch im sekundären Herzfeld wird $c S z l$ von $B M P 2$ aktiviert und von $F G F 8$ herunterreguliert (M. Saborowski, persönliche Mitteilung). FGF8 wird zum Zeitpunkt der sekundären Verlängerung des Trunkus arteriosus im pharyngealen Ekoderm und Endoderm exprimiert und steuert von hier eine koordinierte Morphogenese des Ausflußtraktes (Farrell et al., 1999; Farrell et al., 2001). Diese Steuerung erfordert auch, daß das kardiogene Feld auf das splanchnische Mesoderm um den Ausflußtrakt beschränkt bleibt. Durch den negativen Einfluß auf die $c S z l$-Expression wird diese Begrenzung erreicht. Neben der sekundären Verlängerung des Ausflußtraktes finden innerhalb der $c S z l$-Expressionsdomäne weitere morphogenetische Umgestaltungsprozesse statt. Die vom Trunkus arteriosus ausgehenden Arterien werden in den Stadien HH14 bis HH25, während der Morphogenese der Kiemenbögen, zum segmentalen primitiven Aortenbogenarteriensystem aufgebaut und dann in einem komplexen Prozeß zum Ausflußsystem des vierkammrigen Wirbeltierherzens umgestaltet (Abb. 4. 4., B). Während dieser morphogenetischen Remodellierung migrieren Zellen der kardialen Neuralleiste durch die Kiemenbögen an das cSzl-exprimierende Mesoderm heran (Abb. 4. 4., B). Wenn cSzl im Stadium HH25 herunterreguliert wird, beginnen die Neuralleistenzellen das aortikopulmonare Septum zu bilden (Kirby et al., 1983). Auch vor der Septierung sind die Zellen der kardia- 
len Neuralleiste an der Herzentwicklung beteiligt (Farrell et al., 1999; Waldo et al., 1999). Nur in Anwesenheit der Neuralleistenzellen differenziert das frühe Myokard zu funktionierendem Herzgewebe (Farrell et al., 1999). Wenn umgekehrt durch Inaktivierung des Transkriptionsfaktors $T B X 1$ die Entwicklung des pharyngealen Mesoderms und des anterioren Herzfeldes unterbrochen wird, kommt es zu Fehlentwicklungen in der Septierung des Ausflußtraktes, die mit den Defekten, die durch die Ablation der kardialen Neuralleistenzellen hervorgerufen werden, vergleichbar sind (Jerome und Papaioannou, 2001). Ebenfalls stört die Überexpression von Noggin im Trunkus arteriosus die Septierung des Ausflußtraktes (Allen et al., 2001). Da Noggin die cSzl-Expression herunterreguliert, ist dies ein indirekter Hinweis auf die zentrale Aufgabe des $c S z l$-positiven Mesoderms bei der regulären Differenzierung des arteriellen Gefäßsystems.

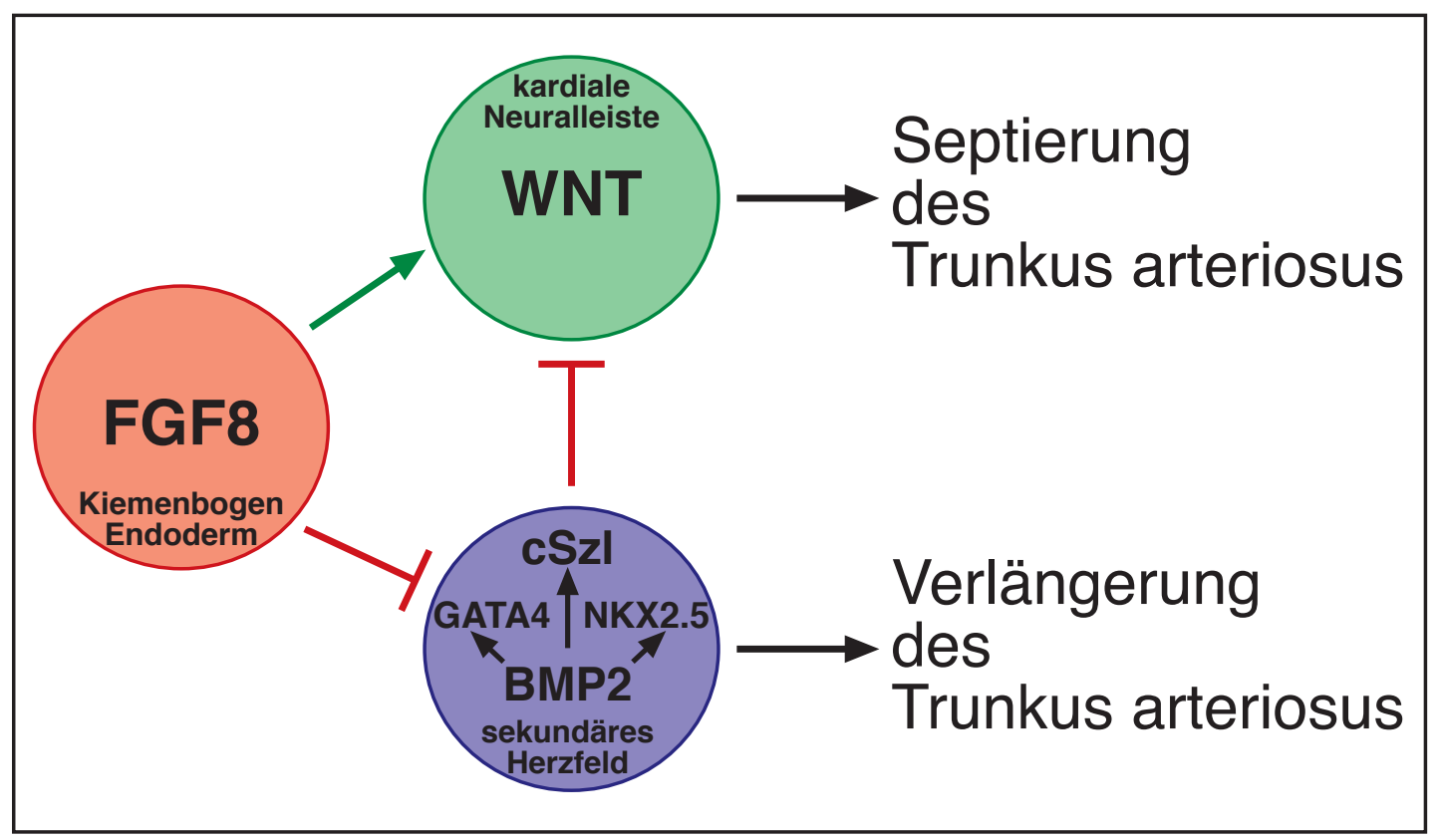

Abb. 4. 5.: Interaktionen von Endoderm-, Mesoderm- und Ektodermderivaten bei der Morphogenese des arteriellen Systems. FGF8 aus dem Kiemenbogenendoderm aktiviert Wnt-Signale, die in den Zellen der kardialen Neuralleiste den kanonischen Wnt-Signalweg erhalten. Gleichzeitig stabilisiert das FGF8-Signal das sekundäre Herzfeld im splanchnischen Mesoderm. Der inhibitorische Einfluß des Wnt-Antagonisten $c S z l$ kontrolliert die kardialen Neuralleistenzellen während der Verlängerung des Trunkus arteriosus; erst nach Abschluß der sekundären Kardiogenese können die kardialen Neuralleistenzellen das aorikopulmonare Septum ausbilden.

Anomalien in der Entwicklung des Trunkus arteriosus sind ein typischer Phänotyp angeborener Herzdefekte. Insbesondere bei neugeborenen Kindern, die am DiGeorgeSyndrom leiden, ist die normale Differenzierung der Neuralleistenzellen gestört 
(Goldmuntz und Emanuel, 1997). Der DiGeorge-Phänotyp kann einerseits durch Ablation der kardialen Neuralleiste im Huhn, andererseits durch die genetische Inaktivierung von TBXI im sekundären Herzfeld nachgestellt werden (Creazzo et al., 1998; Jerome und Papaioannou, 2001). Durch die Anwesenheit von cSzl im Mesoderm des sekundären Herzfelds kann eine mechanistische Verbindung zwischen den Zellen der kardialen Neuralleiste und der Funktion des splanchnischen Mesoderms bei der Differenzierung des arteriellen kardiovasklären Systems hergestellt werden. Bevor die Zellen der Neuralleiste aus dem dorsalen Neuralrohr auszuwandern beginnen, sind in ihnen Wnt3a und Wnt1 aktiv (Conway et al., 2000; Dorsky et al., 1998). Die gleichzeitige genetische Inaktivierung von Wnt3a und Wnt1 in der Maus führte zu Fehlbildungen in der Neuralleiste (Ikeya et al., 1997). In den migrierenden Neuralleistenzellen sind zwar keine Transkripte von Wnt-Faktoren nachweisbar, dennoch unterliegen die Neuralleistenzellen weiterhin Wnt-Signalen. Zum einen können die $W n t 3 a$ - und Wnt1-Proteine weiterhin mit den Neuralleistenzellen assoziiert sein, zum anderen werden im Ektoderm der Kiemenbögen, an dem die Neuralleistenzellen entlangwandern, Wnt6, Wnt7 und Wnt2a (Schubert et al., 2002) exprimiert, die die Zielgene des kanonischen Wnt-Signalweges in den migrierenden Zellen aktiv halten könnten. Die Wnt-Signale steuern die Migration und die Proliferation der Neuralleistenzellen. Erst wenn die Neuralleistenzellen das splanchnische Mesoderm erreichen, werden die Wnt-Proteine durch cSzl inhibiert, die Wanderung der Zellen wird gestoppt und sie ändern ihr Differenzierungsprogramm. Wird cSzl im Stadium HH25 herunterreguliert, können die Neuralleistenzellen das aortikopulmonare Septum bilden.

Mit $c S z l$ wurde ein Faktor analysiert, der sehr selektiv in der Phase der morphogenetischen Remodelierung des arteriellen Pols am Ausflußtrakt des Herzens exprimiert ist. $c S z l$ wird von den Schlüsselmolekülen der Kardiogenese, $B M P 2$ und $F G F 8$ reguliert und hat als Wnt-Antagonist eine zentrale Funktion im Zusammenspiel von ektodermalen Neuralleistenzellen, dem endodermalen Pharynx und dem splanchnischen Mesoderm bei der Differenzierung des arteriellen Gefäßsystems. Fehler in dieser kritischen Phase der Entwicklung des Kreislaufsystems führen zu kardialen Defekten, die auch bei angeborenen Herzfehlern im Menschen eine wichtige Rolle spielen. Die Expression des Wnt-Antagonisten $c S z l$ ist ein Hinweis darauf, daß Wnt-Antagonismus 
während der entscheidenden Differenzierungsvorgänge am Ausflußtrakt ein bisher unbekannter morphogenetischer Mechanismus sein kann. In zukünftigen Experimenten muß geklärt werden, inwiefern Wnt-Antagonisten an der Ausprägung von Entwicklungsdefekten in der Ausbildung des Ausflußtraktes beteiligt sind. 


\section{Zusammenfassung}

Im ersten Teil der vorliegenden Arbeit wurde die Rolle des Knotens des Mausembryos als Quelle für Signale, die eine anteriore Neuralplatte induzieren können, untersucht. Die Initiierung der Vorderhirnanlage beruht im Säuger auf Signalen aus dem anterioren, primitiven Endoderm. Dennoch sind, wie in dieser Arbeit gezeigt werden konnte, Signale aus der Spitze des Primitivstreifens ausreichend und notwendig, um eine stabile Vorderhirnidentität zu etablieren. Die Ergebnisse erlauben eine Neubewertung der Hypothese um räumlich getrennte Kopf- und Rumpforganisatoren im Säugerembryo. Anteriore Neuralinduktion kann demnach durch ein erweitertes Aktivierungs-Transformations-Modell beschrieben werden, bei der die Neuralidentität durch extraembryonales Endoderm initiiert und durch den frühen Gastrula-Organisator stabilisiert wird.

Im zweiten Teil der Arbeit wurde innerhalb eines Expressionsscreens eine Synexpressionsgruppe gefunden, deren Gene im Endo-, Meso- und Mesendoderm, aber nicht im Ektoderm der prächordalen Region exprimiert sind. Eines dieser Gene ist der bisher im Huhn noch nicht bekannte, sekretierte Wnt-Antagonist $c S z l$. cSzl ist im anterioren Endoderm und in der Herzanlage vom Stadium HH4 bis zum Stadium HH25 exprimiert und markiert dort den anterioren Pol des Herzschlauches. $c S z l$ wird von den wichtigsten Signalmolekülen der frühen Musterbildung und der Kardiogenese reguliert. Mit Hilfe der untersuchten regulativen Mechanismen konnte ein Modell für die Etablierung des anterioren lateralen Mesoderms im Gastrulaembryo aufgestellt werden, in dem $c S z l$ als Wnt-Antagonist eine zentrale Rolle spielt. Während der Kardiogenese ist $c S z l$ ein einzigartiger Marker für das sekundäre Herzfeld, einer Schlüsselstruktur in der Differenzierung des arteriellen kardiovaskulären Systems. Da die Zellen der kardialen Neuralleiste mit den $c S z l$-positiven Zellen in direkter Beziehung stehen, könnte Wnt-Antagonismus ein bisher unbekannter Mechanismus bei der Septierung des Trunkus arteriosus sein, dessen Fehlsteuerung zu angeborenen Herzdefekten führt, wie sie beim humanen DiGeorge-Syndrom beobachtet werden. 


\section{Literaturverzeichnis}

Acampora, D., Mazan, S., Lallemand, Y., Avantaggiato, V., Maury, M., Simeone, A. und Brulet, P. (1995). Forebrain and midbrain regions are deleted in otx2(-/-) mutants due to a defective anterior neuroectoderm specification during gastrulation. Development 121, 3279-3290.

Adelmann, H. B. (1922). The significance of the prechordal plate. Am. J. Anat. 31, 55-101.

Allen, S. P., Bogardi, J. P., Barlow, A. J., Mir, S. A., Qayyum, S. R., Verbeek, F. J., Anderson, R. H., Francis-West, P. H., Brown, N. A. und Richardson, M. K. (2001). Misexpression of noggin leads to septal defects in the outflow tract of the chick heart. Dev. Biol. 235, 98-109.

Andree, B., Duprez, D., Vorbusch, B., Arnold, H. H. und Brand, T. (1998). Bmp-2 Induces Ectopic Expression of Cardiac Lineage Markers and Interferes With Somite Formation in Chicken Embryos. Mech. Dev. 70, 119-131.

Ang, S.-L., Conlon, R. A., Jin, O. und Rossant, J. (1994). Positive and negative signals from mesoderm regulate the expression of mouse Otx2 in ectoderm explants. Development 120, 2979-2989.

Ang, S. L. und Rossant, J. (1994). HNF-3 beta is essential for node and notochord formation in mouse development. Cell 78, 561-574.

Arendt, D. und Nubler-Jung, K. (1999). Rearranging gastrulation in the name of yolk: evolution of gastrulation in yolk-rich amniote eggs. Mech. Dev. 81, 3-22.

Azar, Y. und Eyal-Giladi, H. (1979). Marginal zone cells- the primitive streak-inducing component of the primary hypoblast in the chick. J. Embryol. exp. Morph. 52, 79-88.

Bachiller, D., Klingensmith, J., Kemp, C., Belo, J. A., Anderson, R. M., May, S. R., McMahon, J. A., McMahon, A. P., Harland, R. M., Rossant, J. und De Robertis, E. M. (2000). The organizer factors Chordin and Noggin are required for mouse forebrain development. Nature 403, 658-661.

Bachvarova, R. F., Masi, T., Hall, L. und Johnson, A. D. (2001). Expression of Axwnt-8 and Axszl in the urodele, axolotl: comparison with Xenopus. Dev. Genes Evol. 211, 501-505. 
Bachvarova, R. F., Skromne, I. und Stern, C. D. (1998). Induction of primitive streak and Hensen's node by the posterior marginal zone in the early chick embryo. Development 125, 3521-3534.

Basilico, C. und Moscatelli, D. (1992). The FGF family of growth factors and oncogenes. Adv. Cancer Res. 59, 115-165.

Beddington, R. S. (1994). Induction of a second neural axis by the mouse node. Development 120, 613-620.

Beddington, R. S. P. und Robertson, E. (1998). Anterior patterning in mouse. Trends Genet. 14, 277-284.

Boettger, T., Knoetgen, H., Wittler, L. und Kessel, M. (2001). The avian organizer. Int. J. Dev. Biol. 45, 281-287.

Chapman, S. C., Collignon, J., Schoenwolf, G. C. und Lumsden, A. (2001). Improved method for chick whole-embryo culture using a filter paper carrier. Dev. Dyn. 220, 284-289.

Chapman, S. C., Schubert, F. R., Schoenwolf, G. C. und Lumsden, A. (2002). Analysis of spatial and temporal gene expression patterns in blastula and gastrula stage chick embryos. Dev. Biol. 245, 187-199.

Chen, Y. L., Pollet, N., Niehrs, C. und Pieler, T. (2001). Increased XRALDH2 activity has a posteriorizing effect on the central nervous system of Xenopus embryos. Mech. Dev. 101, 91-103.

Chong, J. M., Uren, A., Rubin, J. S. und Speicher, D. W. (2002). Disulfide bond assignments of secreted frizzled-related protein-1 provide insights about frizzled homology and netrin modules. J. Biol. Chem. 277, 5134-5144.

Conway, S. J., Bundy, J., Chen, J., Dickman, E., Rogers, R. und Will, B. M. (2000). Decreased neural crest stem cell expansion is responsible for the conotruncal heart defects within the splotch $(\mathrm{Sp}(2 \mathrm{H})) / \mathrm{Pax} 3$ mouse mutant. Cardiovasc. Res. 47, 314328 .

Creazzo, T. L., Godt, R. E., Leatherbury, L., Conway, S. J. und Kirby, M. L. (1998). Role of cardiac neural crest cells in cardiovascular development. Ann. Rev. Physiol. $60,267-286$.

Dattani, M. T., Martinezbarbera, J. P., Thomas, P. Q., Brickman, J. M., Gupta, R., Martensson, I. L., Toresson, H., Fox, M., Wales, J. K. H., Hindmarsh, P. C., Krauss, S., Beddington, R. S. P. und Robinson, I. (1998). Mutations in the homeobox gene Hesx1/Hesx1 associated with septo-optic dysplasia In human and mouse. Nat. Genet. $19,125-133$. 
de la Cruz, M. V., Sanchez Gomez, C., Arteaga, M. M. und Arguello, C. (1977). Experimental study of the development of the truncus and the conus in the chick embryo. J. Anat. 123, 661-686.

De Robertis, E. M. (1995). Dismantling the organizer. Nature 374, 407-408.

De Robertis, E. M., Larrain, J., Oelschläger, M. und Wessely, O. (2000). The establishment of Spemann's organizer and patterning of the vertebrate embryo. Nature Rev. Genet. 1, 171-181.

Dennis, S., Aikawa, M., Szeto, W., d'Amore, P. A. und Papkoff, J. (1999). A secreted Frizzled related protein, FrzA, selectively associates with Wnt-1 protein and regulates Wnt-1 signaling. J. Cell Sc. 112, 3815-3820.

Dias, M. S. und Schoenwolf, G. C. (1990). Formation of ectopic neurepithelium in chick blastoderms: age-related capacities for induction and self-differentiation following transplantation of quail Hensen's nodes. Anat. Rec. 228, 437-448.

Dickmeis, T., Rastegar, S., Aanstad, P., Clark, M., Fischer, N., Korzh, V. und Strahle, U. (2001). Expression of the anti-dorsalizing morphogenetic protein gene in the zebrafish embryo. Dev. Genes Evol. 211, 568-572.

Dietrich, S., Schubert, F. R. und Lumsden, A. (1997). Control of dorsoventral pattern in the chick paraxial mesoderm. Development 124, 3895-3908.

Dorsky, R. I., Moon, R. T. und Raible, D. W. (1998). Control of neural crest cell fate by the Wnt signalling pathway. Nature 396, 370-373.

Downs, K. M. und Davies, T. (1993). Staging of gastrulating mouse embryos by morphological landmarks in the dissecting microscope. Development 118, 1255-1266.

Eyal-Giladi, H., Debby, A. und Harel, N. (1992). The posterior section of the chick's area pellucida and its involvement in hypoblast and primitive streak formation. Development 116, 819-830.

Eyal-Giladi, H. und Kochav, S. (1976). From cleavage to primitive streak formation: a complementary normal table and a new look at the first stages of the development of the chick. I. General morphology. Dev. Biol. 49, 321-337.

Farrell, M., Waldo, K., Li, Y. X. und Kirby, M. L. (1999). A novel role for cardiac neural crest in heart development. Trends Cardiovasc. Med. 9, 214-220.

Farrell, M. J., Burch, J. L., Wallis, K., Rowley, L., Kumiski, D., Stadt, H., Godt, R. E., Creazzo, T. L. und Kirby, M. L. (2001). FGF-8 in the ventral pharynx alters development of myocardial calcium transients after neural crest ablation. J. Clinic. Invest. 107, 1509-1517. 
Filosa, S., Riveraperez, J. A., Gomez, A. P., Gansmuller, A., Sasaki, H., Behringer, R. R. und Ang, S. L. (1997). Goosecoid and Hnf-3-beta genetically interact to regulate neural tube patterning during mouseembryogenesis. Development 124, 2843-2854.

Foley, A. C., Skromne, I. und Stern, C. D. (2000). Reconciling different models of forebrain induction and patterning: a dual role for the hypoblast. Development 127, 3839-3854.

Garcia-Martinez, V., Alvarez, I. S. und Schoenwolf, G. C. (1993). Locations of the ectodermal and nonectodermal subdivisions of the epiblast at stages 3 and 4 of avian gastrulation and neurulation. J. Exp. Zool. 267, 431-446.

Garcia-Martinez, V. und Schoenwolf, G. C. (1993). Primitive-streak origin of the cardiovascular system in avian embryos. Dev. Biol. 159, 706-719.

Glinka, A., Wu, W., Delius, H., Monaghan, A. P., Blumenstock, C. und Niehrs, C. (1998). Dickkopf-1 Is a Member of a New Family of Secreted Proteins and Functions in Head Induction. Nature 391, 357-362.

Goldmuntz, E. und Emanuel, B. S. (1997). Genetic disorders of cardiac morphogenesis. The DiGeorge and velocardiofacial syndromes. Circ. Res. 80, 437-43.

Gurdon, J. B. (1987). Embryonic induction - molecular prospects. Development 99, 285-306.

Guthrie, S., Muchamore, I., Kuroiwa, A., Marshall, H., Krumlauf, R. und Lumsden, A. (1992). Neuroectodermal autonomy of Hox-2.9 expression revealed by rhombomere transpositions. Nature 356, 157-159.

Hamburger, V. und Hamilton, H. L. (1951). A series of normal stages in the development of the chick embryo. J. Morph. 88, 49-92.

Hara, K. (1961). Regional neural differentiation induced by prechordal and presumptive chordal mesoderm in the chick embryo. Ph.d. Thesis, Utrecht.

Hatada, Y. und Stern, C. D. (1994). A fate map of the epiblast of the early chick embryo. Development 120, 2879-2890.

Hensen, V. (1876). Beobachtungen über die Befruchtung und Entwicklung des Kaninchens und Meerschweinchens. Z. Anat. Entw. Gesch. 1, 353-423.

Hoang, B. H., Thomas, J. T., Abdul-Karim, F. W., Correia, K. M., Conlon, R. A., Luyten, F. P. und Ballock, R. T. (1998). Expression pattern of two Frizzled-related genes, Frzb-1 and Sfrp-1, during mouse embryogenesis suggests a role for modulating action of Wnt family members. Dev. Dyn. 212, 364-372.

Hogan, B. L. (1996). Bone morphogenetic proteins in development. Curr. Op. Genet. Dev. 6, 432-438. 
Ikeya, M., Lee, S. M. K., Johnson, J. E., McMahon, A. P. und Takada, S. (1997). Wnt Signalling Required For Expansion of Neural Crest and Cns Progenitors. Nature 389, 966-970.

Inagaki, T., Garcia-Martinez, V. und Schoenwolf, G. C. (1993). Regulative ability of the prospective cardiogenic and vasculogenic areas of the primitive streak during avian gastrulation. Dev. Dyn. 197, 57-68.

Inagaki, T. und Schoenwolf, G. C. (1993). Axis development in avian embryos: the ability of Hensen's node to self-differentiate, as analyzed with heterochronic grafting experiments. Anat. Embryol. 188, 1-11.

Itoh, K. und Sokol, S. Y. (1999). Axis determination by inhibition of Wnt signaling in Xenopus. Genes Dev. 13, 2328-2336.

Jaspard, B., Couffinhal, T., Dufourcq, P., Moreau, C. und Duplaa, C. (2000). Expression pattern of mouse sFRP-1 and mWnt-8 gene during heart morphogenesis. Mech. Dev. 90, 263-267.

Jerome, L. A. und Papaioannou, V. E. (2001). DiGeorge syndrome phenotype in mice mutant for the T-box gene, Tbx1. Nat. Genet. 27, 286-291.

Jiang, Y., Tarzami, S., Burch, J. B. und Evans, T. (1998). Common role for each of the cGATA-4/5/6 genes in the regulation of cardiac morphogenesis. Dev. Genet. 22, 263277.

Joubin, K. und Stern, C. D. (1999). Molecular interactions continuously define the organizer during the cell movements of gastrulation. Cell 98, 559-571.

Kiecker, C. und Niehrs, C. (2001). A morphogen gradient of Wnt/beta-catenin signalling regulates anteroposterior neural patterning in Xenopus. Development 128, 41894201 .

Kirby, M. M. L., Turnage, K. L. und Hays, R. M. (1983). Neural crest cells contribute to aorticopumonary septation. Science 220, 1059-1061.

Kishimoto, Y., Lee, K. H., Zon, L., Hammerschmidt, M. und Schulte-Merker, S. (1997). The molecular nature of zebrafish swirl: BMP2 function is essential during early dorsoventral patterning. Development 124, 4457-4466.

Knezevic, V. und Mackem, S. (2001). Activation of epiblast gene expression by the hypoblast layer in the prestreak chick embryo. Genesis 30, 264-273.

Knoetgen, H., Viebahn, C. und Kessel, M. (1999a). Head induction in the chick by primitive endoderm of mammalian, but not avian origin. Development 126, 815-825.

Knoetgen, H., Teichmann, U. und Kessel, M. (1999b). Head-organizing activities of endodermal tissues in vertebrates. Cell. Mol. Biol. 45, 481-492. 
Knoetgen, H., Teichmann, U., Wittler, L., Viebahn, C. und Kessel, M. (2000). Anterior neural induction by nodes from rabbits and mice. Dev. Biol. 225, 370-380

Kuhl, M., Sheldahl, L. C., Park, M., Miller, J. R. und Moon, R. T. (2000). The Wnt/ $\mathrm{Ca} 2+$ pathway: a new vertebrate Wnt signaling pathway takes shape. Trends Genet. $16,279-283$.

Lemaire, L., Roeser, T., Izpisua-Belmonte, J.-C. und Kessel, M. (1997). Segregating expression domains of two goosecoid genes during the transition from gastrulation to neurulation in chick embryos. Development 124, 1443-1452.

Leyns, L., Bouwmeester, T., Kim, S. H., Piccolo, S. und De Robertis, E. M. (1997). Frzb-1 is a secreted antagonist of Wnt signaling expressed in the Spemann organizer. Cell 88, 747-756.

Lopez-Sanchez, C., Garcia-Martinez, V. und Schoenwolf, G. C. (2001). Localization of cells of the prospective neural plate, heart and somites within the primitive streak and epiblast of avian embryos at intermediate primitive-streak stages. Cells Tissues Organs 169, 334-346.

Lough, J. und Sugi, Y. (2000). Endoderm and heart development. Dev. Dyn. 217, $327-$ 342.

Marvin, M. J., Di Rocco, G., Gardiner, A., Bush, S. M. und Lassar, A. B. (2001). Inhibition of Wnt activity induces heart formation from posterior mesoderm. Genes Dev. $15,316-327$.

Massague, J. (2000). How cells read TGF-beta signals. Nature Rev. Mol. Cell Biol. 1, 169-178.

Massague, J., Blain, S. W. und Lo, R. S. (2000). TGFbeta signaling in growth control, cancer und heritable disorders. Cell. 103, 295-309.

Massague, J. und Chen, Y. G. (2000). Controlling TGF-beta signaling. Genes Dev. 14, 627-644.

Matsuo, I., Kuratani, S., Kimura, C., Takeda, N. und Aizawa, S. (1995). Mouse otx2 functions in the formation and patterning of rostral head. Genes Dev. 9, 2646-2658.

Mjaatvedt, C. H., Nakaoka, T., Moreno-Rodriguez, R., Norris, R. A., Kern, M. J., Eisenberg, C. A., Turner, D. und Markwald, R. R. (2001). The outflow tract of the heart is recruited from a novel heart-forming field. Dev. Biol. 238, 97-109.

Montgomery, M. O., Litvin, J., Gonzalez-Sanchez, A. und Bader, D. (1994). Staging of commitment and differentiation of avian cardiac myocytes. Dev. Biol. 164, 63-71.

Moos, M., Jr., Wang, S. und Krinks, M. (1995). Anti-dorsalizing morphogenetic protein is a novel TGF-beta homolog expressed in the Spemann organizer. Development 121, 4293-4301. 
Morgan, B. A. und Fekete, D. M. (1996). Manipulating gene expression with replication-competent retroviruses. Methods in Cell Biology. 51, 185-218.

Muhr, J., Jessell, T. M. und Edlund, T. (1997). Assignment of Early Caudal Identity to Neural Plate Cells By a Signal From Caudal Paraxial Mesoderm. Neuron 19, 487502.

New, D. A. T. (1955). A new technique for the cultivation of the chick embryo in vitro. J. Embryol. exp. Morph. 3, 320-331.

Niehrs, C. (1999). Head in the WNT - the molecular nature of Spemann's head organizer. Trends Genet. 15, 314-319.

Nieuwkoop, P. D. (1952). Activation and organization of the central nervous system in amphibians, parts I-III. J. Exp. Zool. 120, 1-108.

Nordstrom, U., Jessell, T. M. und Edlund, T. (2002). Progressive induction of caudal neural character by graded Wnt signaling Nature Neuroscience 5, 525-530.

Nusse, R. und Varmus, H. E. (1992). Wnt genes. Cell 69, 1073-1087.

Ornitz, D. M. und Itoh, N. (2001). Fibroblast growth factors. Genome Biology. 2, 3005.1-3005.12

Pandur, P., Lasche, M., Eisenberg, L. M. und Kuhl, M. (2002). Wnt-11 activation of a non-canonical Wnt signalling pathway is required for cardiogenesis. Nature 418, 636641.

Pera, E. M. und De Robertis, E. M. (2000). A direct screen for secreted proteins in Xenopus embryos identifies distinct activities for the Wnt antagonists Crescent and Frzb-1. Mech. Dev. 96, 183-195.

Pera, E. M. und Kessel, M. (1997). Patterning of the Chick Forebrain Anlage By the Prechordal Plate. Development 124, 4153-4162.

Pfeffer, P. L., De Robertis, E. M. und Izpisua-Belmonte, J. C. (1997). Crescent, a novel chick gene encoding a Frizzled-like cysteine-rich domain, is expressed in anterior regions during early embryogenesis. Int. J. Dev. Biol. 41, 449-458.

Piccolo, S., Sasai, Y., Lu, B. und De Robertis, E. M. (1996). Dorsoventral patterning in Xenopus: Inhibition of ventral signals by direct binding of chordin to BMP-4. Cell $86,589-598$.

Potts, W. M., Olsen, M., Boettiger, D. und Vogt, V. M. (1987). Epitope mapping of monoclonal antibodies to gag protein p19 of avian sarcoma and leukaemia viruses. J. Gen. Virol. 68, 3177-3182.

Psychoyos, D. und Stern, C. D. (1996). Fates and migratory routes of primitive streak cells in the chick embryo. Development 122, 1523-1534. 
Rattner, A., Hsieh, J. C., Smallwood, P. M., Gilbert, D. J., Copeland, N. G., Jenkins, N. A. und Nathans, J. (1997). A Family of Secreted Proteins Contains Homology to the Cysteine-Rich Ligand-Binding Domain of Frizzled Receptors. Proc. Natl. Acad. Sci. USA 94, 2859-2863.

Rosenquist, G. C. (1966). A radioautographic study of labeled grafts in the chick blastoderm. Development from primitive-streak stages to stage 12. Carn. Contr. Embryol. 38, 31-110.

Saiki, R. K., Gelfand, D. H., Stoffel, S., Scharf, S. J., Higuchi, R., Horn, G. T., Mullis, K. B. und Erlich, H. A. (1988). Primer directed enzymatic amplification of DNA with a thermostable DNA polymerase. Science 239, 487-494.

Salic, A. N., Kroll, K. L., Evans, L. M. und Kirschner, M. W. (1997). Sizzled - a Secreted Xwnt8 Antagonist Expressed in the Ventral Marginal Zone of Xenopus Embryos. Development 124, 4739-4748.

Schlange, T., Andree, B., Arnold, H. H. und Brand, T. (2000). BMP2 is required for early heart development during a distinct time period. Mech. Dev. 91, 259-270.

Schneider, V. A. und Mercola, M. (2001). Wnt antagonism initiates cardiogenesis in Xenopus laevis. Genes Dev. 15, 304-315.

Schoenwolf, G. C. (1983). The chick epiblast: a model for examining epithelial morphogenesis. Scanning Electron Microscopy 3, 1371-1385.

Schoenwolf, G. C., Garcia-Martinez, V. und Dias, M. S. (1992). Mesoderm movement and fate during avian gastrulation and neurulation. Dev. Dyn. 193, 235-248.

Schoenwolf, G. C. und Powers, M. L. (1987). Shaping of the chick neuroepithelium during primary and secondary neurulation: role of cell elongation. Anat. Rec. 218, 182-195.

Schoenwolf, G. C. und Sheard, P. (1990). Fate mapping the avian epiblast with focal injections of a fluorescent-histochemical marker: ectodermal derivatives. J. Exp. Zool. 255, 323-339.

Schoenwolf, G. C. und Watterson, R. L. (1989). Laboratory studies of chick, pig und frog embryos, sixth edition Edition (New York: Macmillan).

Schubert, F. R., Mootoosamy, R. C., Walters, E. H., Graham, A., Tumiotto, L., Munsterberg, A. E., Lumsden, A. und Dietrich, S. (2002). Wnt6 marks sites of epithelial transformations in the chick embryo. Mech. Dev. 114, 143-148.

Schultheiss, T. M., Burch, J. B. E. und Lassar, A. B. (1997). A Role For Bone Morphogenetic Proteins in the Induction of Cardiac Myogenesis. Genes Dev. 11, 451-462. 
Schultheiss, T. M., Xydas, S. und Lassar, A. B. (1995). Induction of Avian Cardiac Myogenesis By Anterior Endoderm. Development 121, 4203-4214.

Selleck, M. A. und Stern, C., D. (1991). Fate mapping and cell lineage analysis of Hensen`s node in the chick embryo. Development 112, 615-626.

Shawlot, W. und Behringer, R. R. (1995). Requirement for Lim1 in head-organizer function. Nature 374, 425-430.

Shibata, M., Ono, H., Hikasa, H., Shinga, J. und Taira, M. (2000). Xenopus crescent encoding a Frizzled-like domain is expressed in the Spemann organizer and pronephros. Mech. Dev. 96, 243-246.

Skromne, I. und Stern, C. D. (2002). A hierarchy of gene expression accompanying induction of the primitive streak by Vg1 in the chick embryo. Mech. Dev. 114, 115118.

Skromne, I. und Stern, C. D. (2001). Interactions between Wnt and Vg1 signalling pathways initiate primitive streak formation in the chick embryo. Development 128, 2915-2927.

Spemann, H. und Mangold, H. (1924). Über die Induktion von Embryoanlagen durch Implantation artfremder Organisatoren. Roux Arch. Entw. Mech. 100, 599-638.

Spratt, N. T. (1952). Localization of the prospective neural plate in the early chick blastoderm. J. Exp. Zool. 120, 109-130.

Stern, C. D. (1993). Avian Embryos, C. D. Stern and P. W. H. Holland, eds. (Oxford: IRL Press).

Stern, C. D. (2000). Conrad H. Waddington's contributions to avian and mammalian development, 1930-1940. Int. J. Dev. Biol. 44, 15-22.

Storey, K. G., Crossley, J. M., De Robertis, E. M., Norris, W. E. und Stern, C. D. (1992). Neural induction and regionalisation in the chick embryo. Development 114, 729-741.

Storey, K. G., Goriely, A., Sargent, C. M., Brown, J., Burns, H. D., Abud, H. M. und Heath, J. K. (1998). Early posterior neural tissue is induced by FGF in the chick Embryo. Development 125, 473-484.

Streit, A., Berliner, A. J., Papanayotou, C., Sirulnik, A. und Stern, C. D. (2000). Initiation of neural induction by FGF signalling before gastrulation. Nature 406, 74-78.

Tam, P. P. L. und Behringer, R. R. (1997). Mouse Gastrulation - The formation of a Mammalian body plan. Mech. Dev. 68, 3-25.

Tam, P. P. L. und Steiner, K. A. (1999). Anterior patterning by synergistic activity of the early gastrula organizer and the anterior germlayer tissues of the mouse embryo. Development 126, 5171-5179. 
Thomas, P. und Beddington, R. (1996). Anterior primitive endoderm may be responsible for patterning the anterior neural plate in the mouse embryo. Curr. Biol. 6, 14871496.

Tsang, T. E., Kinder, S. J. und Tam, P. P. L. (1999). Experimental analysis of the emergence of left-right asymmetry of the body axis in early postimplantation mouse embryos. Cell. Mol. Biol. 45, 493-503.

Tzahor, E. und Lassar, A. B. (2001). Wnt signals from the neural tube block ectopic cardiogenesis. Genes Dev. 15, 255-260.

Uren, A., Reichsman, F., Anest, V., Taylor, W. G., Muraiso, K., Bottaro, D. P., Cumberledge, S. und Rubin, J. S. (2000). Secreted frizzled-related protein-1 binds directly to wingless and is a biphasic modulator of Wnt signaling. J. Biol. Chem. 275, 43744382 .

Varlet, I., Collignon, J. und Robertson, E. J. (1997). nodal expression in the primitive endoderm is required for specification of the anterior axis during mouse gastrulation. Development 124, 1033-1044.

Waddington, C. H. (1932). Experiments on the development of chick and duck embryos, cultivated in vitro. Philos. Trans. R. Soc. London B 221, 179-230.

Waldo, K., Miyagawa-Tomita, S., Kumiski, D. und Kirby, M. L. (1998). Cardiac neural crest cells provide new insight into septation of the cardiac outflow tract: aortic sac to ventricular septal closure. Dev. Biol. 196, 129-144.

Waldo, K., Zdanowicz, M., Burch, J., Kumiski, D. H., Stadt, H. A., Godt, R. E., Creazzo, T. L. und Kirby, M. L. (1999). A novel role for cardiac neural crest in heart development. J. Clinic. Investig. 103, 1499-1507.

Waldo, K. L., Kumiski, D. H., Wallis, K. T., Stadt, H. A., Hutson, M. R., Platt, D. H. und Kirby, M. L. (2001). Conotruncal myocardium arises from a secondary heart field. Development 128, 3179-3188.

Watt, J. M., Petitte, J. N. und Etches, R. J. (1993). Early development of the chick embryo. J. Morph. 215, 165-182.

Weinstein, D. C., Ruiz i Altaba, A., Chen, W. S., Hoodless, P., Prezioso, V. R., Jessell, T. M. und Darnell, J. E., Jr. (1994). The winged-helix transcription factor HNF-3 beta is required for notochord development in the mouse embryo. Cell 78, 575-588.

Wilkinson, D. G. (1992). In situ hybridisation; a practical approach (London: Oxford University Press).

Willert, K. und Nusse, R. (1998). Beta-catenin: a key mediator of Wnt signaling. Curr. Opinion Genet. Dev.. 8, 95-102. 
Wilson, S. I., Graziano, E., Harland, R., Jessell, T. M. und Edlund, T. (2000). An early requirement for FGF signalling in the acquisition of neural fate in the chick embryo. Curr. Biol. 10, 421-429.

Wilson, S. I., Rydstrom, A., Trimborn, T., Willert, K., Nusse, R., Jessell, T. M. und Edlund, T. (2001). The status of Wnt signalling regulates neural and epidermal fates in the chick embryo. Nature 411, 325-330.

Wodarz, A. und Nusse, R. (1998). Mechanisms of Wnt signaling in development. Ann. Rev. Cell \& Dev. Biol. 14, 59-88.

Wolpert, L., Beddington, R., Jessell, T., Lawrence, P., Meyerowitz, E. und Smith, J. (2000). Principles of Development.

Xu, Q., D'Amore, P. A. und Sokol, S. Y. (1998). Functional and biochemical interactions of Wnts with FrzA, a secreted Wnt antagonist. Development 125, 4767-4776.

Yatskievych, T. A., Ladd, A. N. und Antin, P. B. (1997). Induction of cardiac myogenesis in avian pregastrula epiblast: the role of the hypoblast and activin. Development $124,2561-2570$.

Yuan, S., Darnell, D. K. und Schoenwolf, G. C. (1995). Identification of inducing, responding und suppressing regions in an experimental model of notochord formation in avian embryos. Dev. Biol. 172, 567-584.

Zhang, H. und Bradley, A. (1996). Mice deficient for BMP2 are nonviable and have defects in amnion/chorion and cardiac development. Development 122, 2977-2986.

Zhu, L., Belo, J. A., De Robertis, E. M. und Stern, C. D. (1999). Goosecoid regulates the neural inducing strength of the mouse node. Dev. Biol. 216, 276-281. 


\section{Anhang}

\subsection{Tabellarische Zusammenstellung der durch whole mount in situ- Hybridisierung analysierten Klone aus dem Expressionsscreen}

Die Auflistung enthält den Arbeitsnamen des Klons, die zu den jeweiligen cDNAs gefundenen Homologien und eine Beschreibung der Expressionsdomänen in drei verschiedenen Entwicklungsstadien: GS: Gastrulastadium, faßt die Stadien HH4/HH5 zusammen; NS: Neurulastadium, hier sind die Stadien HH6 und HH7 zusammengenommen; VS: Stadien, in denen sich das Vorderhirn zu entwickeln beginnt (HH8HH10). Klone, die zu der ventralen Synexpressionsgruppe gehören, sind mit einem Stern markiert.

\begin{tabular}{|l|l|l|l|l|}
\hline $\begin{array}{c}\text { cDNA- } \\
\text { Nummer }\end{array}$ & \multicolumn{1}{|c|}{$\begin{array}{c}\text { Homologie der } \\
\text { cDNA }\end{array}$} & \multicolumn{1}{|c|}{$\begin{array}{c}\text { Expression } \\
\text { GS }\end{array}$} & \multicolumn{1}{|c|}{$\begin{array}{c}\text { Expression } \\
\text { NS }\end{array}$} & $\begin{array}{c}\text { Expression } \\
\text { VS }\end{array}$ \\
\hline NP009 & keine & ps/np & nf & nu \\
\hline NP013 & keine & ps/np & nu & nu \\
\hline NP021* & keine & aendo, pps & aip & nu \\
\hline NP023 & keine & ps/np & nf & nu \\
\hline NP035 & keine & ps/np & nu & nf/nr \\
\hline NP039 & keine & ne & hk & nu \\
\hline NP073 & keine & ne & ne & ne \\
\hline NP076 & $\begin{array}{l}\text { hs hypothetisches } \\
\text { Protein }\end{array}$ & hk & axmes & nu \\
\hline NP082 & hs Chromosom 14 & ps/np & ps/nf & nu \\
\hline NP085 & $\begin{array}{l}\text { gg Fettsäure- } \\
\text { bindendes Protein }\end{array}$ & ne & ps/nf & nu \\
\hline NP090 & $\begin{array}{l}\text { mm Proliferationas- } \\
\text { soziiertes Gen }\end{array}$ & ps & ps/nf & nu \\
\hline
\end{tabular}




\begin{tabular}{|c|c|c|c|c|}
\hline $\begin{array}{l}\text { cDNA- } \\
\text { Nummer }\end{array}$ & $\begin{array}{l}\text { Homologie der } \\
\text { cDNA }\end{array}$ & $\begin{array}{l}\text { Expression } \\
\text { GS }\end{array}$ & $\begin{array}{l}\text { Expression } \\
\text { NS }\end{array}$ & $\begin{array}{c}\text { Expression } \\
\text { VS }\end{array}$ \\
\hline NP102 & keine & ne & ne & $\mathrm{nu}$ \\
\hline NP104 & keine & ne & hk/anf & nu \\
\hline NP106 & $\begin{array}{l}\text { hs hypothetisches } \\
\text { Protein }\end{array}$ & ne & anf & nu \\
\hline NP130 & keine & ne & ne & anf \\
\hline NP141 & keine & ne & ne & nu \\
\hline NP145 & $\begin{array}{l}\text { mm MOESIN, } \\
\text { Zytoskelettprotein }\end{array}$ & ne & $\mathrm{np} / \mathrm{dnf}$ & $\mathrm{np} / \mathrm{dnf}$ \\
\hline NP148 & keine & $\mathrm{ps} / \mathrm{np}$ & nu & nu \\
\hline NP154 & keine & ne & nu & ne \\
\hline NP155 & $\begin{array}{l}\text { hs hypothetisches } \\
\text { Protein }\end{array}$ & $\mathrm{ps} / \mathrm{np}$ & $\mathrm{ps} / \mathrm{nf}$ & nu \\
\hline NP159 & keine & $\mathrm{ps} / \mathrm{np}$ & $\mathrm{ps} / \mathrm{nf}$ & nu \\
\hline NP160 & leptin Rezeptor Gen & $\mathrm{nu}$ & $\mathrm{ps} / \mathrm{nf}$ & nu \\
\hline PP005 & keine & ne & ne & ne \\
\hline PP009 & $\operatorname{cr} Y p t C l$ & hk & hk & nu \\
\hline PP017 & $\begin{array}{l}\text { xl Zellzykluspro- } \\
\text { tein }(X O R C 1)\end{array}$ & $\mathrm{np}$ & nu & nu \\
\hline PP021 & $\begin{array}{l}\text { hs hypothetisches } \\
\text { Protein }\end{array}$ & hk & axmes & nu \\
\hline PP037 & $\begin{array}{l}\text { hs Zellzykluspro- } \\
\text { tein }(C I N P)\end{array}$ & ubi & ubi & ubi \\
\hline PP038 & $\begin{array}{l}\text { gg Hitzeschockpro- } \\
\text { tein }\end{array}$ & ne & ne & nu \\
\hline PP042 & $\begin{array}{l}\text { mm hypothetisches } \\
\text { Protein }\end{array}$ & ne & $\mathrm{hk} / \mathrm{nf}$ & nu \\
\hline PP046 & $\begin{array}{l}\text { mm hypothetisches } \\
\text { Protein }\end{array}$ & $\mathrm{nu}$ & $\mathrm{ps} / \mathrm{nf}$ & nu \\
\hline PP052 & $\begin{array}{l}\text { rn Inhibitorprotein } \\
(P I N)\end{array}$ & $\mathrm{ps} / \mathrm{np}$ & $\mathrm{ps} / \mathrm{nf}$ & $\mathrm{nr} / \mathrm{np}$ \\
\hline PP069 & $\begin{array}{l}\text { hs hypothetisches } \\
\text { Protein }\end{array}$ & ne & ne & nu \\
\hline
\end{tabular}




\begin{tabular}{|c|c|c|c|c|}
\hline $\begin{array}{l}\text { cDNA- } \\
\text { Nummer }\end{array}$ & $\begin{array}{l}\text { Homologie der } \\
\text { cDNA }\end{array}$ & $\begin{array}{l}\text { Expression } \\
\text { GS }\end{array}$ & $\begin{array}{c}\text { Expression } \\
\text { NS }\end{array}$ & $\begin{array}{c}\text { Expression } \\
\text { VS }\end{array}$ \\
\hline PP076 & $\begin{array}{l}\text { mm Matrix Metallo- } \\
\text { proteinase }(M M P)\end{array}$ & ubi & ubi & ubi \\
\hline PP082 & $\begin{array}{l}\text { hs enhancer of zeste } \\
\text { (Chromatinprotein) }\end{array}$ & $\mathrm{ps} / \mathrm{np} / \mathrm{hk}$ frei & $\begin{array}{l}\mathrm{ps} / \mathrm{nf} / \mathrm{hk} \text { und } \\
\text { ax frei }\end{array}$ & $\mathrm{nr} / \mathrm{np} / \mathrm{ax}$ frei \\
\hline PP092 & $\begin{array}{l}\text { hs hypothetisches } \\
\text { Protein }\end{array}$ & ubi & ubi & ubi \\
\hline PP095 & $\begin{array}{l}\text { gg Transmembran- } \\
\text { protein }(L A M P)\end{array}$ & nu & nu & $\mathrm{tel} / \mathrm{nc}$ \\
\hline PP101 & $\begin{array}{l}\text { mm Zinkfingerpro- } \\
\text { tein }(Z A N 75)\end{array}$ & $\mathrm{np}$ & $\mathrm{nf} / \mathrm{np}$ & $\mathrm{nu}$ \\
\hline PP106 & $\begin{array}{l}\text { hs Mikrotubuli } \\
\text { assoziiertes Protein }\end{array}$ & $\mathrm{ps} / \mathrm{np}$ & $\begin{array}{l}\text { nf } / \mathrm{hk} \text { und ax } \\
\text { frei }\end{array}$ & $\mathrm{nr}$ \\
\hline PP112 & $\begin{array}{l}\text { gg Serin/Tyrosinki- } \\
\text { nase }(N E K l)\end{array}$ & hk & hk/axmes & anf \\
\hline PP116* & $\begin{array}{l}\text { gg Transkriptions- } \\
\text { faktor }(G A T A 2)\end{array}$ & aendo & aip/latendo & extraend \\
\hline PP120 & $\begin{array}{l}\text { rn Kaliumkanal } \\
\text { Regulator }\end{array}$ & ne & nu & mes \\
\hline PP124* & $\begin{array}{l}\text { gg Stamzellantigen } \\
(S C A 2)\end{array}$ & vendo & aip & herz/kb \\
\hline PP130 & $\begin{array}{l}\text { hs hypothetisches } \\
\text { Protein }\end{array}$ & $\mathrm{ps} / \mathrm{np}$ & $\mathrm{ps} / \mathrm{nf}$ & $\mathrm{dnf} / \mathrm{nc}$ \\
\hline PP134 & $\begin{array}{l}\text { gg Chromatin Pro- } \\
\text { tein }(H M G 17)\end{array}$ & ne & ubi & ubi \\
\hline PP155 & keine & ne & ne & ne \\
\hline PP156 & $\begin{array}{l}\text { hs hypothetisches } \\
\text { Protein }\end{array}$ & ubi & ubi & ubi \\
\hline PP157 & $\begin{array}{l}\text { Signaltransdutions- } \\
\text { komplexprotein }\end{array}$ & $\mathrm{ps} / \mathrm{np}$ & $\mathrm{nf}$ & $\mathrm{nr}$ \\
\hline PP158 & $\begin{array}{l}\text { hs hypothetisches } \\
\text { Protein }\end{array}$ & ubi & ubi & ubi \\
\hline PP180 & keine & ne & ne & ne \\
\hline PP190 & $\begin{array}{l}\text { hs Transkription- } \\
\text { assoziiertes Protein }\end{array}$ & ne & ne & ne \\
\hline PP192 & gg EST & ps & $\operatorname{dnf}$ & $\mathrm{dnf} / \mathrm{dnr} / \mathrm{nc}$ \\
\hline
\end{tabular}




\begin{tabular}{|c|c|c|c|c|}
\hline $\begin{array}{l}\text { cDNA- } \\
\text { Nummer }\end{array}$ & $\begin{array}{l}\text { Homologie der } \\
\text { cDNA }\end{array}$ & $\begin{array}{l}\text { Expression } \\
\text { GS }\end{array}$ & $\begin{array}{l}\text { Expression } \\
\text { NS }\end{array}$ & $\begin{array}{c}\text { Expression } \\
\text { VS }\end{array}$ \\
\hline PP205 & $\begin{array}{l}\text { hs hypothetisches } \\
\text { Protein }\end{array}$ & ne & ne & ne \\
\hline PP207 & $\begin{array}{l}\text { hs hypothetisches } \\
\text { Protein }\end{array}$ & hk & ne & ne \\
\hline PP208 & $\begin{array}{l}\text { hs p53-bindendes } \\
\text { Protein }\end{array}$ & ne & $\mathrm{nf}$ & $\mathrm{nr}$ \\
\hline PP214 & $\begin{array}{l}\text { hs hypothetisches } \\
\text { Protein }\end{array}$ & $\mathrm{ps} / \mathrm{np}$ & $\mathrm{ps} / \mathrm{nf}$ & $\mathrm{nr}$ \\
\hline PP216 & keine & aps & ne & ne \\
\hline PP219 & gg EST & ubi & ubi & ubi \\
\hline PP227* & $\begin{array}{l}\text { hs hypothetisches } \\
\text { Protein }\end{array}$ & pps & aend & aip \\
\hline PP232 & $\begin{array}{l}\text { gg Rezeptor Tyro- } \\
\text { sinkinase }\end{array}$ & ne & ne & ne \\
\hline PP234 & $\begin{array}{l}\text { GTP bindendes Pro- } \\
\text { tein }\end{array}$ & $\mathrm{ps} / \mathrm{np}$ & nu & $\mathrm{nf} / \mathrm{nr}$ \\
\hline PP242 & keine & ne & hk/anf & $\mathrm{nr}$ \\
\hline PP246 & $\begin{array}{l}\text { hs RNA bindendes } \\
\text { Protein }\end{array}$ & nu & hk/axmes & $\mathrm{nf} / \mathrm{nr}$ \\
\hline PP269 & $\begin{array}{l}\text { mm hypothetisches } \\
\text { Protein }\end{array}$ & $\mathrm{np}$ & $\mathrm{nf}$ & $\mathrm{nr}$ \\
\hline PP274 & $\begin{array}{l}\text { mm Pannexin } \\
(P A N X 1)\end{array}$ & aps & anf & anr \\
\hline PP283* & $\begin{array}{l}\text { xl Wnt-Antagonist } \\
(\text { SIZZLED) }\end{array}$ & aend & aip & kmes \\
\hline PP285 & gg EST & ubi & ubi & ubi \\
\hline $1 \mathrm{c} 03$ & keine & $\mathrm{ps} / \mathrm{np}$ & $\mathrm{ps} / \mathrm{np}$ & $\mathrm{nr}$ \\
\hline $2 \mathrm{a} 05$ & $\mathrm{~mm}$ EST & ne & $\mathrm{np} / \mathrm{nf}$ & $\mathrm{nf} / \mathrm{nr}$ \\
\hline $2 \mathrm{~b} 01$ & keine & ubi & ubi & ubi \\
\hline $2 \mathrm{c} 01$ & keine & ps & $\mathrm{ps} / \mathrm{hk} / \mathrm{axmes}$ & $\mathrm{ps} / \mathrm{dnr}$ \\
\hline $2 \mathrm{e} 11 *$ & $\begin{array}{l}\text { Zellskelettprotein } \\
(E Z R I N)\end{array}$ & pps & aip/endo & phendo/pp \\
\hline $2 \mathrm{~g} 10 *$ & mm METAXIN2 & aend & aip & aip \\
\hline
\end{tabular}




\begin{tabular}{|l|l|l|l|l|}
\hline $\begin{array}{c}\text { cDNA- } \\
\text { Nummer }\end{array}$ & \multicolumn{1}{|c|}{$\begin{array}{c}\text { Homologie der } \\
\text { cDNA }\end{array}$} & $\begin{array}{c}\text { Expression } \\
\text { GS }\end{array}$ & $\begin{array}{c}\text { Expression } \\
\text { NS }\end{array}$ & $\begin{array}{c}\text { Expression } \\
\text { VS }\end{array}$ \\
\hline $2 \mathrm{~h} 02$ & keine & $\mathrm{ps}$ & $\mathrm{ps} / \mathrm{np}$ & $\mathrm{dnf}$ \\
\hline $2 \mathrm{~h} 11$ & $\begin{array}{l}\text { Rezeptorligand } \\
(\text { ENDOZEPIN) }\end{array}$ & $\mathrm{ps} / \mathrm{pmes}$ & $\mathrm{ubi}$ & $\mathrm{ubi}$ \\
\hline
\end{tabular}

Tab. 7.1 Abkürzungen: aend= anteriores Endoderm; aip= anteriores Intestinalportal; anf= anteriore Neuralfalte; anr= anteriores Neuralrohr; aps= anteriorer Primitivstreifen; ax= axiales Gewebe; axmes= axiales Mesoderm; dnf= dorsale Neuralfalten; dnr= dorsales Neuralrohr; endo= Endoderm; extraendo= extraembryonales Endoderm; gg= Gallus gallus; hk= Hensenscher Knoten; hs= Homo sapiens; kb= Kiemenbogen; kmes= kardiales Mesoderm; latend= laterales Endoderm; $\mathrm{nc}=\mathrm{Neural}$ leiste; ne= nicht exprimiert; $\mathrm{nf}=$ Neuralfalte; $\mathrm{np}=$ Neuralplatte; $\mathrm{nr}=$ Neuralrohr; $\mathrm{nu}=$ nicht untersucht; $\mathrm{mm}=$ Mus musculus; phendo= pharyngeales Endoderm; $\mathrm{pp}=$ prächordale Platte; $\mathrm{pps}=$ posteriorer Primitivstreifen; $p s=$ Primitivstreifen; $r n=$ Rattus norvegicus; tel= Telencephalon; ubi= ubiquitär; vend $=$ ventrales Endoderm . 


\section{Publikationen}

Boettger, T., Wittler, L. und Kessel, M. (1999). FGF8 functions in the specification of the right body side of the chick. Curr. Biol. 9: 277-280.

Knoetgen, H., Teichmann, U., Wittler, L., Viehbahn, C. und Kessel, M. (2000). Anterior neural induction by nodes from rabbits and mice. Dev. Biol. 225: 370-380.

Boettger, T., Knoetgen H., Wittler, L. und Kessel, M. (2001). The avian organizer. Int. J. Dev. Biol. 45: 281-287. 


\section{Danksagung}

Mein besonderer Dank gilt Herrn Prof. Dr. Michael Kessel. Ohne seine Betreuung, zahlreiche Diskussionen, Ratschläge, Anregungen sowie tatkräftige Unterstützung bei zeitaufwendigen Experimenten wäre diese Arbeit nicht möglich gewesen. Herrn Prof. Dr. Ulrich Ehlers möchte ich für die bereitwillige Übernahme der Begutachtung dieser Arbeit danken. Herrn Prof. Dr. Peter Gruss danke ich für die Möglichkeit, die hervorragenden Arbeitsbedingungen in seiner Abteilung nutzen zu dürfen.

Allen ehemaligen und momentanen Mitgliedern der Arbeitsgruppe "Entwicklungsbiologie" danke ich für die angenehme, freundschaftliche Arbeitsatmosphäre. Im Einzelnen danke ich Hendrik Knoetgen für viel Sachverstand, Ideenreichtum und Vorarbeiten für den Expressionsscreen sowie für die Zusammenarbeit bei der Veröffentlichung der Knotenexperimente. Ulrike Teichmann danke ich ebenfalls für die Zusammenarbeit bei den Knotentransplantationen. Michael Saborowski danke ich für seine Mitarbeit an der Analyse der späten $c S z l$-Funktion, Ulrike Richter für die weitere Untersuchung einiger vielversprechender Klone aus dem Expressionsscreen und Hilfe bei der Korrektur dieser Arbeit. Hyun-Jin Kim danke ich für den Schnellkurs im Westernblotten und Derek Spieler für seine große Begeisterungsfähigkeit, seinen kreativen Beitrag und die anregenden Diskussionen. Bei Wiebke Behrens möchte ich mich für zahllose Embryokulturen und histologische Schnitte bedanken. Meinen Laborstudentinnen Gizem Dömnez und Sonja Kriks danke ich für tatkräftige Unterstützung im $c S z l$-Projekt und beim Expressionsscreen.

Viele Mitarbeiter aus der Abteilung Molekulare Zellbiologie haben mir durch Diskussionen, Tips und Tricks oder gemeinsame Aktivitäten die Arbeit erleichtert. Besonders möchte ich Dieter Treichel für seine unerschöpfliche Expertise in allen Fragen der Molekularbiologie und seine unermüdliche Hilfsbereitschaft danken. Hans-Peter Geithe und Sigurd Hille danke ich für die vielen Sequenzierungen, Ralf Altschäffel für 
exzellente Photoarbeiten. Außerdem danke ich Joachim Berger und Silke Eckert für die stets mit viel Liebe zum Detail durchgeführten Cocktail-, Video-, oder Grillabende.

Meinen Studienfreunden Stefan Pabst und Till Marquardt, die zusammen mit mir das Studium angefangen und bis zur Promotion durchgehalten haben, danke ich für alle gemeinsamen Aktivitäten im und neben dem Studium.

Bei “Jevers Zeugen”, Arne Baumann, Stefan Gieseke, Raphael Heinrich, Gerrit Leerhoff und Johannes Leonard bedanke ich mich für jahrelange Freundschaft und die Möglichkeit, zusammen mit ihnen in Berlin, Hannover, Rom oder Jever wieder Kraft für die Arbeit tanken zu können. Besonders danke ich Gerrit Leerhoff zudem für das detaillierte Korrekturlesen dieser Arbeit.

Mein ganz besonderer und größter Dank gilt meinen Eltern, die mich immer bestmöglich unterstützt haben. 


\section{Lebenslauf}

Name: $\quad$ Wittler

Vorname: Lars

Geboren: $\quad$ 19. November 1971

Staatsangehörigkeit: deutsch

1978-1982

Besuch der Grundschule Hannover-Mühlenberg.

1982-1983

Besuch der Orientierungsstufe Hannover-Badenstedt.

1983-1992

Besuch des Ratsgymnasiums Hannover.

1992

1992-1993

Abitur am Ratsgymnasium Hannover.

Zivildienst im mobilen sozialen Hilfdienst des Arbeiter-Samariter-Bundes Hannover.

WS 1993/1994 Beginn des Studiums der Biologie an der Georg-August-Universität Göttingen.

Oktober 1995 Vordiplom in den Fächern Zoologie, Mikrobiologie, Allgemeine Chemie und Physik. Note: "sehr gut".

März 1997

bis August 1997 Projektarbeit im Labor von Prof. Dr. Thomas Edlund; Umeå, Schweden. Thema: "Entwicklung des Telenzephalons im Huhnembryo".

Februar 1998

Mündliche Diplomprüfung in den Fächern Entwicklungsbiologie, Zoologie und Biochemie. Note: "sehr gut".

März 1998

bis März 1999 Diplomarbeit am Max-Planck-Institut für biophysikalische Chemie in der Abteilung Molekulare Zellbiologie, Arbeitsgruppe Entwicklungsbiologie von Prof. Dr. Michael Kessel. Thema: "Induktive Einflüsse auf die Anlage der Neuralplatte im Huhn”. 
März 1999

Seit März 1999

Mai 2000

bis Juni 2000

$1999-2002$

Förderungen:
Verleihung des Hochschulgrades "Diplombiologe" an der Georg-August-Universität Göttingen. Note: "sehr gut".

Doktorarbeit am Max-Planck-Institut für biophysikalische Chemie in der Abteilung Molekulare Zellbiologie, Arbeitsgruppe Entwicklungsbiologie von Prof. Dr. Michael Kessel. Thema: “Anteriore Musterbildung im Wirbeltierembryo - die Induktion von Vorderhirn und Herz".

Teilnahme am Second European Advanced Practical Training Course in Evolutionary Developmental Biology, Roscoff, Frankreich.

Stipendiat am Graduiertenkolleg "Molekulare Genetik der Entwicklung", Göttingen 